\title{
REINALDO GIUDICI
}

\section{MODELAGEM MATEMATICA E SIMULAÇAO dO PROCESSO \\ DE GASEIFICAÇÃO DE BIOMASSA EM REATOR ELETROTERMICO DE LEITO MÕVEL}

\author{
Bblioteca da Escola Politéentea \\ São Paulo
}

Dissertação apresentada à Escola Politécnica da Universidade de São Paulo para a obtenção do título de "Mestre em Engenharia".

CONSULTA

FD-665

SÁO PAULO - 1986 


\title{
REINALDO GIUDICI
}

Engenheiro Quỉico, Escola Politécnica da USP, 1983

\section{MODELAGEM MATEMATICA E SIMULAÇAOO DO PROCESSO \\ DE GASEIFICAÇAO DE BIOMASSA EM REATOR \\ ELETROTERMICO DE LEITO MOVVEL}

\author{
Giblloteca da Escola Politeenicz \\ Sào Paulo \\ Dissertação apresentada à Escola \\ Politêcnica da Universidade de \\ São Paulo para a obtenção do tî \\ tulo de "Mestre en Engenharia". \\ Orientador: Prof.Dr. Cläudio Augusto \\ 0ller do Nascimento \\ Professor do Departamento \\ de Engenharia Química da \\ EPUSP.
}

SAOO PAULO - 1986 
para Maria Regina, minha esposa e para meus pais e minhas irmãs 


\section{AGRADECIMENTOS}

Ao Prof. Dr. Cläudio Augusto 01ler do Nascimento, pela orientação e contribuição que deu a esta dissertação, pela sua grande amizade e pelo incentivo em todas as etapas deste traba1ho.

Ao Departamento de Engenharia Química da Escola Politēcni ca da USP, pelas facilidades concedidas.

Ao Instituto de Eletrotêcnica da USP (IEUSP) e à Compa nhia Energética de São Paulo (CESP), pela possibilidade de desenvolver este trabalho.

A Eng. Angélica Chiappetta, pela amizade e pela colaboração e discussão deste trabalho.

Ao Prof. Dr. Giorgio Gambirasio, do Departamento de Engenharia de Eletricidade da EPUSP e do Instituto de Eletrotécnica da USP, pelos ensinamentos de modelagem dos fenômenos elétricos dos reatores eletrotërmicos.

A Prof. Dr. Carmen C. Prado, do Instituto de Fisica da USP, pelo fornecimento do programa de cálculo de equilíbrio químico.

Ao Prof. Tah wun Song, pela amizade e cooperaçāo.

A todos os amigos do Departamento de Engenharia Química da EPUSP, que de alguma forma contribuíram para que este trabatho fosse realizado.

Um agradecimento especial a Maria Regina, minha esposa, pelo carinho e compreensão com que acompanhou as diversas etapas deste trabalho, e a meus pais, que sempre souberam incenti var meus estudos. 


\section{RESUMO}

A gaseificação de madeira com vapor é baseada na reação entre carbono e vapor de água, a qual é fortemente endotérmica. Nos processos convencionais de gaseificação a energia para esta reação é obtida da combustão de parte do sölido que alimenta o gaseificador. No processo eletrotërmico o calor é suprido pela passagem de corrente eletrica entre eletrodos colocados no topo e no fundo do leito. O leito funciona como um aquecedor a resistência.

Neste trabalho é desenvolvido um modelo unidimensional estacionário para o gaseificador eletrotérmico de leito móvel. A cinética das reações heterogêneas gās-sólido ē descri ta pelo modelo de núcleo exposto e a pirólise da madeira por mo delo de equilibrio.

Foi obtido um sistema de equaçōes diferenciais or

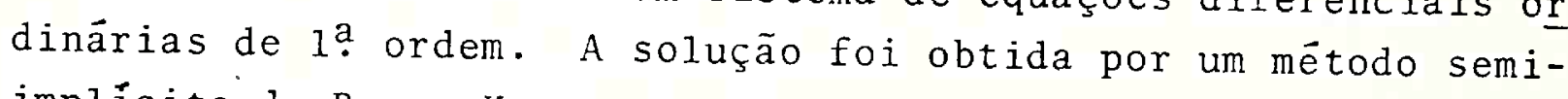
implicito de Runge-Kutta.

teristica do reator é capaz de prever a curva elétrica carac deira e a produção e composição do gäs de sintese.

As previsões do modelo são comparadas com dados de planta piloto de gaseificadores eletrotérmicos da Companhia Energética de São Paulo (CESP). 


\section{ABSTRACT}

Gasification of wood by reaction with steam is based upon the highly endothermic carbon-steam reaction. In the conventional gasification processes, the energy for this reaction is provided by combustion of part of the solid fed to the gasifier. In the electrothermal process heat is supplied electrically by passing current between electrodes placed in the top and botton of bed. The bed works as resistance heater.

In this work is developed a one-dimensional steady state model for the moving bed electrothermal gasifier. The kinetics of heterogeneous gas-solid reactions is described by ash segregated model and the wood pyrolysis by equilibrium model.

\section{A system of nonlinear ordinary differential} equations was obtained. The solution has been undertaken by a semi-implicit Runge Kutta method.

The model is capable of predicting the characteristic electric curve, temperature profile, wood consumption and synthesis gas production and composition.

Model predictions are compared to available pilot plant data for electrothermal gasifiers from Companhia Energéti ca de São Paulo (CESP). 


\section{IND ICE}

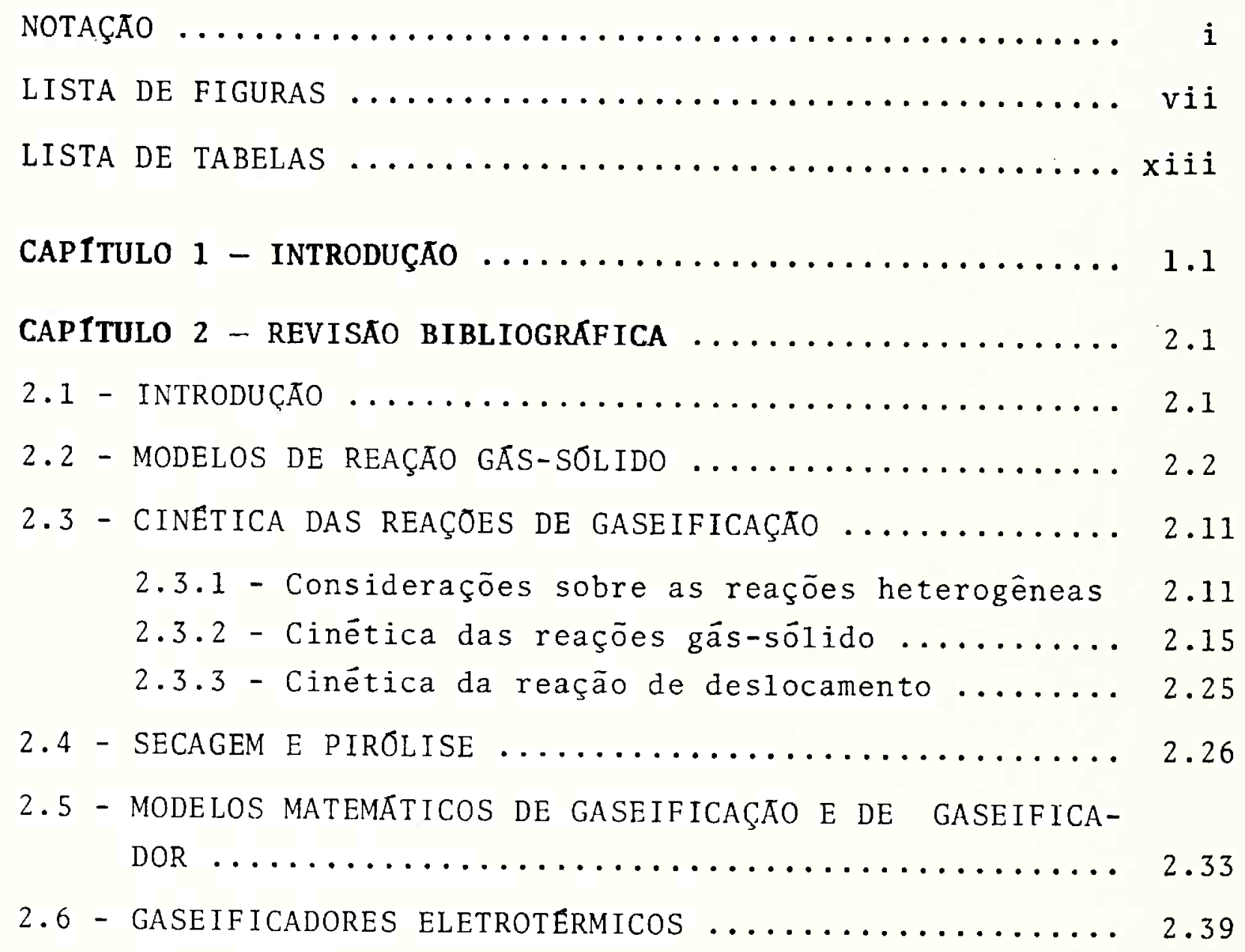

\section{CAPITULO 3 - MODELO MATEMÁtico PARA A REgiÁ ENTRE OS ELE-}

TRODOS DO GASEIFICADOR ELETROTERMICO $\ldots \ldots \ldots 3.1$

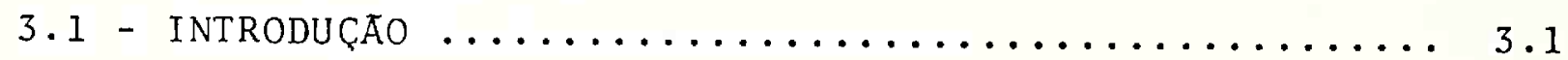

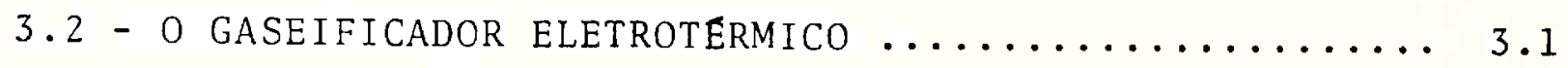

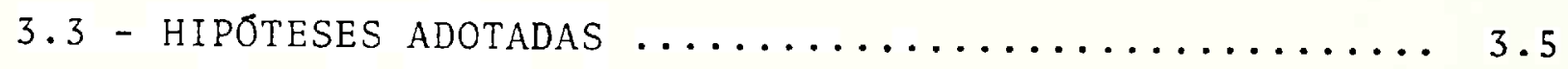

3.4 - REAÇOES QUIMICAS CONSIDERADAS NO MODELO MATEMATICO - 3.9

3.5 - EQUAÇOES QUE DESCREVEM OS FENÖMENOS ELETRICOS .... 3.10

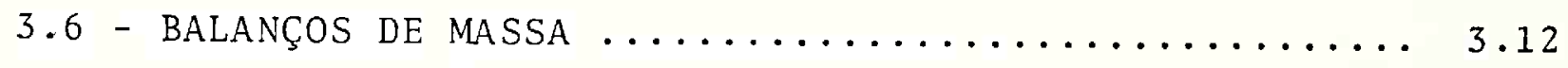

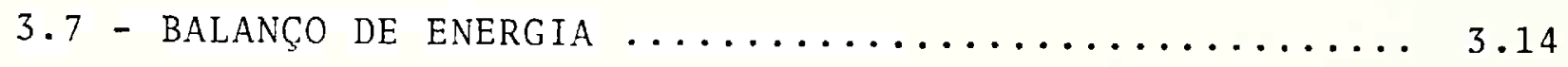




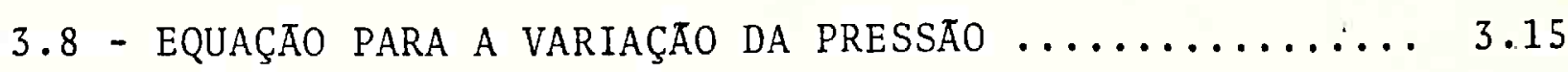

3.9 - CÁlCULO das TAXAS dAS REAÇOES .............. 3.17

3.9 .1 - Reações gäs-sōlido ............... 3.17

3.9 .2 - Reação de Desloćamento ............. 3.20

3.9 .3 - Constantes de Equilíbrio ............. 3.20

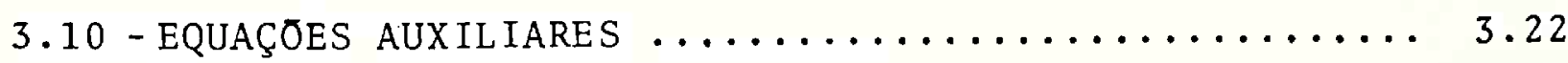

3.11 - FORMA ADIMENSIONAL DAS EQUAÇOES DIFERENCIAIS DO MODE

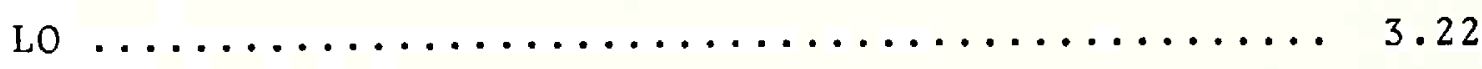

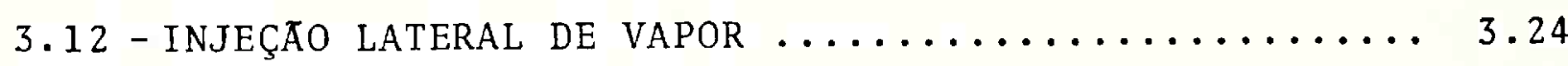

3.13 - METODO NUMERICO .................... 3.27

3.14 - APRESENTAÇAO dO PROGRAMA DE COMPUTAdOR GAS/ELET $\ldots . .3 .31$

CAPITULO 4 - RESULTAdOS DA SIMULAÇÃo do MODELO DA REgí̃o INTERELETRODOS $\ldots \ldots \ldots \ldots \ldots \ldots \ldots \ldots \ldots \ldots \ldots \ldots \ldots$

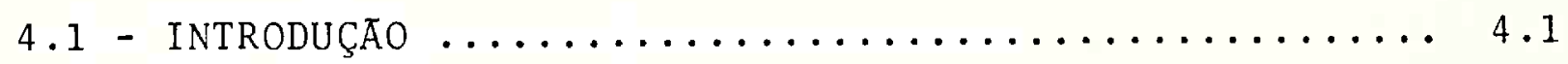

4.2 - ESTUDO NUMERICO $\ldots \ldots \ldots \ldots \ldots \ldots \ldots \ldots \ldots \ldots \ldots \ldots \ldots \ldots \ldots \ldots \ldots \ldots$

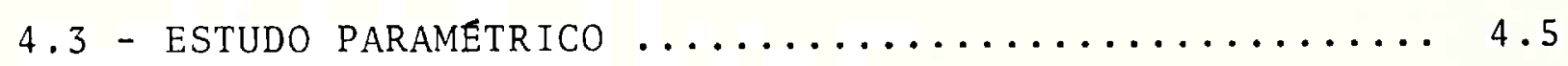

4.3 .1 - Influência da Corrente Elétrica (I) ..... 4.8

4.3 .2 - Influência da Temperatura Inicial $\left(\mathrm{T}_{0}\right) \ldots . .44 .12$

4.3 .3 - Influência da Pressão Inicial $\left(P_{0}\right) \ldots \ldots \ldots 4.15$

4.3 .4 - Influência das Vazões de Processo ......... 4.15

4.3 .5 - Influência da Vazão de Vapor de Água ..... 4.18

4.3 .6 - Influência da Vazão de Sólidos $\left(W_{S}\right) \ldots \ldots \ldots 4.18$

4.3 .7 - Influência da Condutividade Elētrica do Lei-

4.3.8 - Influência do Coeficiente de Transferência de Calor para o Meio Exterior ............ 4.23

4.3.9 - Influência da Distância entre os Eletrodos(L) 4.26

4.3 .10 - Influência do Diâmetro do Reator $\left(D_{t}\right) \ldots \ldots 4.26$

4.3.11 - Influência do Diâmetro Inicial das Partículas 4.28

4.3 .12 - Influência da Distribuição de Vapor pelas In jeções Laterais ................. 4.28 
CAPITULO 5 - MODELO MATEMÁTICO E SIMULAÇÃo DA REgiAo DE PI ROLISE E SECAGEM DA MADEIRA EM REATOR ELETRO-

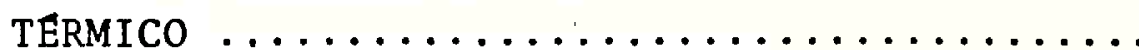

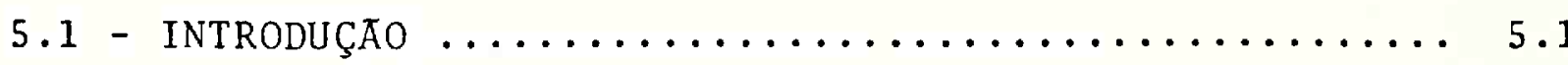

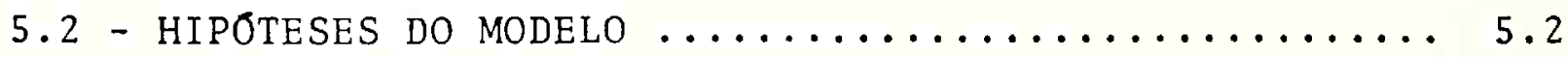

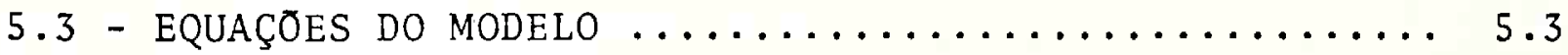

5.4 - PROgRamas de COMPUTAdor Ut ILIZAdos $\ldots \ldots \ldots \ldots \ldots \ldots 5.5$

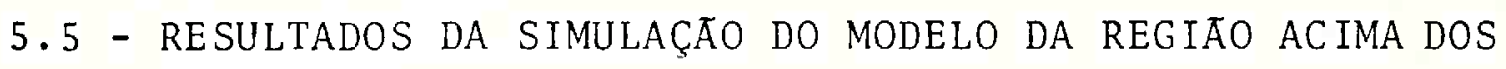

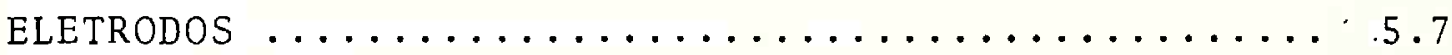

5.6 - AdAPtaÇáo do Modelo de pirólise e SeCAGem ao Modelo DA REGIAOO INTERELETRODOS $\ldots \ldots \ldots \ldots \ldots \ldots \ldots \ldots \ldots \ldots \ldots \ldots \ldots$

CAPITULO 6 - RESULTADOS DA SIMULAÇAO DO GASEIFICADOR ELETROTERMICO - ZONAS DE SECAGEM E PIROLISE E DE GASEIF ICAÇAO $\ldots \ldots \ldots \ldots \ldots \ldots \ldots \ldots \ldots \ldots \ldots \ldots \ldots \ldots$

6.1 - INTRODUÇAO $\ldots \ldots \ldots \ldots \ldots \ldots \ldots \ldots \ldots \ldots \ldots \ldots \ldots \ldots \ldots \ldots \ldots \ldots \ldots \ldots$

6.2 - estudo parametrico do modelo completo $\ldots \ldots \ldots \ldots \ldots 6.1$

6.2 .1 - Influência da Umidade da Madeira ........ 6.1

6.2 .2 - Influência da Temperatura de Pirölise ..... 6.3

6.2 .3 - Influência do Comprimento $\mathrm{L}_{\mathrm{p}} \ldots \ldots \ldots \ldots . \ldots 6.3$

6.3 - COMPARAÇAO DE RESULTADOS DA SIMULAÇÃO COM DADOS EXPE

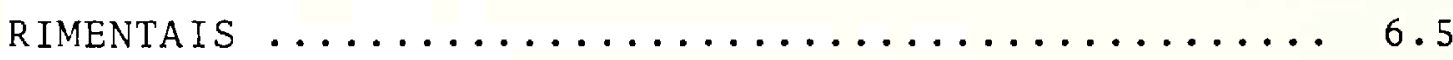

6.4 - ESTUDO DE UM CASO: PREVISAO DE AUMENTO DE PRODUÇÃo

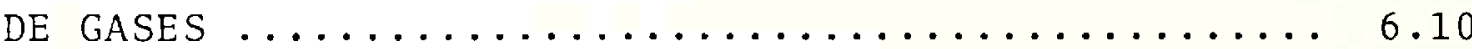

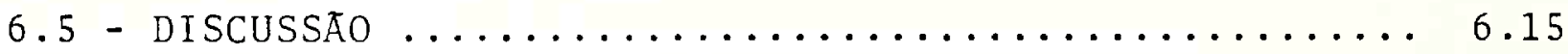

CAPTTULO 7 - CONCLUSOES $\ldots \ldots \ldots \ldots \ldots \ldots \ldots \ldots \ldots \ldots \ldots \ldots \ldots \ldots \ldots \ldots$

APENDICE A - EXPRESSÃO DA TAXA DE REAÇÃo GÁS-SOLLIDO PELO

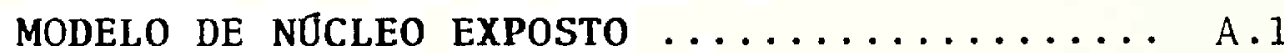


APENDICE B - PROPRIEDADES FISICAS E TERMODINAMICAS ..... B. 1 APENDICE C - PROGRAMA DE COMPUTADOR GAS/ELET $\ldots \ldots \ldots \ldots$ C.1 APENDICE D - PROGRAMA DE COMPUTAdOR PIROLISE $\ldots \ldots \ldots \ldots$ D. 1 REFERENCIAS BIBLIOGRÁFICAS $\ldots \ldots \ldots \ldots \ldots \ldots \ldots \ldots \ldots \ldots \ldots$ R. 1 


\section{NOTAÇÃO}

a, a', a" .... parâmetros cinéticos das equações (2.21), (2.22) e $(2,26), \mathrm{Pa}^{-1}$

$a_{0}, a_{0} \ldots \ldots$ fatores prë-exponenciais das tabelas (2.2) e(2.3) $\mathrm{Pa}^{-1}$

$a_{1} \ldots \ldots \ldots$ constante definida na equação (3.64)

$a_{s}$......... ärea externa específica da particula, $\mathrm{m}^{2} / \mathrm{m}^{3}$

$a_{t} \ldots \ldots \ldots$ área total especifica da particula, $\mathrm{m}^{2} / \mathrm{m}^{3}$

$a_{\sigma} \ldots \ldots \ldots$ constante empírica da equação $(3.7), \Omega-1_{m}-1$

$A_{t} \ldots \ldots \ldots$ área da seção transversal ao escoamento, $m^{2}$

$\mathrm{A}_{1}$ at ........ área da superfície interna do reator, $\mathrm{m}^{2}$

b,b',b" .... parâmetros cinéticos das equações (2.21),(2.22) e $(2.26), \mathrm{Pa}^{-1}$

$b_{0}, b_{0}^{\prime} \ldots \ldots$ fatores pré-exponenciais das tabelas (2.2) e(2.3) $\mathrm{Pa}^{-1}$

$b_{2}, b_{31}, b_{32} \ldots$ constantes definidas nas equações $(3.65),(3.66)$ e (3.67)

$b_{\sigma} \ldots \ldots \ldots$ constante empírica da equação $(3.7),\left({ }^{\circ} \mathrm{C}\right)-1$

$\mathrm{B}_{j} \ldots \ldots \ldots$ fator prê-exponencial dos parâmetros cinéticos, unidades variāveis, ver tabela 3.2

${ }^{c_{1}}, c_{2}, c_{3} \ldots$ constantes definidas nas equações $(3.68),(3.69)$ e $(3.70)$

$c_{a i}, c_{b i}, c_{c i}, c_{d i}$ - constantes empíricas da equação (B.3)

$c_{p g}, c_{p i} \cdot . . c$ calor específico molar da fase gasosa e do gãs $i$, $\mathrm{J} / \mathrm{kmol} / \mathrm{K}$

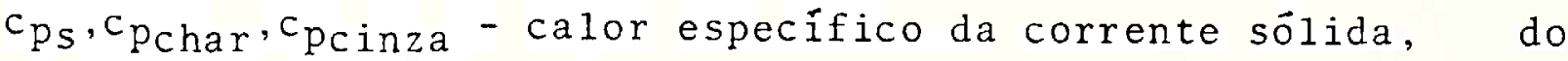
"char" e da cinza, J/kg/K

$\mathrm{C}_{\mathrm{i}} \ldots \ldots \ldots$ concentração molar do reagente $\mathrm{i}, \mathrm{kmol} / \mathrm{m}^{3}$

$\mathrm{C}_{\mathrm{c}} \ldots \ldots \ldots$ concentração molar do "char", $\mathrm{kmol} / \mathrm{m}^{3}$

$\mathrm{C}_{1}, \mathrm{C}_{2}, \mathrm{C}_{3} \ldots$... constante das equações $(2.28)$ e $(2.29)$

$\mathrm{C}_{\mathrm{S}} \ldots \ldots \ldots$ concentraçãodo reagente gasoso na superfície externa da partícula, $\mathrm{kmol} / \mathrm{m}^{3}$ 


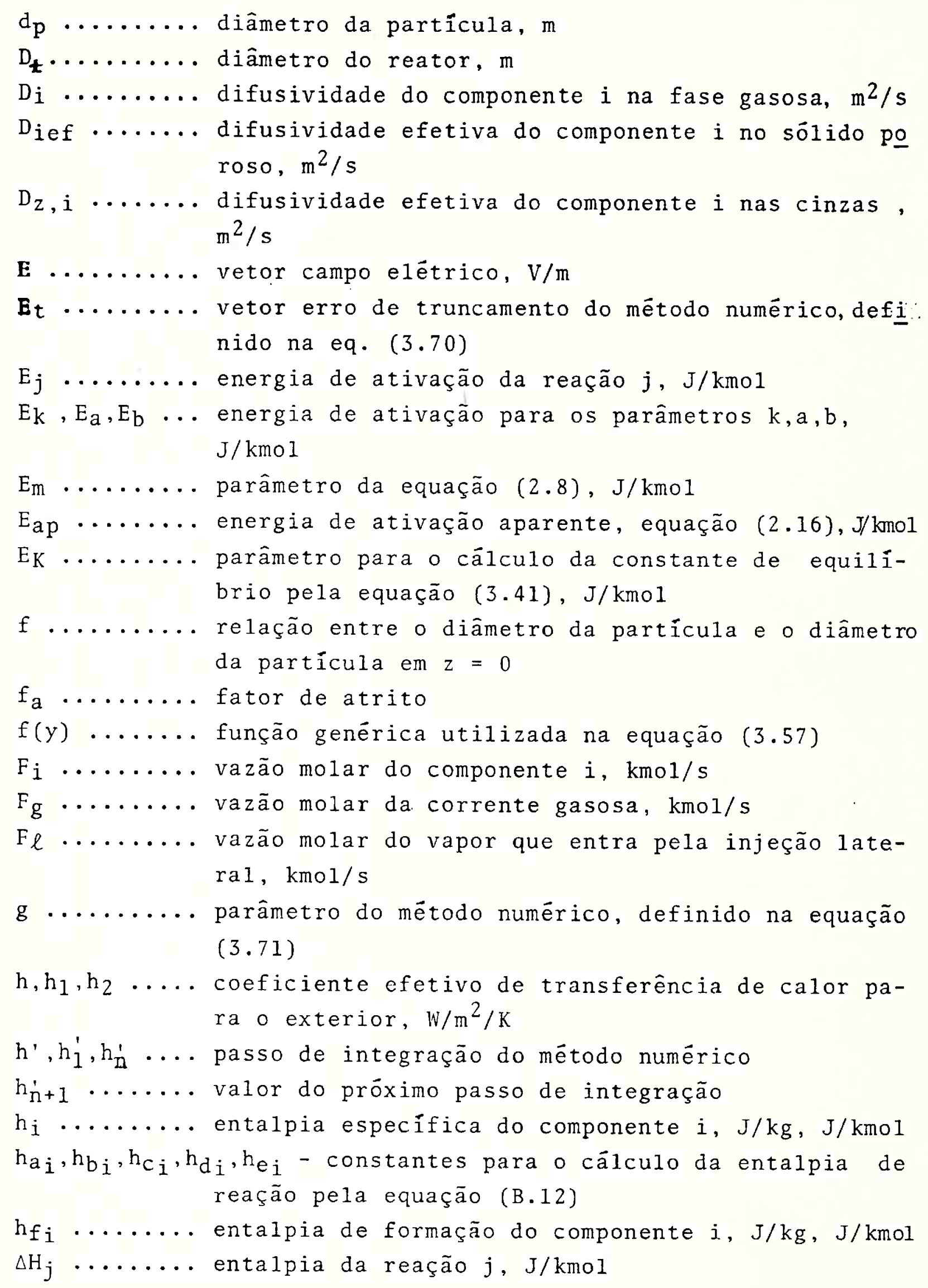




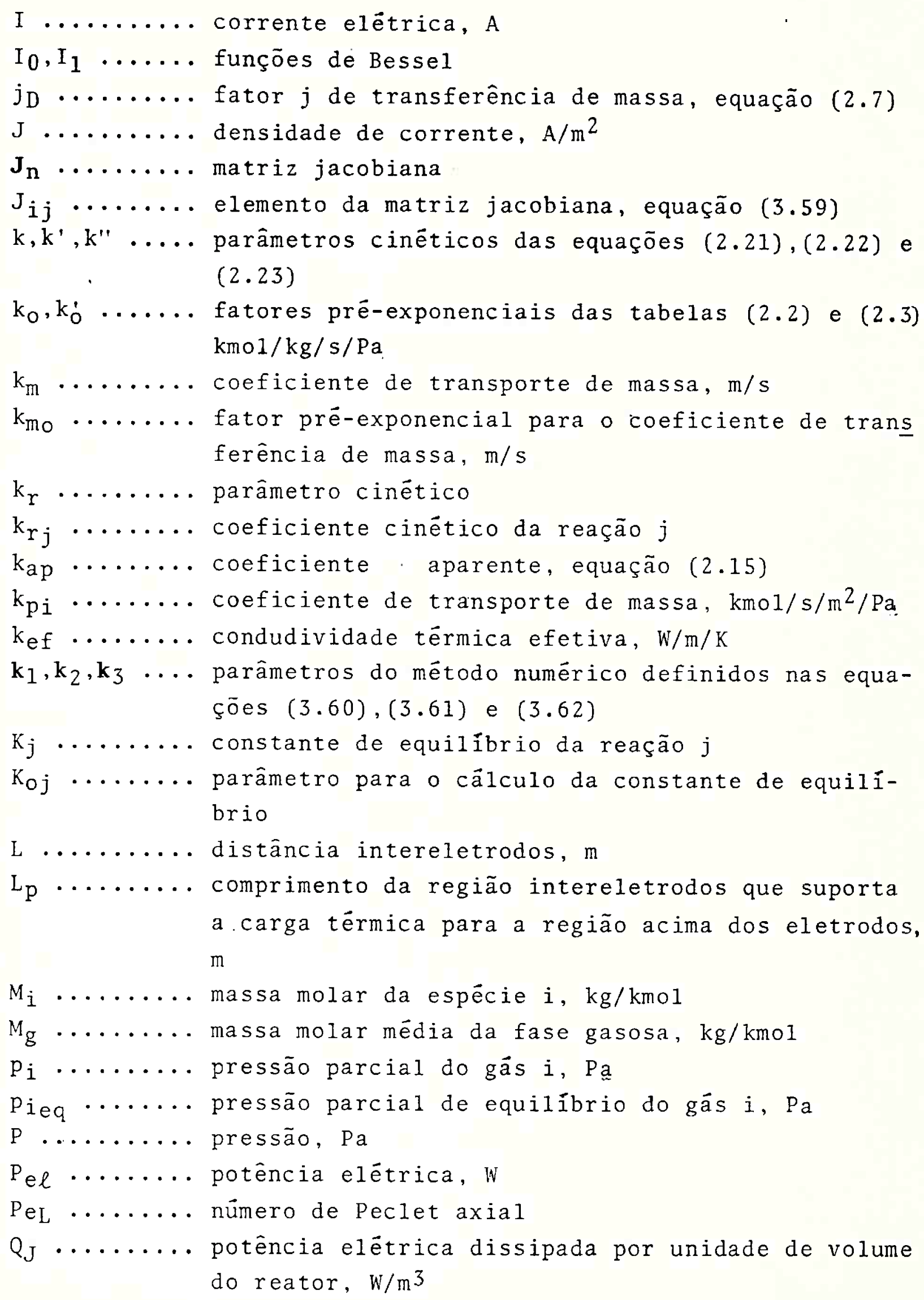




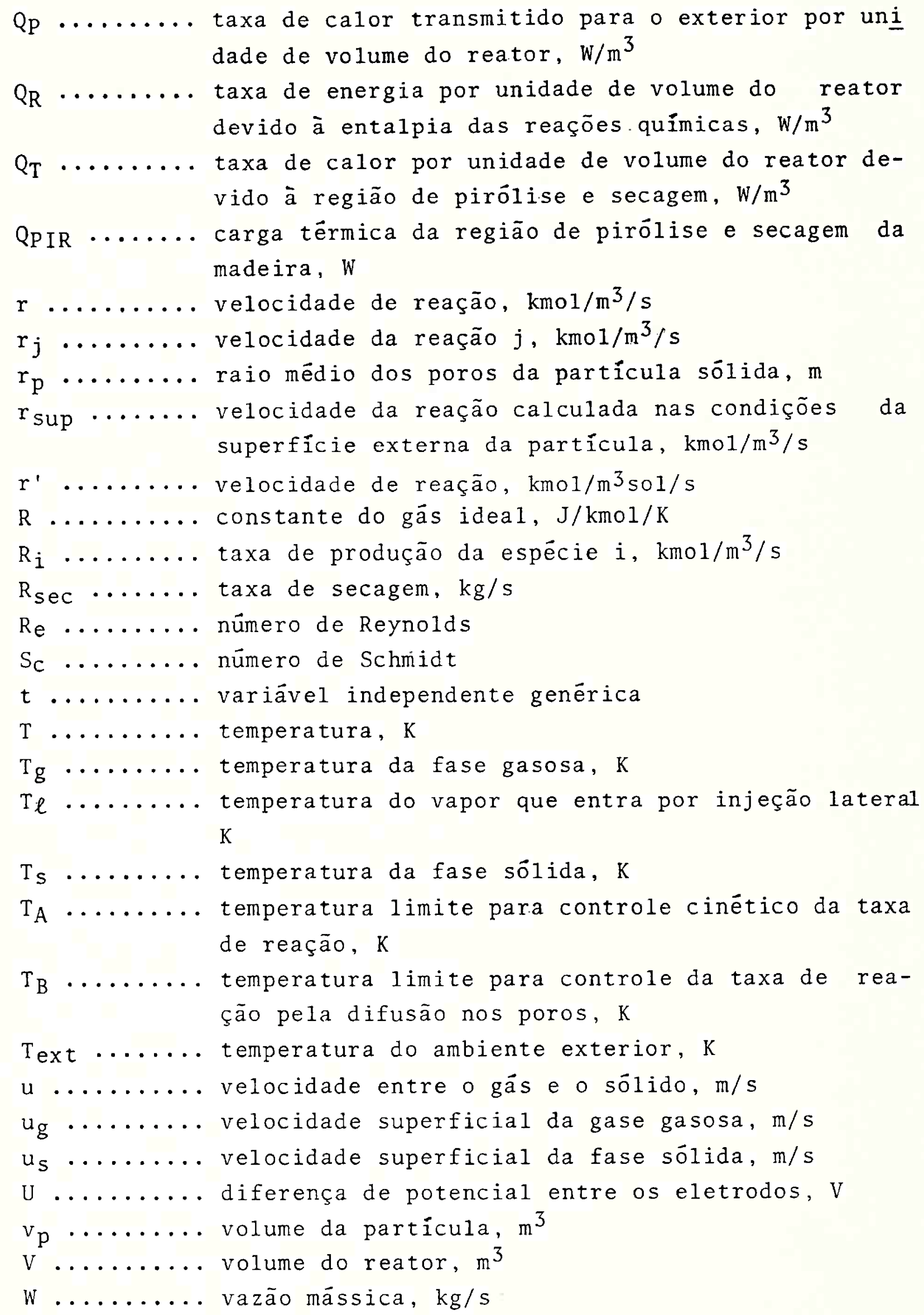




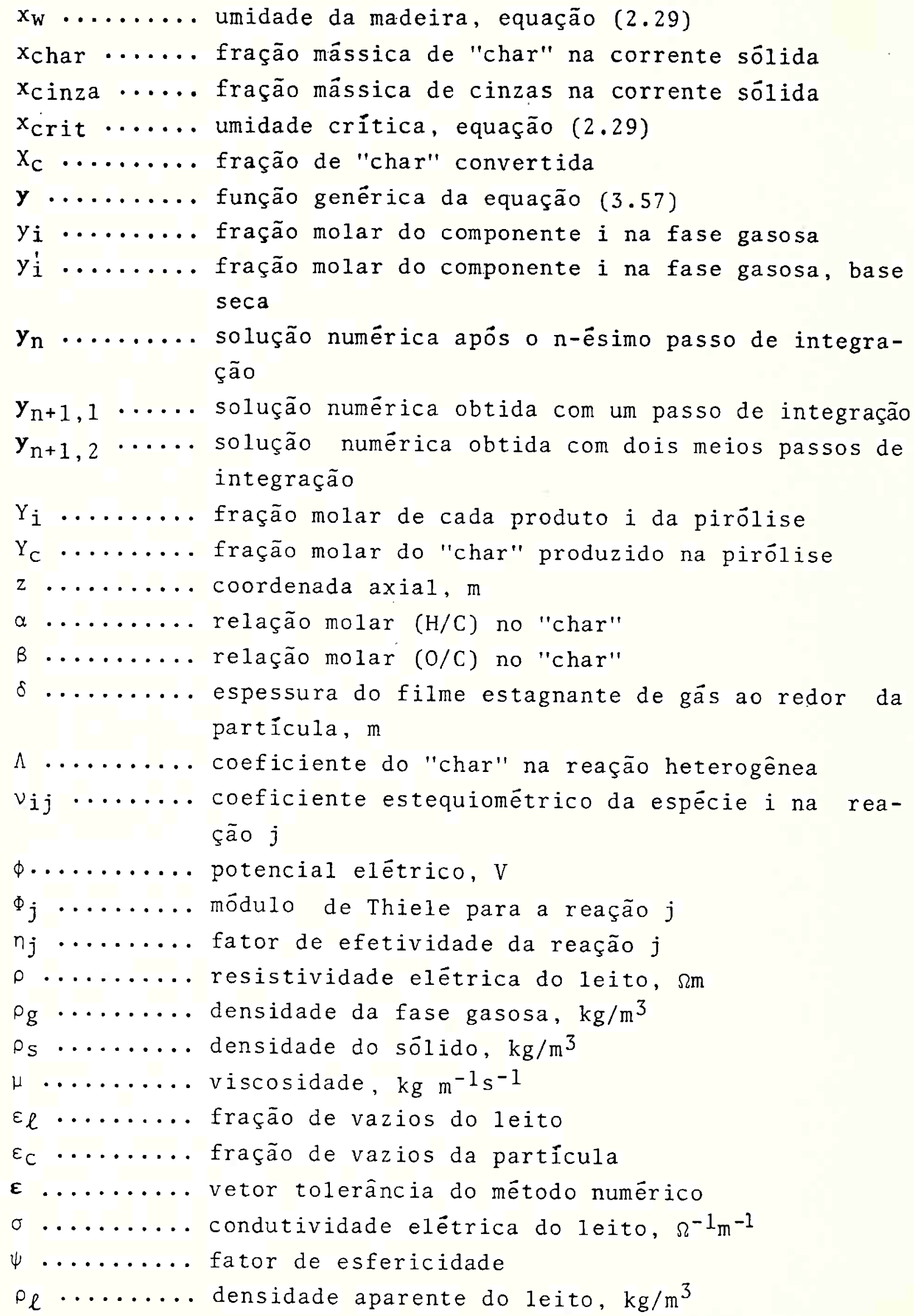


$\psi_{\text {ik }} . . . \ldots$ parâmetro auxiliar para o cálculo da viscosidade da mistura gasosa, equação (B.15)

\section{Indices}

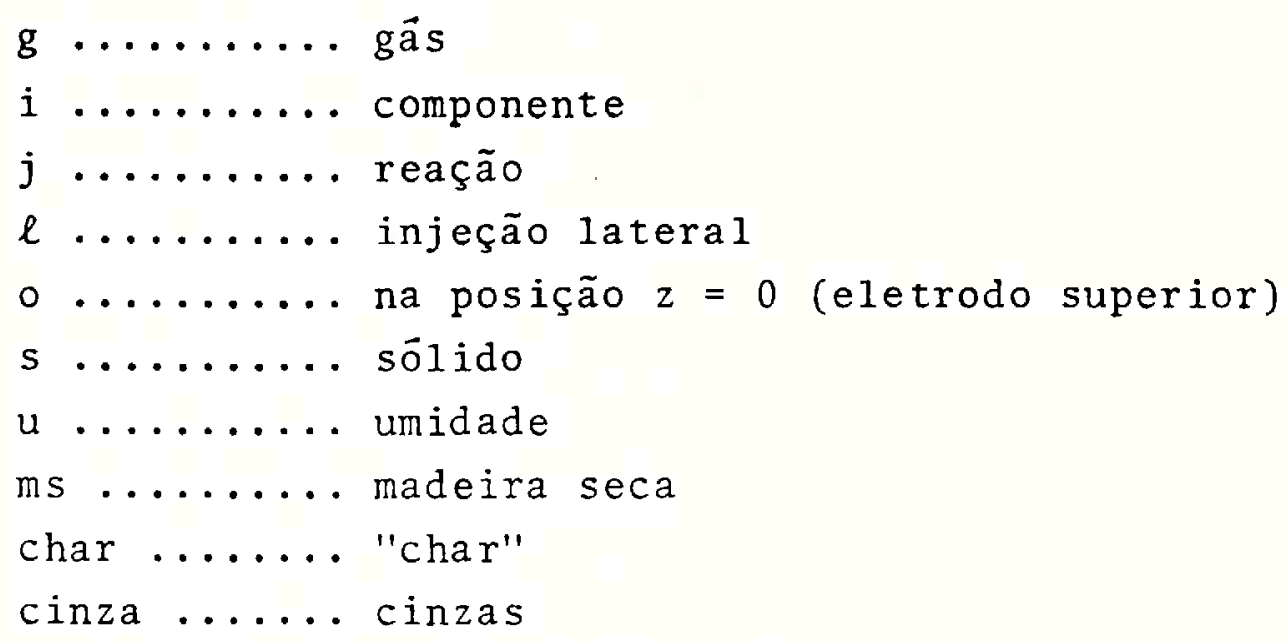

Superescrito

(o) $\ldots \ldots$ na posição $z=0$

+....... imediatamente após a mistura com a injeção lateral

* ........ variável adimensional 
LISTA DE FIGURAS

\begin{tabular}{|c|c|c|}
\hline FIGURA NQ̣ & TITULO & PAGINA \\
\hline 2.1 & $\begin{array}{l}\text { Esquema para a representação do modelo } \\
\text { homogêneo } \ldots \ldots \ldots \ldots \ldots \ldots \ldots \ldots \ldots \ldots\end{array}$ & 2.6 \\
\hline 2.2 & $\begin{array}{l}\text { Esquema para a representação do modelo } \\
\text { volumétrico } \ldots \ldots \ldots \ldots \ldots \ldots \ldots \ldots \ldots \ldots\end{array}$ & 2.6 \\
\hline 2.3 & $\begin{array}{l}\text { Esquema para a representação do modelo } \\
\text { de nücíeo não-reagido } \ldots \ldots \ldots \ldots \ldots \ldots\end{array}$ & 2.6 \\
\hline 2.4 & $\begin{array}{l}\text { Esquema do modelo de zona de reação mó } \\
\text { vel } \ldots \ldots \ldots \ldots \ldots \ldots \ldots \ldots \ldots \ldots \ldots \ldots\end{array}$ & 2.7 \\
\hline 2.5 & $\begin{array}{l}\text { Esquema para representação do modelo } \\
\text { de núcleo exposto } \ldots \ldots \ldots \ldots \ldots \ldots \ldots\end{array}$ & 2.7 \\
\hline 2.6 & $\begin{array}{l}\text { Esquema para representação do modelo } \\
\text { de grão (particle-pellet model") .... }\end{array}$ & 2.7 \\
\hline 2.7 & $\begin{array}{l}\text { Esquema de partícula porosa } \\
\text { Grabosky (1979)) } \ldots \ldots \ldots \ldots \ldots \ldots \ldots\end{array}$ & 2.16 \\
\hline 2.8 & $\begin{array}{l}\text { Efeito da temperatura na velocidade de } \\
\text { reações heterogêneas (fonte: Grabosky } \\
(1979)) \ldots \ldots \ldots \ldots \ldots \ldots \ldots \ldots \ldots \ldots \ldots \ldots\end{array}$ & 2.16 \\
\hline 2.9 & 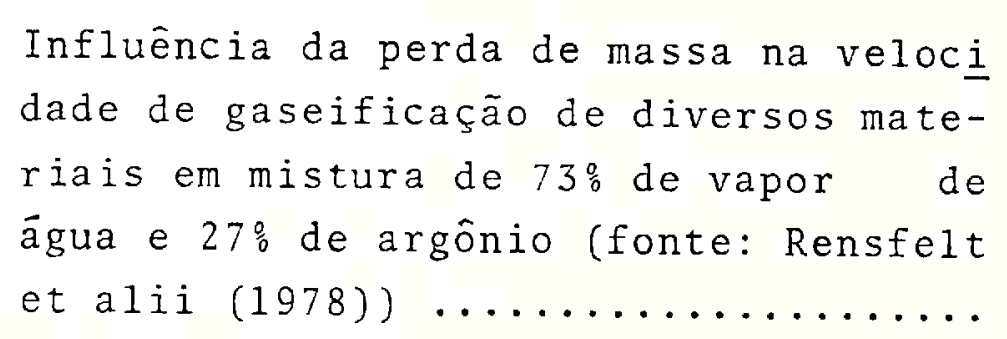 & 2.20 \\
\hline
\end{tabular}




\begin{tabular}{|c|c|}
\hline FI GURA NỌ & TITULO \\
\hline 2.10 & 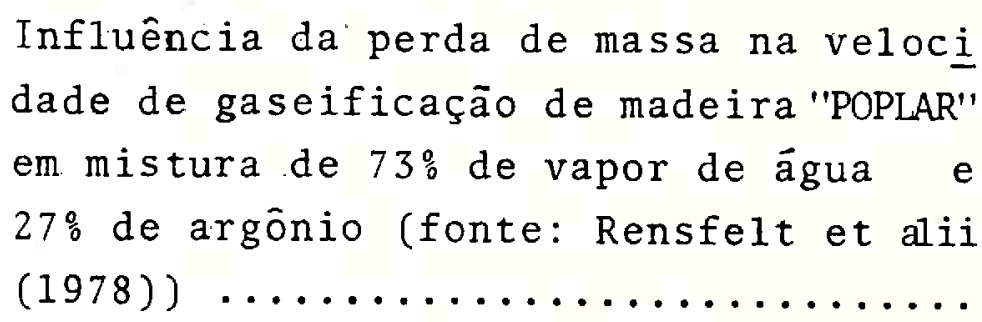 \\
\hline
\end{tabular}

PAGINA

2.11 Exemplo de resultados de análise termo

gravimétrica de madeira de algodão e
seus componentes (fonte: Milne (1979))

gravimétrica de madeira de algodão e
seus componentes (fonte: Milne (1979))

2.12 Distribuição de produtos da pirólise de serragem de pinho em função da temperatura (fonte: Knight (1976)) .....

2.13 Previsão do campo elétrico em reator de leito fluidizado para duas configurações diferentes: (a) eletrodos con cêntricos e (b) eletrodos no fundo e no topo do reator (fonte: Knowlton et

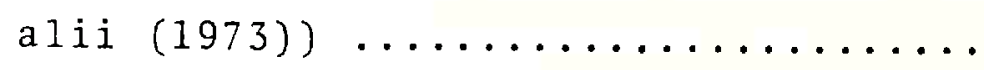

2.14 Resistividade elétrica de leitos de carvão. Resultados obtidos por diver-

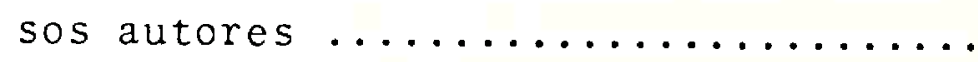

2.15 Previsão da distribuição de temperatu ras e potenciais elétricos em gaseifi cador eletrotérmico, obtida com modelo bidimensional estático. Configuração geométrica com eletrodo superior cilin drico e inferior anelar (fonte: IEUSP

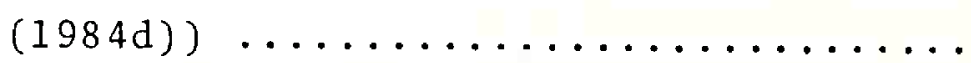




\begin{tabular}{|c|c|c|}
\hline FIGURA NO & TITULO & PAGINA \\
\hline 2.16 & 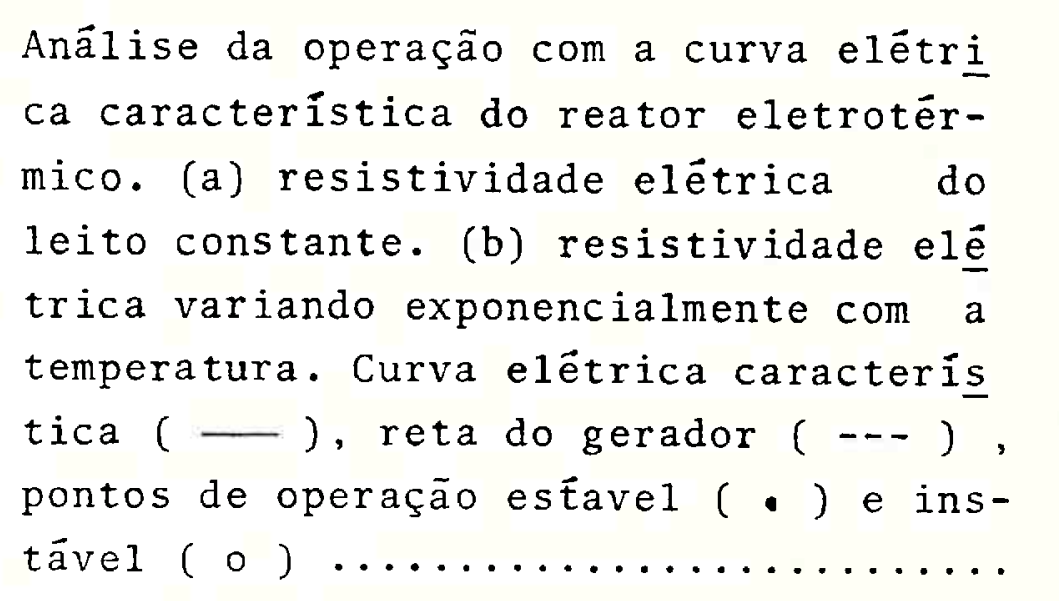 & 2.53 \\
\hline 3.1 & $\begin{array}{l}\text { Esquema do gaseificador eletrotérmico } \\
\text { G3 da Companhia Energëtica de São Paulo } \\
\text { (CESP) } \ldots \ldots \ldots \ldots \ldots \ldots \ldots \ldots \ldots \ldots \ldots \ldots \ldots \ldots \ldots \ldots \ldots\end{array}$ & 3.3 \\
\hline 3.2 & $\begin{array}{l}\text { Esquema do gaseificador eletrotérmico } \\
\text { G5 da Companhia Energētica de São Paulo } \\
\text { (CESP) } \ldots \ldots \ldots \ldots \ldots \ldots \ldots \ldots \ldots \ldots \ldots \ldots \ldots \ldots \ldots\end{array}$ & 3.4 \\
\hline 3.3 & Esquema da injeção lateral .......... & 3.25 \\
\hline 3.4 & $\begin{array}{l}\text { Diagrama de blocos simplificado do pro- } \\
\text { grama GAS/ELET } \ldots \ldots \ldots \ldots \ldots \ldots \ldots \ldots \ldots\end{array}$ & 3.32 \\
\hline 4.1 & $\begin{array}{l}\text { Estudo numérico: teste do vetor de tole } \\
\text { rância } \varepsilon \text {. Conversão incompleta do sólido } \\
\text { (condiçōes mesmas da tabela } 4.1 \text { ) ....... }\end{array}$ & 4.3 \\
\hline 4.2 & $\begin{array}{l}\text { Estudo numërico: teste do vetor de tole- } \\
\text { rância } \varepsilon \text {. Conversão do sólido completada } \\
\text { antes do final do reator (condiçōes mes- } \\
\text { mas da tabela } 4.2 \text { ) } \ldots \ldots \ldots \ldots \ldots \ldots \ldots\end{array}$ & 4.6 \\
\hline 4.3 & $\begin{array}{l}\text { Influência da corrente elétrica sobre os } \\
\text { perfis de conversão e de temperatura (mes } \\
\text { mas condições da tabela } 4.3 \text { ) ......... }\end{array}$ & 4.9 \\
\hline
\end{tabular}




\begin{tabular}{|c|c|c|}
\hline FIGURA NQ & TITULO & PAGINA \\
\hline 4.4 & $\begin{array}{l}\text { Influência da temperatura em } z=0 \text { so- } \\
\text { bre a curva elétrica característica } .\end{array}$ & 4.13 \\
\hline 4.5 & $\begin{array}{l}\text { Influência da temperatura em } z=0 \text { so- } \\
\text { bre os perfis de temperatura, conver- } \\
\text { são do sỏlido e composição do gās } \ldots\end{array}$ & 4.14 \\
\hline 4.6 & $\begin{array}{l}\text { Influência da pressão } P_{0} \text { sobre a curva } \\
\text { elétrica característica } \ldots \ldots \ldots \ldots \ldots\end{array}$ & 4.16 \\
\hline 4.7 & $\begin{array}{l}\text { Influência das vazões de processo so- } \\
\text { bre a curva elétrica característica .. }\end{array}$ & 4.17 \\
\hline 4.8 & $\begin{array}{l}\text { Influência da vazão de vapor sobre } a \\
\text { curva elétrica do reator } \ldots \ldots \ldots \ldots\end{array}$ & 4.19 \\
\hline 4.9 & $\begin{array}{l}\text { Influência da vazão de vapor sobre os } \\
\text { perfis de composição do gás (condições } \\
\text { mesmas da figura } 4.8 \text { ) } \ldots \ldots \ldots \ldots \ldots \ldots\end{array}$ & 4.19 \\
\hline 4.10 & $\begin{array}{l}\text { Influência da vazão de vapor sobre os } \\
\text { perfis de temperatura e conversão do } \\
\text { sólido (condições mesmas da figura } 4.8 \text { ) }\end{array}$ & 4.20 \\
\hline 4.11 & $\begin{array}{l}\text { Influência da vazão de "char" sobre a } \\
\text { curva elëtrica caracteristica do rea- } \\
\text { tor } \ldots \ldots \ldots \ldots \ldots \ldots \ldots \ldots \ldots \ldots \ldots \ldots \ldots \ldots \ldots \ldots\end{array}$ & 4.22 \\
\hline 4.12 & $\begin{array}{l}\text { Influência da condutividade elétrica } \\
\text { sobre a curva elétrica do reator ..... }\end{array}$ & 4.22 \\
\hline 4.13 & $\begin{array}{l}\text { Influência dos coeficientes de trans- } \\
\text { missão de calor sobre a curva elétrica } \\
\text { característica } \ldots \ldots \ldots \ldots \ldots \ldots \ldots \ldots\end{array}$ & 4.24 \\
\hline
\end{tabular}




\begin{tabular}{|c|c|c|}
\hline FIGURA NO & TITULO & PAGINA \\
\hline 4.14 & $\begin{array}{l}\text { Influência do coeficiente efetivo de } \\
\text { transmissão de calor para o exterior } \\
\text { sobre os perfis de composição do gás } \\
\text { (condições mesmas da figura } 4.13 \text { ) } \ldots\end{array}$ & 4.24 \\
\hline 4.15 & $\begin{array}{l}\text { Influência dos coeficientes efetivos } \\
\text { de transmissão de calor para o meio ex } \\
\text { terior sobre os perfis de temperatura } \\
\text { e conversão do "char" (condiçoses mes- } \\
\text { mas da figura 4.13) ................ }\end{array}$ & 4.25 \\
\hline 4.16 & $\begin{array}{l}\text { Influência da distância intereletrodos } \\
\text { sobre a curva elétrica característica } \\
\text { do reator } \ldots \ldots \ldots \ldots \ldots \ldots \ldots \ldots \ldots \ldots \ldots \ldots\end{array}$ & 4.27 \\
\hline 4.17 & $\begin{array}{l}\text { Influência do diâmetro do reator e do } \\
\text { tamanho inicial das particulas sobre a } \\
\text { curva elétrica característica } \ldots . . .\end{array}$ & 4.27 \\
\hline 4.18 & $\begin{array}{l}\text { Esquema dos casos estudados de distri- } \\
\text { buição de vapor na região intereletro } \\
\text { dos nos bocais de injeção lateral nas } \\
\text { cotas } z^{*}=0,25 ; 0,50 \text { e } 0,75 \ldots . . .\end{array}$ & 4.30 \\
\hline 4.19 & $\begin{array}{l}\text { Influência da distribuição do } \\
\text { pelos pontos de injeção lateral sobre } \\
\text { os perfis de conversão de sólido e de } \\
\text { temperatura } \ldots \ldots \ldots \ldots \ldots \ldots \ldots \ldots \ldots\end{array}$ & 4.32 \\
\hline 4.20 & 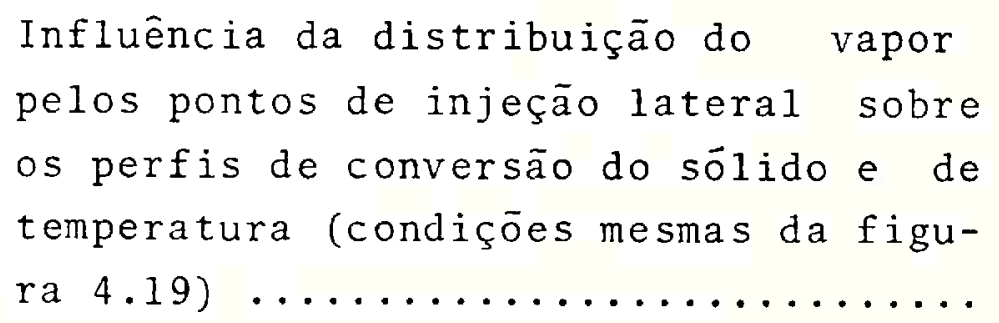 & 4.33 \\
\hline
\end{tabular}




\begin{tabular}{|c|c|c|}
\hline FIGURA NO & TITULO & PAG INA \\
\hline 4.21 & $\begin{array}{l}\text { Influência da distribuiçãa de vapor pe } \\
\text { los pontos de injeção lateral sobre a } \\
\text { curva elétrica caracteristica do rea- } \\
\text { tor } \ldots \ldots \ldots \ldots \ldots \ldots \ldots \ldots \ldots \ldots \ldots \ldots \ldots \ldots \ldots \ldots \ldots \ldots \ldots\end{array}$ & 4.36 \\
\hline 5.1 & $\begin{array}{l}\text { Esquema dos fluxos que entram e saem } \\
\text { da região de pirólise e secagem da ma- } \\
\text { deira } \ldots \ldots \ldots \ldots \ldots \ldots \ldots \ldots \ldots \ldots \ldots \ldots \ldots \ldots \ldots\end{array}$ & 5.5 \\
\hline 6.1 & $\begin{array}{l}\text { Influência da umidade da madeira sobre } \\
\text { os perfis de conversão do "char" e de } \\
\text { temperatura } \ldots \ldots \ldots \ldots \ldots \ldots \ldots \ldots \ldots \ldots\end{array}$ & 6.2 \\
\hline 6.2 & $\begin{array}{l}\text { Influência da temperatura de pirólise } \\
\text { sobre os perfis de temperatura e de } \\
\text { conversão do "char" na região interele } \\
\text { trodos } \ldots \ldots \ldots \ldots \ldots \ldots \ldots \ldots \ldots \ldots \ldots\end{array}$ & 6.4 \\
\hline 6.3 & $\begin{array}{l}\text { Influência do parâmetro Lp sobre os } \\
\text { perfis de conversão e de temperatura do } \\
\text { leito } \ldots \ldots \ldots \ldots \ldots \ldots \ldots \ldots \ldots \ldots \ldots \ldots \ldots\end{array}$ & 6.6 \\
\hline 6.4 & $\begin{array}{l}\text { Comparação das previsões do modelo com } \\
\text { dados experimentais (condições mesmas } \\
\text { das Tabelas } 6.4 \text { e } 6.5 \text { ) } \ldots \ldots \ldots \ldots \ldots\end{array}$ & 6.12 \\
\hline
\end{tabular}




\section{LISTA DE TABELAS}

\begin{tabular}{|c|c|c|}
\hline TABELA NO & TITULO & PATG INA \\
\hline 2.1 & $\begin{array}{l}\text { Parâmetros cinéticos para a gaseifica- } \\
\text { ção de materiais diversos sob } 7,4 \times 10^{4} \\
P_{a} \text { de vapor [segundo Grabosky (1979)]. }\end{array}$ & 2.18 \\
\hline 2.2 & $\begin{array}{l}\text { Constantes da experssão de Arrhenius } \\
\text { para o cálculo dos parâmetros da equa- } \\
\text { ção (2.21). Gaseificação com } \mathrm{CO}_{2}[\text { se- } \\
\text { gundo Fredersdorff e Elliot (1963)].. }\end{array}$ & 2.22 \\
\hline 2.3 & $\begin{array}{l}\text { Constantes da expressão de Arrhenius } \\
\text { para o cālculo dos parâmetros da equa- } \\
\text { ção (2.22). Gaseificação com } \mathrm{H}_{2} \mathrm{O} \text { [se- } \\
\text { gundo Fredersdorff e Elliot (1963) }] .\end{array}$ & 2.23 \\
\hline 2.4 & $\begin{array}{l}\text { Comparação entre os principais modelos } \\
\text { unidimensionais de gaseificadores au- } \\
\text { totérmicos de leito móvel } \ldots \ldots \ldots \ldots\end{array}$ & 2.37 \\
\hline 3.1 & Coeficiente estequiométrico $v_{i j} \ldots \ldots$ & 3.13 \\
\hline 3.2 & $\begin{array}{l}\text { Constantes da expressão de Arrhenius } \\
\text { para o călculo das velocidades das rea } \\
\text { ções heterogêneas } \ldots \ldots \ldots \ldots \ldots \ldots \ldots\end{array}$ & 3.19 \\
\hline 3.3 & $\begin{array}{l}\text { Termo de força motriz }\left(p_{i}-p_{i e q}\right) \text { para } \\
\text { as reações heterogêneas } \ldots \ldots \ldots \ldots \ldots\end{array}$ & 3.21 \\
\hline 3.4 & $\begin{array}{l}\text { Parâmetros para o cảlculo das constan- } \\
\text { tes de equilíbrio } k_{j} \text { usando a equação } \\
(3.41) \quad \ldots \ldots \ldots \ldots \ldots \ldots \ldots \ldots \ldots \ldots \ldots \ldots \ldots\end{array}$ & 3.21 \\
\hline
\end{tabular}




\begin{tabular}{|c|c|c|}
\hline TABELA NO & TITULO & PAGINA \\
\hline 4.1 & $\begin{array}{l}\text { Estudo numérico: influência do vetor } \\
\text { de tolerância } \varepsilon \ldots \ldots \ldots \ldots \ldots \ldots \ldots \ldots\end{array}$ & 4.4 \\
\hline 4.2 & $\begin{array}{l}\text { Estudo numérico: influência do vetor } \\
\text { de tolerância } \varepsilon \ldots \ldots \ldots \ldots \ldots \ldots \ldots\end{array}$ & 4.7 \\
\hline 4.3 & Influência da corrente elétrica ..... & 4.10 \\
\hline 4.4 & $\begin{array}{l}\text { Influência da pressão em } z=0 \quad \text { sobre } \\
\text { os resultados da simulação } \ldots \ldots \ldots\end{array}$ & 4.16 \\
\hline 4.5 & $\begin{array}{l}\text { Influência do tamanho inicial das par- } \\
\text { tículas sobre os resultados da simula- } \\
\text { ção } \ldots \ldots \ldots \ldots \ldots \ldots \ldots \ldots \ldots \ldots \ldots \ldots \ldots \ldots \ldots \ldots\end{array}$ & 4.29 \\
\hline 4.6 & 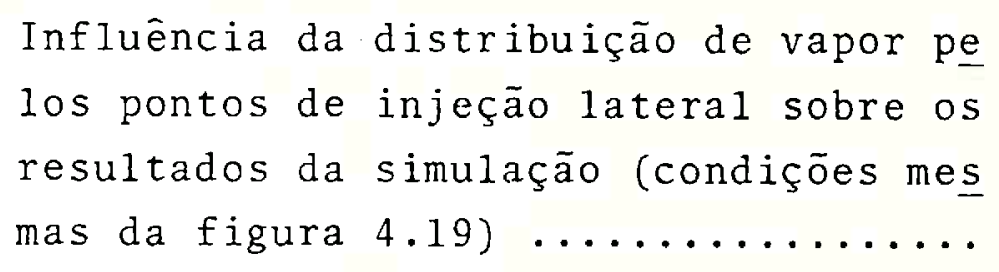 & 4.34 \\
\hline 5.1 & $\begin{array}{l}\text { Dados de caracterização da madeira de } \\
\text { Eucalipto grandis } \ldots \ldots \ldots \ldots \ldots \ldots \ldots\end{array}$ & 5.6 \\
\hline 5.2 & $\begin{array}{l}\text { Resultados da simulação da região } \\
\text { pirólise e secagem (madeira seca) } \ldots\end{array}$ & 5.8 \\
\hline 5.3 & $\begin{array}{l}\text { Resultados da simulação da região de } \\
\text { pirólise e secagem (madeira com } 10 \% \text { de } \\
\text { umidade) } \ldots \ldots \ldots \ldots \ldots \ldots \ldots \ldots \ldots \ldots \ldots \ldots\end{array}$ & 5.9 \\
\hline 5.4 & $\begin{array}{l}\text { Resultados da simulação da região de } \\
\text { pirólise e secagem (madeira com } 20 \% \text { de } \\
\text { umidade) } \ldots \ldots \ldots \ldots \ldots \ldots \ldots \ldots \ldots \ldots\end{array}$ & 5.10 \\
\hline
\end{tabular}




\begin{tabular}{|c|c|c|}
\hline TABELA Nọ & TITULO & PAGINA \\
\hline 5.5 & $\begin{array}{l}\text { Resultados da simulação da região de } \\
\text { pirölise e secagem (madeira com } 30 \% \text { de } \\
\text { umidade) } \ldots \ldots \ldots \ldots \ldots \ldots \ldots \ldots \ldots \ldots \ldots \ldots\end{array}$ & 5.11 \\
\hline 5.6 & $\begin{array}{l}\text { Resultados da simulação da região de } \\
\text { pirólise e secagem (madeira com } 40 \% \text { de } \\
\text { umidade) } \ldots \ldots \ldots \ldots \ldots \ldots \ldots \ldots \ldots \ldots \ldots \ldots\end{array}$ & 5.12 \\
\hline 6.1 & $\begin{array}{l}\text { Influência da umidade da madeira sobre } \\
\text { alguns resultados da simulação (mesmas } \\
\text { condições da figura } 6.1 \text { ) } \ldots \ldots \ldots \ldots\end{array}$ & 6.7 \\
\hline 6.2 & $\begin{array}{l}\text { Influência da temperatura de pirólise } \\
\text { sobre alguns resultados da simulação } \\
\text { (mesmas condições da figura } 6.2 \text { ) .... }\end{array}$ & 6.7 \\
\hline 6.3 & $\begin{array}{l}\text { Influência do parâmetro } L_{p} \text { sobre al- } \\
\text { guns resultados da simulação (mesmas } \\
\text { condições da figura } 6.3 \text { ) } \ldots \ldots \ldots \ldots\end{array}$ & 6.7 \\
\hline 6.4 & $\begin{array}{l}\text { Comparação dos resultados da simulação } \\
\text { com dados experimentais } \ldots \ldots \ldots \ldots \ldots\end{array}$ & 6.9 \\
\hline 6.5 & $\begin{array}{l}\text { Comparação dos resultados da simulação } \\
\text { com dados experimentais } \ldots . . . \ldots \ldots \ldots\end{array}$ & 6.11 \\
\hline 6.6 & $\begin{array}{l}\text { Estudo de um caso em que se dobra a va } \\
\text { zão de madeira } \ldots \ldots \ldots \ldots \ldots \ldots \ldots \ldots\end{array}$ & 6.14 \\
\hline B. 1 & $\begin{array}{l}\text { Entalpia padrão de formação, coeficien } \\
\text { tes da correlação de calor específico a } \\
\text { pressão constante e faixa de validade } \\
\text { da correlação .................... }\end{array}$ & B. 3 \\
\hline
\end{tabular}




\begin{tabular}{clcc}
\hline TABELA Nọ & TITULO & PAGINA \\
\hline B.2 & $\begin{array}{l}\text { Constantes para o cálculo das ental- } \\
\text { pias de reação } \ldots \ldots \ldots \ldots \ldots \ldots \ldots \ldots\end{array}$ & B.6 \\
& Coeficientes e faixa de validade da & \\
B.3 & $\begin{array}{l}\text { correlação de viscosidade dos gases a } \\
\text { baixa pressão } \ldots \ldots \ldots \ldots \ldots\end{array}$ & B.6 $\ldots \ldots \ldots$ \\
& Dados de entrada do programa GAS/ELET & C.13 \\
D.1 & Dados de entrada do programa PIROLISE & D.4
\end{tabular}




\section{CAPITULO 1}

\section{INTRODUÇAO}

A gaseificação é um importante processo de conver são de combustiveis sólidos em gasosos. Consiste no processamento de materias carboniferas (carvōes, madeiras, etc.) poden do reagir com gases (vapor de água, ar, etc.) para obter gases combustiveis $\left(\mathrm{H}_{2}, \mathrm{CO}, \mathrm{CH}_{4}\right.$, etc.) e residuos sólidos (cinzas).

Os gases gerados por este processo, dependendo do seu poder calorifico e composição, podem ser usados como combus tível ou na sintese de combustíveis liquidos.

A utilização de combustiveis sōlidos exige fornathas especiais, com pouca flexibilidade de controle e automação da queima, além de equipamentos adicionais para o. controle da poluição do ar por particulados.

Por outro lado, combustiveis líquidos e gasosos apresentam queima facilmente controlada e automatizada e podem ser utilizados em motores de combustão interna.

Apesar de a gaseificação ser uma técnica relativa mente antiga - a Alemanha jâ a utilizava em escala industrial du rante a Segunda Guerra Mundial para gaseificar carvão e usar o gás de síntese gerado na obtenção de gasolina sintética -, tem sido valorizada em estudos recentes como processo de utilização de fontes de energia alternativas, em especial às de caráter re novável como biomassa (madeiras, resíduos agrícolas).

O material em processamento num gaseificador sofre uma série de processos. Inicialmente uma secagem provoca a perda de umidade. Na volatilização ocorre a liberação de produ tos orgânicos e inorgânicos da pirólise do material, o que au- 
menta seu teor de carbono. Na gaseificação com vapor de água a principal reação que ocorre

$$
\mathrm{C}+\mathrm{H}_{2} \mathrm{O} \rightleftarrows \mathrm{CO}+\mathrm{H}_{2}
$$

é endotērmica, sendo necessārio um suprimento de energia ao gaseificador para que a conversão em gases ocorra.

o suprimento de energia para a reação endotérmica de gaseificação é realizado convencionalmente pela combustão de parte do material com oxigênio ou ar, injetado continuamente junto com o vapor de água, ou ciclicamente, isto $\vec{e}$, alternadamente com o vapor. Os gaseificadores que operam desta maneira são di tos autotérmicos.

Por outro lado, hä os processos ditos alotérmicos em que o suprimento de energia pode ser feito via aquecimento pelas paredes do reator ou pela passagem de corrente elétrica no próprio leito de sólidos, por dissipação pelo efeito joule. Este ültimo processo, conhecido por eletrotérmico, é objeto de estudo deste trabalho.

O desenvolvimento de gaseificadores eletrotērmicos de leito móvel tem sido realizado pela Companhia Energética de São Paulo (CESP), visando a utilização do processo em uma planta para produção de metanol a partir do gás de sintese gera do da gaseificação de madeira.

Pesquisadores da Escola Politécnica, do Instituto de Eletrotécnica e do Instituto de Física da Universidade de São Paulo, sob o patrocínio da CESP, tem estudado o processo, contribuindo para um melhor conhecimento dos gaseificadores ele trotërmicos. O presente trabalho insere-se neste esforço e objetiva obter um modelo matemático capaz de simular o comportamento do gaseificador eletrotêrmico. 
O modelo matemático foi desenvolvido em duas partes, correspondentes a duas regiões do gaseificador. Para a re gião intereletrodos, em que ocorre dissipação por efeito joule, foi elaborado um modelo unidimensional, estātico, com base em balanços diferenciais de massa, energia, quantidade de movimento e equações para o campo elëtrico. Considerou-se a presença de 5 espécies gasosas e 2 na fase sölida e a ocorrência de 4 reações quimicas, 3 das quais heterogêneas - para as quais se utilizou o modelo cinético de nücleo exposto. o modelo resultou em um sistema de equações diferenciais ordinärias de cond ção inicial, que foi resolvido numericamente pelo método de Run ge-Kutta semi-implícito.

Para a região acima do eletrodo superior, corres pondente aos processos de secagem e pirólise da madeira, fo $\bar{i}$ elaborado um modelo macroscópico (dimensão zero) que supõe que a distribuição de produtos seja dada pelo equilíbrio químico.

Foram feitos estudos paramétricos e comparadas as previsões da simulação do modelo com dados experimentais de gaseificadores eletrotërmicos.

Assim, após uma revisão bibliogräfica apresentada no Capitulo 2, é apresentado o modelo para a região intereletro dos no Capitulo 3 e seu estudo paramêtrico no Capitulo 4.

No Capítulo 5 é apresentado o modelo macroscópico da pirólise e secagem e sua simulação.

No Capítulo 6 é feita a simulação do modelo completo, a comparação dos resultados com dados experimentais, e a discussão dos resultados.

Finalmente, no Capítulo 7 são apresentadas as con clusões deste estudo e sugestões para trabalhos futuros. 


\section{CAPITULO 2 \\ REVISAO BIBLIOGRAFICA}

\section{1 - INTRODUÇÃO}

Como parte de importantes subsídios aos capitulos que tratam do modelo matemático do gaseificador eletrotérmico, são apresentadas neste capítulo as principais informaçōes encon tradas na literatura concernentes ao processo de gaseificação.

São apresentados os modelos de reação não-catalítica găs-sōlido, a cinëtica das reaçōes envolvidas na gaseifica ção, os processos de secagem e devolatização, bem como os modelos de gaseificadores tradicionais. Obviamente estes assuntos são objeto de estudo e investigação de vārios pesquisadores e são, portanto, muito amplos. Não se pretendeu por isso, rever completamente a bibliografia sobre tais assuntos, mas apresen tā-los, algumas vezes de maneira qualitativa, com maior ênfase nos aspectos de interesse para os capitulos seguintes.

Tambēm é apresentada uma revisão sobre gaseificadores eletrotérmicos. Neste caso, ao contrārio, o assunto é re lativamente restrito. Na literatura internacional os poucos tra balhos existentes sobre gaseificadores eletrotérmicos referemse a reatores de leito fluidizado. Dada a escassez de informa ções na literatura, apresentou-se uma revisão destes trabalhos, mesmo não se tratando do tipo de reator estudado nesta disserta ção - o de leito fixo. Espera-se, assim, mostrar o que existe desenvolvido, ou em desenvolvimento, sobre reatores eletrotérmi cos. Finalmente, os trabalhos relacionados a gaseificadores ele trotérmicos de leito fixo são apresentados.

Aspectos quantitativos diretamente rclacionados com o modelo matemático foram algumas vezes, quando convenien- 
te, deixados para se apresentar junto ao modelo matemático.

\section{2 - MODELOS DE REAÇÃO GAS-SOLIDO}

As reações químicas que ocorrem nos processos de gaseificação de combustiveis sólidos envolvem fenômenos físicos e químicos em sistemas heterogêneos gās-sôlido. A.velocidade global de reação é influenciada pelos processos físicos associa dos à reação.

Alguns modelos são normalmente utilizados para re presentar a interação entre fenômenos físicos e químicos na velocidade global do processo.

Apresenta-se neste item uma discussão qualitativa desses modelos e sua aplicação para as reações de gaseificação. Não ẻ apresentada aqui a formulação matemātica rigorosa dos modelos de reação gás-sólido, o que pode ser encontrado na litera tura especializada [Wen (1968), Wen (1970), Carberry (1976) , Froment e Bischoff (1976), Smith (1970), Nascimento (1982), Wen e Dutta (1978)].

As reações sólido-fluido foram classificadas por Wen (1968) por dois critérios: um com base nas fases em que se encontram reagentes e produtos da reação e outro com base na ma neira com que a reação progride.

A classificação baseada nas fases em que as várias espécies aparecem apresenta os seguintes tipos:

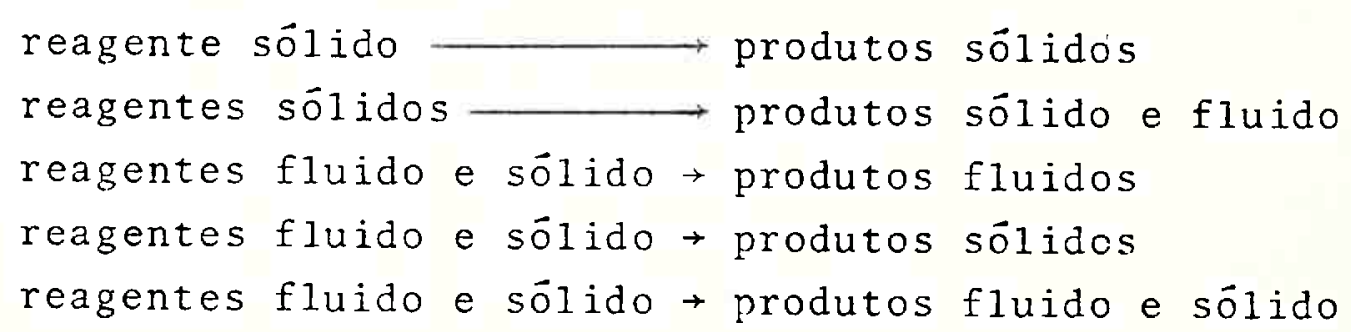


A gaseificação e combustão de materiais carbonífe ros são exemplos de reações do tipo C. Entretanto, se o material encerrar quantidade apreciável de sólidos que não reagem com o reagente gasoso - as cinzas - a reação pode ser melhor re presentada pelo tipo E. A pirôlise de materiais carboniferos en quadra-se no tipo B desta classificação.

Outra classificação è baseada na maneira pela qual a reação avança. Esta classificação considera não apenas como a reação química ocorre mas tambēm as condições do sistema, tais como estrutura interna do sólido, velocidades relativas de reações químicas e difusão de reagentes e produtos, geometria do sólido. Por esta classificação, quatro tipos são considerados [Wen (1968)]:

a) A reação se dã na superfície do sỏlido ou na interface entre o sólido não reagido e uma camada de produto sólido poroso. Este caso ocorre quando a porosidade do sôlido não reagido é muito pequena de tal sorte que o sólido fica praticamente impermeável aos reagentes flui dos. Este comportamento é tambëm observado quando a reação quỉmica é muito rảpida e a difusão do fluido no sôlido ê suficientemente lenta. Nesta situação a. zona de reação fica confinada entre uma estreita região na interface entre o sólido não reagido e o produto.

b) Quando a porosidade do sólido for suficientemente gran de para permitir a livre passagem de reagentes e produ tos fluidos (ou seja, quando a difusividade efetiva de cada componente da fase fluida através do sólido for elevada) pode-se considerar que a reação ocorre homogeamente através da fase sólida.

c) Nas reaçōes acompanhadas de mudança de fase dos componentes sỏlidos ou evolução de matērias voláteis, os sô lidos fundem ou sublimam antes de entrar em contato e 
reagir com os reagentes gasosos. Isto pode ocorrer de vido a uma condução de calor insuficiente na matriz só lida onde está ocorrendo reação exotérmica. Tal mudan ça de fase pode ocorrer, por exemplo, na pirölise e de volatilização freqüentemente associadas aos processos de combustão e gaseificação de combustiveis sôlidos.

d) Em muitos casos o reagente sôlido não pode ser conside rado distribuido de modo homogêneo na fase sōlida, mas na forma de um conjunto de grãos distribuidos na matriz sólida. A reação ocorre entre cada pequeno grão de reagente sôlido e o reagente fluido, que difunde pe la matriz atē atingir o grão.

Alguns modelos conceituais sāo comumente utilizados como uma razoável representação das situações descritas. Es ses modelos são descritos a seguir.

No modelo conhecido por homogêneo, considera-se que - gás penetra na partícula sólida e reage simultaneamente em to da a extensão da partícula. Dessa forma o reagente sólido é convertido continua e progressivamente como um todo, conforme ilustra a figura 2.1 .

O modelo volumétrico [Wen e Dutta (1979)] ou de conversão progressiva [Levenspiel (1974)] trata da reação ocor rendo sobre todo o volume da partícula sólida mas com a concentração dos reagentes sólido e gasoso distribuída não uniforme mente, levando em conta a difusão do reagente gasoso para dentro da particula e a difusão dos produtos para fora da mesma. A figura 2.2 ilustra o modelo volumétrico.

Os modelos homogêneo e volumétrico são normalmen te aplicados às reações do tipo (b) da classificação descrita.

O modelo de núcleo não reagido ou de frente mö- 
vel considera a reação ocorrendo em uma frente que se move progressivamente em direção ao centro da partícula, deixando atrás de si as cinzas do sólido convertido. As cinzas permanecem na estrutura como uma camada ao redor do núcleo näo reagido. A si tuação estā ilustrada na figura 2.3 , em que a partícula é pratí camente impermeável ao gâs ou a reação é muito rápida em relação à difusão.

No caso de sólidos pororos, a reação não se dá em uma superficie mas estende-se em uma zona mais ou menos difusa, caracterizando uma situação representada pelo modelo de zona mó vel, como ilustrado na figura 2.4.

Nos casos em que a cinza formada não permanece $1 \underline{i}$ gada ao núcleo não reagido, mas separa-se deste, a partícula di minui gradativamente de tamanho à medida em que a reação ocorre. Nesta situação não hã uma camada de cinza que constituiria uma resistência a mais à difusão dos reagentes gasosos. Para este caso há o modelo de núcleo exposto ou de segregação de cinza, ilustrado na figura 2.5. Este modelo é aplicável aos casos em que o material sólido possui pequeno teor de cinzas ou quando as cinzas são formadas de maneira frägil, não aderente, ou ainda quando as condições de escoamento das duas fases provocam o des prendimento das cinzas, por atrito ou choques entre as partículas.

Hä também um modelo conhecido por modelo de grão ("particle-pellet model"), em que a partícula sólida é considerada como um conjunto de pequenos grãos, cada um deles reagindo por exemplo, segundo o modelo de núcleo não reagido. Este tipo de modelo, ilustrado na figura 2.6, representa um comportamento intermediārio entre as classificaçōes (a) e (b) descritas anteriormente, e constitui uma boa representação para o tipo (d) da quela classificação.

De uma maneira geral os modelos mais utilizados pa ra representar as reações de gaseificação são o de núcleo não 


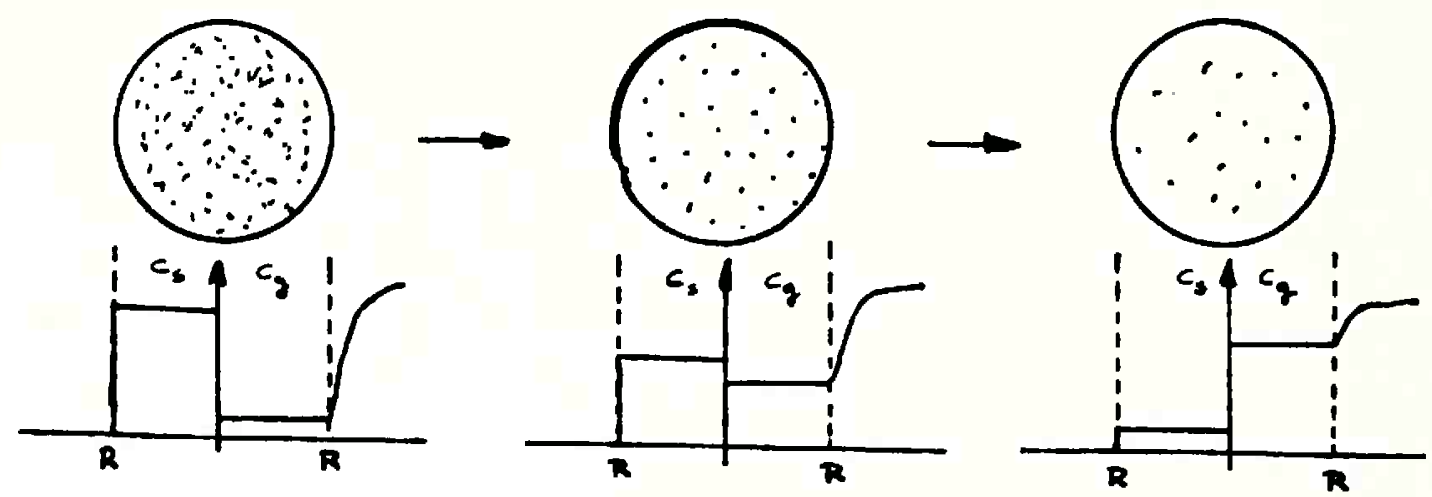

Figura 2.1. Esquema para representação do modelo homogêneo.
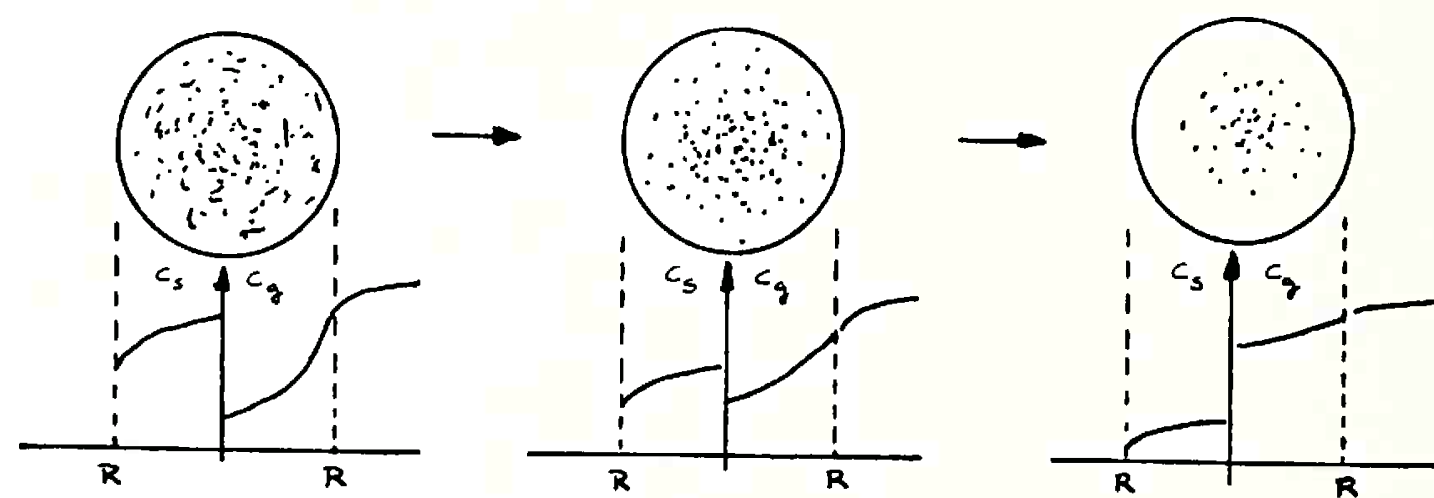

Figura c.a. Esquema para a zepresentação do modelo volumétrico.
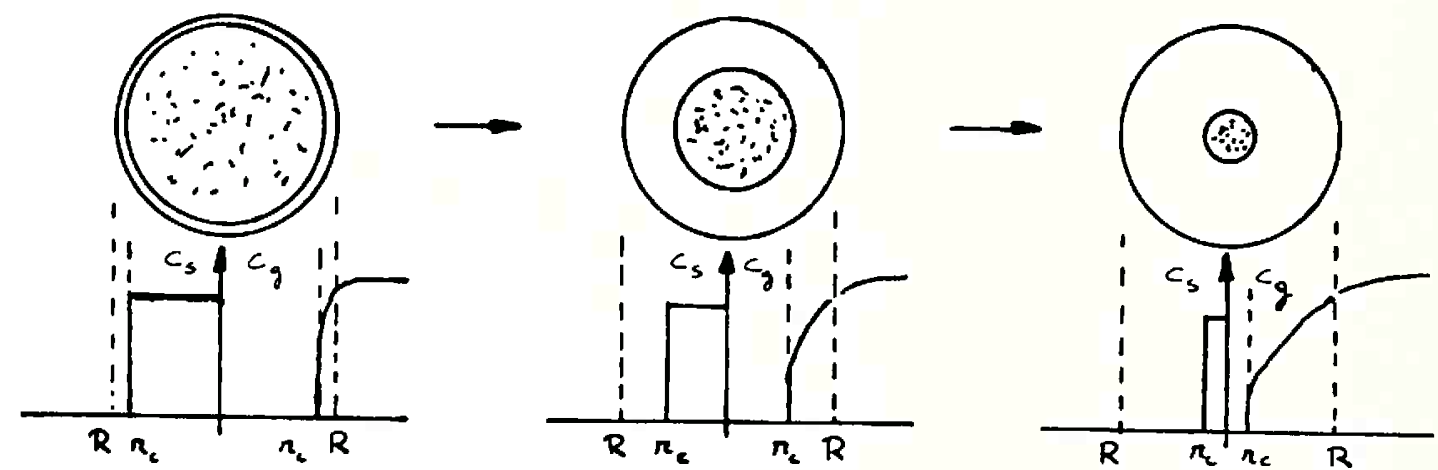

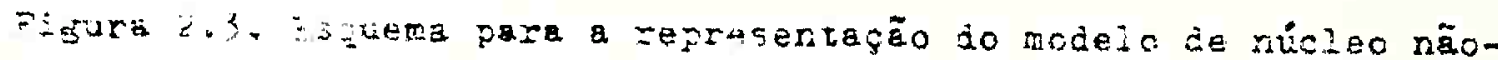
- magide. 

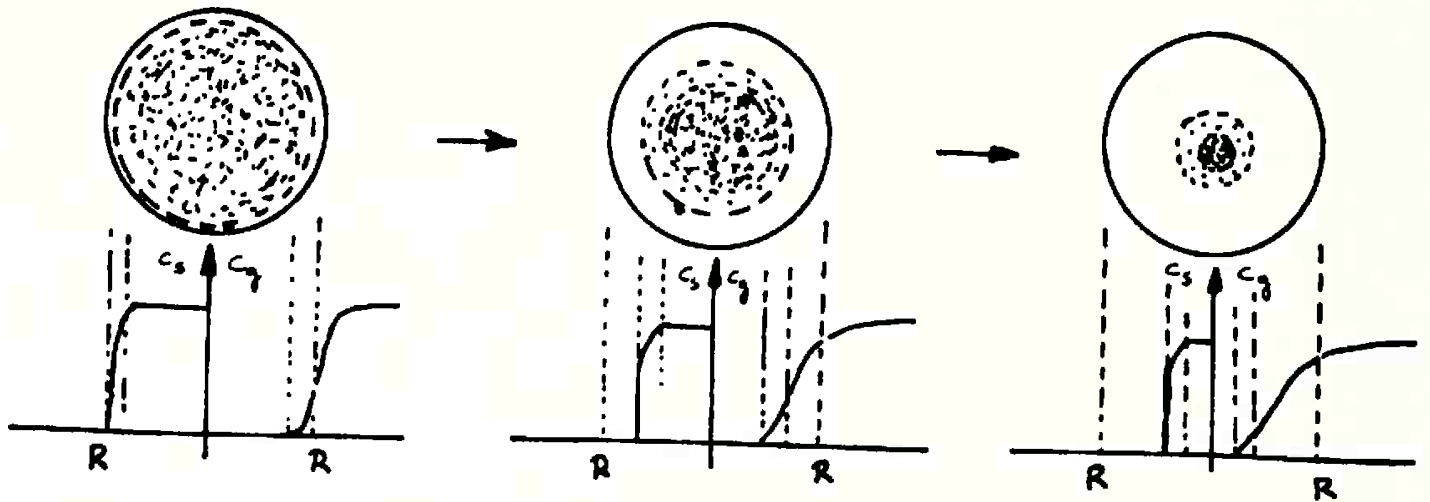

Figura 2.4. Esquema do nodelo de zona de reação móvel.
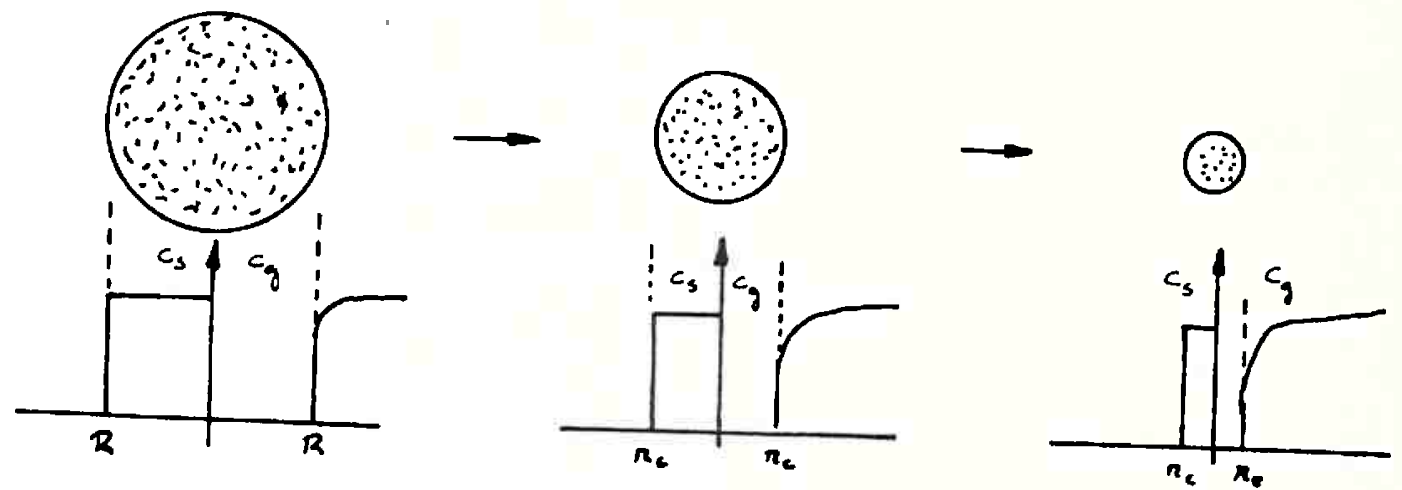

Pigura 2.5. Esquema para representação do modelo de núcleo expos to.
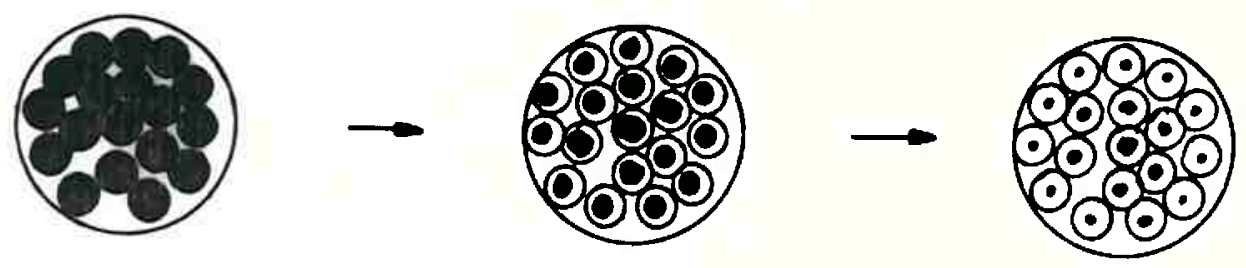

İgurm in " "particie-peilet model"). 
reagido e o de núcleo exposto, motivo pelo qual são enfocados a seguir.

No modelo de núcleo não reagido a cinētica global do processo pode ser limitada por três resistências a saber:

- a resistência à transferência de massa do seio do gás até a superfície externa da partícula;

- a resistência à transferência de massa atravês da camada de cinza que envolve o núcleo central e,

- a resistência correspondente à cinética da reação no nú cleo central.

Estas três resistências em série podem ser combi nadas para fornecer a velocidade global da reação, na forma [Yoon et alii (1978)]:

$$
r_{j}=\frac{\left(1-\varepsilon_{\ell}\right)\left(p_{i}-p_{i_{e q}}\right)}{\frac{d p}{6 k_{p_{i}}}+\frac{d p^{(0) 2}\left(1-f_{l}\right)}{12 f_{r} D_{z, i}}+\frac{1}{\eta_{j} f_{r}^{3} k_{r_{j}} C_{C}^{(0)}}}
$$

No modelo de núcleo exposto ou de segregação de cinza não hã uma camada de cinza separando o núcleo do gás. A segunda resistência do modelo anterior deixa de existir e a taxa de reação pode ser expressa por [Yoon et alii (1978)]:

$$
r_{j}=\frac{\left(1-\varepsilon_{\ell}\right)\left(p_{i}-p_{i_{e q}}\right)}{\frac{d p f_{r}}{6 k_{p i}}+\frac{1}{n_{j} k_{r_{j}} C_{c}^{(0)}}}
$$

$\mathrm{Na}$ dedução dessas expressōes (ver Apêndice A) è assumido que a partícula seja isotêrmica e é adotada a aproxima ção de estado pseudo-estacionärio, isto é, a retração do núcleo considerada muito lenta em relação à velocidade de difusão do 
reagente gasoso at $\vec{e}$ o nücleo.

Em ambas as expressões considera-se a possibilida de de limitação da reação pelo equilíbrio químico no termo da "força motriz" ( $\left.p_{i}-p_{i e q}\right)$.

Também é considerada a resistência à difusão nos poros do nücleo do material pelo uso do fator de efetividade da reação, $\eta_{j}$. Este é definido como a relação entre a taxa média em todo o volume da partícula e a taxa de reação calculada nas condições da superficie externa do núcleo do material, e será tratado no item 2.3.2.

E possivel ainda estabelecer um tratamento mais simplificado, adotando-se temperaturas limitantes para a mudança do passo controlador da reação global. Um exemplo deste tra tamento é apresentado por Biba et alii (1978), que escreveram a taxa de reação limitada pela cinética, pela difusão nos poros e pela difusão no filme gasoso externo, respectivamente, na for ma :

$$
\begin{aligned}
& r_{j}=k_{j}(T) a_{t} C_{i}=k_{j}(T) a_{t} C_{i} \\
& r_{j}=\sqrt{k_{j}(T) D_{i}} \frac{\sqrt{2 r_{p}}}{d_{p}} a_{t} C_{i}=\sqrt{k_{j}(T) k_{j}\left(T_{A}\right)} a_{t} C_{i} \\
& r_{j}=\frac{D_{i}}{\delta} a_{S} C_{i}=\sqrt{k_{j}\left(T_{A}\right) k_{j}\left(T_{B}\right)} a_{t} C_{i}
\end{aligned}
$$

onde $k_{j}\left(T_{A}\right)$ e $k_{j}\left(T_{B}\right)$ representam a influência da difusão nos po ros e difusão externa, sendo calculadas por:

$$
\begin{aligned}
& k_{j}\left(T_{A}\right)=\sqrt{D_{i}} \frac{\sqrt{2 r_{p}}}{d_{p}}=B_{j} \exp \left(\frac{-E_{j}}{R T_{A}}\right) \\
& k_{j}\left(T_{B}\right)=\sqrt{D_{i}} \frac{d_{p}}{\sqrt{2 r_{p}}} \frac{1}{\delta} \frac{a_{s}}{a_{t}}=B_{j} \exp \left(\frac{-E_{j}}{R T_{B}}\right)
\end{aligned}
$$


Assim $\mathrm{T}_{\mathrm{A}}$ e $\mathrm{T}_{\mathrm{B}}$ são limites de temperatura para o passo controlador:

- se $\mathrm{T}<\mathrm{T}_{\mathrm{A}}$, 1imitação pela cinëtica [eq.(2.3)]

- se $\mathrm{T}_{\mathrm{A}}<\mathrm{T}<\mathrm{T}_{\mathrm{B}}$, limitação pela difusão nos poros [eq. $(2.4)]$

- se $\mathrm{T}_{\mathrm{B}}<\mathrm{T}, 1$ imitação pela difusão externa [eq.(2.5)].

Sobre a aplicabilidade desses modelos, Wen (1968) concluiu, com base em estudos de numerosos sistemas, que o mode 10 de núcleo nāo reagido $\bar{e}$ a melhor e a mais simples representa ção para a maioria das reações gâs-sỏlido.

No caso específico de gaseificação de carvão, Wen e Dutta (1979) sugerem o modelo de núcleo não reagido para representar a reação de combustão rápida de carvão, enquanto as reações de gaseificação com vapor de água, dióxido de carbono e hidrogênio seriam melhor representadas pelo modelo volumétrico, por serem relativamente mais lentas. Os mesmos autores advertem, porém, que se as concentrações dos gases reagentes forem altas, as velocidades serão comparāveis, cabendo o uso do mode10 de nücleo não reagido.

Souza Santos (1984) indica que os diversos tipos de carvão mineral apresentam normalmente caracteristicas de cin za bem aderente à partícula, enquadrando-se bem no modelo de nú cleo não reagido, enquanto madeira e por conseqüência carvão vê getal tipicamente não apresentam cinzas aderentes, caracterizan do um comportamento melhor representado pelo modelo de núcleo exposto.

Este argumento è reforçado pelos dados de Grabosky e Bain (1979) que reportam composições de värios materiais carbonäceos, os quais mostram que grande parte das madeiras e car vōes vegetais apresentam teores de cinza menores que $3 \%$ (base 
seca), o das madeiras freqüentemente menores que $1 \frac{\circ}{2}$. Os carvōes minerais, ao contrărio, podem chegar a teores bem maiores que 15: dependendo de sua origem. A pequena porcentagem de cinza nas madeiras e carvões vegetais justificam a escolha para esses materiais, do modelo de núcleo exposto.

\section{3 - CINETICA dAS REAÇOES de GASEIFICAÇÁo}

\subsection{1 - Considerações sobre as reações heterogêneas}

Tanto os carvões vegetais como os minerais são compostos principalmente de carbono. As principais reações heterogêneas de gaseificação são as com vapor de ägua, dióxido de carbono, hidrogênio e oxigênio. Apesar de importante para o es tudo dos gaseificadores autotérmicos tradicionais, onde ocorre combustão parcial do carvão junto ao processo de gaseificação, a reação com oxigênio não será tratada neste trabalho, visto que suas importância é secundāria em gaseificadores eletrotérmicos.

A reatividade dos carvões em presença de atmosfe ras reativas é função complexa da temperatura, da estrutura da partícula sólida, da origem da fonte de carbono e do pré-trata mento térmico sofrido pelo sólido. A cinética global pode ser afetada não só pela cinética química mas tambēm pela transferên cia de massa externa e interna à partícula. Alèm disso os efei tos térmicos associados às reações podem causar gradientes de temperatura significantes na partícula. Assim qualquer discus são sobre a cinética deve incluir os efeitos de transferência de calor e massa.

Grabosky (1979) utiliza para esta discussão o modelo de partícula porosa típica de materiais de pequeno teor de cinzas - como a madeira -, conforme ilustra a figura 2,7. Den tro dessa óptica, os fenômenos que ocorrem na gaseificaçäo podem ser considerados nos seguintes estágios: 
1) Difusão dos reagentes atravês do filme estagnante que envolve a superfície externa da particula;

2) Difusão do gás reagente dentro dos poros da partícula;

3) Adsorção, reação de superfície e dessorção da matriz sōlida;

4) Difusão dos produtos da reação para fora do poro;

5) Difusão dos produtos da reação através do filme estacionário para o meio exterior.

Considera-se tambēm a transferência de calor que deve suprir as necessidades energéticas para que as reaçōes ocor ram nos níveis desejados.

os estágios 1 e 5 são transferências de massa externas em geral expressas por um coeficiente de transporte de massa. Para operações com leito de enchimento, várias correlações são disponiveis, por exemplo a de Gupta e Thodos (1963):

$$
j_{d}=\frac{k_{m}}{u}(S c)^{2 / 3}=\frac{2,06}{\varepsilon_{l}}\left(\frac{\mu}{\rho d p u}\right)^{0,575}
$$

Observa-se que a influência do transporte de massa externo na velocidade global do processo pode ser minimizada aumentando-se a velocidade de passagem do gás pelas partículas ou diminuindo-se o tamanho das partículas.

o estudo de Grabosky (1979) mostraram que na fai$x a$ de 1073 a 1273 K o coeficiente de transferència de massa dos estägios 1 e 5 não é afetado significativamente pela temperatura. Se se representar esta influência por uma expressão do tí po Arrhenius: 


$$
k_{m}=k_{m_{0}} \exp \left(-\frac{E_{m}}{R T}\right)
$$

um valor de $E_{m}$ menor que $17 \times 10^{3} \mathrm{~J} / \mathrm{mol}$ é obtido para faixas de temperatura acima de $1073 \mathrm{~K}$, o que è um valor muito pequeno em comparação com energias de ativação da ordem de $210 \times 10^{3} \mathrm{~J} / \mathrm{mol}$ para a cinētica da reaçāo de superfície (k).

Assim, para altas temperaturas $k$ tende a ser maior do que $k_{m}$ devido à diferença entre as energias de ativação dos dois processos em questão. Como $k_{m}$ apresenta pequena energia de ativação a taxa global torna-se independente da temperatura para temperaturas altas.

A transferencia de calor pode ser tratada de modo anālogo à de massa. Para reações heterogêneas muito rápidas, , com alta entalpia de reação, partículas grandes ou velocidades de escoamento pequenas, a temperatura do sólido pode diferir significativamente da do gás. Este problema, no entanto, desperta menor interesse em reatores eletrotërmicos, onde a diss $\underline{i}$ pação por efeito Joule ocorre no pröprio leito de partículas.

O efeito da difusão nos poros para o gās reagir dentro da partícula pode ser considerado pelo fator de efetividade da reação, definido como a relação entre a taxa média de reação em todo o volume da partícula e a taxa calculada nas con dições da superfície externa:

$$
\eta=\frac{\frac{1}{v_{p}} \int_{v p} r d v}{r_{\text {sup }}}
$$

o fator de efetividade é expresso em função grupo adimensional módulo de Thiele, o qual leva em conta a difusividade efetiva do gás nos poros da matriz sólida ( $D_{e f}$ ), a cinética intrínseca da reação (k), a ordem da reação (m), con- 
centração do gãs na superfície externa $\left(\mathrm{C}_{\mathbf{s}}\right)$ :

$$
\Phi=L\left(\frac{k_{r} C_{s}^{m-1}}{\Lambda D_{\text {ef }}}\right)^{1 / 2}
$$

onde L é uma dimensão característica (meia espessura para placa plana, raio para esfera ou cilindro), $\Lambda$ o coeficiente estequiométrico do reagente sólido.

Para larga faixa de modelos cinéticos o fator de efetividade difere pouco do caso de primeira ordem. Para partí cula isotérmica e reação de primeira ordem tem-se:

$$
\begin{aligned}
& n=\frac{\tanh \Phi}{\Phi} \quad \text { geometria plana } \\
& n=\frac{3}{\Phi} \frac{I_{1}\left(\frac{2}{3} \Phi\right)}{I_{0}\left(\frac{2}{3} \Phi\right)} \text { geometria cilíndrica } \\
& n=\frac{3}{\Phi}\left(\frac{1}{\tanh \Phi}-\frac{1}{\Phi}\right) \text { geometria esférica }
\end{aligned}
$$

Bird et alii(1960) mostraram que para geometrias di ferentes da esférica pode-se exprimir o fator de efetividade pe la equação (2.13) em função de um módulo de Thiele modificado, $\Phi^{\prime}$, com erro menor que $10 \%$, para reações de primeira ordem:

$$
\Phi^{\prime}=\frac{1}{a_{S}}\left(\frac{k_{\dot{r}}}{\Lambda D_{e F}}\right)^{1 / 2}
$$

onde as $\bar{e}$ a superfície externa por unidade de volume da partícu1 a.

Se o processo è controlado pela difusão nos poros a velocidade aparente de reação fica: 


$$
k_{a p} \propto\left(k D_{j}\right)^{1 / 2}
$$

Na hipótese de ser a energia de ativação para a difusão muito menor que a da reação, tem-se

$$
E_{a p}=\frac{E_{\text {reação }}+E_{\text {difusão }}}{2}=\frac{E_{\text {reação }}}{2}
$$

ou seja a energia da ativação do processo global serā aproximadamente igual à metade da energia de ativação da reação de superficie.

o comportamento geral, mostrado na figura $2.8, \mathrm{com}$ bina os efeitos dos vărios estágios. Sob baixas temperaturas a cinética da reação tende a zero e os demais processos tornam-se relativamente mais rāpidos, uma vez que são menos influenciados pela temperatura. Nestas condições a reação de superfície $\vec{e} \quad$ estägio limitante da gaseificação. Aumentando-se a temperatura, a difusão nos poros passa a ser importante e para temperaturas muito altas é o transporte de massa externo que controla o processo.

\subsection{2 - Cinética das reações gäs-sólido}

O comportamento da velocidade das reações de gaseificação é estudado em värios textos e artigos mas, ainda ho je, värios aspectos não estāo. suficientemente esclarecidos. Re visões sobre o assunto são dadas por Baltchelder et alii(1953), Walker et alii (1959), Smoot e Pratt (1979), Wen e Dutta(1979).

Foi observado que a velocidade de reação com um mesmo reagente gasoso pode apresentar variações significativas dependendo do material que estā sendo gaseificado. Os pesquisa dores explicam este fato pelas diferenças na composição das cin zas dos materiais, compostas de vārias substâncias inorgânicas que podem agir como catalisadores das reações e outras que pode 


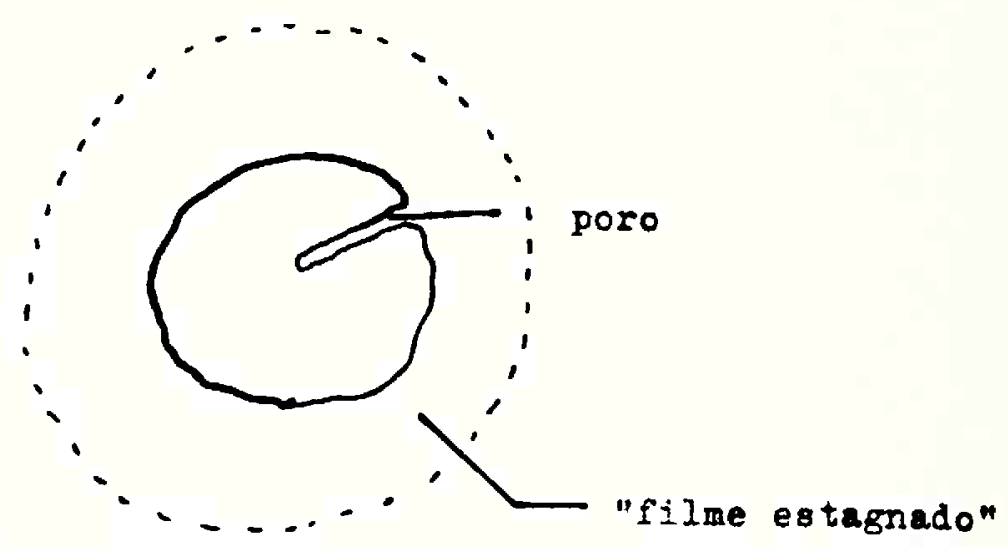

Figura 2.7. Esquema de partícula porosa (fonte: Grabosky(1979)).

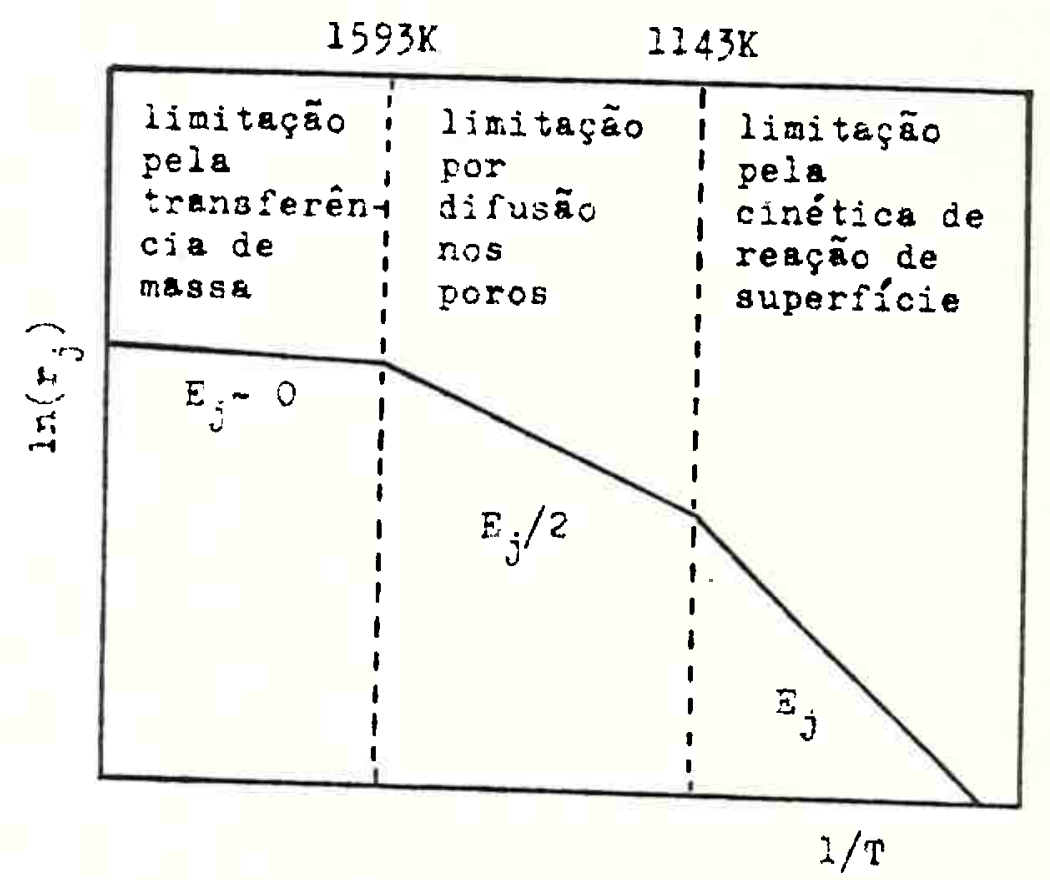

Fieura 2. E. Efejto da temperatira na velocidade de reacoes heterogeneas (conte: Grabosky (1979)). 
riam atuar como venenos catalíticos. Por exemplo Johnson(1979) mostrou que certos sais e óxidos de metais alcalinos e alcalino-terrosos $\left(\mathrm{K}_{2} \mathrm{CO}_{3}, \mathrm{Na}_{2} \mathrm{CO}_{3}, \mathrm{KCl}, \mathrm{NaCl}, \mathrm{CaO}\right)$ e de alguns outros metais podem agir como catalisadores das reações de gaseificação. Impurezas presentes na superfície podem também catalisar a reação de deslocamento, homogênea. Na 1iteratura encontramse estudos sobre impregnação artificial de catalisadores em car vões e madeiras a serem gaseificados.

Outro fator que pode estar associado às variações encontradas nas taxas de reação de superficie $\vec{e}$. a estrutura "cristalina", ou grau de grafitizaçāo ou grau de aromatização do carvão a ser gaseificado. O "char" de carvão mineral, que guar da semelhança com o carvão vegetal, apresenta estrutura química polinuclear aromätica. Pilcher et alii (1955) observaram que a reatividade decresce com o aumento da "cristalinidade" da estru tura do material.

A maior parte dos estudos disponiveis sobre gasei ficação expressam sua velocidade em termos de massa de carbono consumida por massa de carbono original por unidade de tempo, sem estudar a composição do gās gerado.

Alguns resultados experimentais de cinética de ga seificação sob $7,4 \times 10^{4} \mathrm{~Pa}$ de vapor de água são mostrados na Tabela 2.1. Analisando estes dados, verifica-se que a natureza do material é evidenciada pelo fator pré-exponencial que, de mo do geral, diminue com o grau de grafitização. O fator pré-expo nencial está associado ao número de sítios ativos enquanto a energia de ativação relaciona-se com a atividade química dos sí tios (Grabosky (1979)). Os dados da Tabela 2.1 aparentam que a disponibilidade de sitios ativos é maior nos carvões vegetais que nos minerais, sugerindo maior superfície ativa ou estrutura menos ordenada.

O efeito da perda de massa ("carbon burnoff" ou "burnout") sobre a velocidade de gaseificação tem sido objeto 
TABELA 2.1 - Parâmetros cinëtjcos para a gaseificação de materiais diversos sob $7,4 \times 10^{4}$ Pa de vapor [segundo Grabosky (1979)].

$k=k_{0} \exp (-E / R T)$

\begin{tabular}{|c|c|c|}
\hline Material. & $\begin{array}{l}\text { Energia de Ativação } E \\
\qquad(\mathrm{~kJ} / \mathrm{mol})\end{array}$ & $\begin{array}{l}\text { Fator prë-exponencial } \\
k_{0} \quad(\mathrm{~kg} / \mathrm{kg} / \mathrm{s})\end{array}$ \\
\hline madeira "poplar" & 181 & $2,0 \times 10^{6}$ \\
\hline palha & 181 & $9,8 \times 10^{5}$ \\
\hline casca & 155 & $9,7 \times 10^{4}$ \\
\hline turfa & 169 & $8,5 \times 10^{4}$ \\
\hline carvāo betuminoso & 204 & $9,8 \times 10^{5}$ \\
\hline
\end{tabular}


de numerosos estudos e a dependência se apresenta de maneira complexa e algo confusa. Sabe-se que a perda de massa altera a distribuição de tamanho dos poros, o volume do poro e conseqüen temente a área disponível para a reação. Alguns resultados de estudos feitos por Rensfelt et alii (1978) são mostrados nas f $\underline{\mathbf{i}}$ guras 2.9 e 2.10 , ilustrando a influência da perda de massa na velocidade de reação de vapor de água com diversos materiais e para diferentes temperaturas, respectivamente.

Os estudos cinéticos da reação de gaseificação em atmosfera de dióxido de carbono são mais comum que os com vapor de água devido a não ocorrência, no primeiro caso, de reações secundárias com os produtos da reação. A reação com hidrogênio é menos estudada.

0 mecanismo mais comumente atribuido à reação do "char" com gãs carbônico supõe dois passos: a colisão de uma mo lécula de $\mathrm{CO}_{2}$ com um sítio ativo livre $\left(\mathrm{C}_{\ell}\right)$ produzindo uma molécula de $\mathrm{Co}$ e deixando um átomo de oxigênio adsorvido, seguida do desprendimento de uma molécula de CO deixando n sitios ativos 1 ivres.

$$
\begin{array}{r}
\mathrm{C} \ell+\mathrm{CO}_{2} \rightarrow \mathrm{CO}+\mathrm{C}(0) \\
\mathrm{C}(0) \rightarrow \mathrm{CO}+\mathrm{n} \mathrm{C} \ell
\end{array}
$$

O mecanismo normalmente usado para a reação com vapor de água è análogo ao exposto acima:

$$
\begin{array}{r}
\mathrm{Cl}_{\ell}+\mathrm{H}_{2} \mathrm{O} \\
\mathrm{C}(0)+\mathrm{H} 2+\mathrm{C}(0) \\
+\mathrm{nCl}
\end{array}
$$

Tais mecanismos são consistentes com as expressões tipo adsorção de Langmuir, normalmente utilizadas para re presentar a velocidade destas reações: 


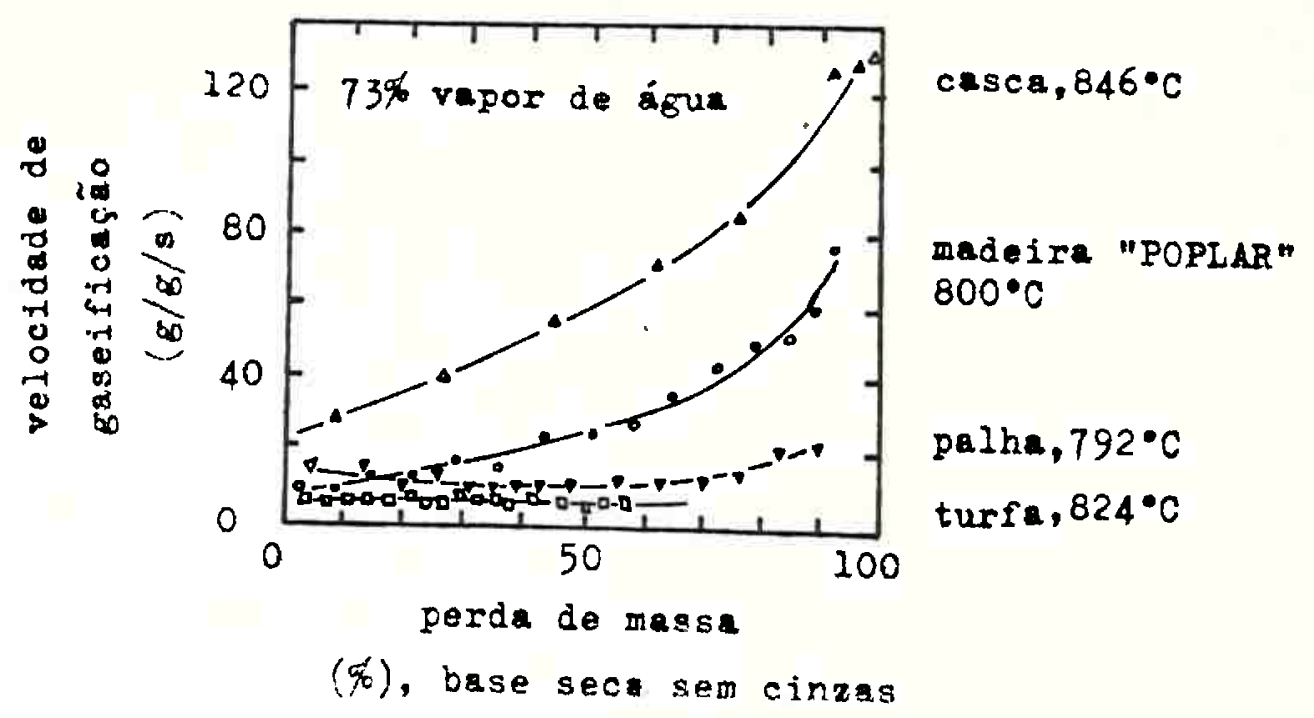

Figura 2.9. Infiuencia da peria de massa na velocidade de Gaseificação de diversos materiais em tistura de $73 \%$ de vapor de água e $27 \%$ de argônio (fonte: Rersfeit et alif(2978)).

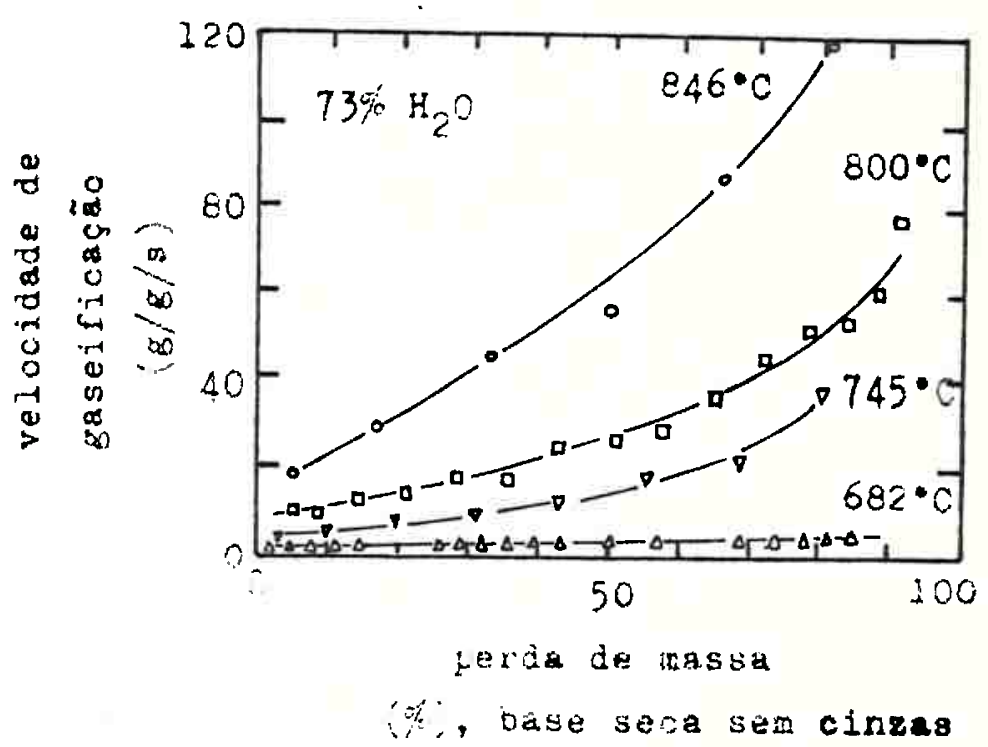

Tiéra 2.20. Inijuência da perda de massa na velocidade de Easéficaçào de madeira "PCFLAR" en misturk de $73 \%$ de vapor de ágis e ?7\% de argonio fonte: Ponerait et azis(1979?). 


$$
\mathrm{r}_{\mathrm{C}+\mathrm{CO}_{2}}=\frac{\mathrm{k} \mathrm{p}_{\mathrm{CO}_{2}}}{1+\mathrm{a} \mathrm{p}_{\mathrm{CO}}+\mathrm{b} \mathrm{p}_{\mathrm{CO}_{2}}}
$$

$$
\mathrm{r}_{\mathrm{C}+\mathrm{H}_{2} \mathrm{O}}=\frac{k^{\prime} \mathrm{p}_{\mathrm{H}_{2} \mathrm{O}}}{1+\mathrm{a}^{\prime} \mathrm{p}_{\mathrm{H}_{2}}+\mathrm{b}^{\prime} \mathrm{p}_{\mathrm{H}_{2} \mathrm{O}}}
$$

Estas expressões mostram a possibilidade de a rea ção com $\mathrm{CO}_{2}$ ser inibida por $\mathrm{CO}$ ou $\mathrm{CO}_{2}$ e de a reação com $\mathrm{H}_{2} \mathrm{O}$ ser inibida por $\mathrm{H}_{2}$ ou $\mathrm{H}_{2} \mathrm{O}$.

Hä diversos outros mecanismos ou passos complemen tares propostos para explicar comportamentos menos comuns destas reações. Estes outros mecanismos e passos podem ser vistos em Walker et alii (1959) e Fredersdorff e Elliot (1963). Dessa ültima revisão foram reproduzidas as tabelas 2.2 e 2.3 que mostram as constantes de Arrhenius para o câlculo dos parâmetros das equaçōes $(2.21)$ e (2.22), para alguns materiais.

A reação de gaseificação com hidrogênio para for mar metano é conhecida por hidrogaseificação. Sabe-se que esta reação pode ocorrer de duas formas. Se o "char" è preparado e estabilizado em atmosfera inerte, a taxa de hidrogaseificação é pequena, ao passo que a reação de hidrogênio com "char" recém formado da pirólise é bem mais rápida. Uma revisão sobre hidro gaseificaçāo foi feita por Anthony e Howard (1976). O mecanismo proposto por Zielke e Gorin (1955) para esta reação envolve a saturação reversível de uma ligação do anel aromático do "char" por hidrogénio, seguido da ruptura do anel com a entrada de outra molécula de $\mathrm{H}_{2}$ e finalmente a desalquilação para formar metano:

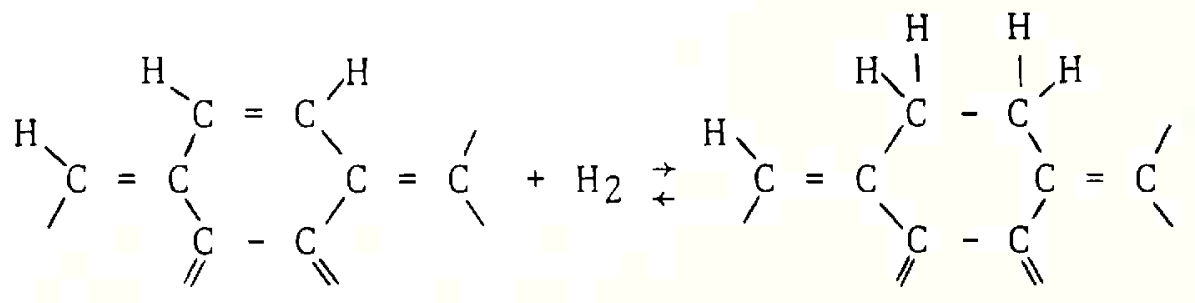




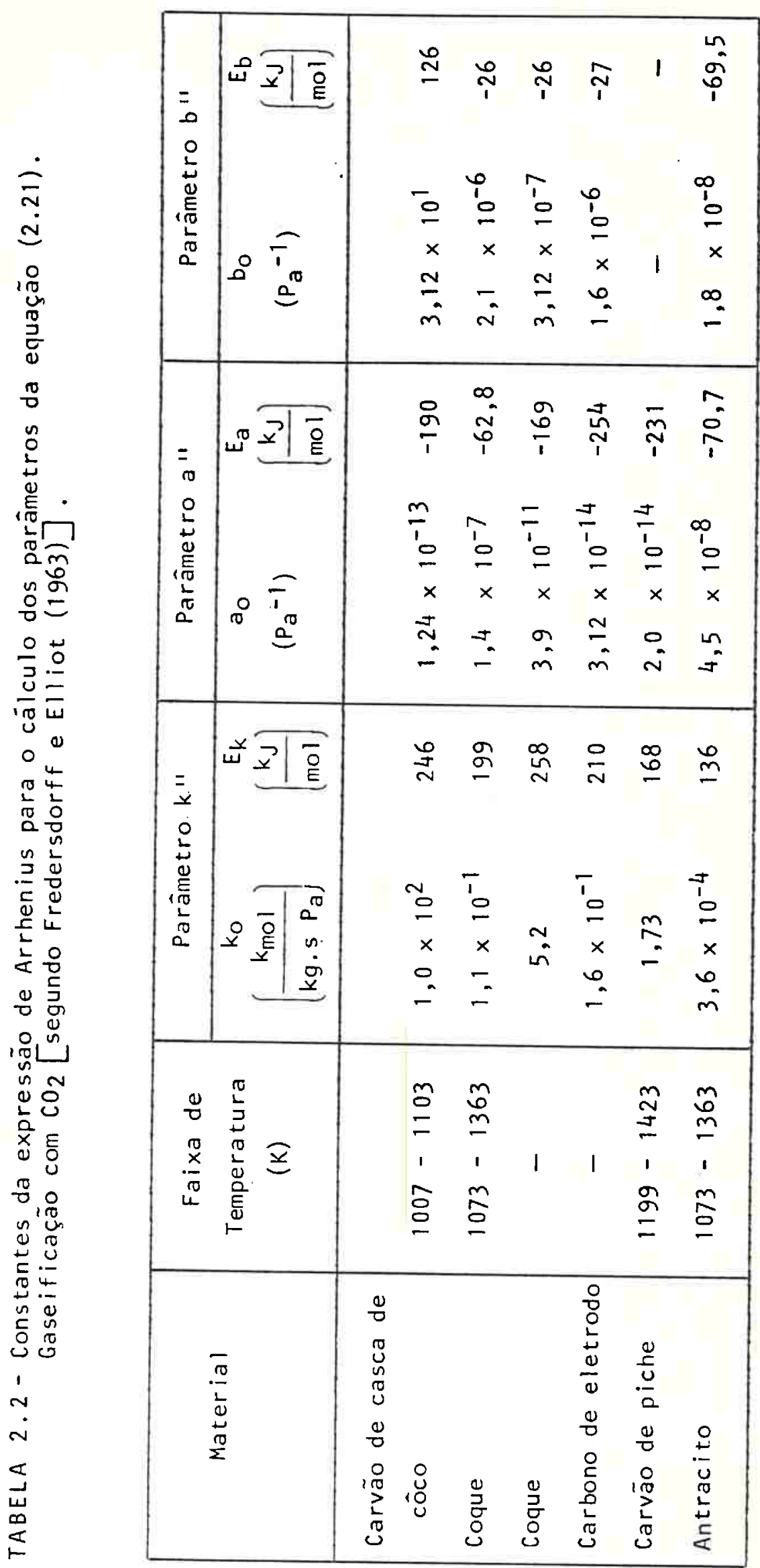




\begin{tabular}{|c|c|c|c|c|c|c|c|c|c|c|c|}
\hline 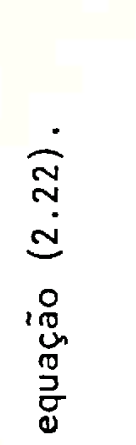 & 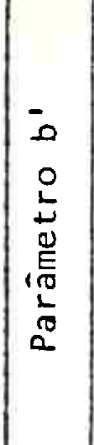 & 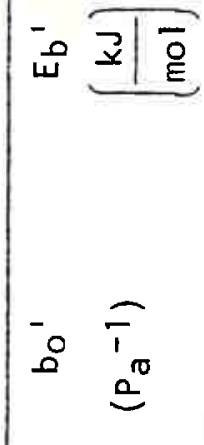 & 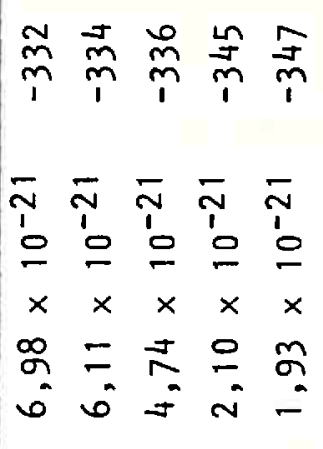 & 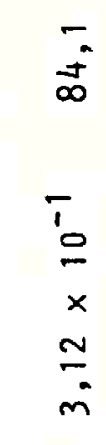 & $\begin{array}{l}1 \\
1\end{array}$ & $\begin{array}{l}1 \\
1\end{array}$ & 1 & 1 & 1 & 1 & I \\
\hline 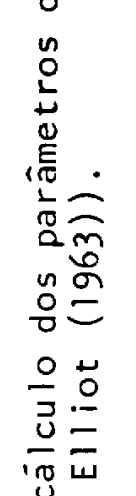 & 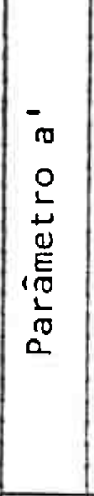 & " & 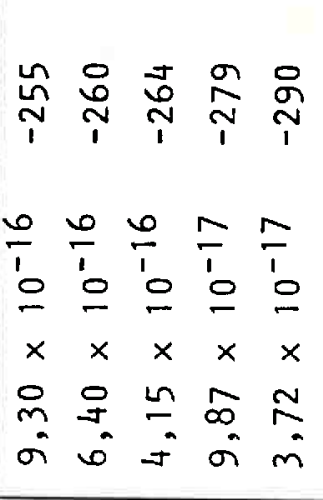 & $\begin{array}{c}0 \\
\overrightarrow{1} \\
0 \\
x \\
m \\
m\end{array}$ & I & 1 & 1 & $\frac{\vec{m}}{\mathrm{r}}$ & 1 & 1 & 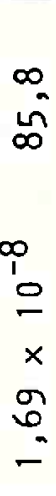 \\
\hline 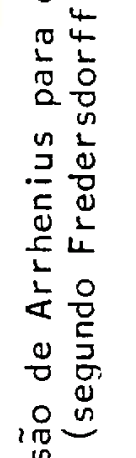 & 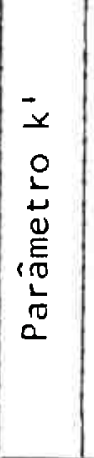 & 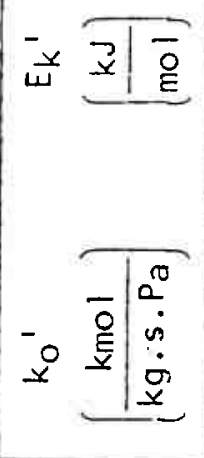 & 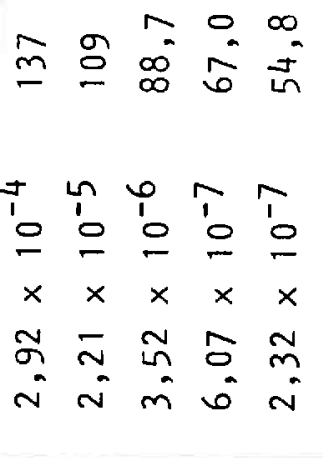 & 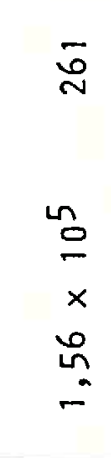 & $\begin{array}{l}\stackrel{\infty}{N} \\
1\end{array}$ & $\underline{\underline{\Xi}}$ & $\cong$ & $\stackrel{g}{ \pm}$ & $\stackrel{ }{=}$ & $\begin{array}{l}\infty \\
\infty \\
-\end{array}$ & $\vec{A}$ \\
\hline 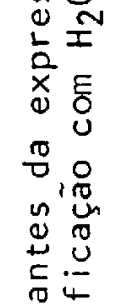 & & 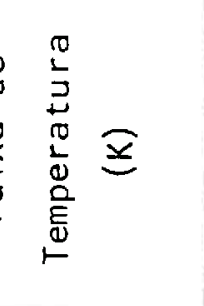 & 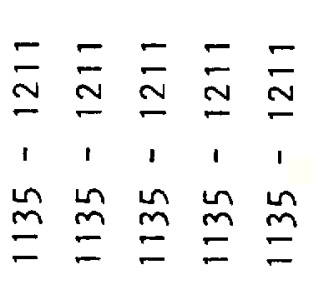 & $\begin{array}{l}m \\
\text { ã } \\
1 \\
\text { ñ }\end{array}$ & $\begin{array}{l}\stackrel{m}{\cong} \\
\cong \\
1 \\
\stackrel{m}{=}\end{array}$ & $\begin{array}{l}m \\
m \\
\Xi \\
1 \\
m \\
\stackrel{m}{N}\end{array}$ & $\begin{array}{l}\stackrel{m}{N} \\
1 \\
\stackrel{m}{\Xi} \\
=\end{array}$ & $\begin{array}{l}\frac{m}{n} \\
1 \\
m \\
\equiv\end{array}$ & $\begin{array}{l}m \\
\stackrel{m}{m} \\
1 \\
\stackrel{n}{\cong}\end{array}$ & $\begin{array}{l}\stackrel{m}{ \pm} \\
\vdots \\
\stackrel{m}{\simeq}\end{array}$ & 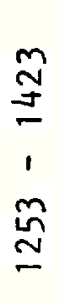 \\
\hline 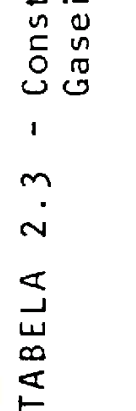 & $\frac{\pi}{\frac{\pi}{2}}$ & $\begin{array}{l}\pi \\
0 \\
0 \\
\widetilde{E} \\
E \\
0 \\
0 \\
0 \\
0 \\
0 \\
0 \\
\infty\end{array}$ & 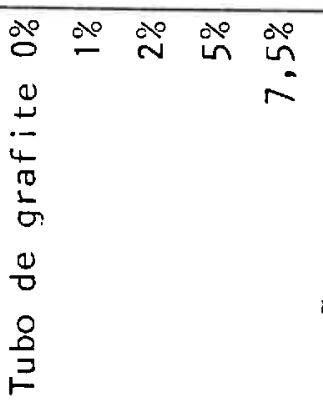 & 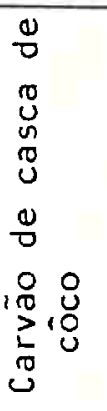 & $\begin{array}{l}\stackrel{0}{ \pm} \\
\frac{1}{4} \\
0 \\
0\end{array}$ & $\frac{0}{4}$ & $\begin{array}{l}\ddot{J} \\
\bar{g}\end{array}$ & $\begin{array}{l}1 \\
0 \\
\vdots \\
0 \\
0 \\
0 \\
0 \\
0 \\
0 \\
0 \\
\stackrel{5}{4} \\
\frac{0}{0} \\
0\end{array}$ & $\begin{array}{l}0 \\
0 \\
0 \\
N \\
: \pm \\
4 \\
0 \\
0 \\
0 \\
0 \\
0 \\
0 \\
0 \\
0\end{array}$ & $\begin{array}{l}\frac{0}{\frac{0}{0}} \\
. \frac{0}{2} \\
0 \\
0 \\
0 \\
\frac{0}{0} \\
0\end{array}$ & $\begin{array}{l} \\
\frac{0}{0} \\
. \frac{1}{0} \\
0 \\
0 \\
0 \\
\frac{0}{0} \\
0 \\
0\end{array}$ \\
\hline
\end{tabular}




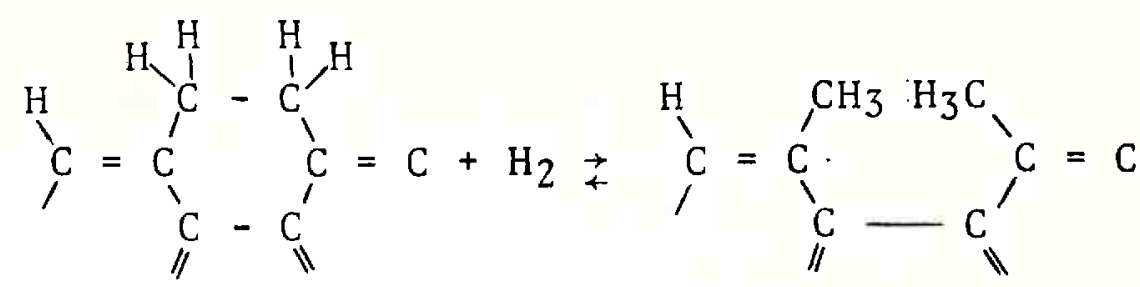

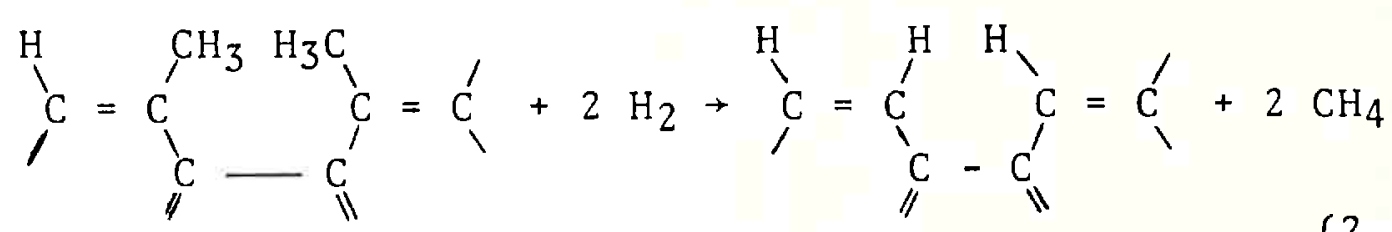

Considerando-se o $\vec{u} 1$ timo passo mais räpido que os demais, chega-se a seguinte expressão para a taxa de reação:

$$
\mathrm{r}_{\mathrm{C}+2 \mathrm{H}_{2}}=\frac{\mathrm{k}^{\prime \prime} \mathrm{p}_{\mathrm{H}_{2}}^{2}}{1+\mathrm{a}^{\prime \prime} \mathrm{p}_{\mathrm{H}_{2}}}
$$

A expressão assim obtida prevê que a reação apresentará ordem próxima de 2 para pequenas pressōes parciais de hidrogênio e ordem próxima de 1 para pressões de $\mathrm{H}_{2}$ muito altas.

Da exposição feita até aqui é possivel compreenser a dificuldade de se utilizar no modelo expressōes cinéticas como as mostradas neste item. Cada um dos parâmetros é função da concentração de sítios ativos e da reatividade desses sítios e, por isso, variam de material para material. Assim, fica cla ro que materiais de diferentes procedencias, com estrutura e composição distintas, apresentam taxas de reação distintas.

A gaseificação de madeira foi, até o momento, me nos estudada que a dos carvōes minerais. Dessa maneira, o levantamento da cinētica das reações de gaseificação específica pa ra o particular material de interesse é desejável e pode ser, em muitos casos, essencial para uma representação adequada do processo. 
E possivel, e às vezes preferível, expressar a ve locidade de reação através de uma relação empírica, visto que os dados experimentais relativos a energia de ativação, constan tes pré-exponenciais e ordem de reação se apresentam dispersos em intervalos bastante grandes de valores [Watanabe (1983)].

Por outro lado, não é incomum a utilização de fatores de correção para adaptar a expressão obtida com um tipo de material aos dados de gaseificação de outro. De maneira geral os trabalhos de modelagem e simulação de gaseificadores utilizam tal procedimento ou então expressões cinéticas empíricas, de ordem simples, caracterizadas por um único par de valores de constante pré-exponencial e energia de ativação. Este ūltimo procedimento foi adotado nesta dissertação.

\section{3 .3 - Cinética da reação de deslocamento}

A reação de deslocamento ("water-gas shift reaction")

$$
\mathrm{CO}+\mathrm{H}_{2} \mathrm{O} \underset{\leftarrow}{\rightarrow} \mathrm{CO}_{2}+\mathrm{H}_{2}
$$

tem importância nos processos de gaseificação, pois altera composição do gás gerado nas reações gãs-sōlido.

Em vários artigos sobre modelos de gaseificadores a reaçãode deslocamento é considerada em equilíbrio [Caram e Amundson(1979), Yoon et alii (1978), Srinivas e Amundson(1980), Haynes (1982), Arri e Amundson(1978)] enquanto em outros é con siderada cineticamente, isto é, não necessariamente em equilíbrio [Biba et alii (1978), Massaquoi e Riggs (1983), Govind e Shah (1984), Wen e Chuang (1979) Purdy et alii (1981), Cho e Joseph (1983), Desai e Wen (1978), Watanabe (1983), Stillman (1979), Souza Santos e Jen (1982)].

Quando tratada cineticamente nestes modelos, via de regra sua expressão de velocidade é adaptada de trabalho em 
que a reação de deslocamento é feita cataliticamente. A adapta ção ê feita por um fator de correção que leva em conta a atividade catalítica do "char" ou de suas cinzas e impurezas presen tes. Cinéticas como as obtidas por Moe (1962) e Singh e Saraf (1977) com catalisadores comerciais são muito utilizadas desta maneira. O primeiro obteve uma cinética de 2 a ordem com energia de ativação da ordem de $40,6 \times 10^{3} \mathrm{~J} / \mathrm{mol}$. Já os dois ū1timos pesquisadores obtiveram uma expressão de primeira ordem em relação ao $\mathrm{CO}$, que leva em conta efeitos de resistências difusionais, envelhecimento do catalisador, pressão e até envenena mento por $\mathrm{H}_{2} \mathrm{~S}$; a energia de ativação obtidaé da ordem de $116,2 \times 10^{\overline{3}}$ $\mathrm{J} / \mathrm{mol}$.

O fato de se utilizar nos modelos de gaseificado res as taxas cataliticas empiricamente corrigidas por um fator de correção e as próprias diferenças entre as cinéticas cata1 ticas normalmente utilizadas vem revelar o quāo pouco se conhece sobre a velocidade da reação de deslocamento acompanhando os processos de gaseificação.

Talvez por isso, a hipótese de se considerā-la em equilíbrio seja tão comum. Yoon et alii (1978) testaram esta hipōtese em seu modelo de gaseificador autotērmico e observaram que a inclusão da cinética desta reação não alterou substan cialmente as previsões do modelo, mas aumentou o tempo de compu tação.

Do ponto de vista da resolução das equações do mo delo, quando a reação de deslocamento é considerada em equilíbrio ocorre maior dificuldade na solução numérica. Isto porque - cálculo do equilíbrio demanda um tratamento numérico diferente do cálculo pela cinética das demais reações.

\section{4 - SECAGEM E PIROLISE}


processos de secagem e pirôlise. Embora esses processos ocorram não necessariamente de maneira separada, são, via de regra, para efeito de estudo, considerados separadamente.

Os materiais processados em gaseificadores - carvões e madeiras - apresentam umidade variando entre 5 e $50 \%$, ou mais. Esta ägua se encontra tanto na forma livre, como na forma combinada, ligada a nível intermolecular. A ảgua livre é re movida sob pressão ambiente a temperaturas atē $378 \mathrm{~K}$ e a água combinada a temperaturas em torno de $573 \mathrm{~K}$ por intervalo de tem po suficientemente longo.

Análises de secagem de carvão mineral feita por McIntosh (1976), incluindo a influência do fluxo de água na par tícula sólida e o transiente de temperatura no núcleo úmido, mos traram que o tempo de secagem é proporcional ao quadrado do diâa metro mêdio da particula. Yoon et alii (1978) utilizaram este resultado para estimar em 60 a 90 segundos o tempo de secagem de carvão com $10 \%$ de umidade, nas condições típicas de um gasei ficador de leito móvel contracorrente. Sendo o tempo de residência do sólido nestes reatores da ordem de 1 hora ou mais, con cluíram que o processo de secagem é rápido e o modelaram como instantâneo. Isto é feito na maioria dos modelos estudados.

Em seus modelos de gaseificadores de leito móvel Biba et alii (1978) assumiram taxa.de secagem constante, enquan to Stillman (1979) e Watanabe (1983) usaram um modelo de secagem por convecção proposto por McIntosh (1976), exprimindo a ta $x a$ de secagem como

$$
R_{\text {sec }}=\frac{C_{1}}{1+\exp \left(C_{2}-C_{3} T\right)}
$$

e uma taxa variāvel com a umidade $x_{w}$ quando esta for menor que um valor crítico $x_{c r i t}$

$$
R_{\text {sec }}=\frac{C_{1}}{1+\exp \left(C_{2}-C_{3} T\right)} \cdot \frac{x_{W}}{x_{C r i t}}
$$


Hâ ainda modelos mais detalhados de secagem de só

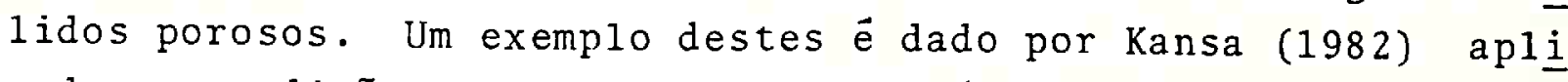
cado as condições de queima de combustíveis sólidos, junto com um modelo simplificado de pirólise.

Quanto a pirölise, embora desperte interesse também como processo industrial independente [Probstein e Hicks (1982)], no presente trabalho sera enfocado apenas como um pro cesso associado à gaseificação.

O fenômeno de pirólise de materiais carboníferos consiste de uma degradação térmica em ausência de ar em que macromolëculas orgânicas são quebradas em unidades menores e rea gem entre si, resultando em produtos gasosos não condensáveis, líquidos (alcatrão e, no caso de madeiras, pirolenhosos) e um resíduo sölido dè alto teor de carbono.

A liberação dos produtos pode ser entendida como se dando em duas etapas. Um estágio inicial ocorre para a maio ria dos materiais, entre 573 e $873 \mathrm{~K}$. Nesta etapa são liberadas, dependendo do tipo de sólido, cerca de $80 \%$ da matëria volá til. Um segundo estágio se completa usualmente em torno de $1273 \mathrm{~K}$ com a possibilidade de várias reações secundärias entre os voláteis formados.

Segundo a taxa de aquecimento a que o material ë submetido, a pirólise é classificada em lenta, intermediāria, ra a pida e instantânea ("flash"). Nos gaseificadores de leito móvel, que operam com partículas relativamente grandes, sujeitas a um aquecimento lento e com elevado tempo de residência, ocorre a pirölise lenta ou intermediária. Neste caso o tempo neces sārio para completar a pirólise é significativamente menor que o requerido para o aquecimento das particulas ate sua temperatu ra de processo.

A maior parte dos trabalhos encontrados na litera tura tratam de pirólise de carvão mineral, devido a grande im- 
portância deste processo para a indústria siderúrgica. Anthony e Howard (1976) e Wen e Dutta (1979) apresentam revisões sobre a pirôlise de carvão.

Muitos pesquisadores tem estudado a pirólise de madeira e materiais celulósicos. Sabe-se que o processo depen de, como no caso de carvão, da temperatura, pressāo, composição do meio gasoso, presença de traços de cinzas, tamanho da partícula, tipo, estrutura e composição do material sólido, taxa de aquecimento. Estes mesmos parâmetros influem na composição dos produtos da pirólise.

Qualquer que seja o material sỏido, os fenômenos envolvidos ainda não são muito bem entendidos. Alēm disso a maioria dos estudos é feita com amostras pequenas, o que torna os dados obtidos difíceis de serem interpretados em nivel de previsāo de comportamento sob condições reais de processamento.

Assim, apesar dos inúmeros estudos sobre os fenômenos de pirólise, não há um consenso no modo de tratá-los quan titativamente. Dada a complexidade do processo e devido. ao grande número de compostos orgânicos envolvidos, a maioria dos estudos utilizam um tratamento global, acompanhando a perda de massa durante um aquecimento controlado do material. As técni cas experimentais típicas deste tipo de abordagem são a anälise termogravimetrica linear e diferencial.

Desse modo, a grande parte dos estudos cinéticos da pirólise empregam modelos de lạ ordem ou de ordem variável para a perda de massa do sólido. Outros modelos usam represen tar a evolução de cada um dos produtos voláteis gerados por uma cinética de primeira ordem.

Há também esquemas alternativos envolvendo duas reações competitivas ou duas reações paralelas independentes. 
Anthony et alii (1976) adaptaram o modelo de um nümero infinito de reações de 1 a ordem independentes, cujas energias de ativação seguiam uma distribuição gaussiana, e seus resultados concordaram bem como dados experimentais de pirölise de linhito e carvão betuminoso. Wen e Chen (1979) obtiveram bom ajuste aos dados de pirólise de carvão mineral com um modelo de três reações: carvão se decompondo em alcatrão e coque e o alcatrão se decompondo por duas reações paralelas dando gás ou coque.

Thurner e Mann (1981) utilizaram esquema semelhan te para a pirólise de madeira. Os produtos foram considerados em três grupos: gās, alcatrão e "char". A decomposição da madeira é descrita por três reações paralelas, cada qual dando um produto e o alcatrão sofrendo decomposição em duas reações secundārias paralelas dando "char" e gäs. Os resultados apresen taram boa concordância com experimentos de pirólise de serragem de carvalho.

Broido (1976) estudou o mecanismo da pirólise da celulose, o que possibilitou analisar uma curva termogravimétri ca de pirólise de celulose e a decompor em trechos que represen tam uma sequência de reações em série para a formação do "char" e uma etapa em paralelo para a formação de alcatrāo:

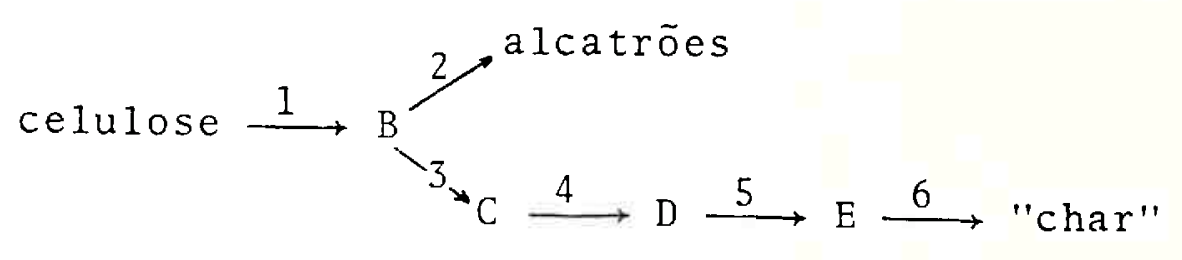

Neste esquema a etapa 1 representa uma despolimerização inicial da celulose, sem perda de massa. O produto B sofre nova despo limerização com liberação de voláteis pesados (alcatrões) e uma série de reações leva a formação do resíduo sólido ("char"). Uma descrição mais detalhada destes processos pode ser encontrada em Watanabe (1983), que o utilizou em seu modelo de gaseificador, supondo, adicionalmente, o craqueamento posterior do alcatrão para formar os gases não condensảveis, supostos em equilí brio. 
Um interessante trabalho de Pyle e Zaror

apresenta o estudo da importância relativa da cinética e trans ferência de calor interna e externa à partícula no comportamento da pirólise de madeira e outros sólidos. Seus resultados mostram que para partículas pequenas o controle é exercido pela cinética ao passo que a transferência de calor parece comandar o processo em partículas de diâmetro acima de 5 a $10 \mathrm{~cm}$.

Revisōes sobre pirólise de madeira são apresentadas por Roberts (1970) e Milne (1979). Este ültimo autor apre senta resultados de anālise termogravimétrica típica de madeira e de seus principais componentes - celulose, hemicelulose (xila no) e lignina. Estes resultados são mostrados na figura 2.11 e sua análise evidencia que o comportamento da madeira reflete as propriedades de seus principais constituintes. A hemicelulose é o constituinte mais reativo e a lignina o menos.

Roberts (1970) analisa os efeitos de composição, catálise e autocatálise, estrutura física da madeira, pressão, tamanho da amostra e efeitos de mudanças das condições experimentais sobre a cinética da pirólise de madeira e seus consti tuintes. O uso de cinética de $1^{\text {a }}$. ordem para descrever a perda de massa durante a pirōlise é questionável teoricamente - pois ocorrem vārias reações simultaneamente e a perda de massa não é a ünica representação do grau de avanço das reações de pirōlise -, mas ainda assim é recomendada por suas vantagens präticas na interpretação e comparação de dados cinēticos.

Quanto à distribuição de produtos gerados na piró lise depende do material e da temperatura, entre outros aspectos. Um exemplo é mostrado na figura 2.12, com os dados de pi rōlise de serragem de pinho obtidos por Knight (1976).

A composição do gās obtido também apresenta grandes variações com os parâmetros de processo, devido à ocorrên cia de reaçōes secundārias na fase gasosa. Este tipo de in- 


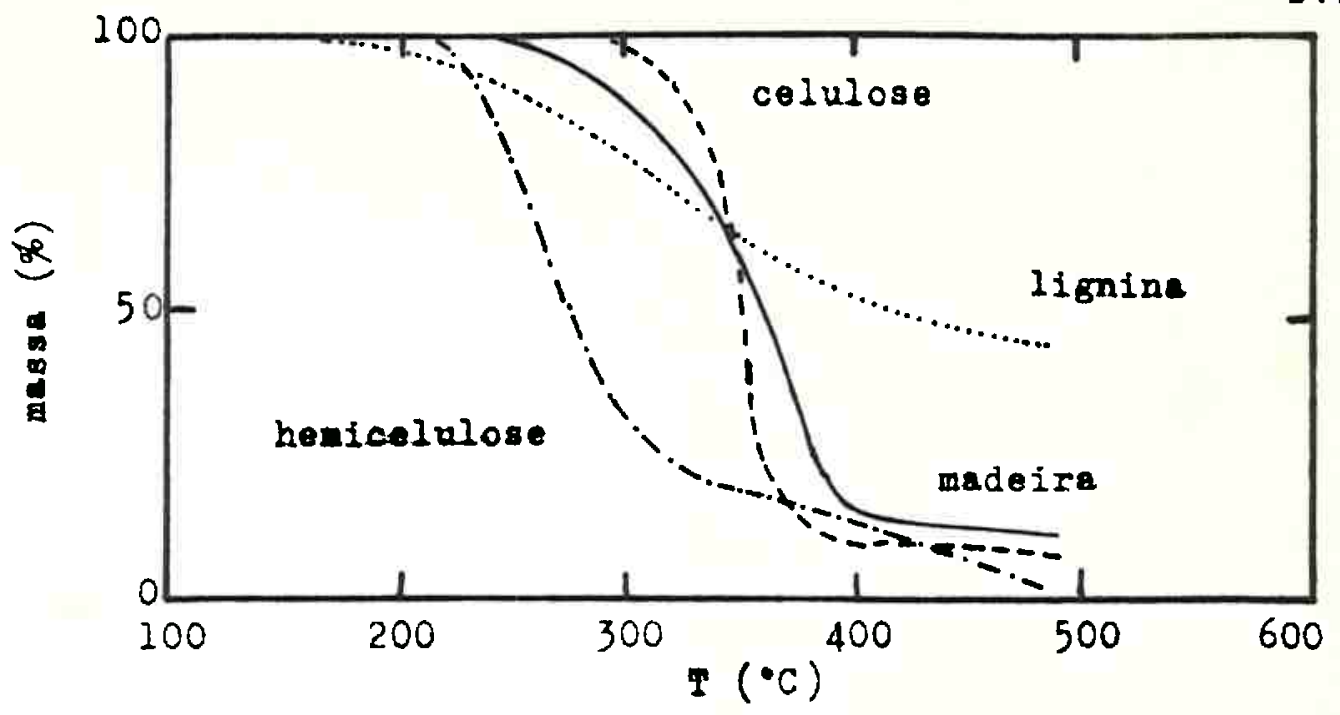

Figura 2.11. Exemplo de resultados de análfge termogravimétrica

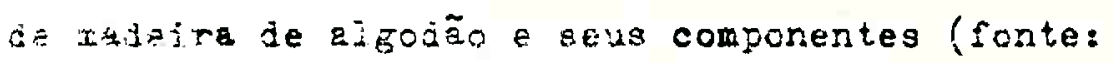
Milne (1979):

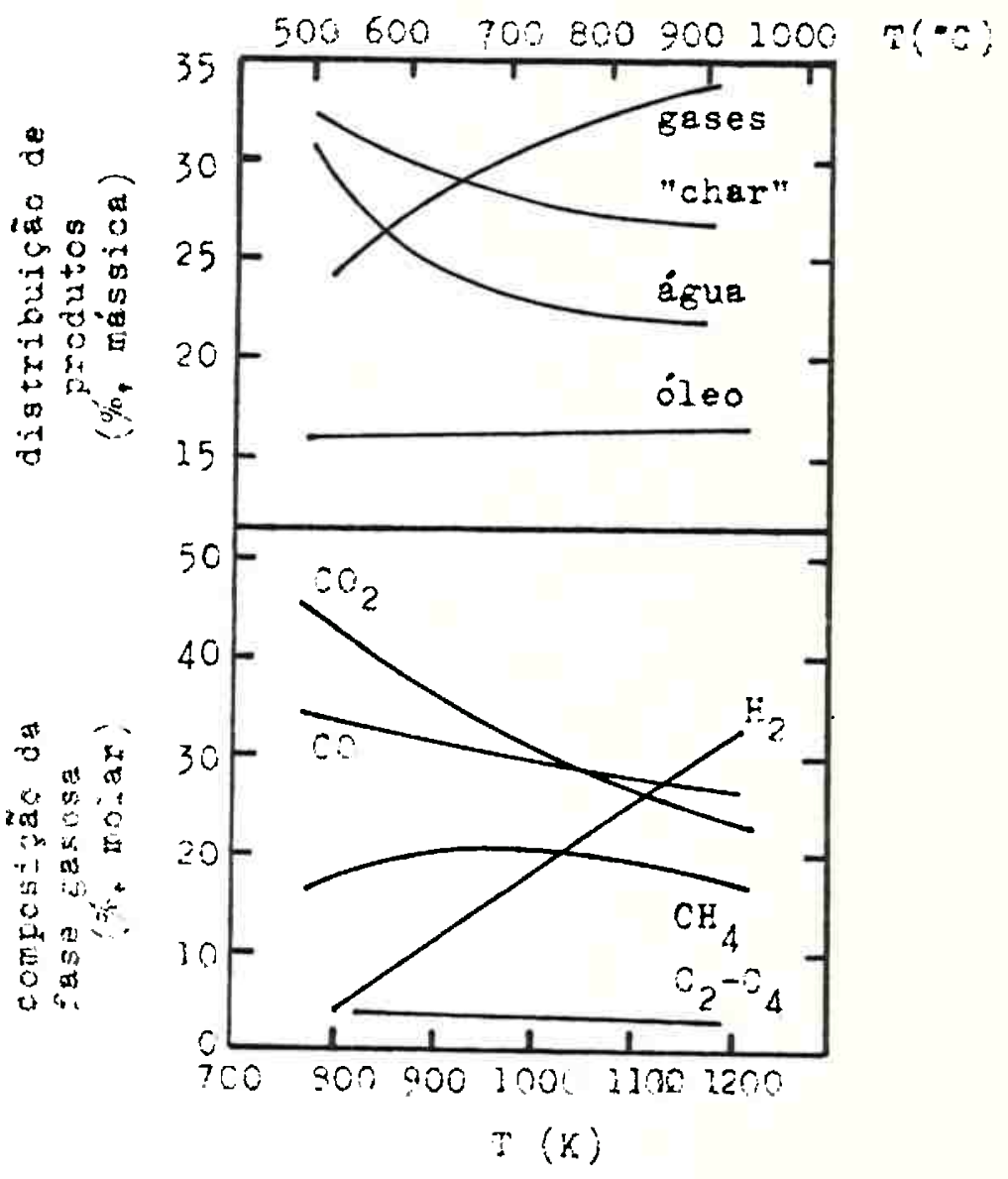

Fisura 2.22. Disiriouigano de produtos da pirjitse de serragem

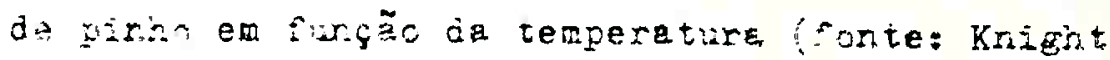
(19-6): 
fluência foi estudado por Antal (1983).

Os métodos usuais de modelar a pirólise que acom panha a gaseificação de carvão mineral envolvem normalmente con siderá-1a como um processo instantâneo e fixar a composição dos gases obtidos nesta etapa. Yoon et alii (1978) comentam que o comportamento global do modelo não é afetado significativamente pelas simplificações feitas na pirôlise pois esta contribui com apenas cerca de $10 \%$ do gás total produzido.

Entretanto esta conclusão não deve ser extraprolada aos modelos para gaseificaçāo de madeiras, uma vez que nestas o teor de voläteis é expressivamente maior que nos carvões minerais.

\section{5 - MOdELOS MATEMATICOS DE GASEIFICAÇÃO E dE GASEIFICADOR}

Os principais trabalhos pesquisados sobre o assun to referem-se a gaseificação de uma única partícula [Wen e Wu (1976), Srinivas e Amundson(1980), Haynes (1982), Massaguoi e Riggs (1983), Arri e Amundson(1978), Kumpinsky et a1ii (1979)] gaseificadores de leito fluidizado [Purdy et alii (1981), Caram e Amundson(1978), Raman et alii ( 1981 )] gaseificador de transporte [Wen e Chuang (1979), Govind e Shah (1984)] e gase $\underline{i}$ ficador de leito móvel [Amundson e Arri (1978), Yoon et alli (1978), Cho e Joseph (1981), K1m e Joseph (1983), Biba et alli (1978), Kosky e Floess (1980), Denn et alii (1979), Souza San tos (1984), Loureiro (1984), Stillman (1979), Watanabe (1983), Desai e Wen (1978)].

Os trabalhos relativos a gaseificação de uma partícula são üteis para o entendimento da cinētica de gaseificação a nível de partícula. Os modelos sobre gaseificadores auto térmicos de leito fluidizado e de transporte tem menos relação com o trabalho desenvolvido nesta dissertação. 
Quanto aos modelos de gaseificadores de leito móvel, apresentam interesse maior já que, apesar das diferenças existentes entre o gaseificador eletrotérmico e os autotérmicos tradicionais, o equacionamento matemático dos balanços de massa e energia guarda semelhança. Por isso esses modelo são descritos e discutidos brevemente a seguir.

A grande maioria dos trabalhos de simulação de ga seificadores de leito móvel apresenta modelos unidimensionais em regime permanente, usados para analisar certos parâmetros opera cionais dos gaseificadores autotérmicos. Por exemplo, um destes parâmetros é a máxima temperatura atingida no reator e sua posição. A máxima temperatura determina se a operação se darā com cinzas sólidas ou fundidas. Outro importante parâmetro é a conversão final da matéria prima, relacionada com a eficiência do processo. A composição do gás gerado é também importante de pendendo da utilização a que se destina o gás produzido.

Arri e Amundson(1978) desenvolveram um estudo matemático analítico para a gaseificação de uma partícula de car vão em um meio contendo oxigênio e vapor de água, considerando o modelo de núcleo não reagido. Este modelo foi aplicado Amunidson e Arri (1978)] para simular em gaseificador de leito móvel em contracorrente. Apesar de não ter sido feita nenhuma comparação com dados de gaseificadores industriais, vārios estudos pa ramétricos foram realizados, com concordância qualitativa de suas previsões com dados experimentais.

Yoon et alii (1978) desenvolveram um modelo deta1hado de gaseificador de leito mövel em contracorrente, incluin do os processos de secagem e pirôlise do carvão tratados simpli ficadamente como instantâneo. As temperaturas das fases sólida e gasosa foram consideradas iguais em qualquer ponto do gaseif $\underline{i}$ cador. Consideraram-se as reações de carvão com dióxido de carbo no e com hidrogênio controladas pela cinética e as reaçōes com oxigênio e vapor de água podendo seguir o modelo de nủcleo não reagido ou o de núcleo exposto. A resolução do sistema de equa 
ções diferenciais ordinärias de condição de contorno requereu, a cada passo de integração, o ajuste da composição do gás e da temperatura devido à. reação de deslocamento ter sido considerada em equilíbrio.

Cho e Joseph (1983) estenderam o modelo de Yoon et alii (1978) incluindo balanços de energia separados para as fases sólida e gasosa, isto è, considerando diferentes as tempe raturas do sólido e do gäs. O sistema de equações diferenciais ordinárias apresentou problemas de "stiffness" no balanço de energia da fase sólida, devido à pequena capacidade térmica do sólido próximo ao fundo do reator. A hipótese de estado pseudo -estacionário para a temperatura da fase sólida eliminou o problema. Os perfis de temperatura apresentaram-se fortemente in fluenciados pelo coeficiente de transferência de calor entre as fases. Recomenda-se um valor menor deste coeficiente do que o calculado por correlações para sistemas não reativos. Os estu dos paramétricos indicaram que a eficiência térmica máxima ocor re para conversões praticamente completas de carvão.

Desai e Wen (1978) simularam um gaseificador para carvão mineral com um modelo homogêneo, empregando expressões empíricas para as taxas de gaseificação e o modelo de nú cleo exposto para a combustão. Stillman (1979) apresenta modelo semelhante, mas considerando diferentes as temperaturas de só lido e gás. Neste ültimo trabalho, ao contrārio dos anteriores, a secagem é modelada cineticamente e a pirólise é tratada como reações de $1^{a}$. ordem para a evolução de cada gás obtido do carvão mineral.

Biba et alii (1978) modelaram o gaseificador de carvão sob pressão dividindo-o em 4 regiões, onde cada processo é considerado separadamente. Na região de secagem e na de piró lise aplicam-se simplificaçōes usuais como velocidade dos processos constante e composição do gás obtido pré-fixada. As ex pressões cinéticas para as regiōes de gaseificação e combustão 
tambēm foram simplificadas com a especificação de temperaturas limitantes para a transição do passo controlador da taxa global.

Hā também trabalhos voltados para carvão vegetal e madeira. Souza Santos e Jen (1982) simularam gaseificador de. leito mỏvel com modelo homogêneo em que adaptaram expressões ci néticas obtidas na literatura para o caso de carvão vegetal. Ver são posterior do modelo, com balanços de energia separados para as duas fases foi apresentada por Souza Santos (1984). Watanabe (1983) apresentou modelo semelhante, heterogêneo, para carvão vegetal, com cinéticas empiricas obtidas na literatura. Loure $\underline{i}$ ro (1984) adaptou o modelo de Yoon et alii (1978) introduzindo expressōes cinéticas de gaseificação de madeira e de devolatili zação.

Uma comparação entre os modelos citados evidencia uma estrutura semelhante no que se refere ao equacionamento dos balanços diferenciais, cuja resolução é feita numericamente por algum método "passo a passo". As maiores diferenças se referem a considerar ou não equilíbrio tërmico entre as fases, ou no cálculo da perda de calor para o exterior [Stillman (1979) e Loureiro (1984) consideram reator adiabático, Yonn et alii(1978) Souza Santos e Jen (1982) consideram uma camada limite envolven do um nücleo adiabätico, Desai e Wen (1978) fixam uma porcenta gem da entalpia de reação como perdas; Cho e Joseph (1983), Sou za Santos (1984), Watanabe (1983) e Biba et alii (1978) consideram um termo de perda por convecção no balanço de energia da fá se sólida ou da gasosa]. Alguns consideram a variação de pres são com o escoamento do gás linear com a extensão do reator é outros consideram o processo essencialmente isobārico. Também o nümero de compostos considerados e de equaçōes diferenciais do modelo diferem de um trabalho para outro. Estas diferenças po dem ser comparadas na Tabela 2.4 .

Em todos estes trabalhos são apresentadas compara ções de resultados da simulação com dados experimentais obtidos 


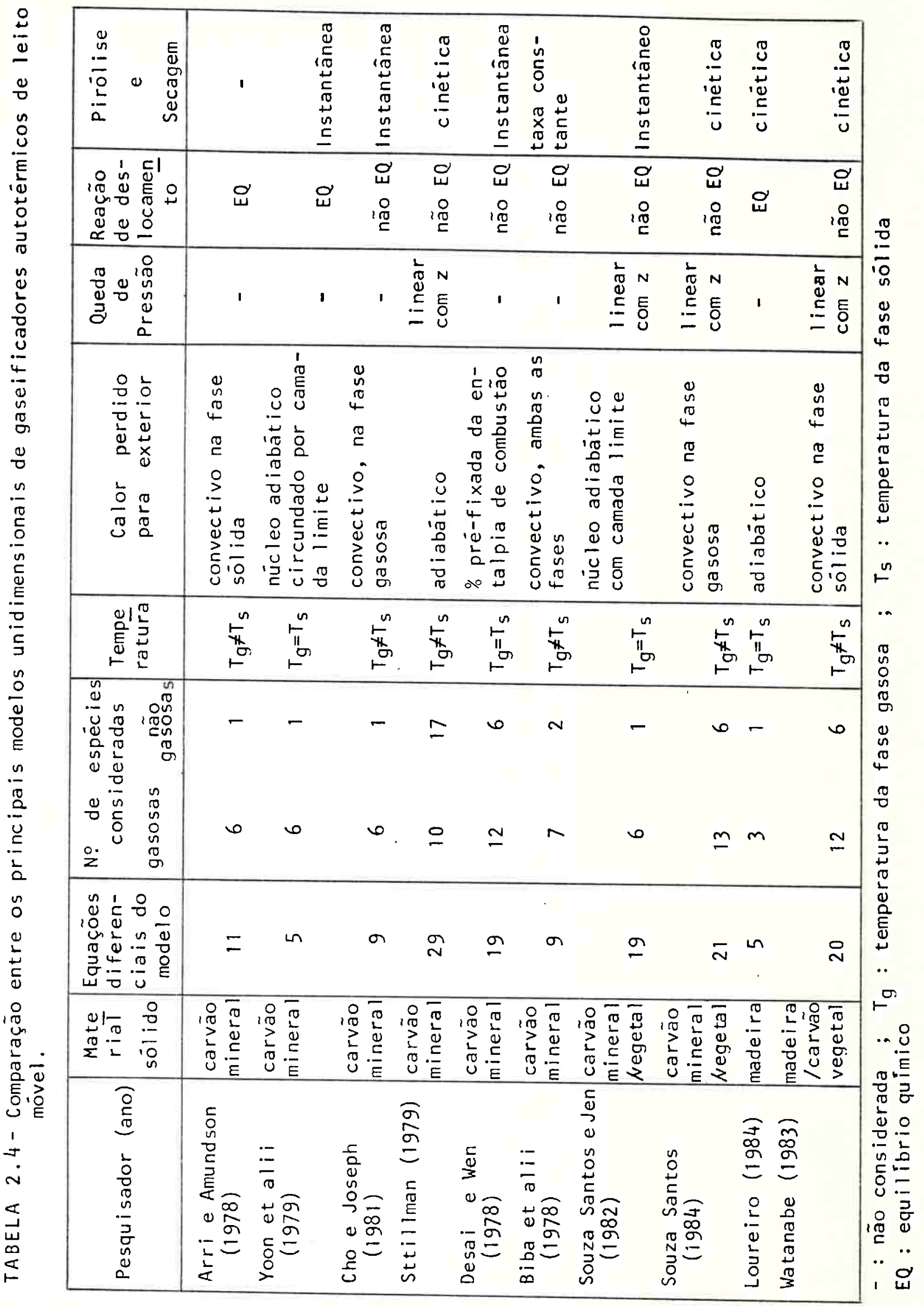


em gaseificadores de escala piloto ou industrial.

Loureiro (1984) foi o único a apresentar comparações com perfis experimentais de composição de alguns gases e de temperatura, obtidos por Derosiers (1981). Os demais fazem comparações com medidas feitas nos efluentes dos gaseificadores, com relativamente boa concordância. Todos os trabalhos apresentam estudos paramétricos do processo ou de parâmetros do modelo.

Trabalhos com modelo unidimensional transiente de gaseificadores de leito móvel são mais raros. K1m e Joseph (1983) o fizeram com um modelo semelhante ao de Cho e Joseph (1981) com a presença dos termos de variação com o tempo nas equações de balanços de massa e energia. O sistema de equações diferenciais parciais foi resolvido pelos métodos numéricos de diferenças finitas e Runge-Kutta. As previsōes de estado estacionārio concordam com dados experimentais publicados e se apre sentam estudos paramétricos de controle do reator frente a pertubações típicas das variāveis de processo. Yoon et alii (1979a) usaram seu modelo estacionārio para a previsão aproximada do comportamento dinâmico do gaseificador. Assumiram uma estreita zona de reação onde o carbono é quase totalmente consumido por reações de combustão e gaseificação. O comportamento dinâmico foi aproximado por uma série de modelos estacionários nos quais a zona de reação se move lentamente.

A quase totalidade dos modelos unidimensionais de gaseificadores em regime permanente é validada, como dito ante riormente, comparando a composição, temperatura e conversão à saida, com dados experimentais. Denn et alii (1979) criticaram este procedimento, mostrando que o comportamento das saídas des tes modelos é normalmente pouco sensivel às variações paramétri cas. Já os perfis de temperatura e composição são sensiveis a certas condições de entrada e operação e, dessa forma, validação completa de um modelo unidimensional deveria incluir a comparação com perfis experimentais, alëm das condições dos efluen tes. Sugerem, assim, um modelo "sem cinētica", que seria ütil na estimativa da performance do reator para altas conversões de 
carbono. Os resultados deste modelo apresentaram boa concordân cia para carvões minerais com pequena reatividade à hidrogaseificação.

Dentro desse enfoque, Kosky e Floess (1980) rela tam um modelo "global" para gaseificadores contracorrente, baseados na hipótese de equilíbrio da reação de deslocamento na região de gaseificação, considerando completa a conversão de carbono.

Outros trabalhos como os de Makray (1984), Assump ção (1981), Derosiers (1979), Desai e Wen (1978) apresentam mo delos para a previsão da composição de equilíbrio dos efluentes de gaseificadores.

Wei (1979) apresenta uma análise da gaseificação de carvão baseada em considerações estequiométricas e de balanço térmico das reações envolvidas. Yoon et alii (1979b) mostra ram que as operaçōes de gaseificadores autotérmicos podiam ser analisadas em um diagrama triangular de relaçōes de alimentação de carbono, vapor de ägua e oxigênio. Foi possível delimitar neste diagrama regiões limites de operação a partir de consideraçōes estequiomētricas e termodinâmicas. Mostrou-se, tambēm, que os pontos usuais de operação de gaseificadores não correspondem às linhas de equilíbrio termodinâmico.

\section{6 - GASEIFICADORES ELETROTERMICOS}

Os fornos elētricos são conhecidos hä muitas décá das, sendo empregados em processos que requeiram altas temperaturas. Por exemplo, o processo de fabricação de carbeto de si Iício utiliza um reator semelhante a um forno elétrico de resis tência, fazendo a corrente elétrica passar na própria massa de reagente sólidos, operando em batelada [Shreve e Brink (1977)].

A idéia de se utilizar o aquecimento elétrico di- 
retamente no reator, por dissipação joule no pröprio leito de reagentes não ê nova. Diferentes concepçōes de reatores que utilizam tal têcnica de modo contínuo, em especial no campo da gaseificação, é que são mais recentes.

Johnson (1961) foi talvez o primeiro pesquisador a descrever um reator eletrotérmico de leito fluidizado, suas caracteristicas de projeto e operação, propriedades elétricas e eficiência térmica para leitos de coque. Sugeriu seu uso em processos com reações que, por efeitos cinéticos ou termodinâmi cos, fossem favorecidos pelas elevadas temperaturas obtidas. Dentre as aplicações citadas estão a fabricação de dissulfeto de carbono a partir de coque e enxofre ou sulfeto de hidrogênio, a gaseificação de carvão com vapor de água ou dióxido de carbono, a fabricação de gás cianídrico a partir de amônia, coque e hidrocarbonetos. Värios desses processos foram patenteados na primeira metade da década de 1960.

Goldberger et alii (1965) descreveram o reator eletrotérmico de leito fluidizado como um sistema de rápido aque cimento e fácil controle, atravēs da variação da velocidade do gás fluidizante, ou pela aproximação dos eletrodos, ou pela variação da potência elétrica fornecida. Dentre as possíveis apli cações citam cloração de óxido de zircônio, produção de fósforo e adaptaçōes para leitos fluidizados de processos químicos e me talürgicos tradicionalmente realizados em forno elétrico.

Um processo de calcinação de coque em reator ele trotērmico de leito fluidizado foi estudado por Paquet e Foulkes (1965).

A maior parte da literatura a respeito de gaseif cadores eletrotérmicos consiste nos trabalhos da equipe de pesquisadores da Iowa State University [Pulsifier et alii (1969), Beeson et alii (1970; Pulsifer e Wheelock (1972), Beeson et alii (1974), Pulsifer e Wheelock (1977/78)] que estudaram a gaseificação de carvão mineral com vapor de água a pressão atmosférica 
em reator de leito fluidizado.

Operando em batelada sob temperaturas de 816 a $1071 \mathrm{~K}$ em reator de $10,2 \times 10^{-2} \mathrm{~m}$ de diâmetro com várias amostras de carvão mineral, Pulsifer et alii (1969) obtiveram as se guintes conclusões:

- a taxa de gaseificação aumenta com a temperatura, com a vazão de vapor e com a perda de massa;

- a velocidade de reação não è significativamente afetada pela passagem de corrente elétrica no leito;

- o gäs resultante era constituido de $60 \%$ de hidrogênio, o restante predominantemente monóxido e dióxido de carbono;

- não houve problema no controle da temperatura e da potência inserida no reator;

- os eletrodos apresentaram vida muito curta, devido a um elevado desgaste.

Posteriormente passaram a estudar um reator contí nuo de $30,5 \times 10^{-2} \mathrm{~m}$ de diâmetro [Beeson et alii (1970), (1974)]. Testaram diferentes amostras de carvão, diferentes materiais de eletrodo, utilizando corrente alternada mono e trifásica. Os en saios duraram de 10 a 20 horas e a conversão de vapor e a velocidade de reação atingiam niveis satisfatórios a temperaturas $\underline{u}$ periores a $1143 \mathrm{~K}$.

A configuração nestes reatores, com um eletrodo central e outro sendo a própria parede lateral, causava problemas de superaquecimento e erosão no eletrodo central. Uma nova configuração foi testada, com eletrodos na parte superior e inferior do leito, portanto com fluxo de corrente elétrica longitudinal ao contrário do antigo sistema de fluxo transversal ra dial. A parede lateral foi trocada por outra de material não condutor de corrente elëtrica. Nesta nova configuração foram 
realizados vârios ensaios sem maiores problemas de erosão ou su peraquecimento dos eletrodos [Pulsifer e Wheelock (1977/78)].

Estudos sobre as caracteristicas elétricas; dos reatores de leito fluidizado foram realizados por Goldschmidt e Le Goff (1963), em leitos constituídos de coque e metais. Seus dados mostram um aumento contínuo na resistência elētrica do leito com a velocidade do gás, desde a condição de leito fixo até a de fluidizado.

A resistência elétrica total intereletrodos pode ser dividida em uma parcela de resistência de contato entre o leito e os eletrodos e outra correspondente à resistência do próprio leito. Graham e Harvey (1965): 'mediram a resistência total de leitos fluidizados de grafite e coque de petróleo e sugeriram ser pequena a resistência de contato nesses leitos. Glidden e Pulsifer (1968) mediram a resistência de contato pelo seguinte método: posicionaram-se quatro sensores de potencial elé trico a vārias distâncias entre os eletrodos; foram feitos gräficos de queda de potencial entre os sensores e o eletrodo em função da distância ao eletrodo; extrapolando o grafico para dis tância igual a zero o valor do potencial obtido era considerado a queda de potencial no contato leito-eletrodo. A resistência de contato era obtida a partir desses valores e da densidade de corrente elétrica.

Pulsifer e Wheelock $(1977 / 78)$ reportam que a resistência de contato varia inversamente com a ārea do eletrodo e depende da velocidade do gás, da densidade de corrente, da na tureza do leito e depende fortemente do material do eletrodo. Por exemplo, à temperatura ambiente a resistência de contato en tre o eletrodo de grafite e o leito fluidizado de coque calcina do é desprezível mas não é para eletrodos de carbeto de silício ou aço inoxidâvel.

A passagem de corrente elétrica em leitos fluidi 
zados pode ser entendida por um mecanismo de cadeias sucessivas de particulas condutoras, com ocorrência de alguns arcos entre as particulas para voltagens mais elevadas. A condutividade des sas cadeias, e, portanto, do leito, $\vec{e}$ influenciada pela velocidade do gâs, temperatura, tamanho da partícula e condutividade inerente a cada particula individual. Resultados experimentais mostram que para pequenos valores de densidade de corrente eletrica, a resistividade é independente deste parâmetro mas para maiores valores surge alguma dependência. O efeito da densidade de corrente na resistividade do leito é, no entanto, muito menos pronunciada que o efeito sobre a resistência de contato [Pulsifer e Wheelock (1977/78)].

Quando a resistividade do leito for independente da densidade de corrente e uniforme através do leito é possivel aplicar as equações básicas de campos eletromagnéticos para ana lisar e prever o comportamento elétrico do leito. Knowlon et alii (1973) aplicaram a teoria do campo eletromagnëtico ao gaseificador eletrotérmico de leito fluidizado. Assumiram que o leito se comportava como um condutor homogêneo axialmente simétrico, com resistividade constante e submetido a corrente estacionária. Sob essas condiçōes o campo elétrico é conservativo e irrotacional, representado pela equação de Laplace:

$$
\nabla^{2} \phi=0
$$

A resolução desta equação permite obter um diagra ma mostrando as linhas equipotenciais e isocorrentes que dividem o leito em incrementos de igual queda de potencial ou igual corrente, como na figura 2.13. Das informações contidas no dia grama e o conhecimento da resistividade do leito é possivel pré ver a resistência elétrica do leito. O espaçamento das linhas equipotenciais indica o gradiente de potencial elétrico. Altos gradientes de potencial podem provocar o aparecimento de arcos. Desde que a mesma quantidade de energia é dissipada em cada seg mento do leito limitado pelas equipotenciais e isocorrentes, $\bar{e}$ 


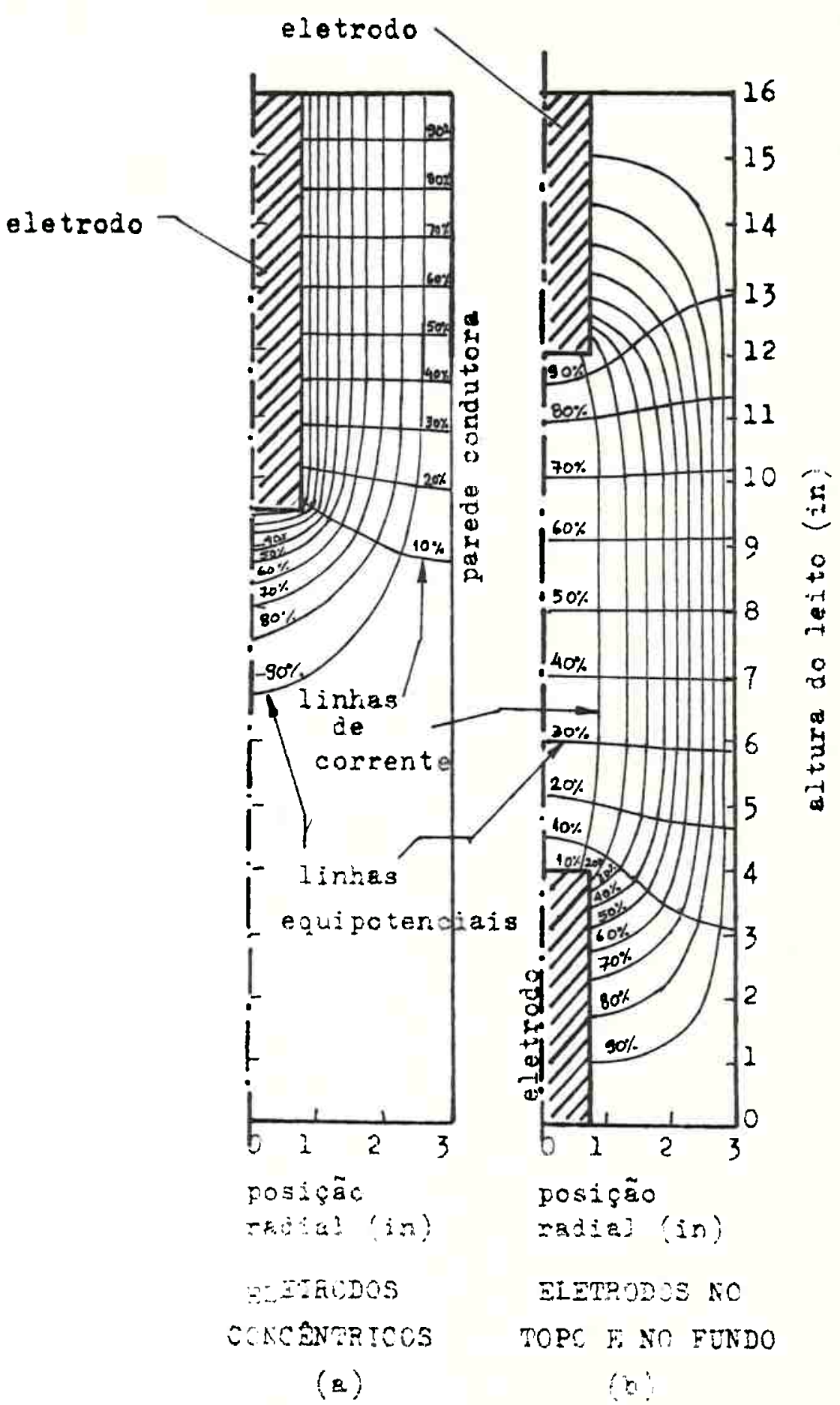

Fienua 7.13. Previsão do campo elétrico ed reator de leito rluidzado para duas configuraçies diferentes: (a) eletrodos concéntricos (b) ejerrodos no rundo e no topo do reator (ronte: Knowiton ot al: $: 1973):=$ 
possível visualizar onde haverä maior "geração de calor".

Os perfis de potencial obtidos da resolução da equação de Laplace foram confirmados com perfis medidos exper mentalmente, mostrando que o modelo parece representar satisfatoriamente o sistema estudado por knowton et alii (1973).

Um modelo simples para a previsão da composição dos gases efluentes e das necessidades de energia nos gaseifica dores eletrotérmicos de leito fluidizado foi apresentado por Pulsifer e Wheelock (1972). Trata-se de um modelo macroscópico, que supõe a ocorrência das reaçōes de deslocamento e de hi drogaseificação em equilíbrio, além da reação carbono-vapor de água. Fixando a temperatura e a pressão de operação, a conversão de vapor pela reação com carbono e a conversão final de car bono, utilizam-se balanços de massa e estequiometria das reações para a previsão da composição do gäs produzido e balanço de energia para a previsão da energia elétrica e da energia requerida para o superaquecimento do vapor.

No que se refere a reator eletrotērmico de leito móvel, um processo de gaseificação de madeira neste tipo de rea tor vem sendo desenvolvido no Brasil pela Companhia Energética de São Paulo - CESP. Paula (1982) e Zagatto (1981) reportam descriçōes deste processo, que visa a utilização de madeira de eucalipto como matéria prima.

O gaseificador eletrotërmico de leito móvel consta na sua forma atual, de um corpo cilíndrico contendo um eletrodo de grafite superior, e um eletrodo inferior, metálico, na forma de uma coroa, por onde são retiradas as cinzas. O agente de ga seificação, vapor de água, pode ser injetado em diversos níveis e o gás produto é retirado pelo fundo. O gaseificador é descr to com mais detalhes no capitulo seguinte.

As condições de operação deste tipo de reator de- 
pendem fortemente das caracteristicas elétricas do leito. Assim, a resistividade elētrica do leito é um importante parâme tro de funcionamento do equipamento. Medidas de resistividade elétrica realizadas no IEUSP (1982) permitiram observar que em temperaturas menores que $873 \mathrm{~K}$ há ocorrência de arcos nas pontas de contato entre os pedaços de carvão. Tais arcos tendem a desaparecer à medida que a temperatura se eleva, não tendo sido observados acima de $1173 \mathrm{~K}$. Isto sugere um comportamento de uma mistura de dois condutores diferentes - o sölido e o gäs que o envolve - com importância maior na condução pelos sólidos a baixas temperaturas mas com participação maior do gás à medida em que aumenta a temperatura.

Os resultados deste estudo são mostrados na figura 2.14 junto a outros dados obtidos na 1iteratura. Foram 1evantados dois tipos de resistividade, sob condiçōes de corrente continua e alternada: uma dita "aparente", do leito, correspon dente aos sölidos mais ar e gases de combustão presentes no leito, e outra dita resistividade "de massa", correspondente ao sólido apenas. Apesar da grande dispersão da nuvem de pontos experimentais foi possivel quantificar a resistividade aparente do leito como cerca de 13 vezes maior que a resistividade de massa (valores médios da ordem de $4,0 \times 10^{-2} \Omega \mathrm{m}$ e $0,3 \times 10^{-2} \Omega \mathrm{m}$, respectivamente). O aumento de temperatura e o da pressão exer cida sobre a amostra provocam uma diminuição da resistividade, o que também foi observado por Silveira (1977).

Este pesquisador estudou a resistividade elétrica dos leitos de coque e carvão vegetal em forno elétrico de redução. A dependencia da resistividade com a temperatura mostrouse ser na forma exponencial. Tal fato se deve possivelmente a mudanças na estrutura e grau de grafitização do material e à ex pansão tērmica das partículas.

A diminuição da resistividade elétrica com o aumento do tamanho das particulas, observada por Silveira e Melo 


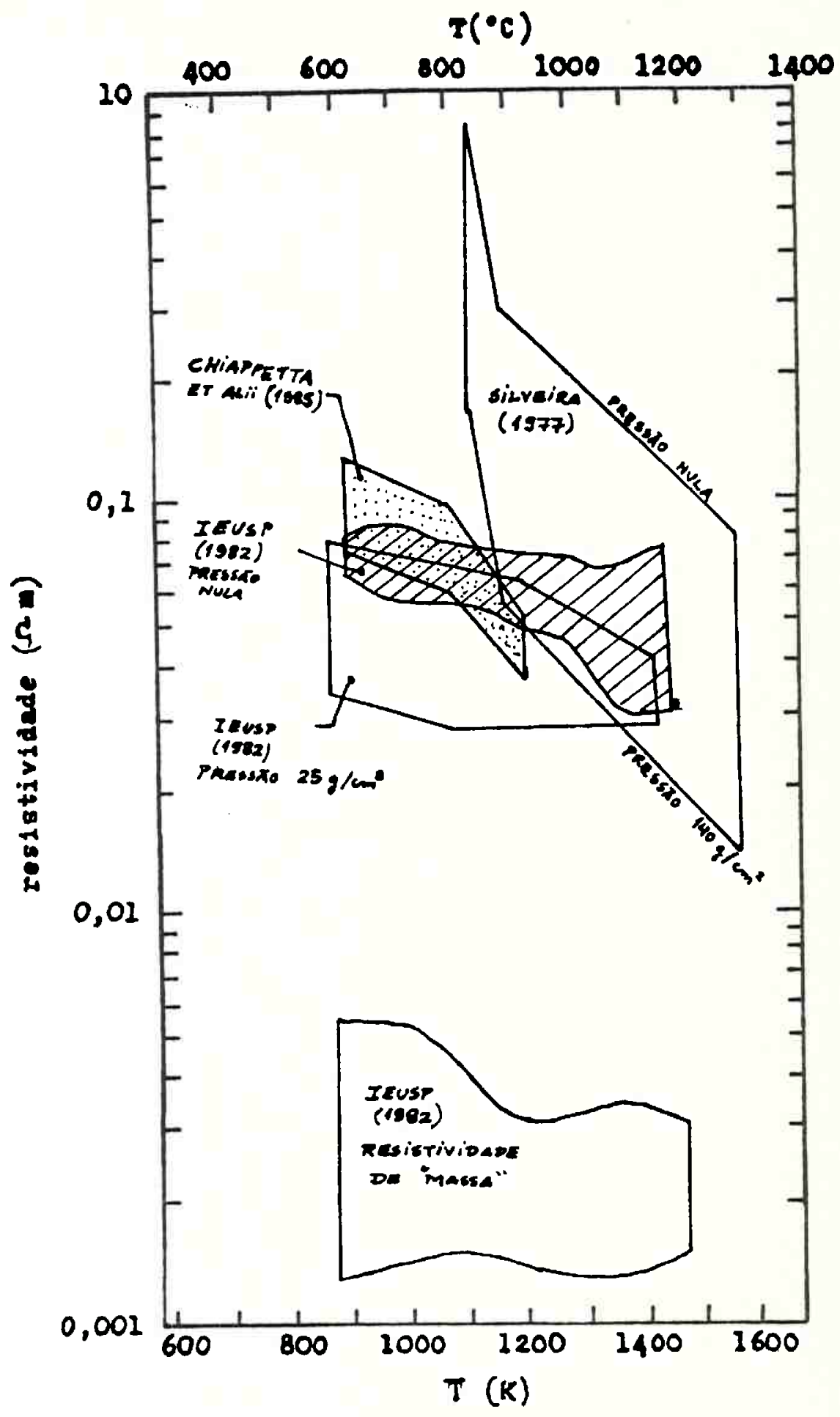

Fjgura c. Z4. Jesistividade elétrica de leitos di carvão. Fesultados obtidos por diversos autores. 
(1973) poderia ser explicada, segundo Silveira (1977), pela estrutura física do leito. A resistência total compõe-se da resistência do sôlido e da resistência de passagem nas áreas de contato entre os dois grãos. Se esta resistência nas áreas de contato for considerada uma resistência ôhmica, dependerá do nú mero de contatos e portanto do tamanho das partículas. Para um dado volume de leito, quanto menores as particulas, maior o número de contatos. Para partículas pequenas, a extensão da ärea de contato entre duas particulas será pequena; isto causa maior contração nas linhas de fluxo de corrente elétrica, aumentando a resistividade do leito. Para partículas maiores, a extensão das āreas de contato serā maior e a resistividade elétrica dos leitos de carvão é influenciada tanto pelo número de äreas de contato como pela sua extensão.

A diminuição da resistividade elétrica do leito com o aumento da pressão é explicada pelo aumento das áreas de contato devido à solicitação mecânica, sem mudar significativamente o número de contatos entre as partículas [Silveira (1977)].

Chiappetta et alii (1985a) mediram a resistividade elétrica de leito fixo de carvão vegetal em reator eletrotér mico paralelepipedal de dimensões $0,25 \times 0,25 \times 0,75 \mathrm{~m}$, com cor rente elétrica contínua passando na direção da maior dimensão, com e sem passagem de vapor atravës do leito. Os resultados pu deram ser representados pela expressão:

$$
\rho=0,9 \exp [-0,0033(\mathrm{~T}-273)]
$$

que dá a dependência exponencial da resistividade elétrica com a temperatura. As demais influências, como granulometria, pres são, natureza do material não foram estudadas.

A comparação entre os resultados de resistividade elëtrica de leitos de carvão obtidos por diversos pesquisadores, ilustrada na figura 2.14, mostra uma dispersão acentuada. Esta 
dispersão deve-se possivelmente ao fato de tais estudos foram feitos com amostras de carvão de origens diversas, com granulometria diferente, não controlada, usando densidade de corrente de diferentes ordens de grandeza. Outro ponto de dificuldade é uniformização da temperatura em todo o leito em que se faz a me dida, que $\vec{e}$ muito difícil neste tipo de experiência.

Um grupo de pesquisadores da Escola Politécnica e do Instituto de Eletrotécnica da Universidade de São Paulo tem estudado o processo de gaseificação em reator eletrotérmico ví sando modelar matematicamente o comportamento do gaseificador. As considerações básicas para a modelagem dos reatores eletrotërmicos são dadas em IEUSP (1984a). Nesse trabalho inicial es tabeleceu-se uma forma gradual de abordar o problema da modelagem. Partiu-se inicialmente de modelos parciais, simples, com a inclusão de fenômenos elétricos e térmicos, ou fenômenos químicos e de escoamento separadamente, modelos de estado estacionärio e considerando um menor número de dimensões, passando-se posteriormente à modelos que incluem maior número de fenômenos, em maior número de dimensões e que considerem variaçōes no tempo (dinâmicos).

Assim, alguns trabalhos tratam apenas de fenômenos elétricos e térmicos que ocorrem no reator, sem maiores considerações sobre o escoamento das fases e sobre as reações químicas [IEUSP $(1984 \mathrm{~b}),(1984 \mathrm{c}),(1984 \mathrm{~d})$, Bennaton et a1ii(1985); Gambirasio e Bennaton (1985)]. Dentro deste enfoque as equações que descrevem os fenômenos elétricos e térmicos foram resolvidas, obtendo-se deste modo as linhas equipotenciais (elétricas) e isotérmicas para a operação em estado estacionārio. As configurações geométricas utilizadas variaram desde considerar - reator como um cilindro vertical com os eletrodos constituin do suas tampas superior e inferior, até geometrias mais comple xas, como a ilustrada na figura 2.15, geometria esta mais de acordo com os gaseificadores eletrotérmicos existentes. Resul tados como estes, obtidos com modelos bidimensionais permitem 


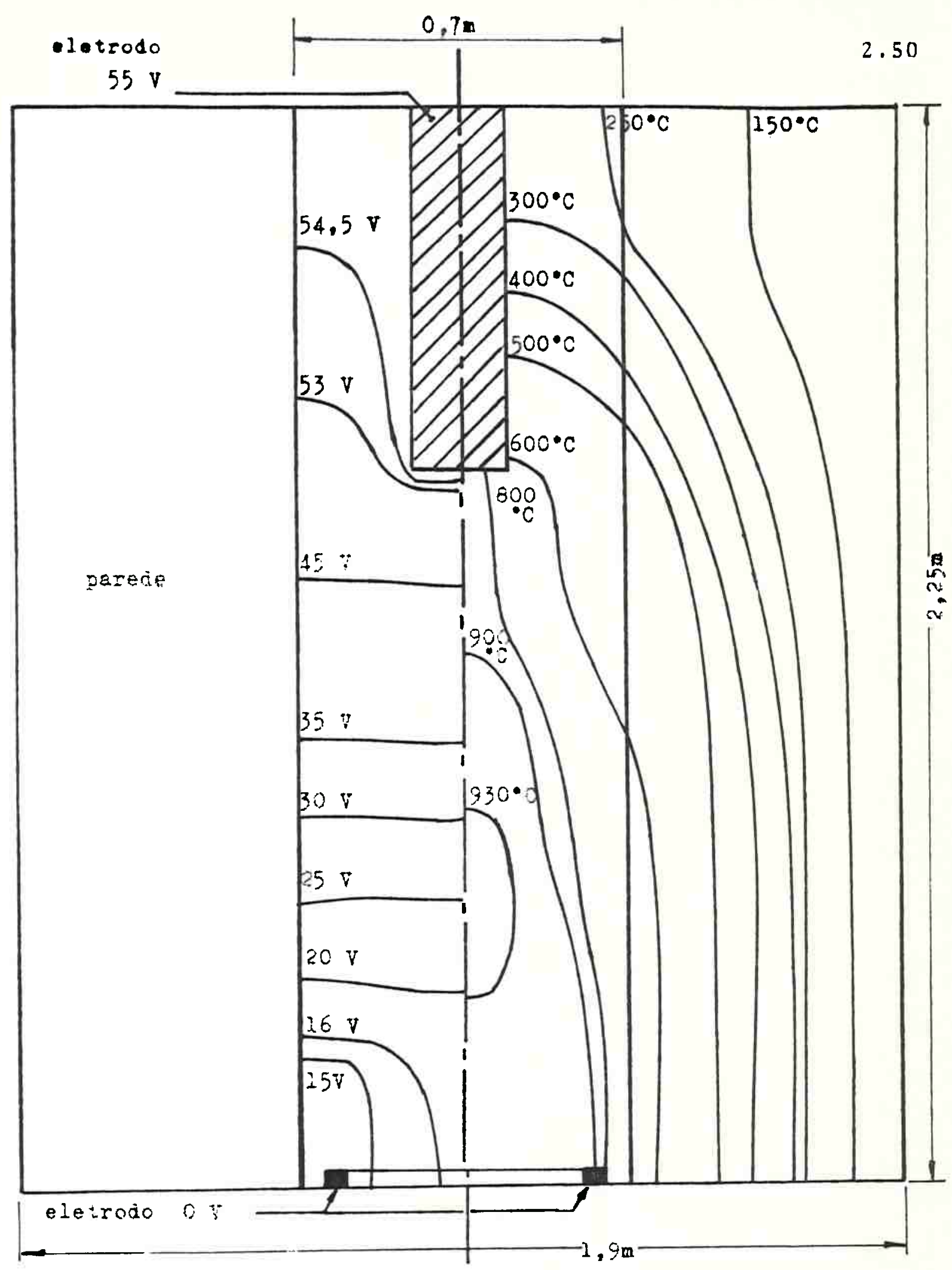

Figure 2.15. Previsếo da distribuigão de iedperaturas a potenciais elétricos ex easeiricador eletrotérmico, obtida com modelo tidimensionaj estético. Conígursção gecmétrica cor eletrodc superior cilíndricc e inferior enelar (forte: IEUSF $(2984 a))$. 
avaliar níveis de temperatura em diversos pontos do gaseificador e do refratärio das paredes laterais.

Em outros trabalhos apresentam-se modelos voltados à descrição dos fenômenos químicos e do escoamento das fases. Um modelo unidimensional foi utilizado para descrever o gaseificador supondo a ocorrência de apenas uma reação química - a mais importante nos gaseificadores eletrotẻrmicos, entre car bono e vapor de água, gerando hidrogênio e monóxido de carbono. As temperaturas das fases sólida e gasosa foram consideradas iguais. O escoamento do vapor através do leito foi considerado sem dispersão e não se considerou a condução de calor no leito [IEUSP (1984e)]. A validade desta última hipótese foi verifica da por IEUSP (1984f) e Chiappetta et a1ii (1985b), pela introdu ção do termo de condução de calor na equação de conservação dé energia do modelo. Estudos paramétricos mostraram que a influência da condução de calor no leito sobre o comportamento do reator é pequena em comparação com a de outros parâmetros, quan do há escoamento do vapor através do leito.

A simulação dinâmica dos fenômenos elétricos e térmicos foi realizada com modelos de dimensão zero [IEUSP(1984a)] para a avaliação dos transitôrios do reator eletrotérmico quando ocorre mudança na tensão aplicada.

Um modelo dinâmico unidimensional foi usado para simular um reator eletrotérmico cujo campo elétrico está em direção perpendicular ao escoanento das fases [IEUSP (1984g), Chiappetta et alii (1985c)] supondo uma configuração diferente daquela mostrada na figura 2.15. Estudou-se de maneira qualitativa a possibilidade de con trole do reator pela variação da tensão aplicada aos eletrodos.

Embora todos os modelos até aqui propostos consti tuam abordagens parciais do gaseificador, deve ser lembrado que mesmo os modelos simples possibilitam o levantamento de informa ções úteis à análise da operação e mesmo ao projeto de unidades maiores. 
Um exemplo deste tipo de informação è a relação entre a tensão aplicada aos eletrodos e a corrente elétrica que atravessa o reator. Modelos para a operação em regime permanen te permitem obter esta relaçāo que caracteriza o comportamento elétrico do reator em operaçāo em estado estacionārio. Esta re lação pode ser apresentada graficamente no plano tensão-corrente como uma curva característica do reator. No mesmo plano, a equação da fonte de alimentação elétrica ou gerador é representada por uma reta de coeficiente linear igual ao valor de sua força eletromotriz (ou tensão em vazio) e de coeficiente angular igual ao valor de sua resistência interna, com sinal negativo. A intersecção da reta do gerador com a curva elétrica característica define um ou mais pontos de operação do sistema reatorgerador em regime permanente.

Observa-se que para um leito cuja resistividade é constante, a curva caracteristica do gaseificador é uma reta e haverá um único ponto de intersecção com a reta do gerador, e, portanto, apenas um ponto de operação estacionário. por outro lado, se a resistividade elétrica varia exponencialmente com a temperatura, como na equação (2.32), a curva elétrica caracteristica apresenta um ponto de máximo. Neste caso, pelo número de intersecções possiveis com a reta do gerador, poderá haver nenhum, um ou dois pontos de operação em regime estacionārio. A situação é ilustrada na figura 2.16 .

Resultados como este são üteis não só na anâlise da operação do conjunto gerador-reator mas tambëm para o projeto adequado de um gerador para alimentar um reator de determina das caracteristicas. 


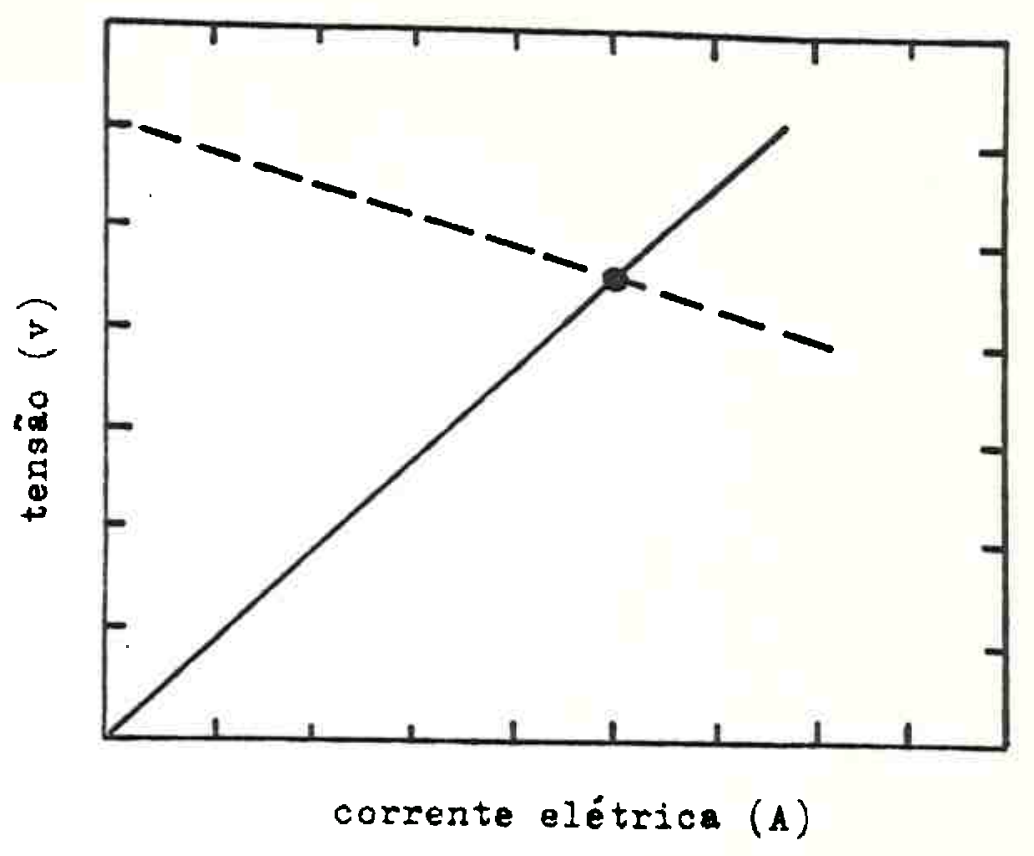

2.53

(1)

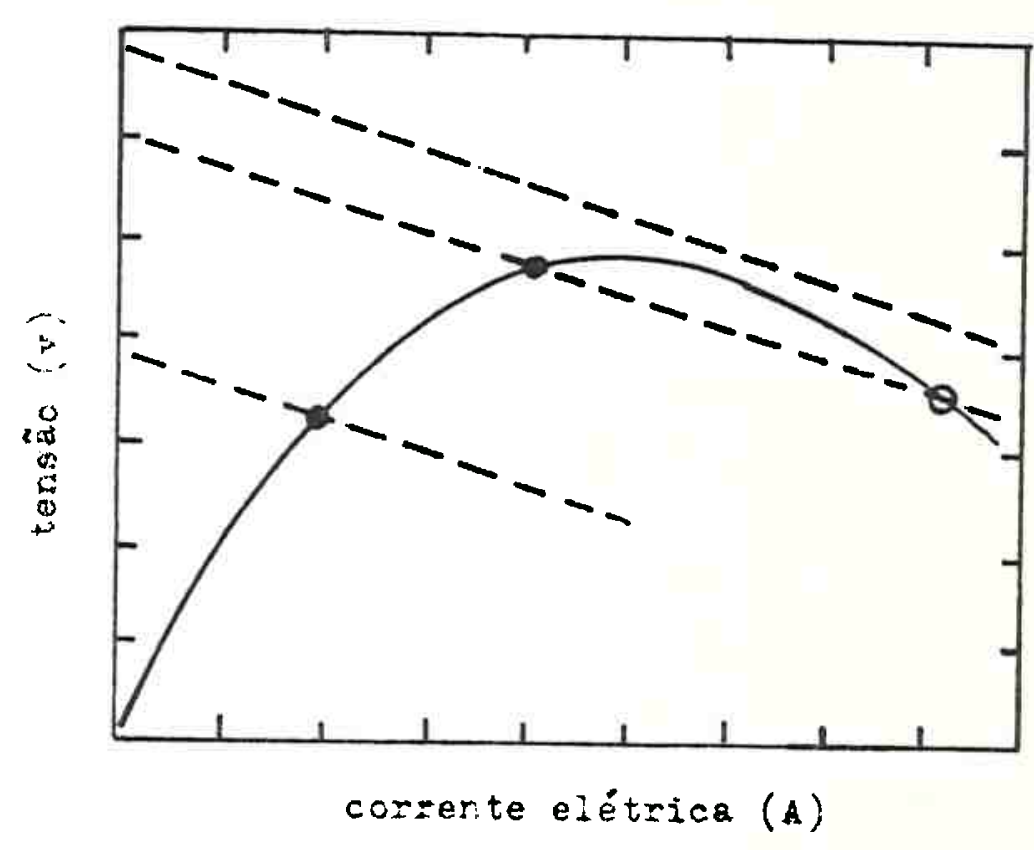

(b)

Ḟ̇ura 2.ló. Snílise da operag̃o coll a curva elétrica caracterígtica do reator eletrotérnico. (a) Resistividade elétrice do leito constante. (b) Resiatividade elétrica veriando exponencialmente com temperetura. Curva elétrió carboterística (- $)$, reto do geredor(---)

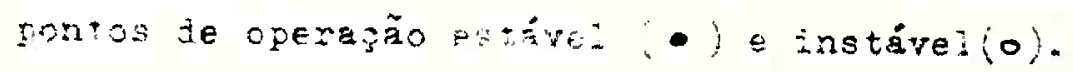




\section{CAPITULO 3 \\ MODELO MATEMATICO PARA A REGIAO ENTRE OS \\ ELETRODOS DO GASEIFICADOR ELETROTERMICO}

\section{1 - INTRODUÇAO}

Neste capítulo é apresentado o gaseificador eletrotérmico de leito móvel descendente e o modelo matemático pa ra a região entre os eletrodos.

O modelo foi elaborado com base em balanços diferenciais de massa e energia no gaseificador. E um modelo unid mensional, pseudo-homogêneo, que simula a região entre os eletro dos com o gaseificador operando em regime permanente. 0 escoa mento foi considerado pistonado para ambas as fases e utilizouse o modelo de núcleo exposto para as taxas de reações gās-sólí do.

A verificaçāo do modelo foi feita comparando-se os resultados com dados experimentais de dois gaseificadores eletrotérmicos, de escala piloto, descritos a seguir.

\section{2 - O GASEIFICADOR ELETROTERHICO}

Os reatores aqui descritos como base para a elabo ração do modelo matemātico são os gaseificadores eletrotérmicos G3 e G5 da Companhia Energētica de Sāo Paulo (CESP), instalados no Núcleo Experimental de Corumbataí, no estado de são Paulo.

Tais gaseificadores foram desenvolvidos como parte de um programa de pesquisas de novas alternativas energéti cas, que se fundamenta na gaseificação de madeira de eucalipto. o gảs gerado pode ser utilizado como combustível de mëdio a bai 
xo poder calorifico ou como gäs de sintese, matëria-prima para a produção de metanol.

O nome dos gaseificadores (G3 e G5) apresenta um número que dá indicação de sua capacidade nominal de geração de gás para a produção de metanol. Por exemplo, o reator G5 tem capacidade nominal de produção de $600 \mathrm{Nm} 3 / \mathrm{h}$ de gâs de sintese equivalente a 5 toneladas/dia de metanol.

Esquemas destes gaseificadores são mostrados nas figuras 3.1 e 3.2 , com indicação de suas dimensōes principais . Em ambos os reatores, a madeira é alimentada pelo topo, de maneira intermitente; à medida em que o leito descendente se apro xima da região intereletrodos a madeira passa por regiōes de temperatura crescente, e sofre os processos de secagem e piróli se. Na região intereletrodos há bocais de injeção de vapor em várias cotas. As cinzas são retiradas pelo centro do eletrodo inferior, atravess de um mecanismo de caçamba rotativa com rampa em espiral, vedada por selo de água.

O eletrodo inferior ê metālico, em forma de anel, refrigerado internamente por água corrente. o eletrodo superior $\ddot{e}$ de grafite.

A retirada dos gases é feita pelo fundo, em saidas próximas ao eletrodo inferior. Testes realizados com o ga seificador G3 operando em contracorrente - parte do gás retirado por um bocal ao nivel do eletrodo superior e outra parte pe 10 topo, ao nível da entrada da madeira, reinjetada próxima ao eletrodo inferior - mostraram que o gás apresentava relativa contaminação por pirolenhosos e, por esse motivo, nas demais campanhas, operou-se em versão concorrente, ou seja, retirando os gases pelo fundo.

A principal diferença entre os gaseificadores G3 e G5 está no topo. O eletrodo superior do reator G3 $\vec{e}$ formado 


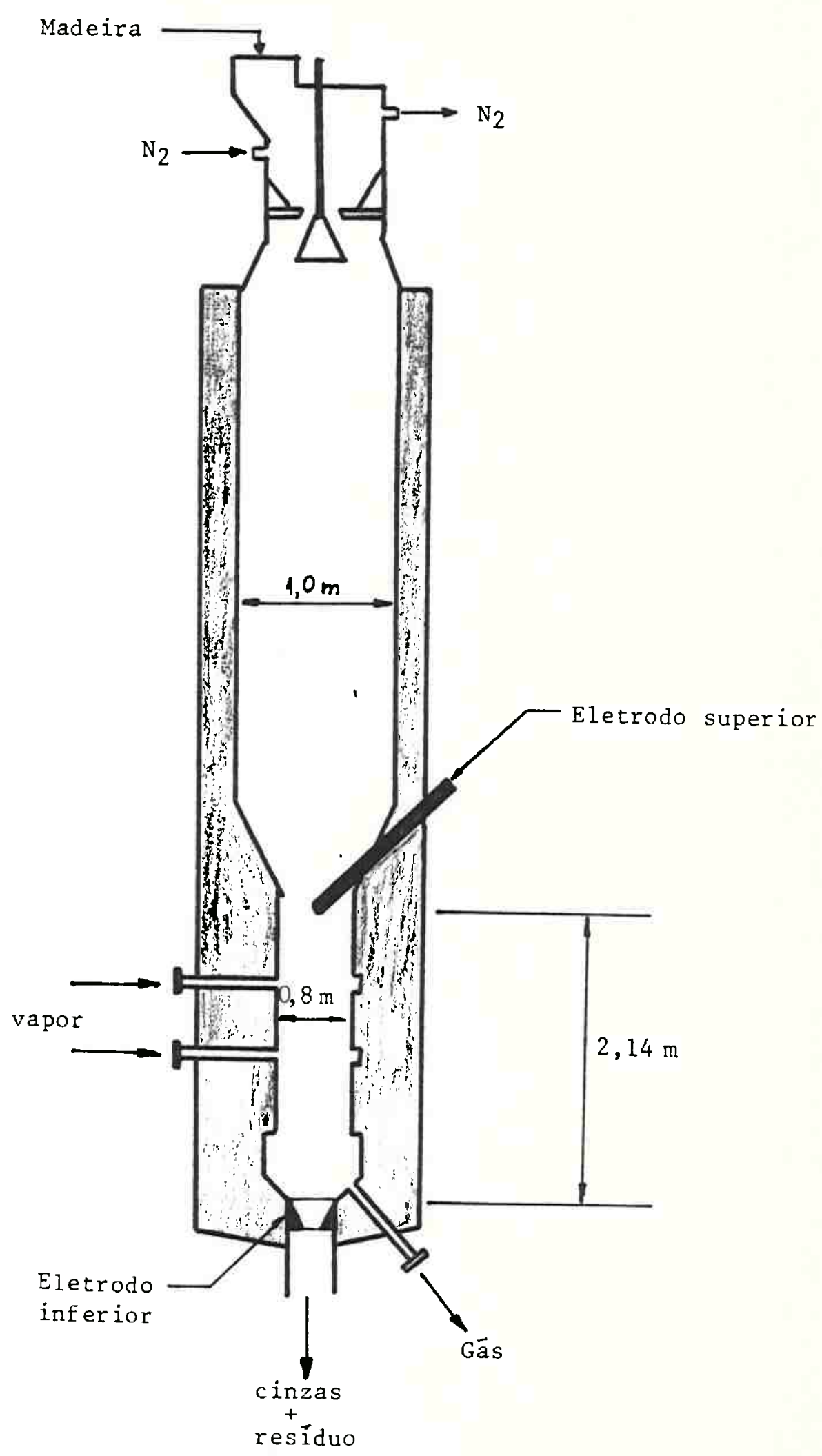

Figura 3.1 - Esquema do gaseificador eletrotérmico G3 da Companhia Energética de São Paulo (CESP). 


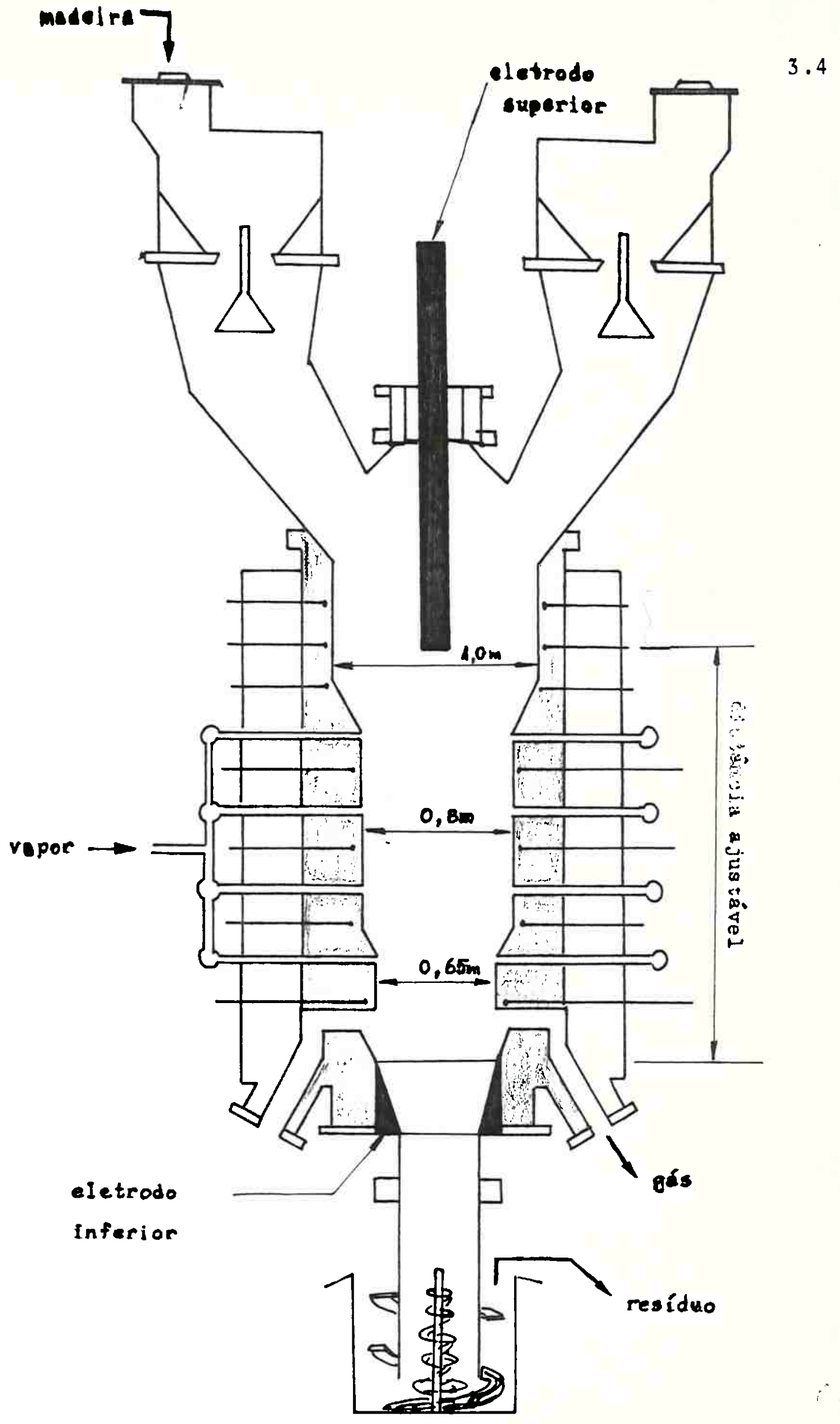

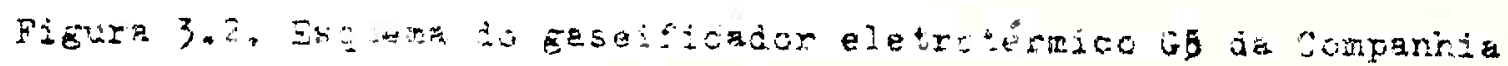

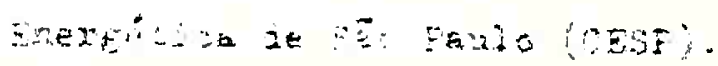


por um feixe de três cilindros de grafite, dispostos de maneira inclinada a partir da parede lateral. Esta disposição apresentou inconvenientes em relação ao escoamento do leito e excessi vo desgaste dos eletrodos. No reator G5 este sistema foi modificado, com a colocação vertical de um único eletrodo superior, cilindrico, de grafite, coaxial ao corpo do reator. Este eletrodo é sustentado na carcaça do reator por um mecanismo que permite sua movimentação vertical, possibilitando variar, dentro de certa faixa de valores a distância entre os eletrodos su perior e inferior. A entrada de madeira, no G5, foi dividida em duas partes, com volume total acima da região intereletrodos me nor que no $\mathrm{G} 3$.

Esta configuração do reator 65 possibilita uma operação mais versätil por permitir compatibilizar a distância intereletrodos, e por consequência o volume desta região, com a potência elétrica disponivel. Além disso, favorece o escoamento da carga no reator.

Os bocais laterais de injeção de vapor, existentes em vários niveis (com quatro bocais em cada cota, dispostos simetricamente sobre o perimetro da seção cilíndrica) permitem manter a temperatura do refratārio da parede interna sob temperaturas adequadas.

0 aquecimento é obtido por efeito Joule, com o leito atuando como resistência elétrica. A corrente elétrica é do tipo continua, obtida a partir de uma fonte de potência máxi ma $300 \mathrm{~kW}$.

\section{3 - HIPOTESES ADOTADAS}

São apresentadas a seguir as hipöteses simplifica doras adotadas na elaboração do modelo matemático. 
a) Regime permanente. Embora na operação real do gaseifi cador a alimentação de madeira seja de operação intermitente, é esperado um efeito pequeno desses transitó rios na região entre os eletrodos. 0 modelo não se aplica, em princípio, à situação de partida ou encerra mento da operação.

b) Modelo unidimensional. As variações de propriedades e fenômenos são consideradas apenas na direção axial. do gaseificador. Isto significa considerar achata dos os perfis de velocidade, temperatura e concentração, o que é um comportamento característico de leitos de enchimento. Isto também significa considerar os eletrodos como placas (tampas) estendendo-se por toda a seção transversal do cilindro. Nas demais direçōes não foi considerado nenhum fenômeno, exceto a interação de calor com o ambiente exterior, através das pare des laterais do reator.

c) O calor transferido ao exterior foi considerado propor cional à diferença de temperatura entre o leito e o am biente exterior e à ārea da superfície lateral cilíndrica que os separa. Um coeficiente global médio representa as várias resistências de transferência de ca lor-condução radial no leito, convecção com a parede interna, condução na parede, convecção exterior, radia ção. Este enfoque permite diminuir o número de parâme tros do modelo.

d) Considerou-se que o transporte de energia na direção axial é dado apenas pela contribuição da convecção dos gases e sólidos, sendo desprezada a condução de calor nessa direçāo. A condução radial estā implicitamente incluída no coeficiente de transferência de calor para o exterior. A hipótese de desprezar a condução na direção axial facilita a resolução das equações diferen 
ciais do modelo, pois evita o aparecimento de um termo diferencial de 2 a ordem no balanço de energia. Esta hi pótese está apoiada nos trabalhos de Chiappetta et alii (1985c) e IEUSP (1984f)que mostraram que o termo de condução de calor na direção axial não è importante quando hả um escoamento apreciảvel no reator.

Esta hipótese também é justificada no trabalho de Yoon et alii (1978), através das seguintes considerações. A convecção e a radiação são os dois principais mecanismos de transmissão de calor em reatores de leito fixo com fluxo axial dominante e temperaturas elevadas. A condutividade térmica efetiva por estes dois mecanismos a $1373 \mathrm{~K}$ e para particulas de diâmetro médio $0,01 \mathrm{~m}$ é da ordem de $10 \mathrm{~W} / \mathrm{m} / \mathrm{K}$, com a radiação contribuindo com cerca de $10 \%$ da condutividade térmica efetiva e a mistura turbilhonar (convecção) com cerca de $90 \%$. Sob es tas condições o número de Peclet axial $\left(\mathrm{Pe}_{\mathrm{L}}=\mathrm{c}_{\mathrm{p}} \rho \mathrm{u} \mathrm{L} / \mathrm{k}_{\mathrm{e}_{f}}\right)$ é de cerca de 500 para o leito e 2 para a partícula. Isto indica que o leito pode ser aproximado por 250 rea tores de mistura em série [Levenspiel (1972)], que equivale a aproximadamente a um reator de escoamento pistonado sem dispersão tērmica.

e) Não se considerou a difusão de massa na direção axial, por ser a convecção de massa muito maior que a difusão nesta direção. A difusão de massa entre o gás e as partículas sólidas é, no entanto, considerada nos mode los de cinética das reaçōes gás-sōlido, onde a difusão tem uma contribuição importante.

As hipóteses (b), (d) e (e) constituem o modelo de escoamento pistonado, do reator tubular ideal [Grove et alii $(1969)]$.

f) Modelo pseudo-homogêneo, isto é, não se considerou a distinção entre as fases sôlida e gasosa. Apesar de o 
sistema ser heterogêneo, as equaçōes dos balanços de massa e energia foram escritas considerando-se uma úni ca fase. Isto diminuiu o nümero de equações de balanço de massa e energia, facilitando a resolução. Esta simplificação mostrou-se satisfatória quando usada em outros trabalhos, como os de Yoon et alii (1978), Loureiro (1984) e Souza Santos e Jen (1982).

os efeitos de transferência de massa entre as partícu las e a fase gasosa foram consideradas nos modelos de cinética de reação heterogênea, o que, segundo Souza Santos e Jen (1982) poderia compensar, de certo modo, o desvio que o equacionamento pseudo-homogêneo introduz.

Tambēm as temperaturas das fases sōlidas e gasosa são consideradas iguais em cada secção transversal do reator. Isto equivale a desprezar a resistência à transferência de calor entre o gás e o sólido, o que pode ser parcialmente justificado pela grande área específi. ca do leito disponível para a troca de calor e massa entre as fases.

g) As particulas foram consideradas isotérmicas, o que po de ser justificado pela alta condutividade térmica das partículas de carvão a temperaturas elevadas.

h) A geometria das particulas sólidas foi considerada esférica. No processo em questão, o reator é alimentado com toletes de madeira de eucalipto, com formato cilin drico de comprimento médio $0,085 \mathrm{~m}$ e diâmetro médio $0,075 \mathrm{~m}$. Assim, sendo a forma aproximadamente de um cilindro equilátero, não hā grande erro em se conside rar a forma esférica, cujo tratamento matemático é mais simples.

Associada a esta hipötese, considerou-se também que as partículas sólidas são isotrópicas, isto é, desprezou- 
se as diferenças de propriedades nas diferentes direçōes da partícula.

\section{4 - REAÇÕES QUIMICAS CONSIDERADAS NO MODELO MATEMATICO}

$$
\begin{aligned}
& \text { As reações consideradas no modelo são: } \\
& \mathrm{C}^{\star}(\mathrm{s})+\mathrm{H}_{2} \mathrm{O}(\mathrm{g}) \rightleftarrows \mathrm{H}_{2}(\mathrm{~g})+\mathrm{CO}(\mathrm{g}) \\
& \mathrm{C}^{*}(\mathrm{~s})+\mathrm{CO}_{2}(\mathrm{~g}) \rightleftarrows 2 \mathrm{CO}(\mathrm{g}) \\
& \mathrm{C}^{*}(\mathrm{~s})+2 \mathrm{H}_{2}(\mathrm{~g}) \rightleftarrows \mathrm{CH}_{4}(\mathrm{~g}) \\
& \mathrm{CO}_{(\mathrm{g})}+\mathrm{H}_{2} \mathrm{O}(\mathrm{g}) \rightleftarrows \mathrm{CO}_{2}(\mathrm{~g})+\mathrm{H}_{2}(\mathrm{~g})
\end{aligned}
$$
não com carbono puro.

Aqui, como no trabalho de Cho e Joseph (1981), con siderou-se que "char" apresenta composição aproximada $\mathrm{C}_{\alpha} \mathrm{O}_{\beta}$, onde $\alpha$ e $\beta$ são calculados a partir da análise elementar da madeira e de balanços de massa sobre a região de pirólise. Desse modo, as reações consideradas podem ser escritas como:

$$
\begin{aligned}
& \mathrm{CH}_{\alpha} \mathrm{O}_{\beta}+(1-\beta) \mathrm{H}_{2} \mathrm{O} \rightleftarrows \mathrm{CO}+\left(1-\beta+\frac{\alpha}{2}\right) \mathrm{H}_{2} \\
& \mathrm{C}_{\alpha} \mathrm{O}_{\beta}+\mathrm{CO}_{2} \rightleftarrows 2 \mathrm{CO}+\beta \mathrm{H}_{2} \mathrm{O}+\left(\frac{\alpha}{2}-\beta\right) \mathrm{H}_{2} \\
& \mathrm{C} \mathrm{H}_{\alpha} \mathrm{O}_{3}+\left(2+\beta-\frac{\alpha}{2}\right) \mathrm{H}_{2} \rightleftarrows \mathrm{CH}_{4}+\beta \mathrm{H}_{2} \mathrm{O} \\
& \mathrm{CO}+\mathrm{H}_{2} \mathrm{O} \rightleftarrows \mathrm{CO}_{2}+\mathrm{H}_{2}
\end{aligned}
$$




\section{5 - EQUAÇÕES QUE DESCREVEM OS FENOMENOS ELETRICOS}

Considerando um sistema no qual a corrente elêtri ca é estacionāria, ou seja, com distribuição de carga independente do tempo, tem-se

$$
\nabla \cdot \mathbf{J}=0
$$

o campo elétrico está relacionado com a densidade de corrente pela lei de Ohm:

$$
J=\sigma \cdot \mathbf{E}
$$

onde $\sigma e \bar{e}$ a condutividade elétrica do meio.

Para um campo estacionārio, a cada ponto da região está associado uma função escalar $\phi$, o potencial elétrico, cuja relação com o campo elétrico è

$$
\mathbf{E}=-\nabla \phi
$$

Substituindo (3.3) em (3.2) e esta em (3.1) obtẻm-se a equação que rege a distribuição de potenciais elētri$\cos$ :

$$
\nabla \cdot(\sigma \nabla \phi)=0
$$

Considerando-se que a corrente elëtrica se distribui uniformemente na seção transversal do reator, a densidade de corrente é dada por:

$$
J=I / A_{t}
$$

Para o caso do presente trabalho, onde o modelo è unidimensional, é conveniente substituir (3.3) en (3.2) para obter a distribuição do potencial elêtrico ao longo da dimensão 
$z$ do reator:

$$
\frac{\mathrm{d} \phi}{\mathrm{d} z}= \pm \frac{\mathrm{J}}{\sigma}
$$

A escolha do sinal na equação acima esta relacionada à orientação do eixo $z$ e à polaridade da tensão aplicada entre os eletrodos.

A condutividade elétrica $\sigma$ è uma propriedade do meio, no caso do leito, que depende do material e da temperatura, alèm de outras variảveis. Para um dado meio pode-se obter a relação empírica entre a condutividade elétrica e a temperatu ra. Estudos feitos por IEUSP (1982) mostraram que para leitos de carvão vegetal esta relação podia ser expressa na forma:

$$
\sigma=a_{\sigma} \exp \left[b_{\sigma}(T-273)\right]
$$

No presente trabalho foram utilizados os valores $a_{\sigma}=8,795 \Omega^{-1} \cdot m^{-1}$ e $b_{\sigma}=6,89 \times 10^{-4}\left({ }^{\circ} \mathrm{C}\right)^{-1}$, conforme IEUSP (1982).

\section{6 - BALANÇOS DE MASSA}

Com base nas hipóteses de regime permanente, mode 10 unidimensional, e desprezado o transporte de massa por difusão, o balanço de massa para cada componente i da corrente gaso sa pode ser escrito na forma:

$$
\frac{d F_{i}}{d z}=A_{t} R_{i}
$$

A taxa de produção do componente i por unidade de volume do reator pode ser expressa em função das taxas das värias reações químicas: 


$$
R_{i}=\sum_{j=1}^{m} v_{i j} r_{j}
$$

onde $v_{i j}$ é o coeficiente estequiométrico da espećie i na reação $j$, como apresentado na tabela 3.1. Aqui seguiu-se a convenção usua 1:

$$
\left\{\begin{array}{l}
v_{i j}>0 \text { para produtos } \\
v_{i j}<0 \text { para reagentes } \\
v_{i j}=0 \text { para inertes }
\end{array}\right.
$$

As expressões para o câlculo das taxas $r_{j}$ das rea ções são apresentadas no item 3.9 .

Os balanços diferenciais de massa [equação (3.8)] são escritos apenas para os componentes da fase gasosa. Não é necessário considerar o balanço diferencial de massa para os sólidos. Considerou-se que a fase sôlida ê formada de "char" e cinzas. A vazão molar do "char" pode ser obtida em cada cota do gaseificador por um balanço do elemento carbono entre o final da regiãode pirólise e cada cota da região de gaseificação:

$$
F_{\text {char }}=F_{C h a r}^{(0)}-\left[\left(F_{C O}-F_{C O}^{(0)}\right)+\left(F_{C_{2}}-F_{C O}(0)\right)+\left(F_{C H_{4}}-F_{C H_{4}}^{(0)}\right)\right]
$$

A vazão de cinzas é constante ao tempo longo da fase sólida e a vazão da corrente sólida é dada em cada cota por:

$$
W_{S}=w_{\text {char }}+w_{\text {cinza }}
$$

A composição da fase sôlida em termos de fração mássica é calculada em cada cota por: 
TABELA 3.1 - Coeficiente estequiométrica $v_{i j}$.

\begin{tabular}{|c|c|c|c|c|c|c|c|}
\hline $\begin{array}{c}\text { Reação } \\
R_{j}\end{array}$ & $\begin{array}{c}\text { Componente } \\
\mathrm{i} \\
\end{array}$ & $\begin{array}{c}\mathrm{H}_{2} \mathrm{O} \\
1 \\
\end{array}$ & $\begin{array}{r}\mathrm{H}_{2} \\
2 \\
\end{array}$ & $\begin{array}{r}60 \\
3 \\
\end{array}$ & $\begin{array}{c}\mathrm{CO}_{2} \\
4 \\
\end{array}$ & $\begin{array}{c}\mathrm{CH}_{4} \\
5 \\
\end{array}$ & $\mathrm{CH}_{\alpha} \mathrm{O}_{\beta}$ \\
\hline R1 & & $-(1-\beta)$ & $\left(1-\beta+\frac{\alpha}{2}\right)$ & 1 & 0 & 0 & -1 \\
\hline R2 & & $B$ & $\left(\frac{\alpha}{2}-\beta\right)$ & 2 & -1 & 0 & -1 \\
\hline R3 & & $\beta$ & $-\left(2+\beta-\frac{\alpha}{2}\right)$ & 0 & 0 & 1 & -1 \\
\hline R4 & & -1 & 1 & -1 & 1 & 0 & 0 \\
\hline
\end{tabular}




$$
\begin{aligned}
& x_{\text {char }}=\frac{W_{\text {char }}}{W_{S}} \\
& x_{\text {cinza }}=\frac{W_{\text {Cinza }}}{W_{S}}
\end{aligned}
$$

A fração de "char" convertida (gaseificada) é dada por:

$$
x_{c}=1-\frac{F_{\text {char }}}{F_{\text {char }}}
$$

A composição da fase gasosa em termos de fração molar de cada componente é calculada por:

$$
y_{i}=\frac{F_{i}}{F_{g}}=\frac{F_{i}}{\sum_{i=1}^{5} F_{i}}
$$

ou, em base seca, por:

$$
y_{i}^{\prime}=\frac{F_{i}}{F_{g}-F_{H_{2} O}}=\frac{F_{i}}{\sum_{i=2}^{5} F_{i}}
$$

\section{7 - balanço de energia}

De acordo com as hipóteses descritas no item 3.3 , - balanço de energia pode ser escrito como:

$$
\frac{1}{A_{t}}\left(W_{s} C_{p s}+F_{g} C_{p g}\right) \frac{d T}{d z}=Q_{R}+Q_{J}-Q_{P}
$$

Deve-se observar que as temperaturas das fases só 
lida e gasosa foram consideradas iguais e que foram desprezados termos usualmente pouco importantes em reatores químicos tais como dissipação viscosa, energia cinética e potencial.

O termo de entalpia de reação leva em conta efeito de todas as reações químicas consideradas:

$$
Q_{R}=\sum_{j=1}^{4}\left(-\Delta H_{j}\right) r_{j}
$$

O termo de interação de calor com o meio exterior conforme a hipótese (c) descrita no item 3.3 é dada por:

$$
Q_{p}=h \frac{A_{1 a t}}{V}\left(T-T_{\text {ext }}\right)
$$

Para a geometria cilindrica, a superfície lateral por unidade de volume é:

$$
\frac{A_{1 a t}}{V}=\frac{\pi D L}{\frac{\pi D^{2} L}{4}}=\frac{4}{D t}
$$

A potência dissipada por efeito Joule por unida de de volume do reator é dada em cada ponto do reator, por:

$$
Q_{J}=\frac{\mathrm{J}^{2}}{\sigma}
$$

\section{8 - EQUAÇÃO PARA A VARIAÇĀO DA PRESSÃO}

A variação da pressão do gās ao longo do leito foi prevista usando-se a equação de Ergun [Bird et alii (1960), Froment e Bischoff (1979), Sheel e Grove (1969)] : 


$$
\begin{aligned}
& \frac{d P}{d z}=-2 f_{a} \frac{\rho_{g} u^{2}}{d_{p}} \\
& f_{a}=\frac{1-\varepsilon_{\ell}}{\varepsilon_{\ell}^{3}}\left[1,75+150 \frac{1-\varepsilon_{\ell}}{R e}\right]
\end{aligned}
$$

välida para $10<\operatorname{Re} /\left(1-\varepsilon_{\ell}\right)<1000$, onde o número de Reynolds é:

$$
\operatorname{Re}=\psi \frac{\mathrm{d}_{\mathrm{p}} \mathrm{u} \rho_{\mathrm{g}}}{\mu_{\mathrm{g}}}
$$

e $\psi$ é o fator de forma ou esfericidade da particula definido co mo a relação entre a superfície de uma esfera de mesmo volume que a partícula e a superfície da partícula.

Neste trabalho as partículas foram consideradas esféricas e, portanto, $\psi$ foi assumido igual a 1 .

A velocidade $u$ è a velocidade relativa entre $\circ$ gās e o sólido:

$$
u=u_{g}-u_{s}
$$

onde :

$$
\begin{aligned}
& u_{g}=\frac{F_{g} M_{g}}{\rho_{g} A_{t} \varepsilon \ell} \\
& u_{S}=\frac{W_{S}}{\rho_{S} A_{t}(1-\varepsilon \ell)} \\
& M_{g}=\sum_{i} y_{i} M_{i}
\end{aligned}
$$




\section{9 - CALCULO dAs taXas das REAÇÕES}

\section{9 .1 - Reações gás-sōlido}

Seguindo a discussão apresentada no item 2.2, para as reações heterogêneas (R1), (R2) e (R3) foi adotado o mode 10 cinético de núcleo exposto. Neste modelo a resistência ao transporte de massa exterior à partícula e a resistência devido à reação química são combinadas para obter a taxa global [ver Apêndice A] :

$$
r_{j}=\frac{\left[1-\varepsilon_{\ell}\right]\left[P_{i}-P_{i} q\right]}{\frac{d_{p}^{0} f_{r}}{6 k_{p i}}+\frac{1}{n_{j} k_{r_{j}} C_{c}(0)}}
$$

O coeficiente de transferência de massa entre. 0 gás e a superficie da particula è obtido a partir da correlação de Gupta e Thodos (1963), rearranjada na forma:

$$
\mathrm{k}_{\mathrm{p}_{\mathrm{i}}}=\frac{2,06}{\varepsilon_{\ell} \mathrm{P}} \mathrm{S}_{\mathrm{C}}^{-2 / 3} \mathrm{Re}^{-0,575} \frac{\mathrm{F} g}{\mathrm{~A}_{\mathrm{t}}}
$$

onde o número de Reynolds é definido na equação (3.25) e o núme ro de Schmidt é

$$
S_{c}=\frac{\mu_{g}}{\rho_{g} D_{i}}
$$

Para o cálculo da difusividade do componente i na mistura de gases foi tomada como a média da difusividade dos principais componentes através da mistura como em Souza Santose Jen (1982) e dada por:

$$
D_{i}=\frac{43,16}{P}\left[\frac{T}{1800}\right]^{1,75}
$$


A relação entre o diâmetro da partícula e o diâmetro inicial é calculado por:

$$
f_{r}=\left[1-x_{C}\right]^{1 / 3}
$$

o efeito da difusão interna é levado em conta no fator de efetividade que é calculado considerando-se a reação de 1. ordem e partícula esférica. Assim o fator de efetividade e o módulo de Thiele são calculados por [Yoon et alii (1978)].

$$
\begin{aligned}
& n_{j}=\frac{1}{\Phi_{j}}\left[\frac{1}{\tanh \left(3 \Phi_{j}\right)}-\frac{1}{3 \Phi_{j}}\right] \\
& \Phi_{j}=\frac{d_{p}^{(0)} f_{r}}{6}\left[\frac{k_{r j} C_{c}^{(0)} R T}{\Lambda D_{i_{e f}}}\right]^{1 / 2}
\end{aligned}
$$

onde $\Lambda$ é o coeficiente estequiométrico do "char" na reação considerada $(\Lambda=1)$.

A difusividade efetiva da espēcie i. na matriz sólida $\vec{e}$ expressa por:

$$
D_{i_{e f}}=D_{i} \varepsilon_{c}^{2}
$$

A cinética intrínseca de cada reação segue a expressāo de Arrhenius:

$$
k_{r_{j}}=B_{j} \exp \left[-\frac{E_{j}}{R T}\right]
$$

e seus parâmetros estão apresentados na tabela 3.2 .

A "força motriz" para a reação química ( $\left.p_{i}-p_{i e q}\right)$ leva em conta a limitação da velocidade de reação pelo equilíbrio químico e a possibilidade de uma inversão quando a compos $\underline{i}$ 
TABELA 3.2 - Constantes da expressão de Arrhenius para o cãlculo das veloci dades das reações heterogêneas.

\begin{tabular}{|c|cc|c|c|}
\hline $\begin{array}{c}\text { Reação } \\
R_{j}\end{array}$ & \multicolumn{2}{|c|}{$B_{j}$} & $\frac{E_{j}}{R}\left(K^{-1}\right)$ & Fonte \\
\hline$R 1$ & $1,37 \times 10^{2}$ & $(\mathrm{kmol})(\mathrm{kmol} \mathrm{c})^{-1}(\mathrm{~Pa})^{-1}(\mathrm{~s})^{-1}$ & 26100 & \\
$R 2$ & $1,37 \times 10^{2}$ & $(\mathrm{kmol})(\mathrm{kmol} \mathrm{C})^{-1}(\mathrm{~Pa})^{-1}(\mathrm{~s})^{-1}$ & 26100 & Loureiro \\
$R 3$ & $8,12 \times 10^{-14}(\mathrm{kmol})(\mathrm{kmol} \mathrm{C})^{-1}(\mathrm{~Pa})^{-2}(\mathrm{~s})^{-1}$ & 8059 & \\
\hline
\end{tabular}


ção do meio assim o requerer.

Os termos $\left(p_{i}-p_{i_{e q}}\right)$ para as reaçōes consideradas estãomostrados na tabela 3.3 .

\subsection{2 - Reação de Deslocamento}

A reação de deslocamento (R4):

$$
\mathrm{CO}+\mathrm{H}_{2} \mathrm{O} \rightleftarrows \mathrm{CO}_{2}+\mathrm{H}_{2}
$$

foi considerada elementar de $2^{\text {a }}$ ordem, homogênea, reversivel, cu ja expressão cinética adotada é a dada por Biba et alii (1978):

$$
\begin{aligned}
& r_{4}=k_{r_{4}}\left(y_{\mathrm{CO}} y_{\mathrm{H}_{2} \mathrm{O}}-\frac{y_{\mathrm{H}_{2}} y_{\mathrm{CO}_{2}}}{\mathrm{k}_{4}}\right)\left(\frac{\mathrm{p}}{\mathrm{RT}}\right)^{2} \\
& \mathrm{k}_{\mathrm{r}_{4}}=2,78 \times 10^{4} \exp \left(-\frac{1511}{\mathrm{~T}}\right)
\end{aligned}
$$

\subsection{3 - Constantes de Equilibrio}

As constantes de equilíbrio das reações foram cal culadas pela expressão:

$$
K_{j}=K_{o_{j}} \exp \left(-\frac{E_{K}}{T}\right)
$$

sendo seus parâmetros mostrados na tabela 3.4 . 

TABELA 3.3 - Termo de força motriz $\left(p_{i}-p_{i} i_{\text {eq }}\right)$ para as reações heterogè-
neas.

\begin{tabular}{|c|c|c|c|}
\hline \multirow{2}{*}{$\begin{array}{c}\text { REAÇÃO } \\
R_{j}\end{array}$} & \multicolumn{2}{|c|}{ REAGENTE GASOSO } & $\left(\mathrm{p}_{\mathrm{i}}-\mathrm{P}_{\mathrm{i}}{ }_{\mathrm{eq}}\right)$ \\
\cline { 2 - 4 } $\mathrm{R} 1$ & FORMULA & $\mathrm{i}$ & $\mathrm{P}_{2} \mathrm{O}-\mathrm{PCO}_{\mathrm{P}} / \mathrm{K}_{1}$ \\
$\mathrm{R} 2$ & $\mathrm{H}_{2} \mathrm{O}$ & 1 & $\mathrm{PCO}_{2}-\mathrm{P}_{\mathrm{CO}}^{2} / \mathrm{K}_{2}$ \\
$\mathrm{CO} 3$ & $\mathrm{H}_{2}$ & 2 & $\mathrm{P}_{\mathrm{H}_{2}}^{2}-\mathrm{PCH}_{4} / \mathrm{K}_{3}$ \\
\hline
\end{tabular}

TABELA 3.4 - Parâmetros para o cálculo das constantes de equilíbrio $k_{j}$ usando a equação (3.41).

\begin{tabular}{|c|c|c|c|c|}
\hline $\begin{array}{c}\text { REAÇĀo } \\
R_{j}\end{array}$ & $\begin{array}{c}\text { RELAÇĀO DE } K_{j} \text { COM } \\
\text { AS PRESSOES PARCIAIS }\end{array}$ & $\mathrm{K}_{\mathrm{o}_{j}}$ * & $E_{K}\left(K^{-1}\right)$ & FONTE \\
\hline R1 & $\left(\mathrm{pH}_{2} \quad \mathrm{PCO}_{\mathrm{CO}} \mathrm{P}_{\mathrm{H}_{2} \mathrm{O}}^{-1} \mathrm{eq}\right.$ & $3,139 \times 10^{12}$ & 16335 & \\
\hline R2 & $\left(p_{\mathrm{CO}}^{2} p_{\mathrm{CO}}^{-1}\right)_{\mathrm{eq}}$ & $1,238 \times 10^{14}$ & 20282 & Yoon \\
\hline R3 & $\left(\mathrm{PCH}_{4} \mathrm{P}_{\mathrm{CO}}^{-2}\right)_{\mathrm{eq}}$ & $1,453 \times 10^{-11}$ & -10999 & $\begin{array}{l}\text { et } \\
\text { ali i }\end{array}$ \\
\hline R4 & $\left(\mathrm{P}_{2} \mathrm{P}_{\mathrm{CO}_{2}} \mathrm{p}_{\mathrm{H}_{2} \mathrm{O}}^{-1} \mathrm{p}_{\mathrm{CO}}^{-1}\right)_{\mathrm{eq}}$ & $2,65 \times 10^{-2}$ & -3956 & (1978) \\
\hline
\end{tabular}




\subsection{0 - EQUAÇÕES AUXILIARES}

Para a resolução numërica das equações do modelo são necessārias equações auxiliares para o cālculo das propriedades físicas.e termidinâmicas das substâncias envolvidas. Tais equações são apresentadas no Apêndice B.

A potência elétrica utilizada no reator é calcula da por

$$
\mathrm{P}_{\mathrm{el}}=\mathrm{U} \mathrm{I}
$$

onde $U$ é a diferença de potencial entre os eletrodos

$$
\mathrm{U}=\phi_{\mathrm{z}=\mathrm{L}}-\phi_{\mathrm{O}}
$$

\subsection{1 - FORMA ADIMENSIONAL DAS EQUAÇÕES DIFERENCIAIS DO MODELO}

0 modelo para a região entre os eletrodos fica forma do basicamente pelas equações diferenciais ordinárias de $1^{a}$. ordem:

$$
\begin{aligned}
& \frac{\mathrm{d} \phi}{\mathrm{d} z}=\frac{J}{\sigma} \\
& \frac{\mathrm{d} F_{i}}{\mathrm{~d} z}=A_{t} R_{i} \\
& \frac{\mathrm{dT}}{\mathrm{dz}}=\frac{\left(Q_{R}+Q_{J}-Q_{P}\right) A_{t}}{W_{S} c_{p s}+F_{g} c_{p g}} \\
& \frac{\mathrm{dP}}{\mathrm{d} z}=-2 f_{\mathrm{a}} \frac{\rho g u^{2}}{d_{p}}
\end{aligned}
$$

com condição inicial

$$
\begin{gathered}
z=0 \quad \phi=0 \\
F_{i}=F_{i}(0) \\
T=T_{0} \\
P=P_{O}
\end{gathered}
$$


Quando resolvidas no dominio de $z=0$ ate $z=L$, obtēm-se os perfis de potencial elëtrico, vazões, temperatura e pressão na região entre os eletrodos.

E conveniente, para efeitos computacionais, utili zar variáveis dependentes e independentes na forma adimensional. Assim foram definidas as seguintes variáveis adimensionais:

$$
\phi^{*}=\frac{\phi \sigma_{0}}{J J_{t}}
$$

onde $\sigma_{0} \bar{e}$ o valor da condutividade elëtrica do leito calculada à temperatura $\mathrm{T}_{\mathrm{O}}$

$$
\begin{aligned}
& F_{i}^{*}=F_{i} / F_{g}(0) \\
& T^{*}=T / T_{0} \\
& P^{*}=P / P_{O} \\
& z^{*}=z / L
\end{aligned}
$$

Substituindo-se no conjunto de equações diferenciais do modelo, resulta o sistema de equações adimensionais apresentado a seguir:

$$
\begin{aligned}
& \frac{\mathrm{d} \phi^{*}}{\mathrm{~d}^{*}}=\frac{\sigma_{O}}{\sigma} \\
& \frac{\mathrm{d} \mathrm{F}_{i^{*}}}{\mathrm{~d} z^{*}}=\frac{A_{t} R_{i} L}{F_{g}(0)} \\
& \frac{\mathrm{dT}^{*}}{\mathrm{~d} z^{*}}=\frac{\left(Q_{R}+Q_{J}-Q_{P}\right) A_{t} \cdot L}{\left(W_{S} c_{p_{S}}+F_{g} C_{p_{g}}\right) T_{O}} \\
& \frac{\mathrm{dP}^{*}}{d z^{*}}=-2 f_{a} \frac{\rho_{g} u^{2} L}{d_{p} P_{O}}
\end{aligned}
$$


As condições iniciais são tambẻm expressas na for ma adimensional:

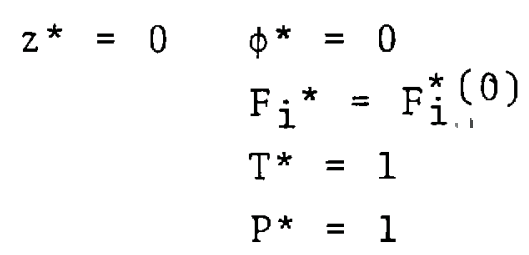

\subsection{2 - INJEÇÃo LATERAL DE VAPOR}

o fato de o gaseificador eletrotérmico possuir bocais de injeção lateral de vapor em.värias cotas deve ser tam bëm considerado no modelo. O vapor entra radialmente no reator para, em seguida, escoar no sentido axial, em concorrente com o sólido, sendo que o gás é retirado por um anel colocado no fundo do reator, próximo ao eletrodo inferior.

Dentro do contexto do modelo proposto neste traba 1ho, a modelagem desta região onde ocorre injeção de vapor pelas laterais apresenta certas dificuldades, das quais destaca-se:

- o vapor apresenta velocidade na direção radial, e esta direção não fora considerada no modelo (unidimensional);

- o vapor entra com temperatura diferente da temperatura do leito (menor que a temperatura do leito);

- ao entrar no leito o vapor pode reagir com o "char"pró $x$ imo ao bocal de entrada lateral, pela reação endotérmica $(R-1)$, resfriando esta fração do leito. Isto cer tamente causa diferenças de temperatura na mesma seção do leito, apesar de que em cada nivel de injeção o vapor entra por quatro bocais distribuidos circularmente no perímetro da seção. (Este fato é utilizado na opera ção prática do gaseificador, regulando-se a vazāo de 
injeção lateral para manter as paredes internas de material refratário sob temperaturas controladas).

Tendo em vista a complexidade em se modelar a injeção lateral de uma maneira rigorosa, adotou-se nesta disserta ção um modelo simplificado para esta região do reator.

A figura 3.3 mostra um esquema de um trecho do ga seificador em que ocorre na cota $z \ell$ a injeção lateral de vapor de água de vazão $\mathrm{F}_{\ell}$ e temperatura $\mathrm{T}_{\ell}$. Nesta cota passam, vindas do topo, a corrente de gases com vazão $F_{g}$ e a corrente de sólidos com vazão $W_{S}$, ambas à temperatura $T$. Estas correntes entram em contato com a corrente lateral de vapor, com a qual tendem a se misturar.

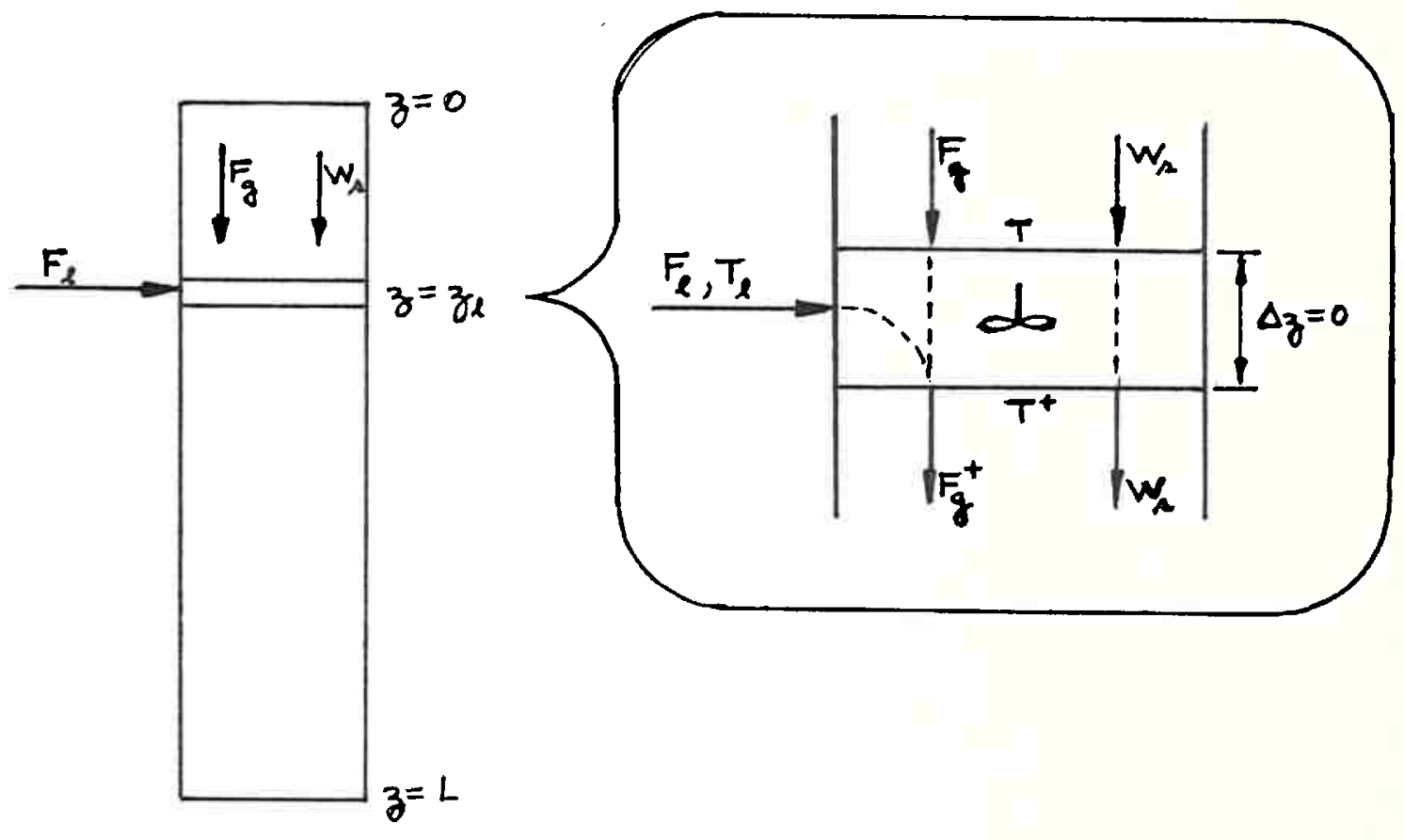

Figura 3.3 - Esquema da injeção lateral. 
Com respeito a este processo, foram adotadas seguintes hipóteses simplificadoras:

(h.1) mistura perfeita da injeção lateral com a corrente descendente gasosa;

(h.2) a mistura se completa após as correntes percorrerem. no reator uma extensão de comprimento desprezí vel;

(h.3) ocorre equilíbrio tērmico entre as fases após uma extensão do reator de comprimento desprezível.

As hipöteses (h.l) e (h.2) estão relacionadas com - caráter unidimensional do modelo, enquanto que a hipótese(h.3) baseia-se no fato de o modelo ser pseudo-homogêneo, onde não há distinção de fases.

As hipóteses $(h .1),(h .2)$ e (h.3) podem parecer drásticas demais em relação à maneira como ocorre o processo de injeção lateral na prática. Entretanto apresentam a vantagem de gerar um modelo bastante simples para a injeçāo lateral, per mitindo obter informaçōes de caráter qualitativo bastante impor tantes.

Considerando-se as hipóteses adotadas e tomandose um volume de controle englobando a secção em que ocorre inje ção lateral, pode-se calcular os novos valores das variáveis:

- a vazão de vapor de água e a vazão total de găs sāo acrescidas da vazão que entra lateralmente:

$$
\begin{aligned}
& \mathrm{F}_{1}^{+}=F_{1}+F_{\ell} \\
& F_{g}^{+}=F_{g}+F_{\ell}
\end{aligned}
$$


- a temperatura do leito è alterada para a de equilíbrio térmico com a corrente lateral:

$$
\mathrm{T}^{+}=\frac{\left(\mathrm{F}_{\mathrm{g}} \mathrm{c}_{\mathrm{g}}+\mathrm{w}_{\mathrm{s}} \mathrm{c}_{\mathrm{p}_{\mathrm{S}}}\right) \mathrm{T}+\mathrm{F}_{\ell} \mathrm{c}_{\mathrm{p} \ell} \mathrm{T}_{\ell}}{\mathrm{F}_{\mathrm{g}}^{+} \mathrm{c}_{\mathrm{p}}^{+}+\mathrm{w}_{\mathrm{s}}^{+} \mathrm{c}_{\mathrm{s}}^{+}}
$$

- a vazão e composição de corrente sôlida, a pressão e o potencial elëtrico não se alteram.

A adaptação deste modelo da injeção lateral com o modelo diferencial do gaseificador é feita do modo descrito a seguir. A integração das equações diferenciais ao longo da direção axial do reator é iniciada ao nível do eletrodo superior $(z=0)$ e finda ao nivel do eletrodo inferior $(z=L)$. Existindo um ponto em que há injeção lateral, a integração é interrompida neste ponto, e são aplicadas as equações (3.54), (3.55) e (3.56) para calcular as variáveis imediatamente abaixo do ponto de injeção. Calculadas estes novos valores, a. integração das equações diferenciais é reiniciada. Para cada ponto de injeção la teral o procedimento acima descrito é repetido.

Deve-se ressaltar que, devido à maneira como fora concebido este modelo, a injeção lateral não. afeta as variações nos pontos superiores à cota em que ocorre injeçāo. Isto gera, como será visto adiante, pontos de descontinuidade nos perfis de temperatura, composição da fase gasosa e vazão dos gases.

\subsection{3 - METODO NUMERICO}

0 sistema de equações diferenciais ordinärias de 1 a ordem (EDO) de valor inicial formado pelas equações (3.7) , $(3.10),(3.20)$ e (3.25) foi resolvido numericamente pelo método de Runge-Kutta semi-implícito proposto por Michelsen (1976). Tal método, apresentado a seguir se aplica à resolução de sistemas 
de equações diferenciais ordinärias de $1^{\text {a }}$ :ordem que apresentam problemas de "stiffness".

O desenvolvimento do método è feito da

seguinte

forma: dado o sistema de equações diferenciais

$$
\frac{d}{d t} y=f(y)
$$

com condição inicial

$$
y\left(t_{n}\right)=y_{n}
$$

calcula-se a matriz Jacobiana, cujos elementos são dados por:

$$
J_{i j}=\left(\frac{\partial f_{i}}{\partial y_{i}}\right)_{y_{n}}
$$

A solução a $t=t_{n}+h^{\prime}, y_{n+1}$ é obtida a partir do seguinte algoritmo:

$$
\begin{aligned}
& k_{1}=h\left[I-h^{\prime} a_{1} J_{n}\right]^{-1} f\left(y_{n}\right) \\
& k_{2}=h\left[I-h^{\prime} a_{1} J_{n}\right]^{-1} f\left(y_{n}+b_{2} k_{1}\right) \\
& k_{3}=\left[I-h^{\prime} a_{1} J_{n}\right]^{-1}\left[b_{31} k_{1}+b_{32} k_{2}\right] \\
& y_{n+1}=y_{n}+c_{1} k_{1}+c_{2} k_{2}+c_{3} k_{3}
\end{aligned}
$$

onde $h^{\prime}$ é o passo da variāvel independente $t$, I é a matriz iden tidade e o indice $n$ denota o número do passo.

As constantes ou parâmetros das equações acima tem seus valores dados por: 


$$
\begin{aligned}
& a_{1}^{3}-3 a_{1}^{2}+\frac{3}{2} a_{1}-\frac{1}{6}=0 ; a_{1}=0,435867 \ldots \\
& b_{2}=0,75 \\
& b_{31}=\frac{-1}{6 a_{1}}\left(8 a_{1}^{2}-2 a_{1}+1\right)=-0,630172 \\
& b_{32}=\frac{2}{9 a_{1}}\left(6 a_{1}^{2}-6 a_{1}+1\right)=-0,24235 \\
& c_{1}=\frac{11}{27}-b_{31}=1,03758 \\
& c_{2}=\frac{16}{27}-b_{32}=0,83494 \\
& c_{3}=1
\end{aligned}
$$

A cada passo de integração a matriz jacobiana é calculada apenas uma vez é necessário calcular f em apenas um ponto intermediārio.

O ajuste do passo de integração é feito do seguin te método: inicialmente integra-se de $t_{n}$ até $t_{n+1}$ com passo com pleto $h^{\prime}=h_{1}^{\prime}$ obtendo $y_{n+1,1}$. A mesma integração é realizada por dois passos de comprimento $h^{\prime}=h_{1}^{\prime} / 2$ obtendo $y_{n+1,2}$. Seja $\varepsilon$ o vetor de tolerância, calcula-se

$$
g=\max _{i}\left|\left(\frac{y_{n+1,2}-y_{n+1,1}}{\varepsilon}\right)_{i}\right|
$$

Se $g \leqslant 1$ o resultado da integração é aceito e o erro de trunca mento $E_{t}$ é dado por:

$$
\mathrm{E}_{\mathrm{t}}=\frac{8}{7}\left(\mathrm{y}_{\mathrm{n}+1,2}-\mathrm{y}_{\mathrm{n}+1,1}\right)
$$


e a solução è dada por:

$$
y_{n+1}=y_{n+1,2}+\frac{E t}{8}
$$

Se, por outro lado, $g>I$, o resultado não é ace $\underline{i}$ to e a integração a partir de $t_{n}$ é repetida com passos $h_{1}^{\prime} / 2$ e $h_{1}^{\prime} / 4$. Apenas a integração com dois passos $h_{1}^{\prime} / 4$ é requerida jä que a integração com $h_{1}^{\prime} / 2$ jā fora realizada.

Uma vez que o passo foi aceito, o novo passo de integração é dado por:

$$
h_{n+1}^{\prime}=h_{n}^{\prime} \cdot \min \left[(4 g)^{-0,25}, 3\right]
$$

Esta expressão permite um aumento no passo quando $g<0,25$ e uma aceleração por um fator de 3 quando $g \ll 1$. O fator de 4 na equação (3.74) e a restrição empírica de um aumento máximo por um fator de 3 são recomendados por Michelsen (1976) como mar gem de segurança, para evitar a seleção de novos passos muito grandes que levariam a sua rejeição posterior (com valores de $\mathrm{g}>$ 1).

A combinação linear das duas soluções aproximadas dada na equação (3.73) fornece um valor mais preciso de $y_{n+1}$ do que $y_{n+1,1}$ ou $y_{n+1,2}$, pois o termo dominante do erro $O\left(h^{4}\right)$ ten de a se cancelar quando as duas soluções são combinadas e o mé-

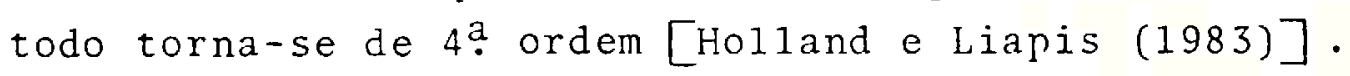

Este método numérico foi programado na forma de uma subrotina, denominada RKSI, que pode ser aplicada à solução de sistemas de equaçōes diferenciais ordinārias de lạ ordem que apresentem problemas de "stiffness". Para a utilização desta subrotina à integração de um sistema de EDOs basta dispor de uma subrotina que calcule o vetor $f(y)$, das equaçōes particula- 
res do problema. A matriz jacobiana pode ser calculada numericamente ou analiticamente; neste ültimo caso é necessário acres centar as expressões para o cálculo de seus elementos.

\subsection{4 - APRESENTAÇAO DO PROGRAMA DE COMPUTADOR GAS/ELET}

A resolução das equações do modelo é efetuado numericamente atravês do programa de computador GAS/ELET. 0 ro teiro básico de resolução ē apresentado no diagrama de blocos simplificado, apresentado na figura 3.4 .

As variảveis de entrada são fornecidas na forma de um arquivo de dados, em formato livre, conforme descrito na Apêndice C.

As subrotinas utilizadas são as seguintes:

a) RKSI - Efetua a integração de um sistema de equações diferenciais ordinärias de lă ordem de valor inicial, utilizando o método de Runge-Kutta semi-implícito com ajuste do passo de integração pelo método proposto por Michelsen (1976).

b) DYCALC - Calcula as derivadas das variāveis $\phi^{*}, \mathrm{~F}_{i}{ }^{*}$, $\mathrm{T}^{*}$ e $\mathrm{P}^{*}$, em relação ao comprimento adimensional $z^{*}$, utilizadas pela RKSI. Para este cálculo são utilizadas as equações diferenciais do modelo e as demais equações algëbricas associadas.

c) IMPRIM - Promove a impressão das variáveis de interes se a cada passo de integração.

d) HMATF - Multiplica uma matriz NxN por uma matriz Nxl. E utilizada pela RKSI. 


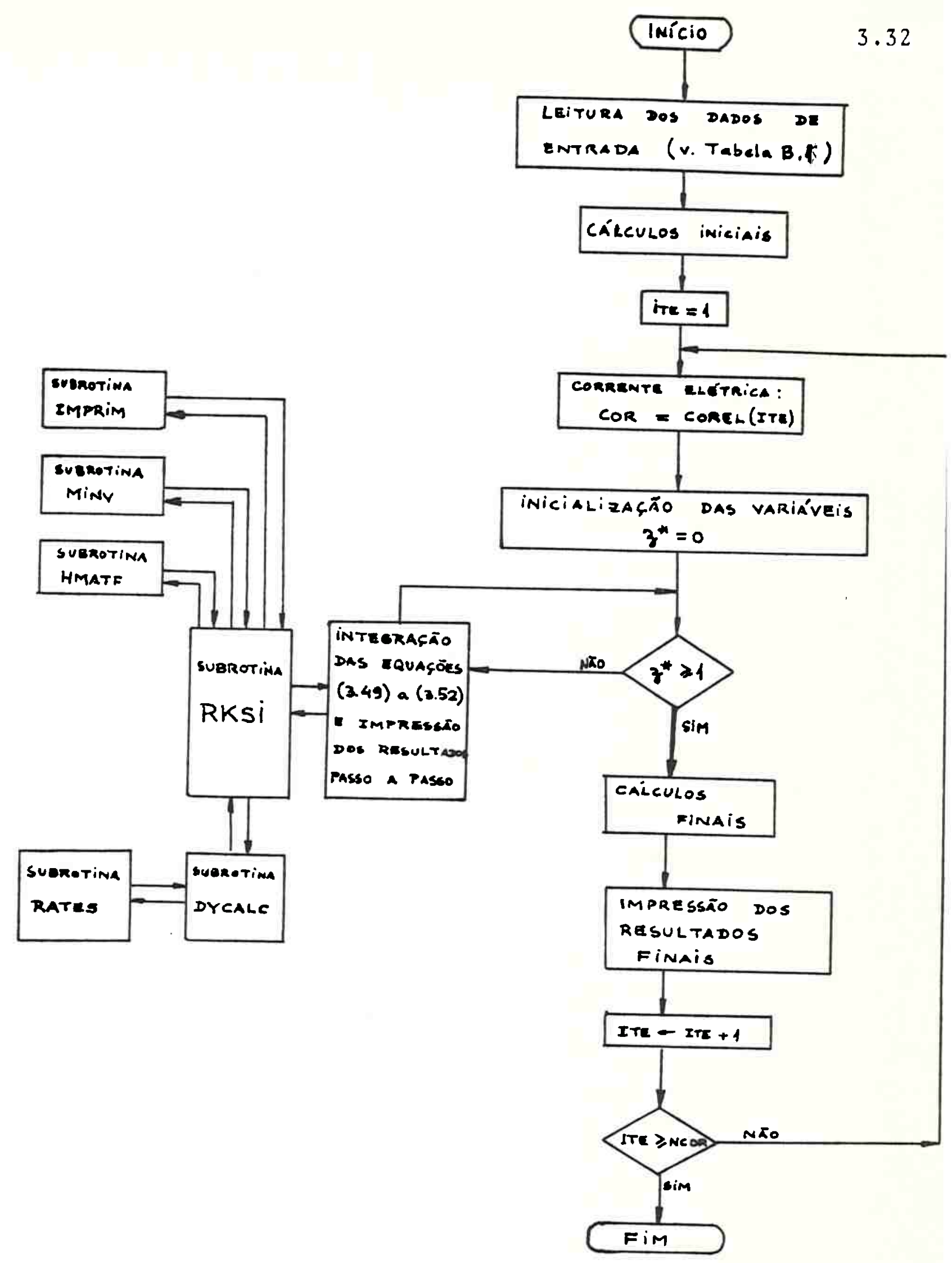

Fia. 3.4 - Diagrama de blocos simplificado do proqrama GAS/ELET. 
e) MINV - Inverte uma matriz NxN. E utilizada pela RKSI para inverter a matriz jacobiana.

f) ADERIV - Reservada para o cálculo analítico da matriz jacobiana. Não foi efetivamente utilizada pois a matriz jacobiana foi calculada numericamente, dentro da subrotina RKSI.

g) RATES - Calcula as taxas de reações químicas.

Alēm dessas subrotinas, são utilizadas as seguintes funções:

a) CP - Calcula o calor específico dos gases.

b) VISCM - Calcula a viscosidade da mistura gasosa.

c) CPC - Calcula o calor específico da corrente sólida.

d) EQK - Calcula as constantes de equilíbrio das reaçōes químicas.

e) DELTAH - Calcula a entalpia das reaçōes químicas.

f) RST - Calcula a resistividade elétrica do leito (inver so da condutividade elétrica).

A saida do programa contêm as seguintes informações:

- condições de operação do gaseificador;

- impressão, a cada passo de integração, dos seguintes resultados:

- $\operatorname{cota}(z)$ e cota adimensional $\left(z^{*}\right)$

- fração de "char" convertido $\left(X_{C}\right)$ 
- vazão $\left(F_{g}\right)$ c composição da fase gasosa $\left(y_{i}, y_{i}^{\prime}\right)$

- pressão (P)

- potencial elétrico ( $\phi)$

- temperatura (T)

- potência elétrica (Pel), diferença de potencial (U), va zão de gás seco gerado (Fgs), temperatura média do leito $(\overline{\mathrm{T}})$.

A listagem completa do programa, um exemplo de ar quivo de dados de entrada e listagem de resultados são apresentados no Apêndice $B$. 


\section{CAPITULO 4}

\section{RESULTAdOS DA SIMULAÇÃO dO MODELO DA REGIAO INTERELETRODOS}

\section{1 - INTRODUÇÃO}

Neste capítulo são apresentados os resultados ob tidos atravēs da simulação do modelo matemätico apresentado no Capitulo 3. E apresentado um estudo paramétrico para mostrar a influência das principais variäveis do processo e dos parâmetros do modelo.

os resultados apresentados neste capítulo, a me nos de indicação em contrário, se referem a condição em que o sólido que entra na regiāo intereletrodos apresenta composição 98\% de carbono e $2 \%$ de cinzas, base mássica, e o gās que entra tambëm junto ao eletrodo superior $\vec{e}$ apenas vapor de ägua. Nos casos em que o sólido possui composição diferente da citada, ou que o vapor entra através de injeções laterais haverá indicação explícita destas condições.

\section{2 - ESTUDO NUMERICO}

Quando sistemas de equaçōes diferenciais ordinārias são resolvidas por mëtodos explícitos, por exemplo o de Runge-Kutta de $4 \stackrel{a}{\text {. }}$ ordem, o passo de integração é o parâmetro cu jo valor deve ser convenientemente escolhido para garantir um bom desempenho do método. A estabilidade de tais métodos re quer que o passo de integração seja inversamente proporcional ao maior autovalor do sistema de equações e isto faz com que, em sistemas com "stiff", frequentemente seja requerido um passo tão pequeno que o tempo de computação torna-se proibitivo. 
Neste trabalho utilizou-se um método semi-implíci to, estável. Como se pode observar no item 3.14 o método dé Michelsen promove um ajuste e controle do passo durante a integração. Este controle é feito a partir da comparação entre um vetor de tolerância e a diferença dos resultados da integração com um passo e com dois meios-passos. O parâmetro de precisão do método é o vetor de tolerância $\varepsilon$, utilizado na equação(3.71).

Foram realizados testes numéricos para a escolha adequada do vetor de tolerância. Uma vez que as variäveis a in tegrar foram convenientemente tornadas adimensionais, foi possi vel estipular um valor ūnico de $\varepsilon$ para todas as variāveis (embo ra este procedimento não seja necessärio para a utilização do método).

Na figura 4.1 são apresentados os perfis de conversão do "char", $x_{C}$, e de temperatura $T$, ao longo do reator, obtidos para $\varepsilon=10^{-1}, 10^{-2}$ e $10^{-3}$. Pode-se observar que os perfis obtidos com diferentes valores de tolerância são pratica mente coincidentes. Não se observam problemas de "stiff", e po de-se perceber a aceleração do passo ao longo da integração, sendo o número de passos total 5, 9 e 15 respectivamente.

Os valores finais das variāveis de integração são apresentados na tabela 4.1. Observa-se que os desvios destas variáveis são pequenos em relação ao caso com $\varepsilon=10^{-3}$, ficando em torno de $2 \%$ o desvio máximo. Trata-se de um caso em que não se observam variações bruscas de comportamento das funções inte gradas, que ocorre normalmente quando não há conversão completa do "char" antes do final do gaseificador.

o mesmo teste foi realizado para um caso em que a conversão do "char" se completava antes do final do reator. Nes te caso, por não ocorrer reações endotërmicas de gaseificação nos pontos posteriores àqueles em que $x_{c}=1$, a temperatura se eleva bruscamente. Na figura 4.2 são mostrados os perfis de 

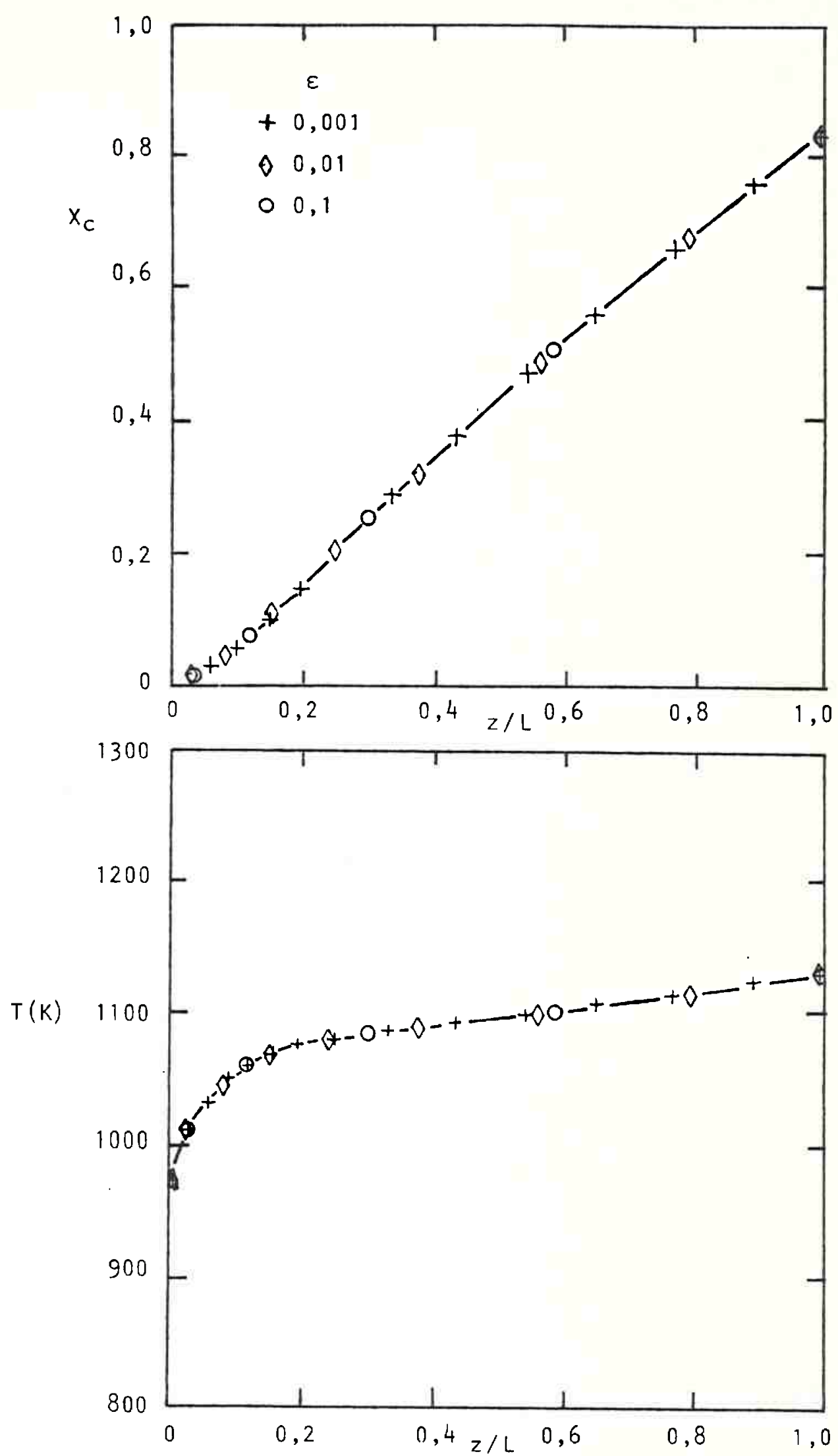

4.3

Fig. 4.1 - Estudo numérico: teste do vetor de tole rância $E$. Conversão incompleta do sōli= do (condições mesmas da tabela 4.1). 


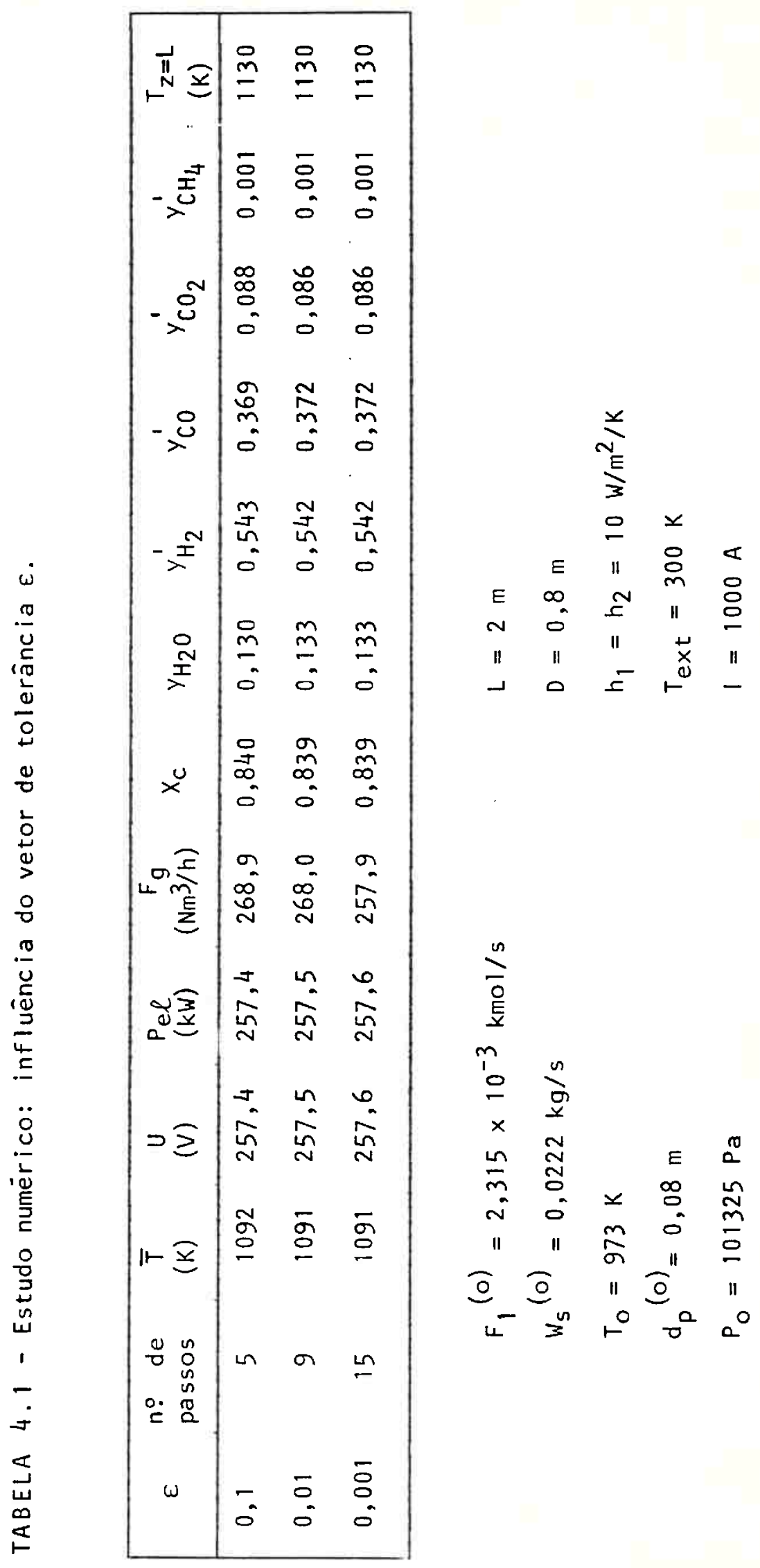


$x_{C}$ e $T$ obtidos pela simulação com $\varepsilon=10^{-3}, 10^{-2}$ e $10^{-1}$. Obser va-se que enquanto a conversão não se completa e não se manifes tam problemas de "stiff", os perfis são praticamente coincidentes, mas alëm do ponto $z^{*}=0,77$, em que ocorre conversão completa, o resultado numérico ontido com $\varepsilon=0,1$ e bastante dis cordante dos demais.

0 mesmo se pode verificar na tabela 4.2 em rela ção aos valores finais da integração. Os desvios para $\varepsilon=0,1$ são acentuados, ao passo que os para $\varepsilon=0,01$ são aceitáveis.

A figura 4.2 permite apreciar também uma importan te característica do método numërico empregado: nos pontos em que as variações são acentuadas, o passo é desacelerado, permitindo melhor conhecimento da evolução do perfil, enquanto que nas regiões onde não hã variações significativas no perfil o passo é acelerado.

\section{3 - ESTUdo PARAMETRICO}

Este estudo visa conhecer a sensibilidade dos resultados da simulaçāo frente a variações dos parâmetros do mode 10 e das variáveis do processo.

Neste estudo foram considerados os seguintes parâ metros:

- coeficiente de transferência de calor para o meio exterior:

- condutividade elétrica do leito;

e as seguintes variâveis do processo:

- temperatura em $z=0$

- pressão do gás em $z=0$ 


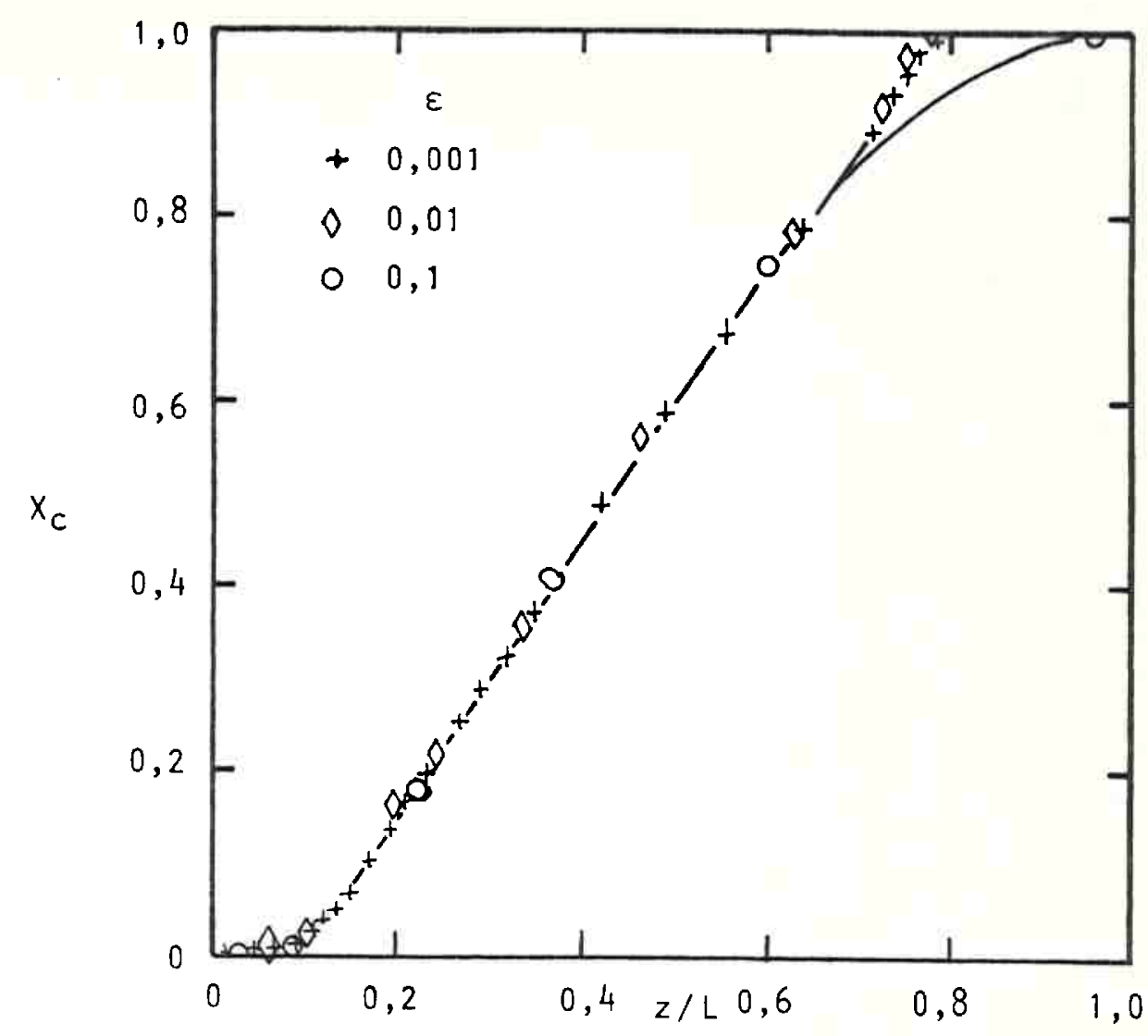

4.6

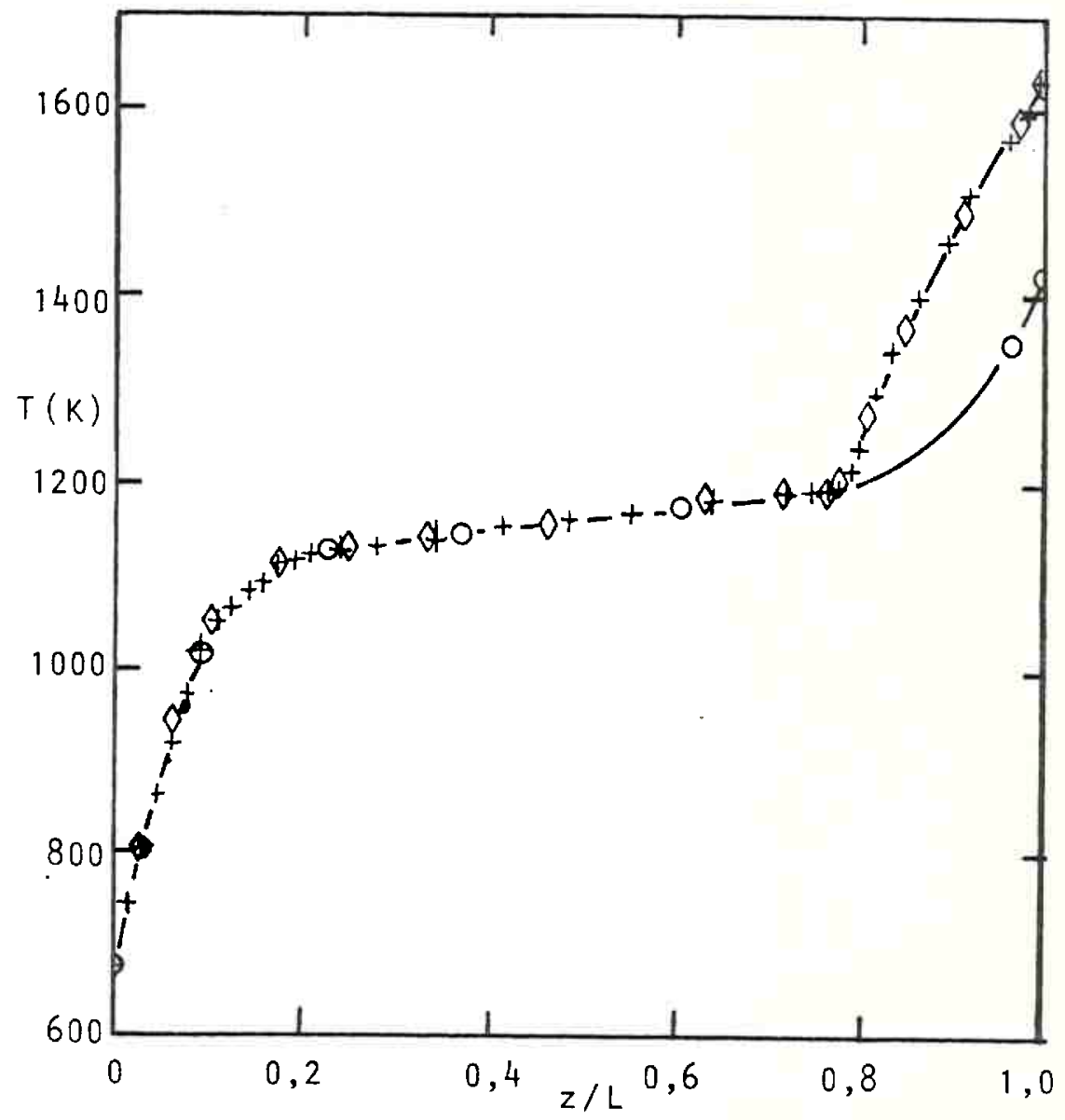

Fig. 4.2 - Estudo numérico: teste do vetor de tole rância $\varepsilon$. Conversão do sōlido completada antes do final do reator (condições mesmas da tabela 4.2). 


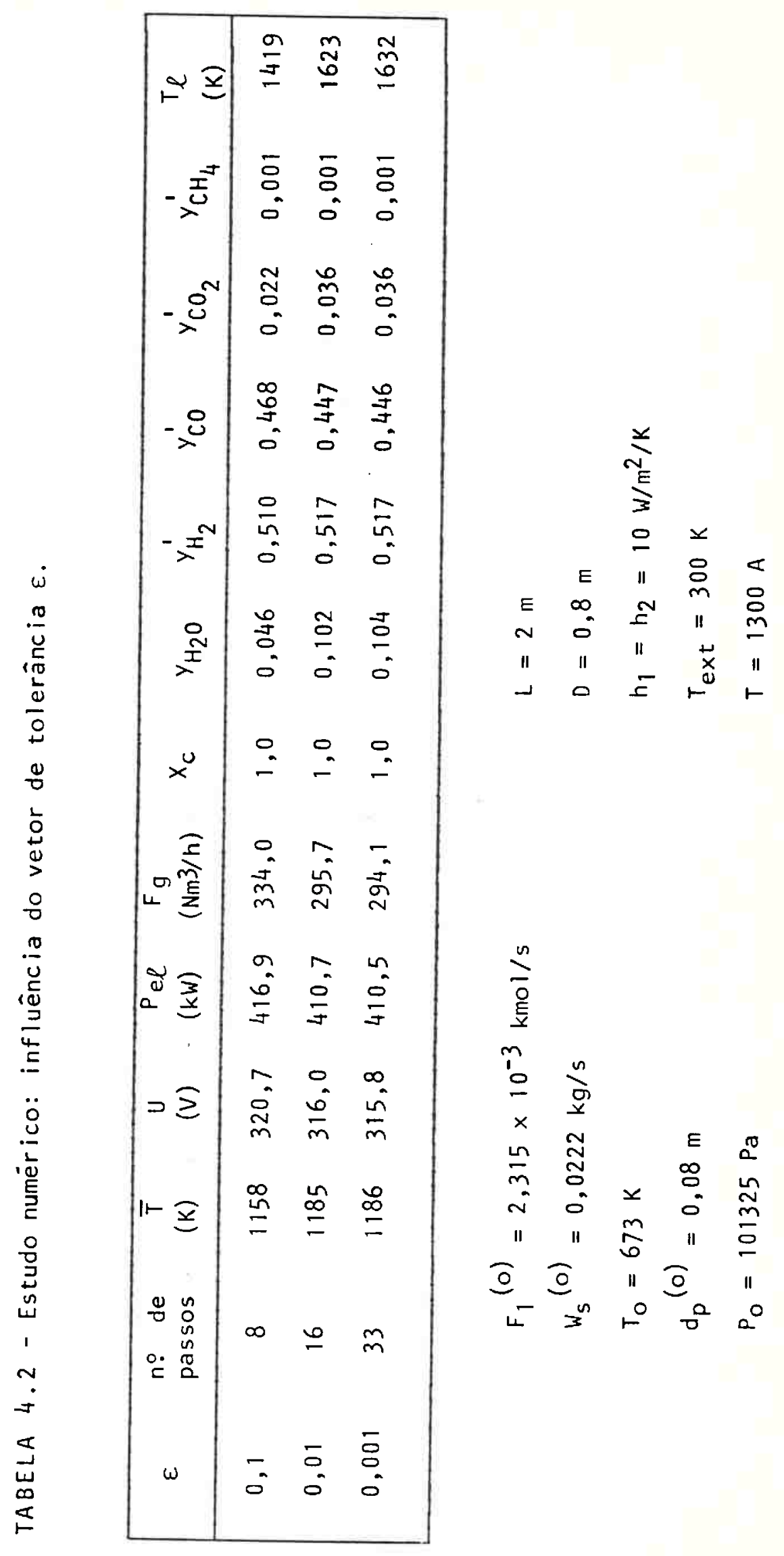


- vazão de sólidos

- vazão de vapor de água

- corrente elētrica

- distribuição do vapor pelas injeções laterais

- diâmetro inicial das partículas sólidas

e os seguintes característicos geomëtricos:

- diâmetro do reator

- comprimento do reator.

Analisou-se a influência dos parâmetros e variā veis acima sobre os principais resultados obtidos pela simula ção: os perfis de temperatura, conversāo de "char" e composição da fase gasosa, a vazão de gás seco produzido e sua composição, a queda de pressão do escoamento dos gases, a potência elétrica.

Tambëm foi estudada a influência dos citados parâ metros e variáveis sobre a chamada curva elétrica caracteristica do reator eletrotérmico. Esta curva, conforme explicado no item 2.6, permite uma anâlise da operação do sistema fonte elétrica-reator.

\subsection{1 - Influência da Corrente Elétrica (1)}

Os niveis de temperatura e conversão de "char" são bastante influenciados pela corrente elétrica que passa no leito, como ilustrado na figura 4.3. Este é um fato esperado, uma vez que aumentando a corrente, aumenta a potencia dissipada no leito, o que eleva a temperatura do reator. A temperatura in flui nas taxas de gaseificação e, portanto, na conversão. Tam bém a composição do gás obtido é influenciada. Estes fatores podem ser observados na tabela 4.3 .

Para obter a curva elétrica característica do rea 


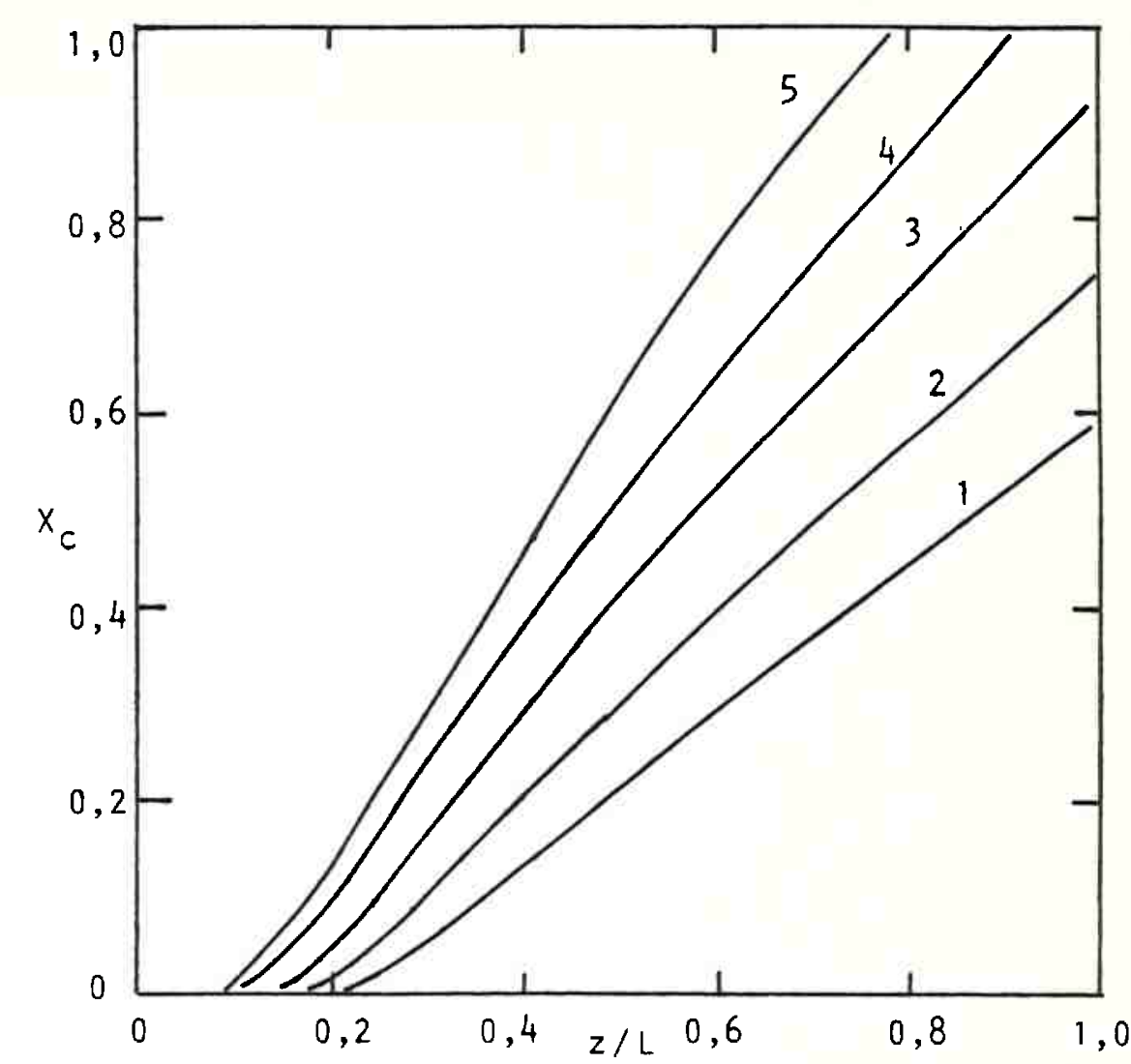

4.9

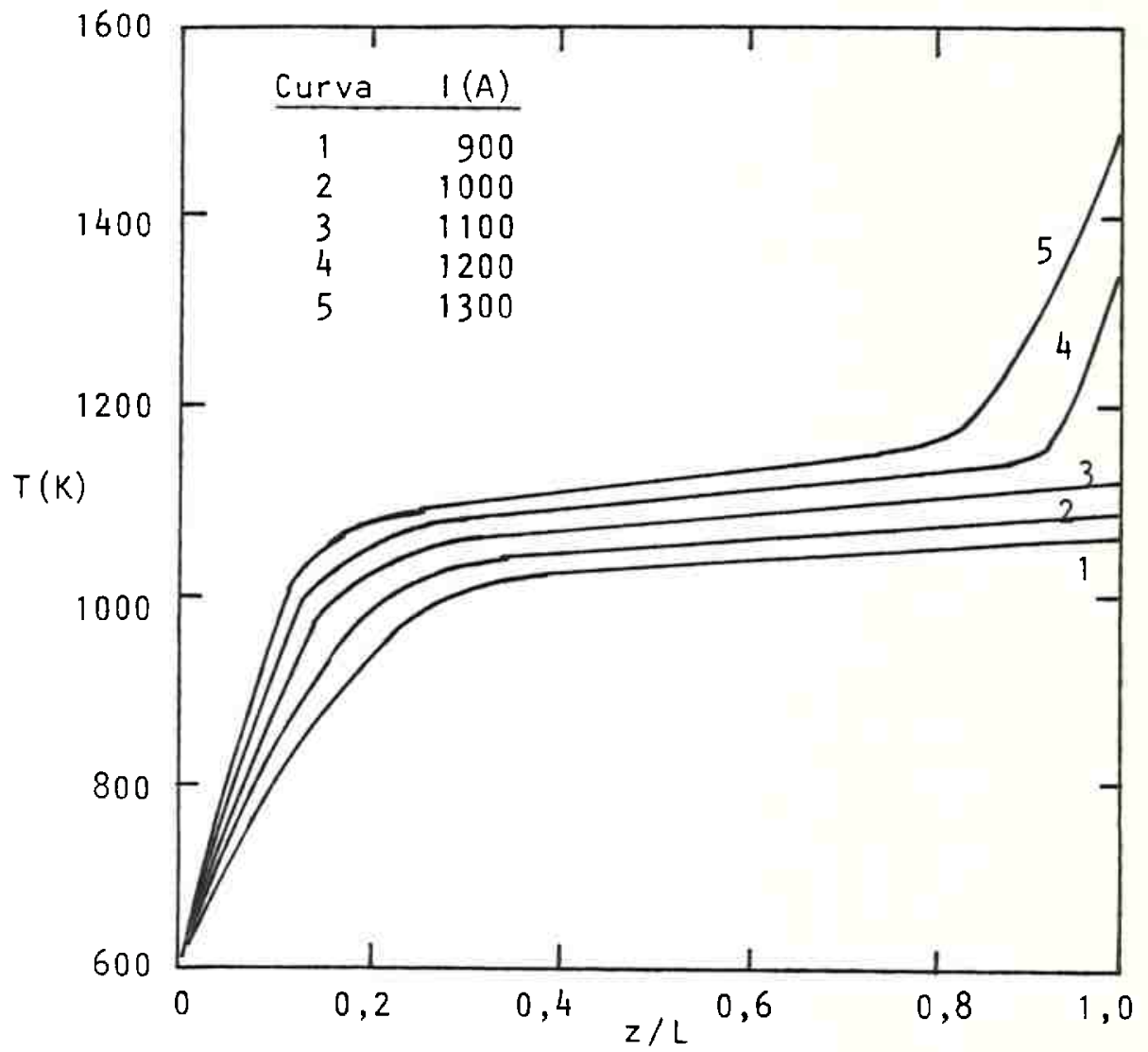

Fig. 4.3 - Influência da corrente elétrica sobre os perfis de conversão e de temperatura (mes mas condições da tabela 4.3). 


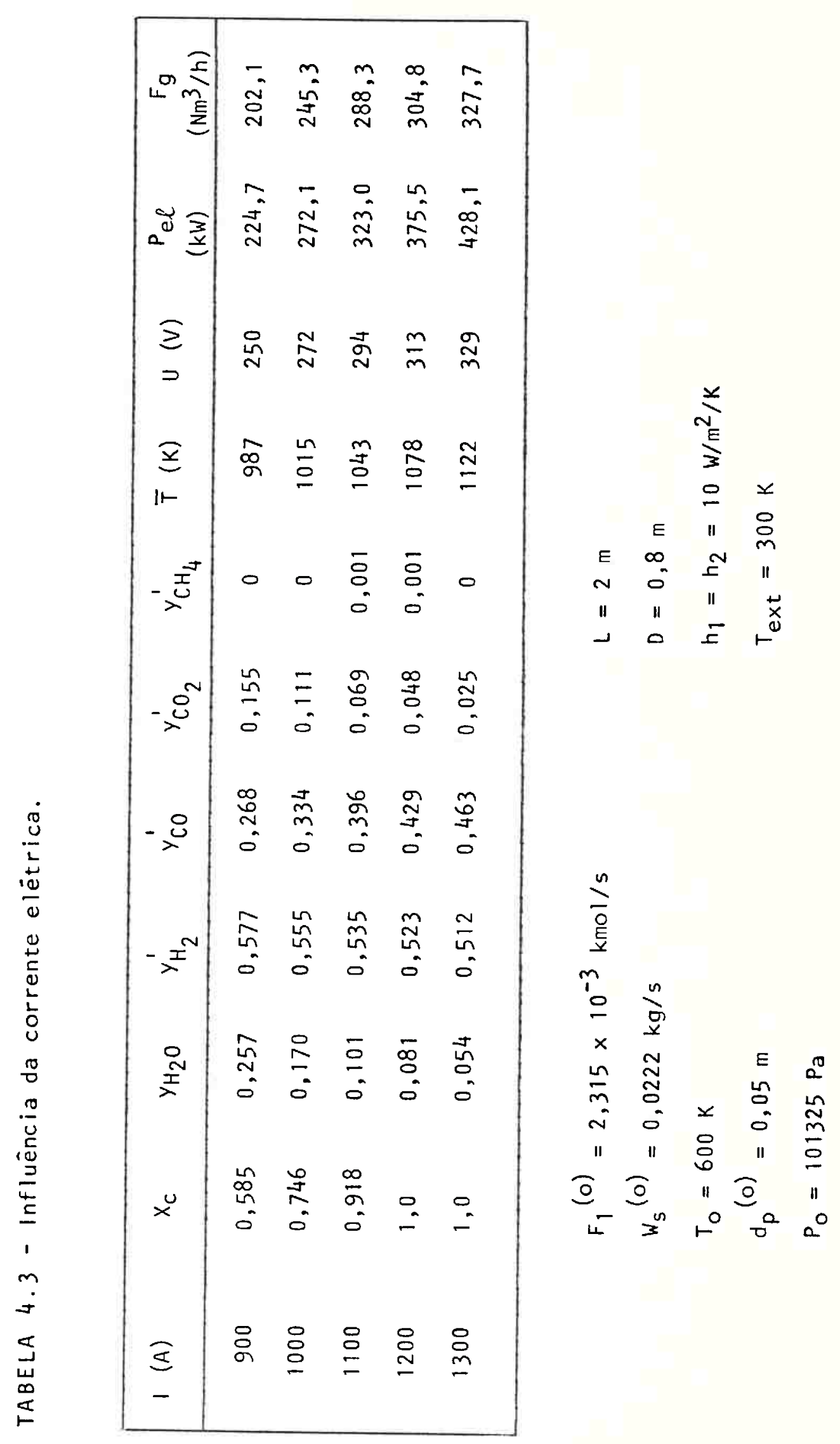


tor eletrotérmico é preciso resolver as equações para diversos valores de corrente elétrica, obtendo assim diversos pares de valores $(U, I)$. As curvas U X I apresentadas nesta dissertação apresentam um ponto que as dividem em dois ramos. Este ponto corresponde à operação em que a conversão do "char" é completa da ex atamente ao final do reator. $(z=L)$. Ao ramo da esquerda ( 1 inha cheia) com menores valores de corrente elétrica, corres pondem pontos de operação com conversão incompleta do "char" . Ao ramo da direita, com maiores valores de corrente elétrica, correspondem pontos de operação em que a conversão completa se dá antes do final do reator $(z<L)$.

O ramo da direita das curvas U X I é representa do por uma linha tracejada. Para a obtenção de tais pontos fixou-se no modelo $x_{C}=0,99$ como a máxima conversão possível, ga rantindo, deste modo, a presença de partículas de sólido (de diâmetro não nulo) quando a conversão for máxima. Isto é neces sârio para que não ocorra problema com a equação para a quedá de pressão. Este procedimento está relacionado à hipótese implicitamente adotada no uso da equação (3.30) para as taxas de reação gás-sôlido: a de que a retração da partícula sōlida seja lenta relativamente aos demais fenômenos envolvidos na reação. No caso de a conversão ser muito próxima de 1 a taxa de retração do diâmetro da particula torna-se excessivamente alta.

Deve-se observar que na operação real a taxa de retirada de sólidos pelo fundo do reator é que controla a conversāo final do "char" e isto é feito, na prätica, de maneira a se ter no fundo uma conversāo de 90 a 95\% do "char". Portanto, do ponto de vista da operação real há interesse em se operar o gaseificador em pontos do ramo à esquerda do ponto de conversāo completa da curva U X I, próximo a este ponto. 


\subsection{2 - Influência da Temperatura Inicial ( $\left.T_{0}\right)$}

A influência da temperatura inicial $\mathrm{T}_{\mathrm{O}}$ sobre a curva elétrica $U \times I$ é apresentada na figura 4.4. Variando o valor de $\mathrm{T}_{0}$ as correspondentes curvas $U \times$ I apresentam-se prati camente com a mesma forma, levemente deslocadas. Esta pequena sensibilidade se deve aos parâmetros utilizados na equação (3.7) do modelo, que indicam uma variação pequena da condutividade elé trica do leito com a temperatura.

A influência de $T_{0}$ sobre os perfis de temperatura conversão do sólido e composição do gās é ilustrada na figura 4.5 .

A influência de $T_{0}$ sobre os perfis de temperatura mostrou-se acentuada apenas no trecho inicial dos perfis, sendo que, após este trecho inicial os perfis de temperatura tendem a se comportar de maneira semelhante. Porém, os perfis de conver são do sólido e composição da fase gasosa são mais sensíveis à $\mathrm{T}_{0}$. A figura 4.5 ilustra que as reações sô se iniciam após a temperatura atingir um valor suficientemente elevado (em torno de $900 \mathrm{~K})$. Isto é devido à influência da temperatura nas taxas de reação (energias de ativação).

A defasagem de conversão no trecho inicial do rea tor causada por valores diferentes de $\mathrm{T}_{\mathrm{O}}$ não é compensada no restante do reator, o que leva a diferentes graus de conversão do sólido no final do reator.

A composição do gãs na saída do reator apresentou - se pouco sensivel a $\mathrm{T}_{O}$, apesar de os perfis de composição serem sensiveis a $T_{0}$ no trecho inicial do reator. 


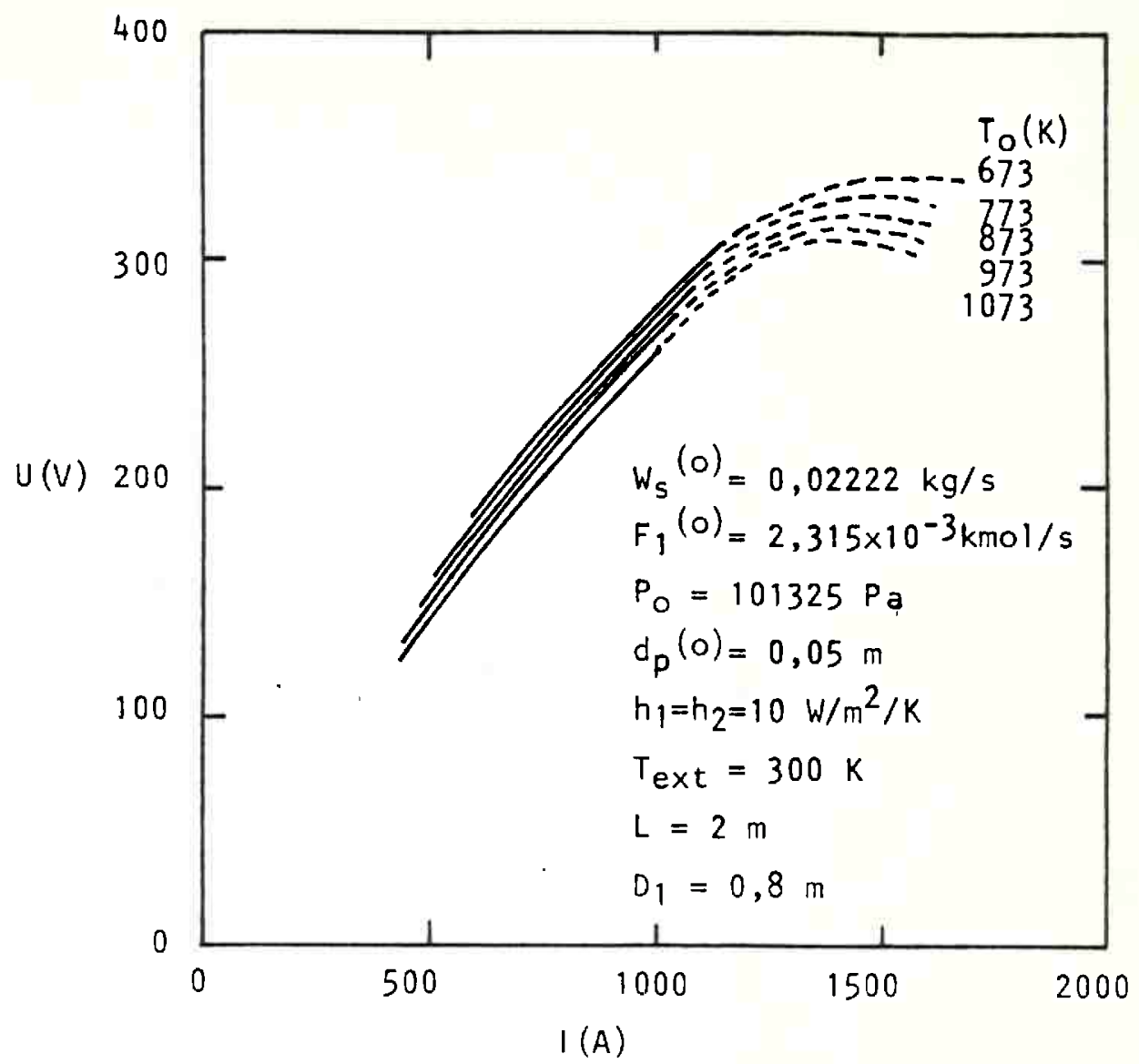

4.13

Fig.4.4 - Influēncia da temperatura em $z=0$ sobre a curva elétrica caracteristica. 


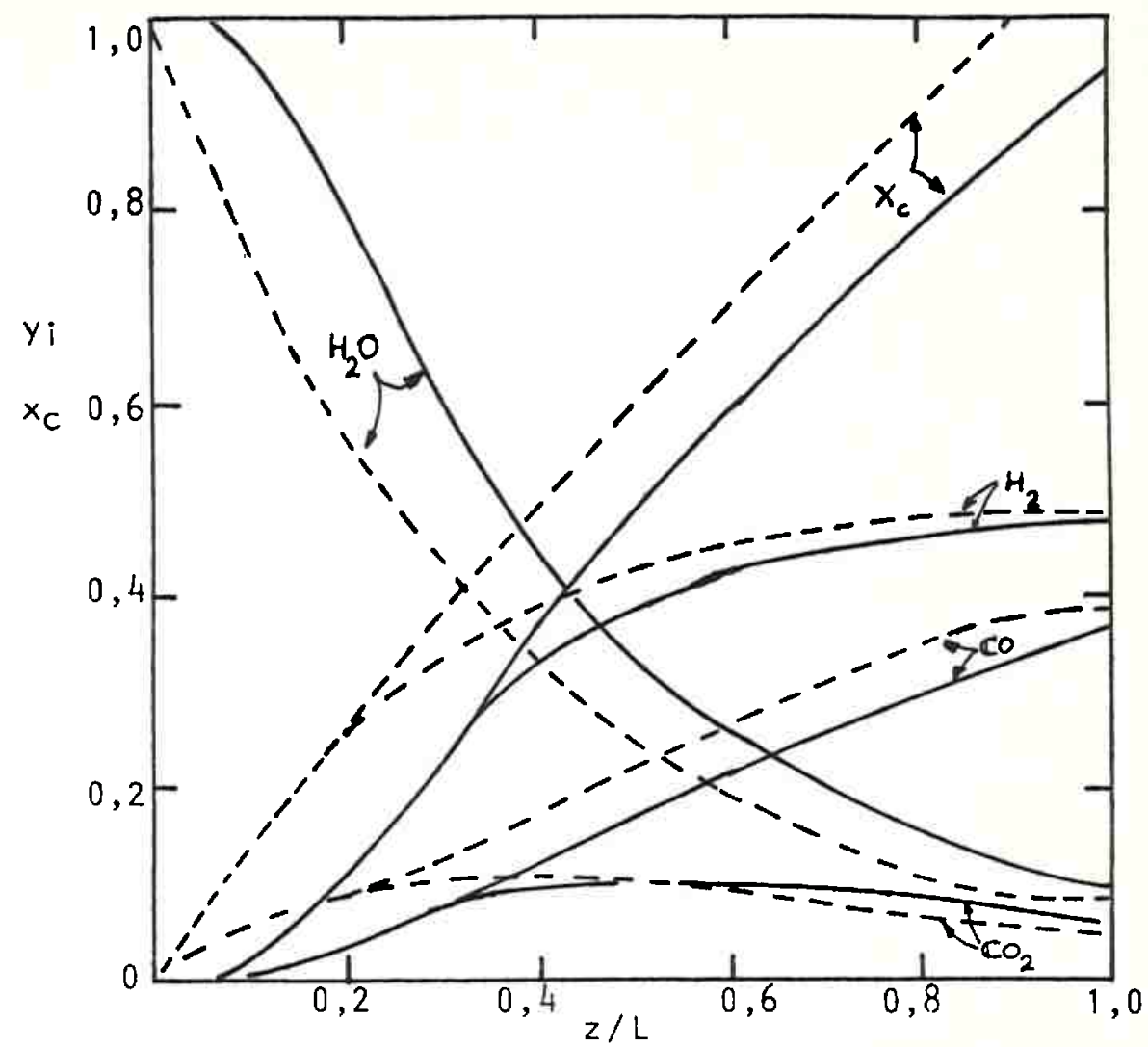

4.14

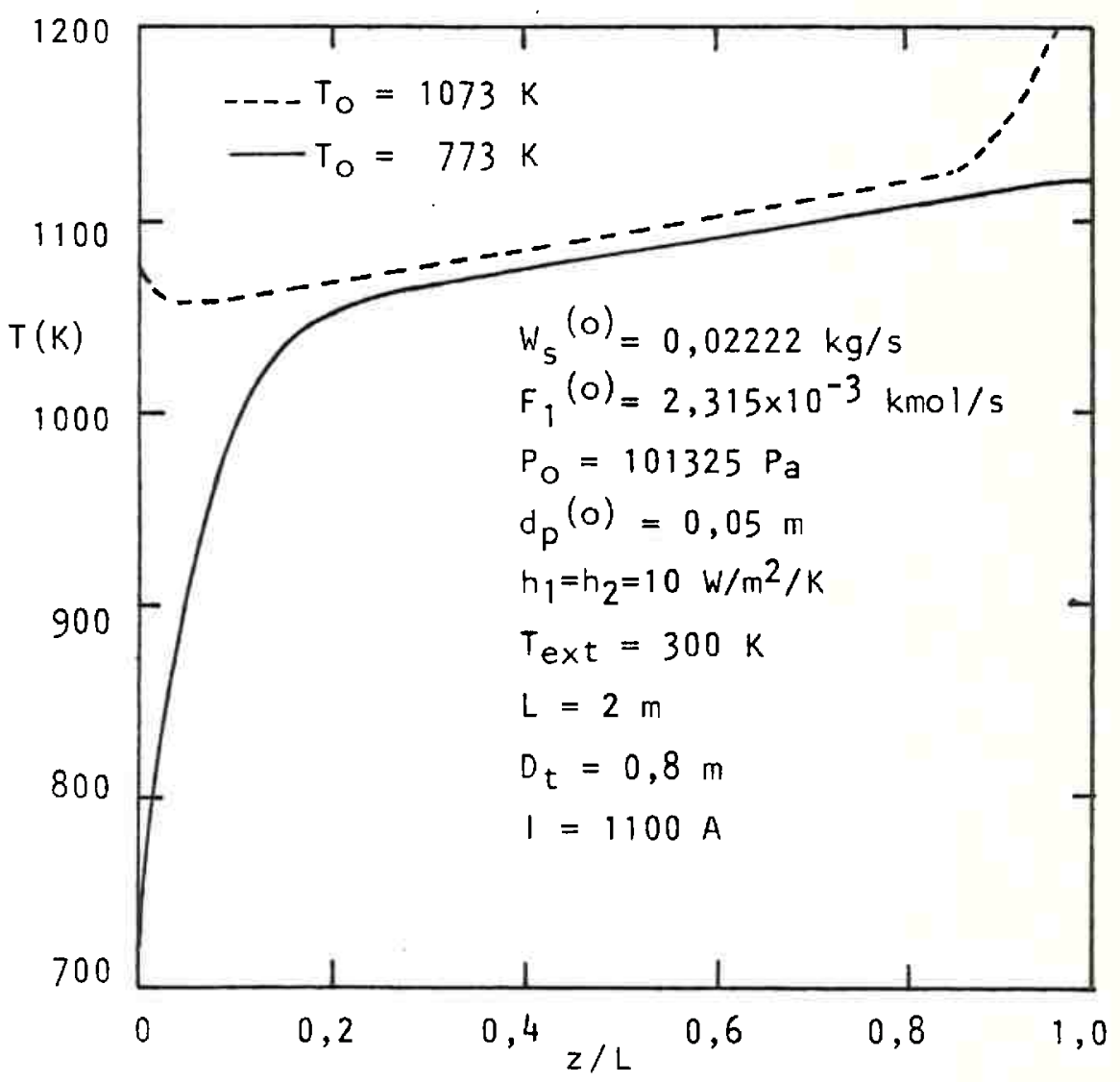

Fig. 4.5 - Influência da temperatura em $z=0$ sobre os perfis de temperatura, conversão do sólido e composição do gās. 


\subsection{3 - Influência da Pressão Inicial (Po)}

Foram simulados quatro casos, com valores de $\mathrm{P}_{\mathrm{O}}$ iguais a $101325,1013250,4053000$ e $8106000 \mathrm{~Pa}$. Os resultados são apresentados na figura 4.6 e na tabela 4.4 .

O ramo inicial das curvas U.X I não apresenta grandes variações para diferentes valores de $\mathrm{P}_{\mathrm{O}} \cdot 0$ ponto de operação para conversão completa do sólido ê, no entanto, bastante influenciado por $P_{O}$. $O$ aumento da pressão de operação ele va as taxas de reação e isso permite ocorrer conversão completa com valores menores de corrente elëtrica.

$\mathrm{Na}$ tabela 4.4 são mostrados os valores de composi ção do gás, corrente, tensāo e potência elétrica, conversão e queda de pressão para a operação com mesmas vazões de vapor e "char". Verifica-se, como esperado, que o aumento da pressão de operação eleva o teor final de $\mathrm{CH}_{4}$ e $\mathrm{CO}_{2}$, diminuindo o de $\mathrm{H}_{2}$ e $\mathrm{co}$.

\section{3 .4 - Influência das Vazões de Processo}

Este estudo relaciona-se com o aumento da capacidade de processamento do reator. Foram variadas simultaneamen te as vazōes do "char" e de vapor de água, mantendo-se entre elas uma proporção constante.

As curvas $U \times$ I são mostradas na figura 4.7. As vazões não afetam a inclinação do trecho das curvas U X I correspondentes à conversão incompleta do sólido. 0 ponto em que ocorre conversão completa é, no entanto, bastante influenciado pelas vazões de processo, uma vez que o aumento das vazōes de processo requer um aumento na potência elétrica. 


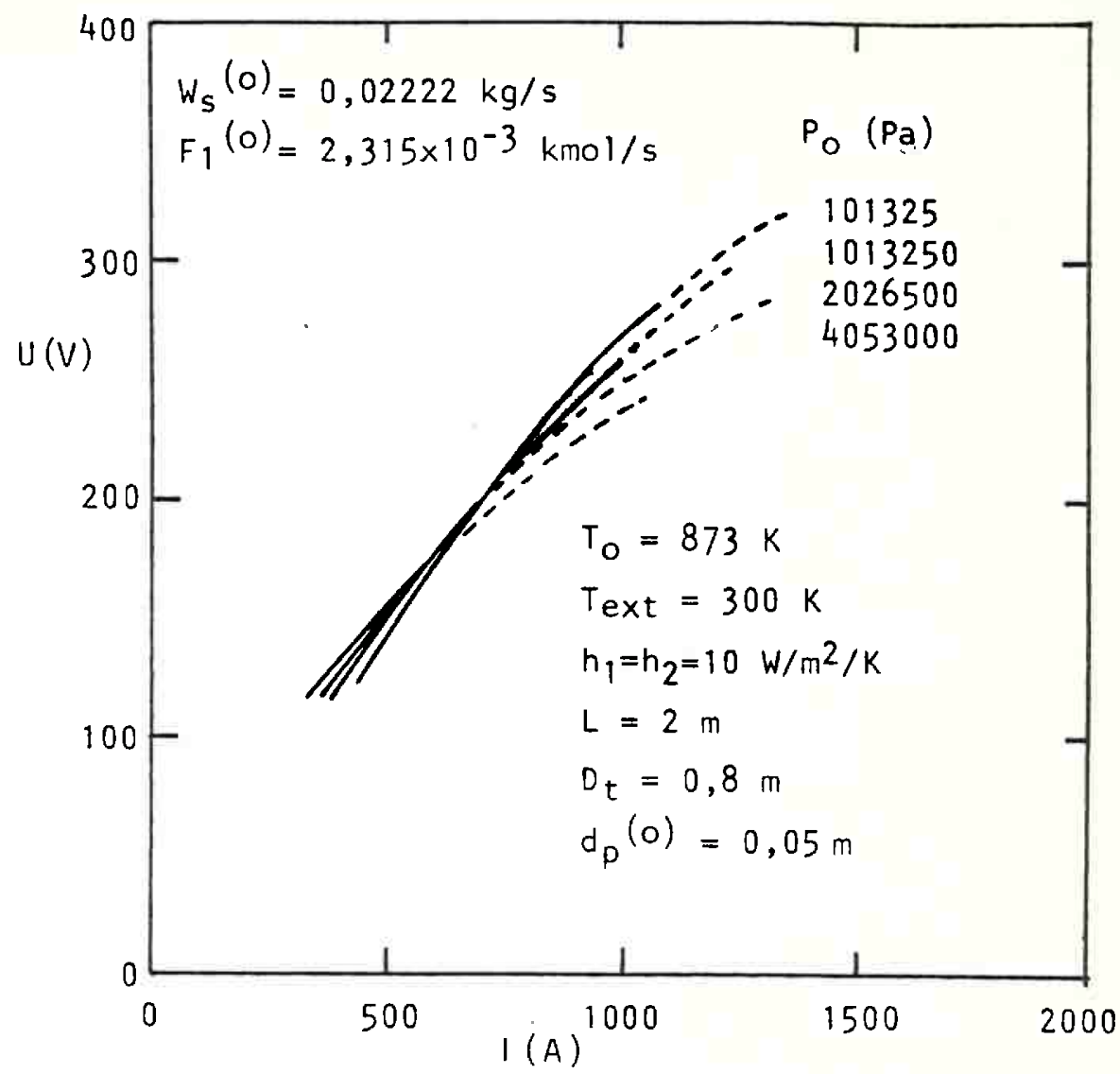

4.16

Fig. 4.6 - Influência da pressão $P_{0}$ sobre a curva elétrica característica.

TABELA 4.4 - Influência da pressão em $z=0$ sobre os resultados da simula ção.

\begin{tabular}{|c|c|c|c|c|c|c|c|c|c|c|}
\hline $\begin{array}{c}P_{0} \\
\left(P_{a}\right)\end{array}$ & $x_{c}$ & $\dot{y}_{\mathrm{H}_{2} \mathrm{O}}$ & $y^{\prime} \mathrm{H}_{2}$ & $y^{\prime} \mathrm{CO}$ & $y^{\prime} \mathrm{CO}_{2}$ & $y^{\prime} \mathrm{CH}_{4}$ & $\begin{array}{c}F_{g} \\
\left(\mathrm{Nm}^{3} / \mathrm{h}\right)\end{array}$ & $\begin{array}{c}\Delta P \\
\left(P_{a}\right)\end{array}$ & $\begin{array}{c}u \\
(V)\end{array}$ & $\begin{array}{l}\text { Pel } \\
\text { (kW) }\end{array}$ \\
\hline 101325 & 0,520 & 0,299 & 0,587 & 0,239 & 0,174 & 0 & 184,1 & 38 & 216,5 & 173,2 \\
\hline 1013250 & 0,616 & 0,245 & 0,554 & 0,249 & 0,175 & 0,022 & 202,3 & 4 & 223,3 & 178,6 \\
\hline 4053000 & 1,0 & 0,184 & 0,316 & 0,259 & 0,198 & 0,227 & 199,1 & 3 & 217,4 & 174,0 \\
\hline 3106000 & 1,0 & 0,221 & 0,152 & 0,266 & 0,262 & 0,319 & 173,8 & 3 & 210,7 & 173,8 \\
\hline
\end{tabular}




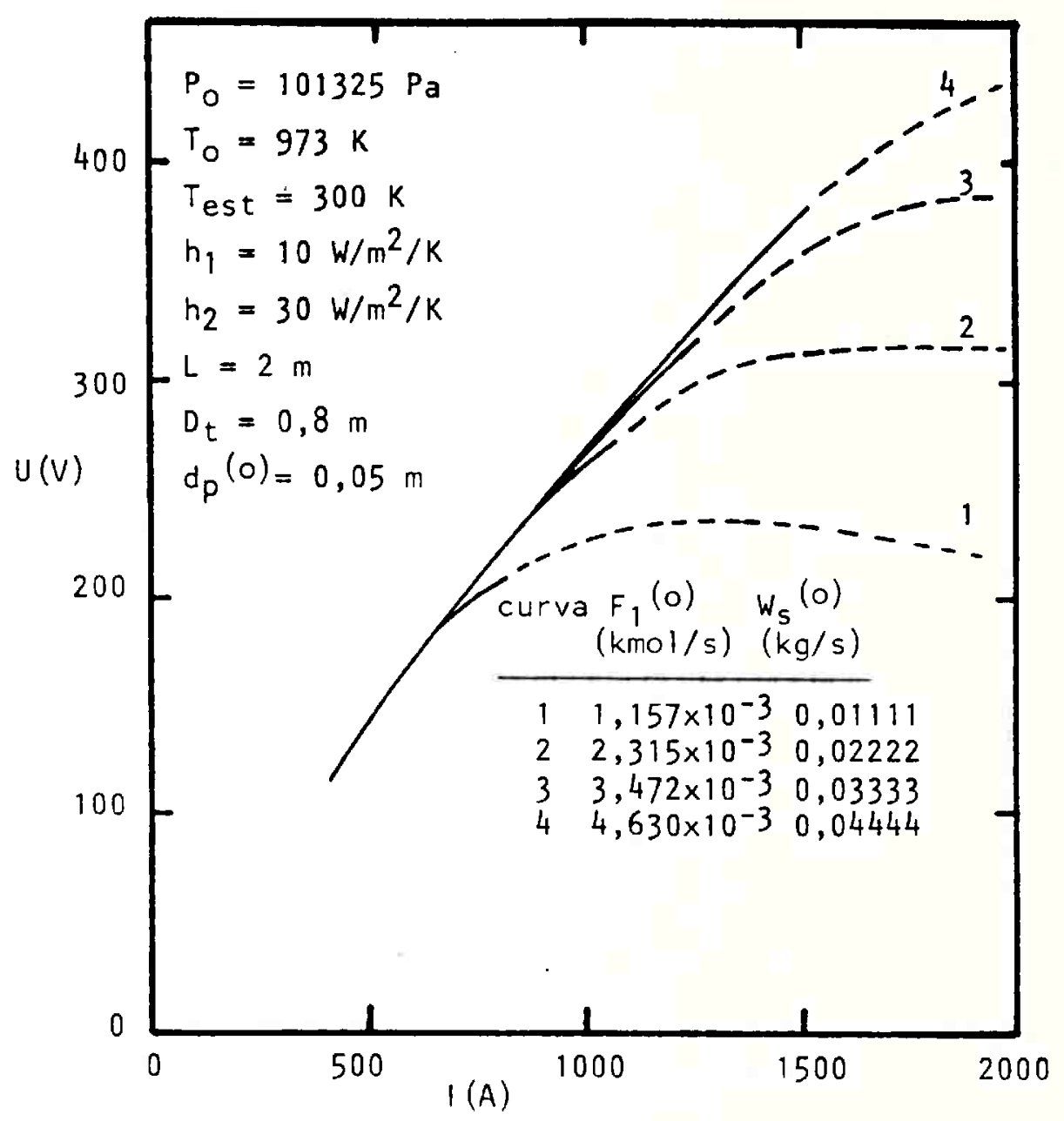

Figura 4.7 - Influência das vazōes de processo sobre a curva elétrica caracaterística. 


\subsection{5 - Influência da Vazão de Vapor de Água}

Foi estudada a influência da vazão de vapor de ägua mantida constante a vazão de "char" ( $\left.W_{S}=0,0222 \mathrm{~kg} / \mathrm{s}\right)$.

A figura 4.8 ilustra esta influência sobre as cur vas $U \times I$. As curvas correspondentes a $F_{1}^{(0)} \leqslant 1,81 \cdot 10^{-3} \mathrm{kmo1} / \mathrm{s}$ não apré sentam conversão completa do sólido, pois corresponde a um excesso de "char".

Os perfis de temperatura e conversão, mostrados na figura 4.10, apresentam-se influenciados pela vazão de vapor, principalmente na metade final do comprimento do reator. Isto se deve ao fato de que havendo excesso de vapor no sistema, a temperatura è mantida sem maiores elevações à custa da reação endotérmica do vapor com o "char", que é a principal reação do sistema.

A vazão de vapor tambëm influi nos perfis de composição, apresentados na figura 4.9. O excesso de vapor de àgua desloca o equilíbrio da reação de deslocamento, aumentando os teores de $\mathrm{H}_{2}$ e $\mathrm{CO}_{2}$ e diminuindo o de $\mathrm{CO}$.

\subsection{6 - Influência da Vazão de Sölidos ( $\left.W_{s}\right)$}

Dentro da faixa de variação estudada de $W_{S}$ (entre 100 e $60 \mathrm{~kg} / \mathrm{h}$ ) a curva U X I não apresenta grande variação no seu trecho inicial, como ilustra a figura 4.11 .

No entanto, o ponto de conversão completa se dá com corrente elétrica menor à medida em que se diminue a vazão de "char". 


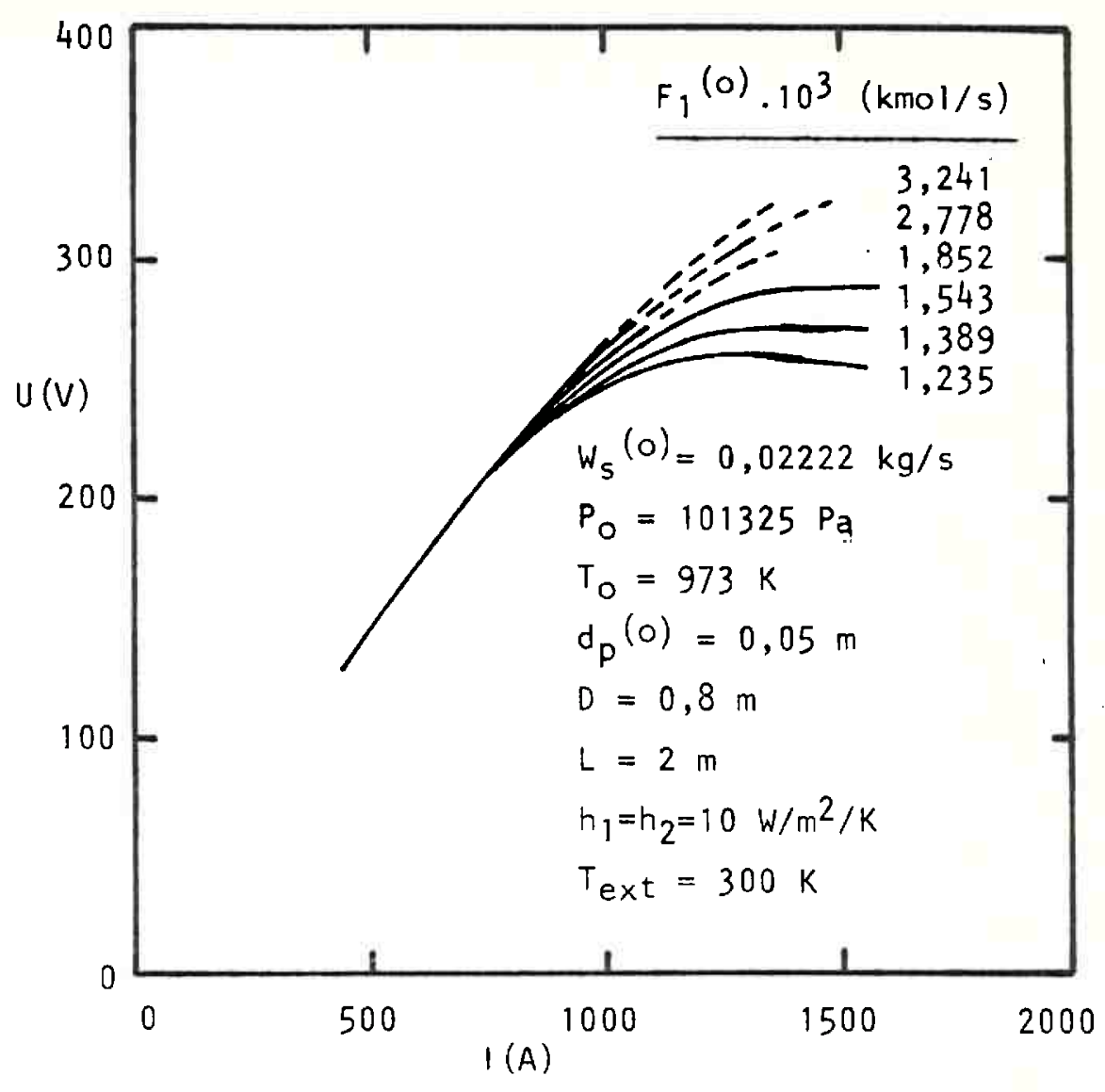

4.19

Fig. 4.8 - Influência da vazão de vapor sobre a curva elétrica do reator.

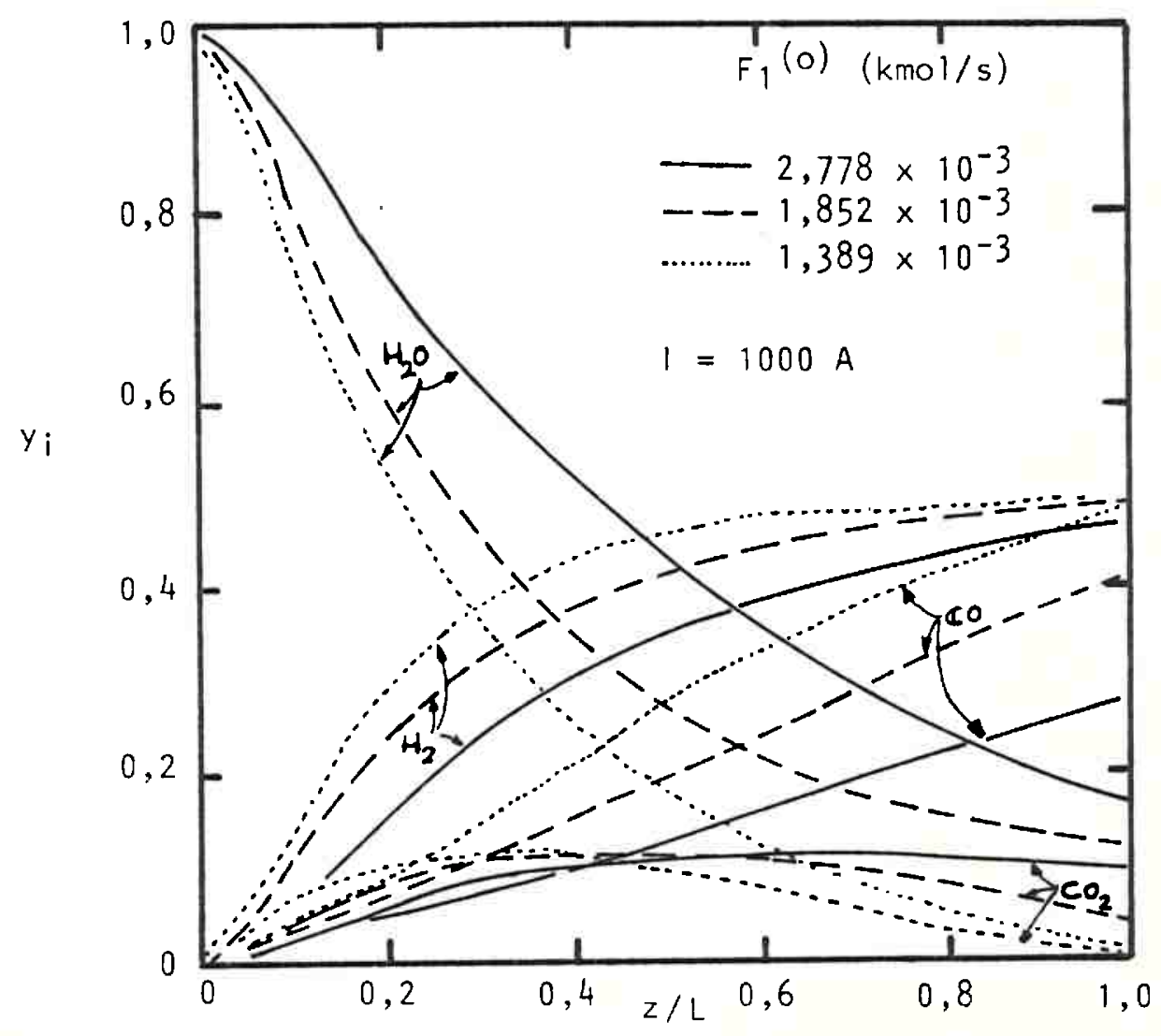

Fig. 4.9 - Influencia da vazão de vapor sobre os perfis de composi ção do gás (condiçöes mesmas da figura 4.8) 

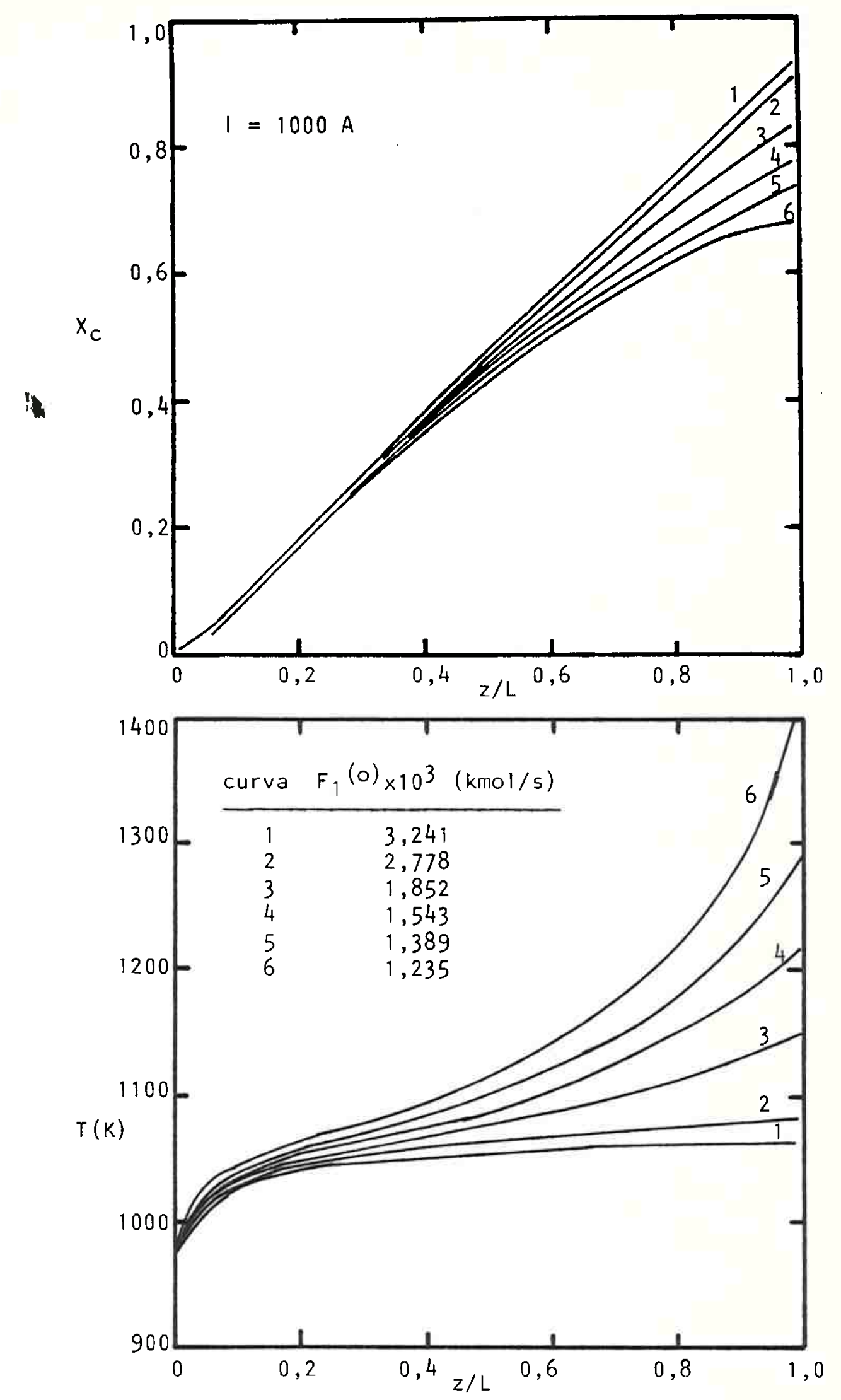

Fig. 4.10 - Influēncia da vazão de vapor sobre os perfis de temperatura e conversão do sólido (condições da figura 4.8). 


\subsection{7 - Influência da Condutividade Elétrica do Leito $(\sigma)$}

Na apresentação do modelo matemätico, no capítulo anterior, foi estabelecida que a condutividade elétrica do leito seria calculada pela expressão:

$$
\sigma=a_{\sigma} \exp \left[b_{\sigma}(T-273)\right]
$$

Esta expressão fora obtida experimentalmente para uma amostra de carvão vegetal de granulometria não controlada. Entretanto, sabe-se que a condutividade elétrica de leitos de carvão é função não sô da temperatura, mas da granulometria, da pressão exer cida sobre o leito e do próprio material que constitui o leito - composição e origem do carvão, grau de volatilização a que fó ra previamente submetido, gâs que envolve as partículas sólidas. Como foi mostrado no Capitulo 2 , os valores experimentais de re sistividade elétrica (e de seu inverso, a condutividade elétrica) apresentam grande dispersão, podendo variar de até uma ordem de grandeza.

Assim, uma vez que a condutividade elétrica não pode ser considerada uma propriedade bem conhecida, procedeu-se a um estudo de sua influência sobre os resultados da simulação.

Este estudo foi feito através da variação da condutividade elétrica $\sigma$ dentro de uma faixa em torno do valor da correlação. O efeito desta variação sobre a curva elétrica do reator é mostrado na figura 4.12 .

Como seria de se esperar, uma variação no valor da condutividade elétrica influencia fortemente a curva elétri ca do gaseificador. E, portanto, um parâmetro importante no ajuste do modelo. 


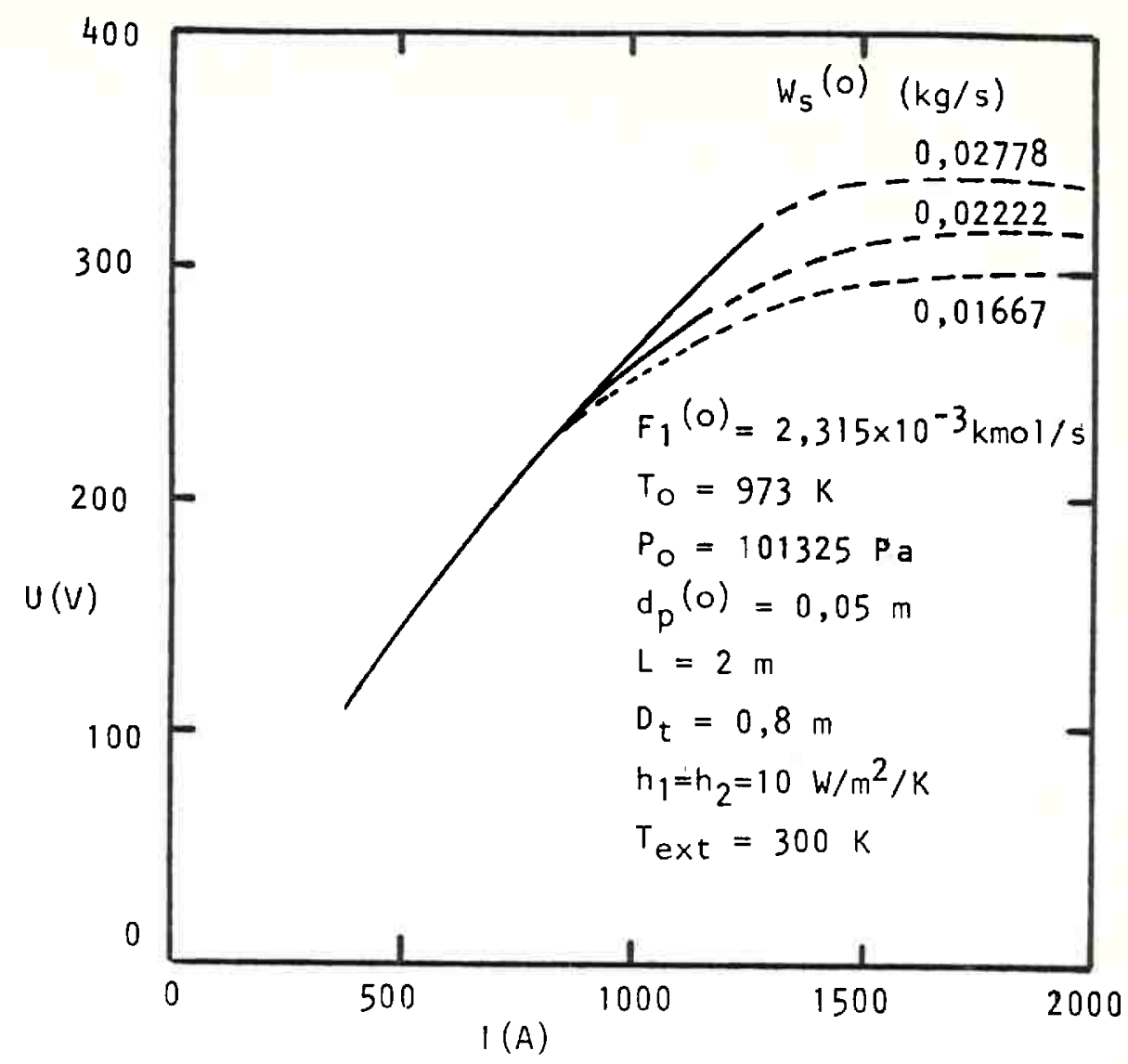

4.22

Fig. 4.11 - Influência da vazão de "char" sobre a curva elétrica característica do reator.

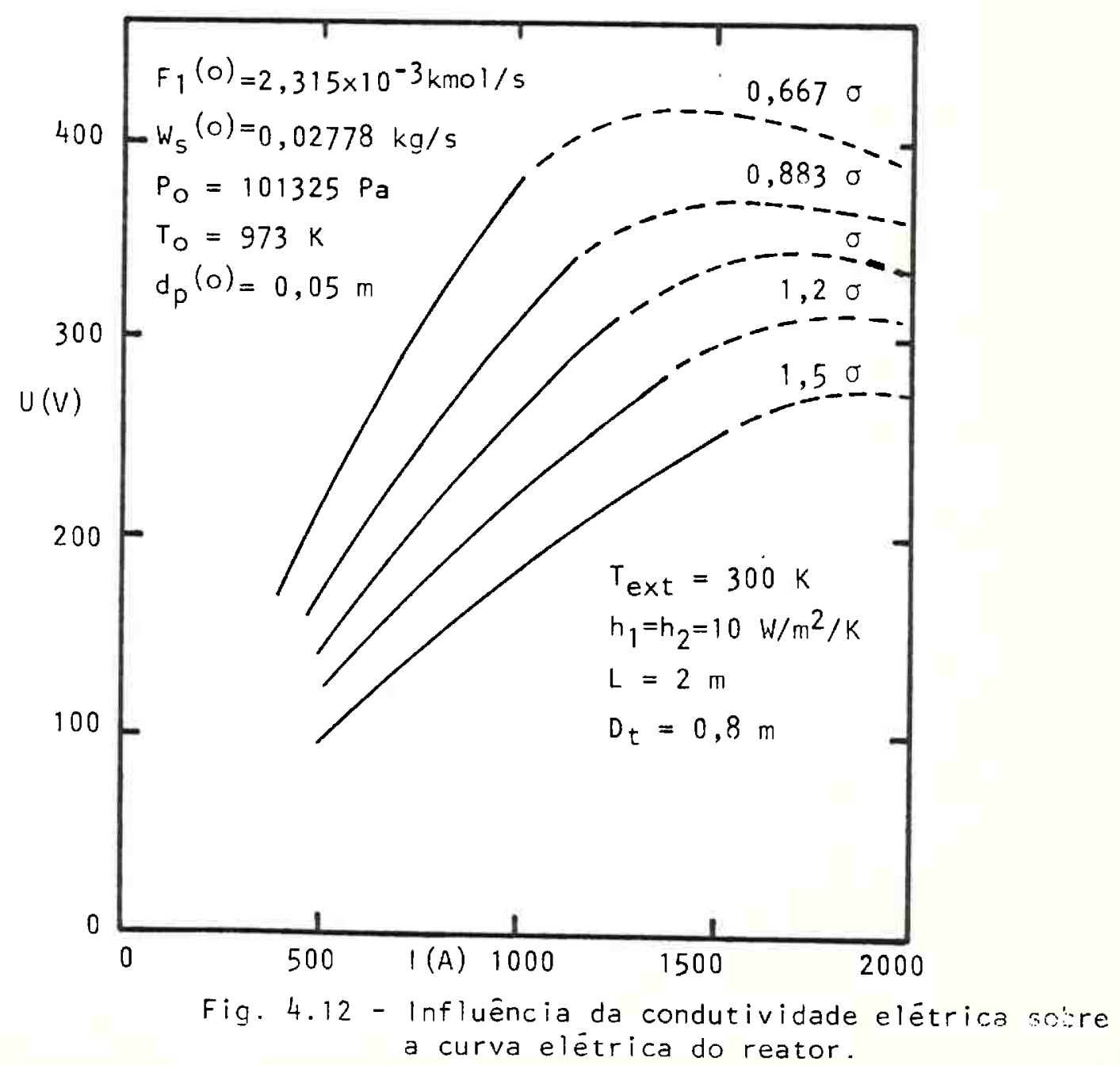




\subsection{8 - Influência do Coeficiente de Transferência de Ca- lor para o Meio Exterior}

o coeficiente convectivo efetivo (h) è um parâmetro que representa a interação de calor do leito com o meio ex terior.

Sua influência sobre a curva elétrica do reator pode ser observada na figura 4.13. Tal curva apresenta razoável sensibilidade ao valor de $h$.

o coeficiente convectivo influencia fortemente os perfis de temperatura e, consequentemente, os de conversão e de composição, como ilustra as figuras 4.14 e 4.15 . Isto revela ser um parâmetro importante para o ajuste do modelo.

No caso real os gaseificadores eletrotérmicos pos suem o eletrodo inferior refrigerado. Este efeito não é levado em conta explicitamente no modelo matemático equacionado no Capítulo 3. No entanto, esta influência de maior saída de calor junto ao eletrodo inferior pode ser feita por uma condição artí ficial, através de um aumento das perdas pelas paredes próximo à região do eletrodo inferior. Utilizam-se então valores diferentes do coeficiente efetivo de transferencia de calor $h$ ao longo do reator.

No presente estudo empregou-se um valor $\mathrm{h}_{1}$ para os primeiros $85 \%$ do comprimento do reator e um valor $\mathrm{h}_{2}$ para os ültimos 15\%. Embora esta abordagem não seja estritamente rigorosa, ela permite representar, com alguma aproximação, o fato de o eletrodo inferior ser refrigerado.

A influência da mudança do valor do coeficiente $h$ ao longo do reator é ilustrado na figura 4.15. Dependendo dos valores utilizados observa-se uma apreciável queda de temperatu ra próximo ao eletrodo inferior. Esta queda de temperatura no 


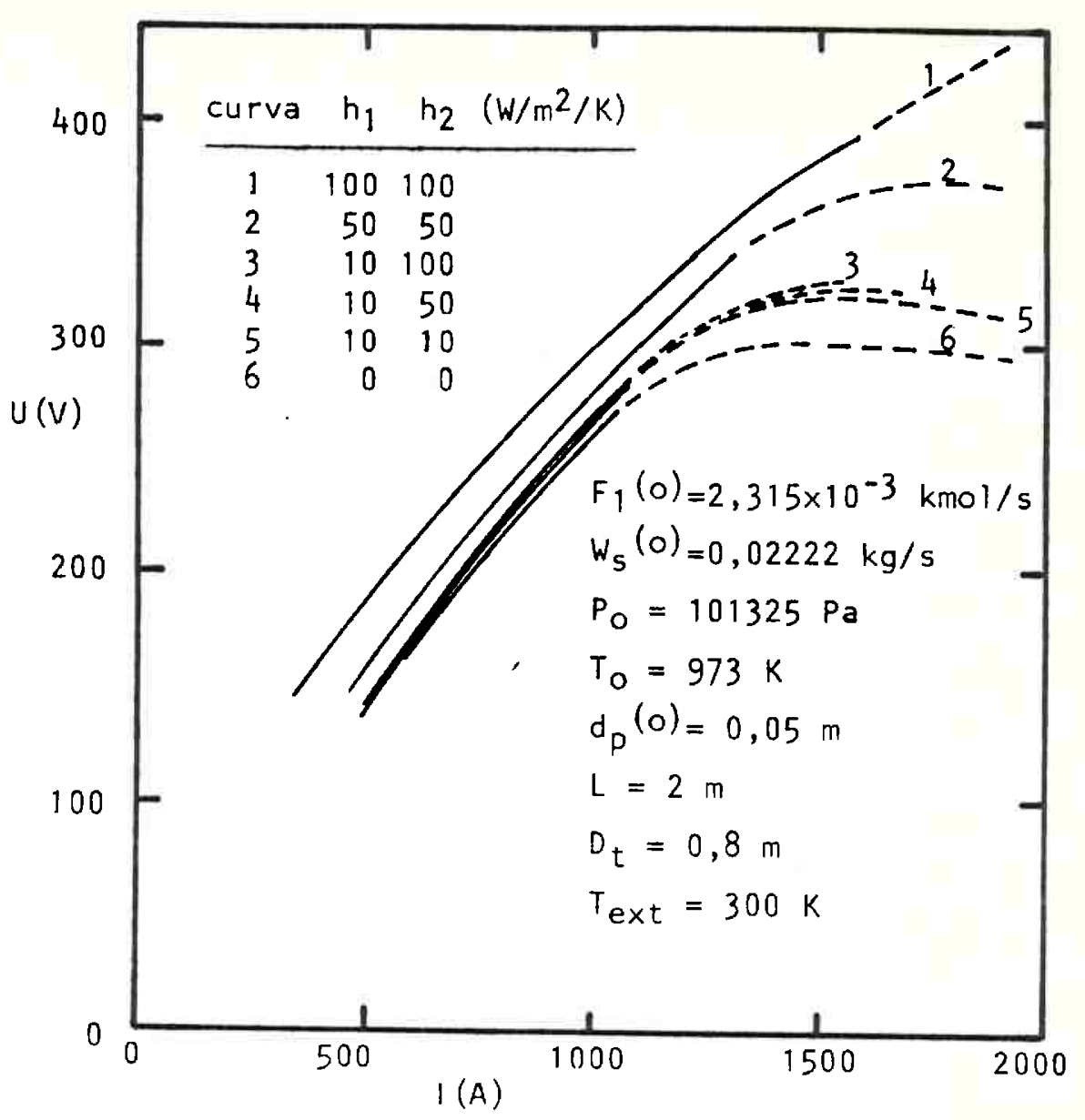

4.24

Fig. 4.13 - Influência dos coeficientes de transmissão de calor sobre a curva elétrica característica.

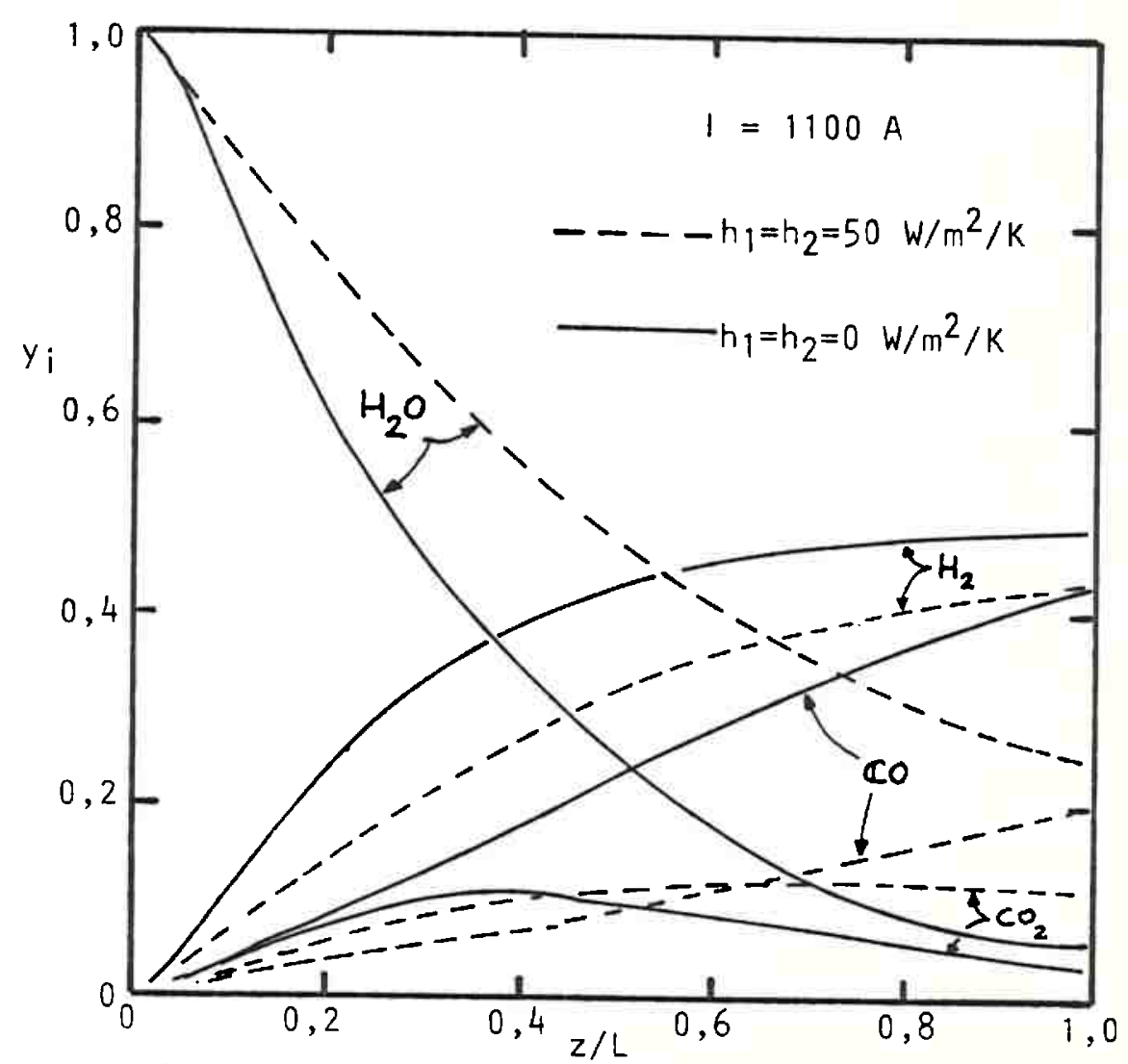

Fig. 4.14 - Influência do coeficiente efetivo de transmissão de calor para o exterior sobre os perfis de composição
do gás (condiçoes mesmas da figura 4.13 ). 


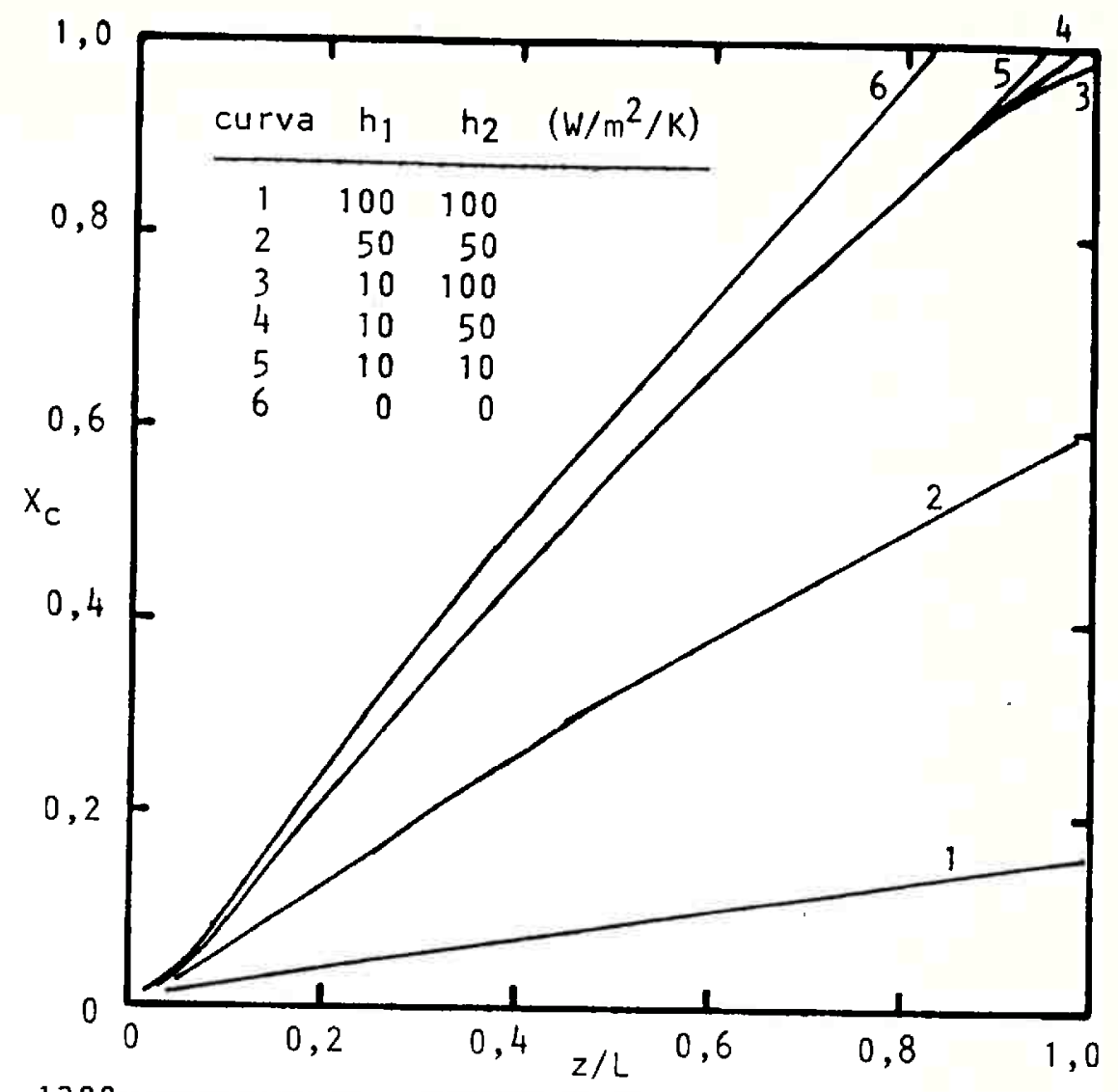

4.25

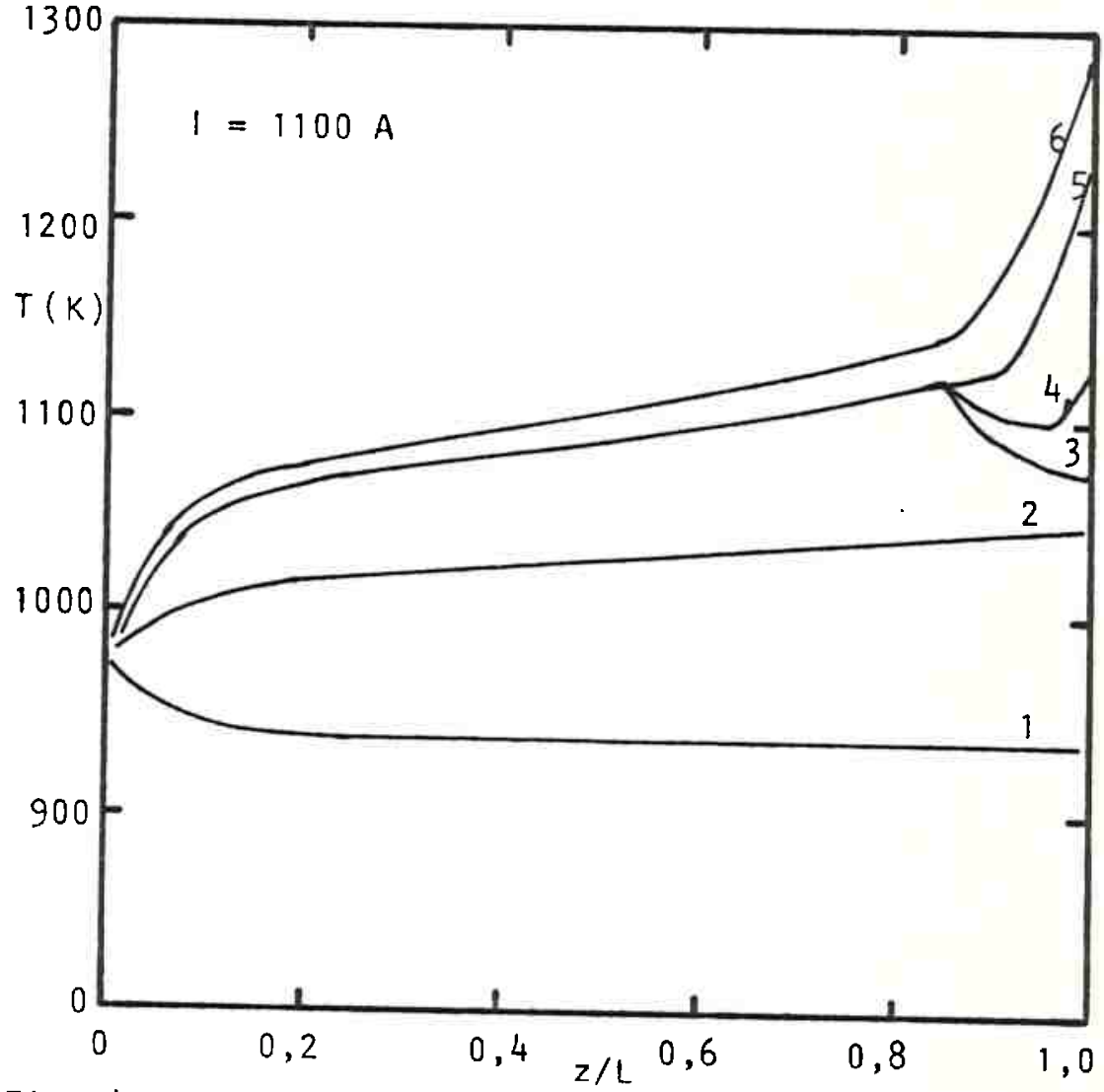

Fig. 4.15 - Influência dos coeficientes efetivos de transmissão de calor para o meio exterior sobre os perfis de temperatura e conversão do "char" (condições mesmas da figura 4.13). 
fundo do reator é observada na operação prática dos gaseificadó res eletrotérmicos.

\subsection{9 - Influência da Distância entre os Eletrodos (L)}

Este ê um parâmetro geométrico, e também um parâmetro de operação dos gaseificadores com eletrodo superior de posição ajustāvel, como o reator G5 da CESP.

A influência deste parâmetro sobre a curva elētrí ca caracteristica é mostrada na figura 4.16. O aumento da distância interletrodos desloca a curva para maiores valores de tensão. Este comportamento é esperado pois o aumento da distân cia intereletrodos provoca um aumento da resistência elétrica do reator.

Isto permite dissipar mais energia no leito, fator intimamente ligado à capacidade de processamento do reator.

\subsubsection{0-Influência do Diâmetro do Reator $\left(D_{t}\right)$}

A influência deste parâmetro sobre a curva elétri ca do reator eletrotërmico e mostrada na figura 4.17. O aumento de $D_{t}$ causa uma queda no valor da tensão necessäria para uma dada corrente passar no reator. Dentro da hipótese de modelo unidimensional, este comportamento é tambẻm esperado pois aumen tando $D_{t}$ aumenta a área da seção transversal diminuindo a resis tência elétrica do leito.

Entretanto, o aumento do diâmetro do reator eletrotérmico pode levar a distribuição menos homogênea de corrente na seção transversal, fato que não pode ser previsto com um modelo unidimensional. Portanto, o estudo correto desta influên cia não pode ser realizado com este modelo e os resultados aqui 


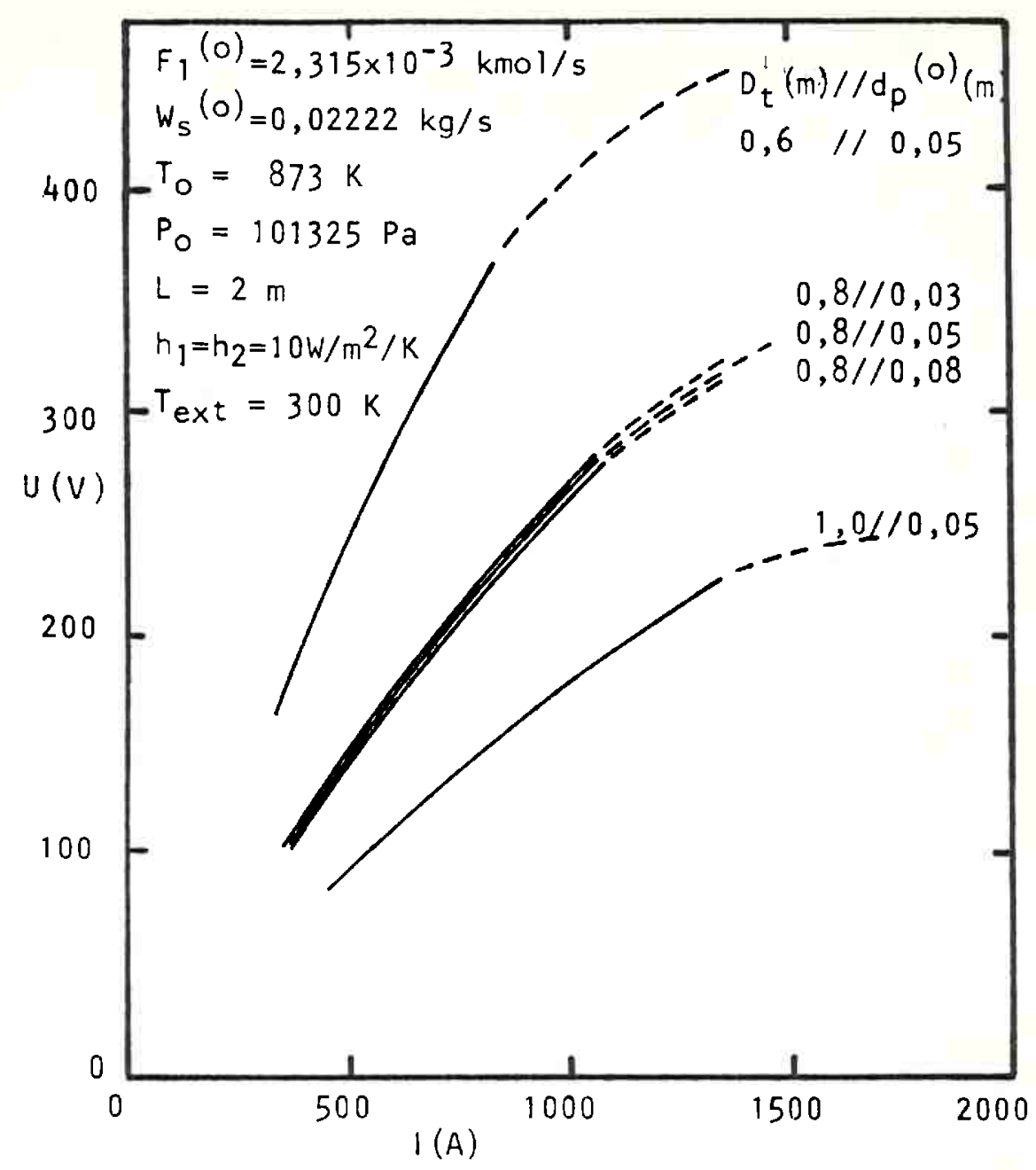

Fig. 4.17 - Influência do diämetro do reator e do tamanho inicial das partículas sobre a curva elétrica caracteristica.

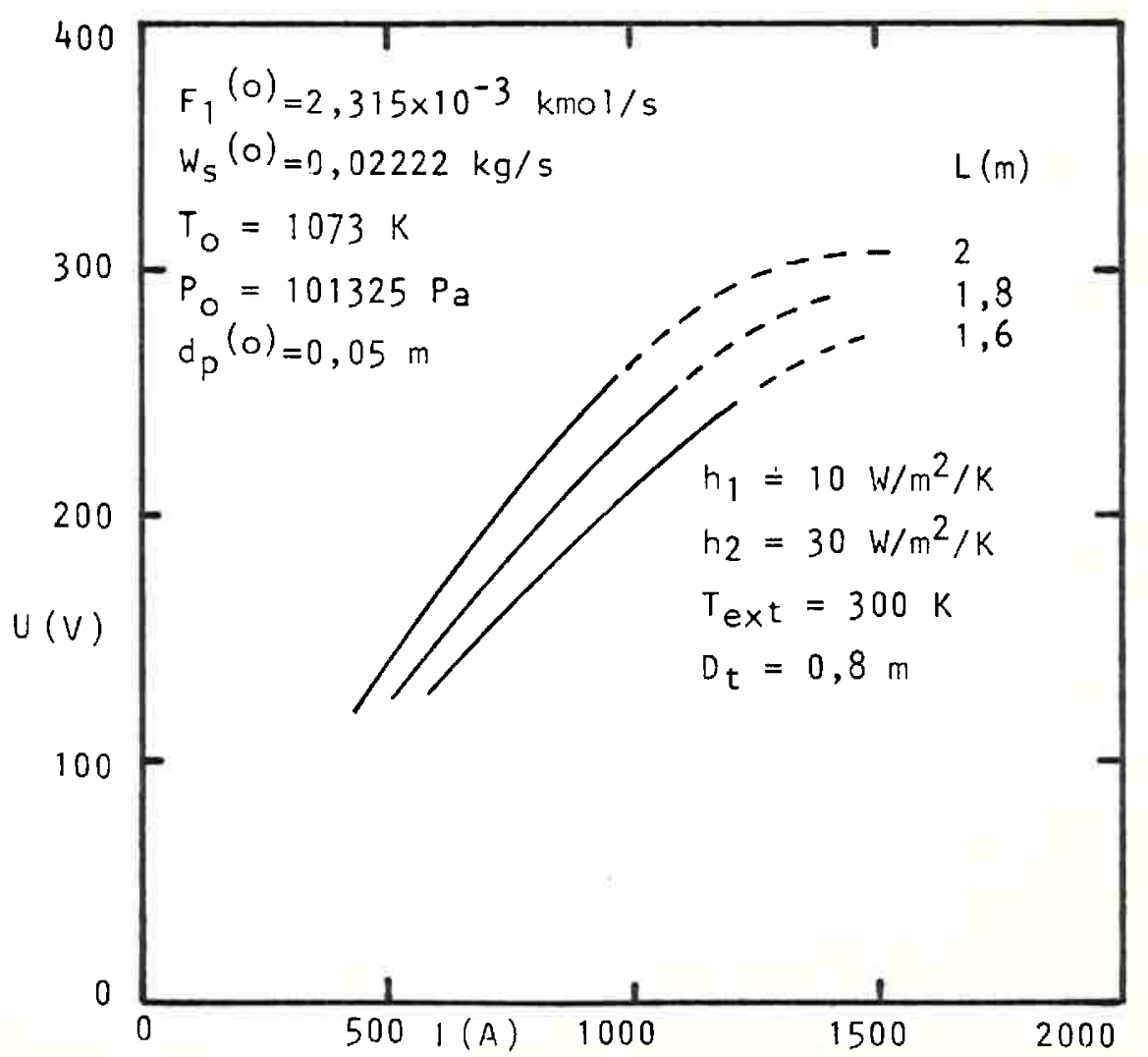

Fig. 4.16 - Influência da distância intereletrodos sobre a curva elétrica caracteristica do reator. 
mostrados devem ser interpretados dentro das limitaçōes do mode 10 .

\subsubsection{1 - Influência do Diâmetro Inicial das Partículas}

A influência do diāmetro inicial das particulas sobre a curva elétrica do reator não pode ser bem estabelecida pelo modelo, porque a condutividade elëtrica (o)do 1eito é função da granulometria. Este fato não está expresso na equação (3.7) utilizada para o cálculo de $\sigma$, e por isso, as previsōes do modelo indicam ser muito reduzida a influência do diâmetro das partículas sobre a curva elétrica, como ilustra a figura 4.17 .

Por outro lado, o modelo prevê corretamente que com a diminuição do tamanho das partículas aumentam a queda de pressão e as taxas de gaseificação (e, portanto, a conversão do "char"), como se observa na tabela 4.5 .

\subsubsection{2 - Influência da Distribuição de Vapor pelas Inje- ções Laterais}

Para a verificação desta influência foram simula dos casos em que, alëm dos outros parâmetros, a vazão total de vapor era mantida constante. A variação da distribuição ao lon go dos bocais esta esquematizada na figura 4.18. Cada caso é referido por um número que indica o tipo de distribuição.

Na figura 4.19 são apresentados perfis de tempera turas e conversão do "char" para os casos de distribuição equilibrada do vapor ao longo do reator e o caso sem injeção lateral (vapor entra so em $z=0$ ). Os perfis de temperatura apre sentam descontinuidades nos pontos de injeção lateral, ao passo que na ausência de injeção lateral o perfil de temperatura é 


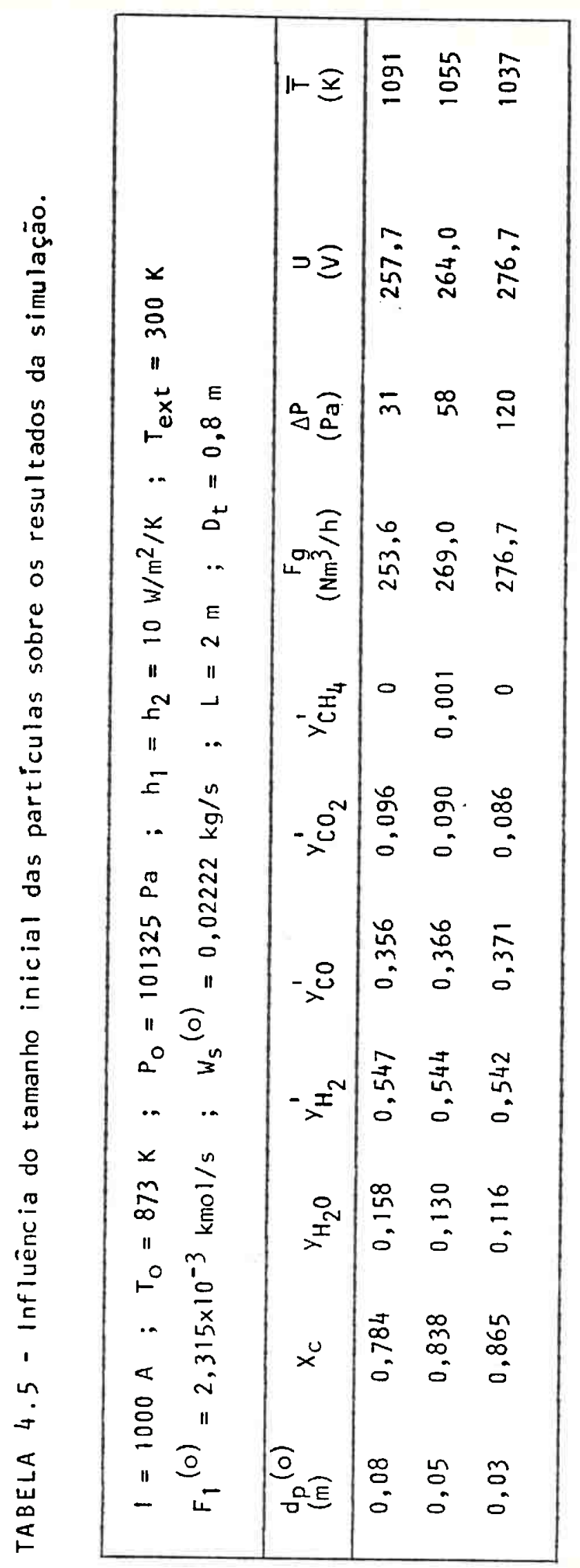



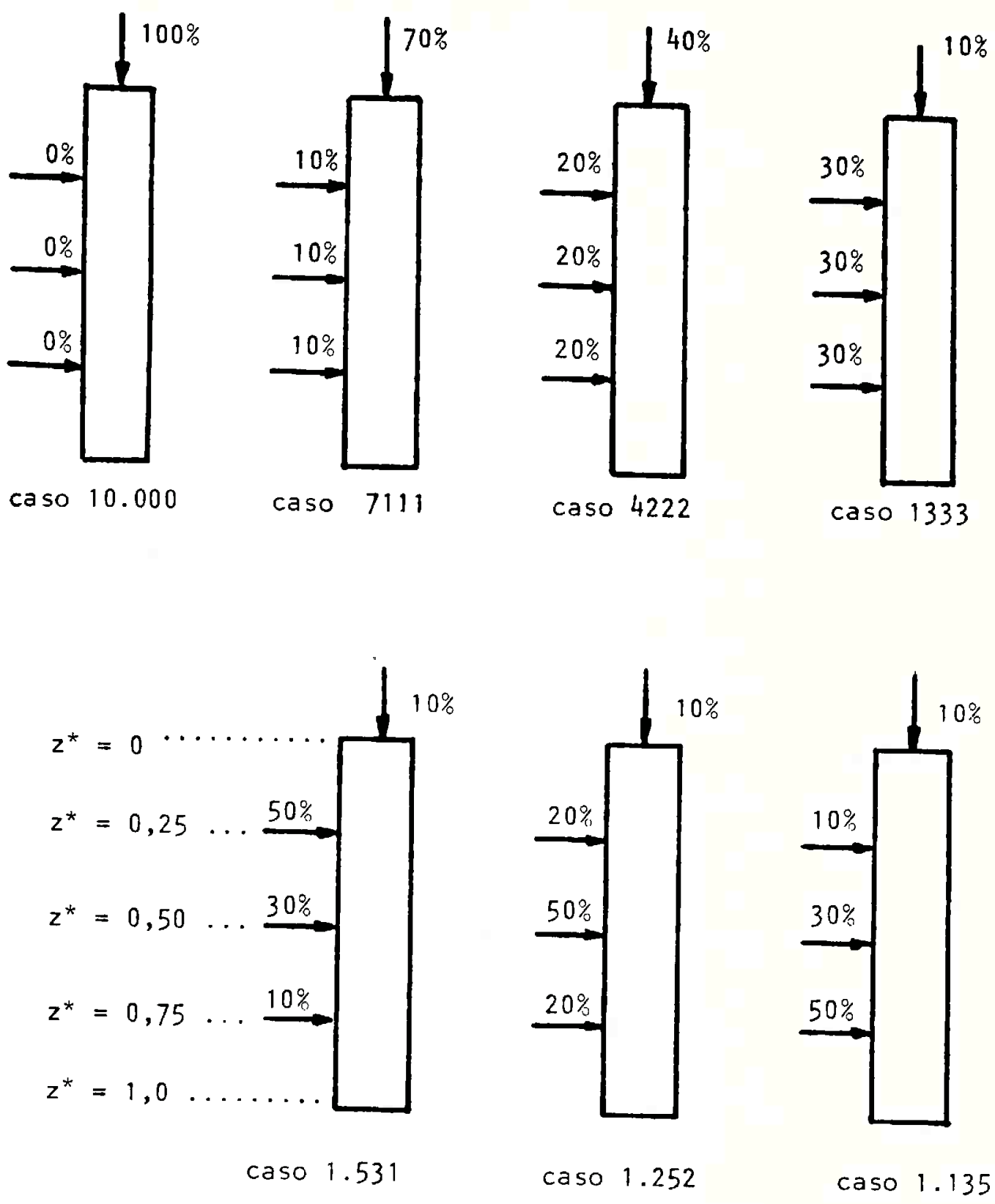

Fig. 4.18 - Esquema dos casos estudados de distribuição de vapor na região intereletrodos nos bocais de injeção lateral nas : $\operatorname{cotas} z^{*}=$ 0,$25 ; 0,50$ e 0,75 . 
continuo. Esta descontinuidade, que também ocorre nos perfis de composição do gãs e no perfil de vazão de vapor, é decorren te da maneira como a injeção lateral foi modelada. 0 salto de temperatura no ponto de injeção lateral corresponde ao efeito de resfriamento do leito devido à mistura com o vapor que entra com menor temperatura.

Diminuindo-se a quantidade de vapor que entra em $z=0$, a elevação de temperatura que o leito apresenta é maior. Por outro lado, ocorre maior salto de temperatura quando a vazão injetada lateralmente é maior. Se a vazão total de vapor é a mesma, os efeitos podem se compensar, para obter no final do reator praticamente a mesma temperatura.

No caso 1333 ocorre uma elevação muito grande na temperatura a partir do ponto $z^{*}=0,15$. Isto $\vec{e}$ devido ao consumo praticamente completo do vapor, impedindo a continuação da principal reação endotérmica de gaseificação.

Nas condições mostradas na figura 4.19 a injeção lateral afeta muito pouco o perfil de conversão do "char".

o efeito da desigualdade na distribuição do vapor ao longo do comprimento do reator é mostrado na figura 4.20 . 0 trecho inicial dos perfis (entre $z^{*}=0 \mathrm{e} z^{*}=0,25$ ) é o mesmo para todos os casos, uma vez que as vazões que entram em $z=0$ são as mesmas. Os perfis de temperatura apresentam-se bem diferentes em função da distribuiçāo do vapor. Em pontos onde o va por é completamente consumido a temperatura apresenta significa tiva elevação e o consumo do "char" torna-se mais lento.

Na tabela 4.6 são apresentados os resultados comparativos da simulação do efeito da injeção lateral. o modelo prevê que a conversão, a produção de gases e a eficiência são sensivelmente maiores para o caso 10.000 , ou seja, com todo o vapor em $z=0$ e sem injeção lateral. 

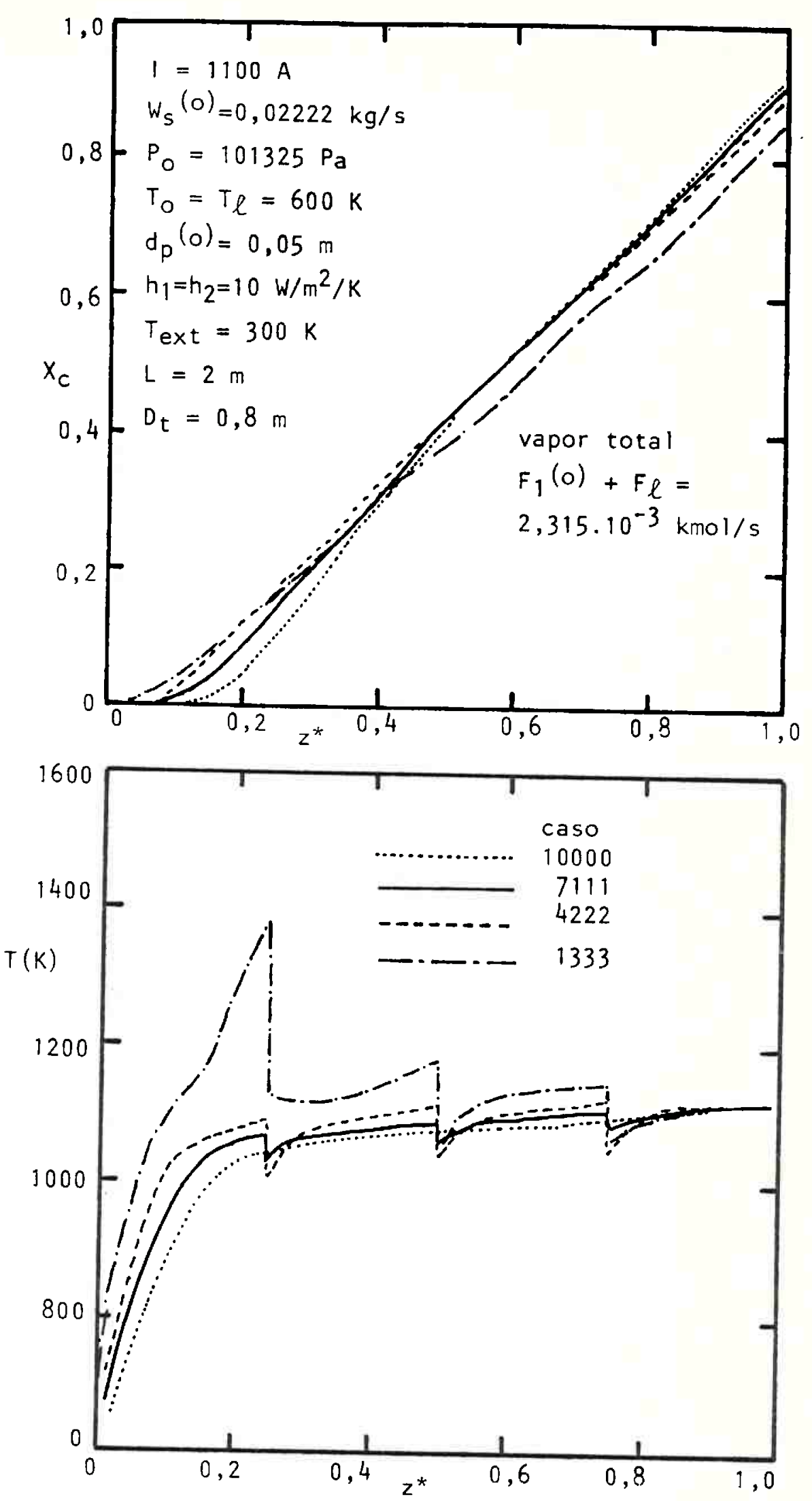

Fig. 4.19 - Influência da distribuição do vapor pelos pontos de injeção lateral sobre os perfis de conversão de sólido e de temperatura. 


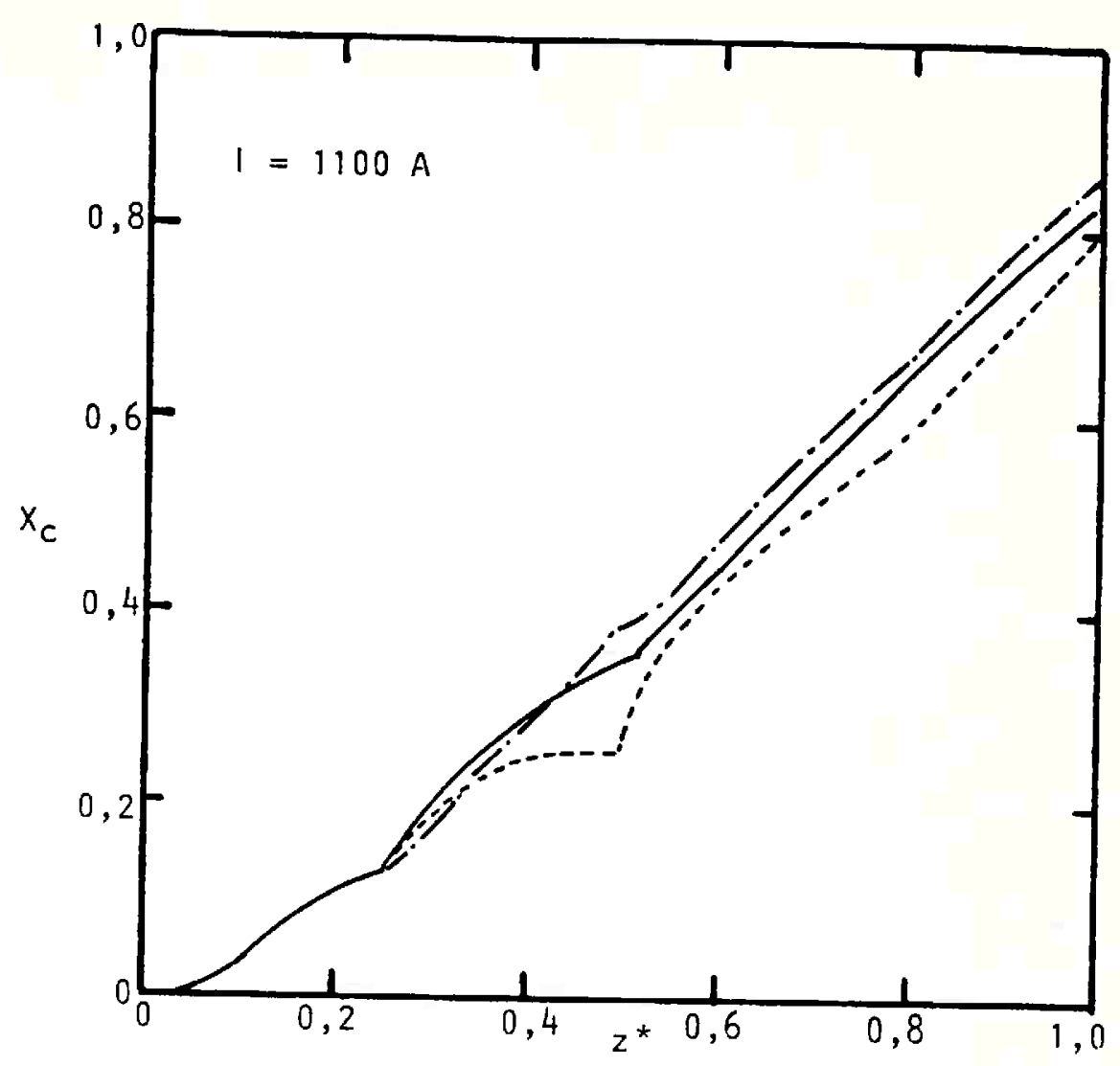

4.33

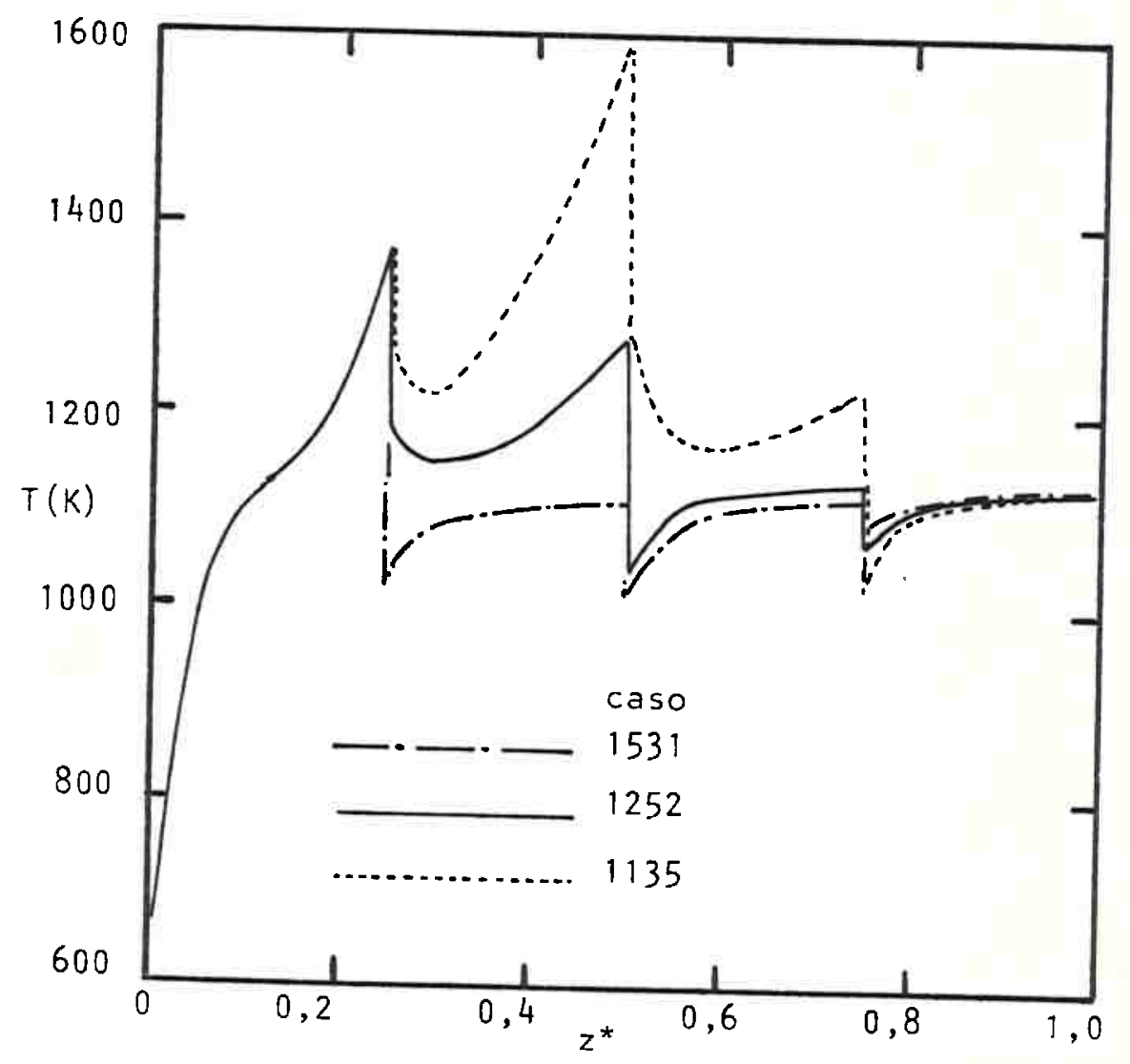

Fig. 4.20 - Influência da distribuição do vapor pelos pontos de injeção lateral sobre os perfis de conversão do sólido e de temperatura (condições mes mas da figura 4.19). 
TABELA 4.6 - Influência da distribuição de vapor pelos pontos de injeção lateral sobre os resultados da simulação (condições mesmas da figura 4.19).

\begin{tabular}{|lccccccc|}
\hline \multicolumn{1}{|c}{ Caso } & 10.000 & 7111 & 4222 & 1333 & 1531 & 1252 & 1135 \\
\hline$X_{\mathrm{C}}$ & 0,918 & 0,897 & 0,885 & 0,855 & 0,866 & 0,844 & 0,800 \\
$y_{\mathrm{H}_{2} \mathrm{O}}$ & 0,101 & 0,111 & 0,116 & 0,129 & 0,123 & 0,133 & 0,154 \\
$y_{\mathrm{H}_{2}}^{\prime}$ & 0,534 & 0,535 & 0,536 & 0,539 & 0,538 & 0,540 & 0,543 \\
$y_{\mathrm{CO}}^{\prime}$ & 0,396 & 0,392 & 0,389 & 0,380 & 0,382 & 0,375 & 0,364 \\
$y_{\mathrm{CO}}^{\prime}$ & 0,069 & 0,072 & 0,074 & 0,080 & 0,079 & 0,083 & 0,091 \\
$y_{\mathrm{CH}}^{\prime}$ & 0,001 & 0 & 0,001 & 0,001 & 0,001 & 0,001 & 0,002 \\
$F_{\mathrm{g}}(\mathrm{Nm} 3 / \mathrm{h})$ & 288,3 & 282,5 & 279,2 & 271,2 & 274,5 & 268,6 & 256,3 \\
$U(\mathrm{~V})$ & 293,7 & 290,0 & 287,0 & 278,5 & 282,5 & 277,6 & 266,6 \\
$\mathrm{P}_{\mathrm{e} \ell}(\mathrm{kW})$ & 323,0 & 319,0 & 315,7 & 306,3 & 310,8 & 305,4 & 293,2 \\
$\bar{T}(\mathrm{~K})$ & 1043 & 1060 & 1075 & 1118 & 1097 & 1123 & 1186 \\
$\Delta \mathrm{P}(\mathrm{Pa})$ & 63 & 54 & 47 & 40 & 45 & 39 & 31 \\
\hline
\end{tabular}


$\mathrm{Na}$ figura 4.21 observa-se a influência da injeçāo lateral sobre a curva elétrica. Dependendo da distribuição do vapor ao longo do reator, a influência pode ser importante ou não. Quanto mais o vapor ê distribuido no final do reator e me nos no início, a temperatura mëdia se eleva e com isso aumenta a condutividade elétrica do leito.

\section{4 - DisCUSSÃo do ESTAdo PARAMETRICO}

Ao finalizar o estudo paramétrico do modelo matemático apresentado no Capítulo 3 , cabem algumas considerações e comentärios.

Dentro das condições simuladas, os parâmetros de maior influência sobre a curva elétrica são a condutividade elé trica, o diâmetro e o comprimento do reator e o coeficiente efé tivo de transferência de calor para o exterior. As vazões de gäs e de sólido e a pressão influenciam principalmente o ponto de conversão completa, mas muito pouco a posição de curva elétrica.

Apesar de a condutividade elétrica do leito ser um dos parâmetros mais importantes do modelo, sua variação com a granulometria, pressão, origem e mesmo com a temperatura não são bem estabelecidas. No modelo foi considerada apenas sua va riação com a temperatura, que è a dependência mais estudada até o momento.

Em todos os casos simulados, a queda de pressão no leito sempre se mostrou muito pequena, menor que $1 \%$ da pressão inicial. Isto indica que a variação de pressão ao longo do rea tor é muito pequena, desprezível até. Assim, o equacionamento apresentado no item 3.8, relacionado à equação diferencial para a queda de pressāo no leito, não se faz necessārio. Poder-seia, sem prejudicar sobremaneira as previsões do modelo, descar 


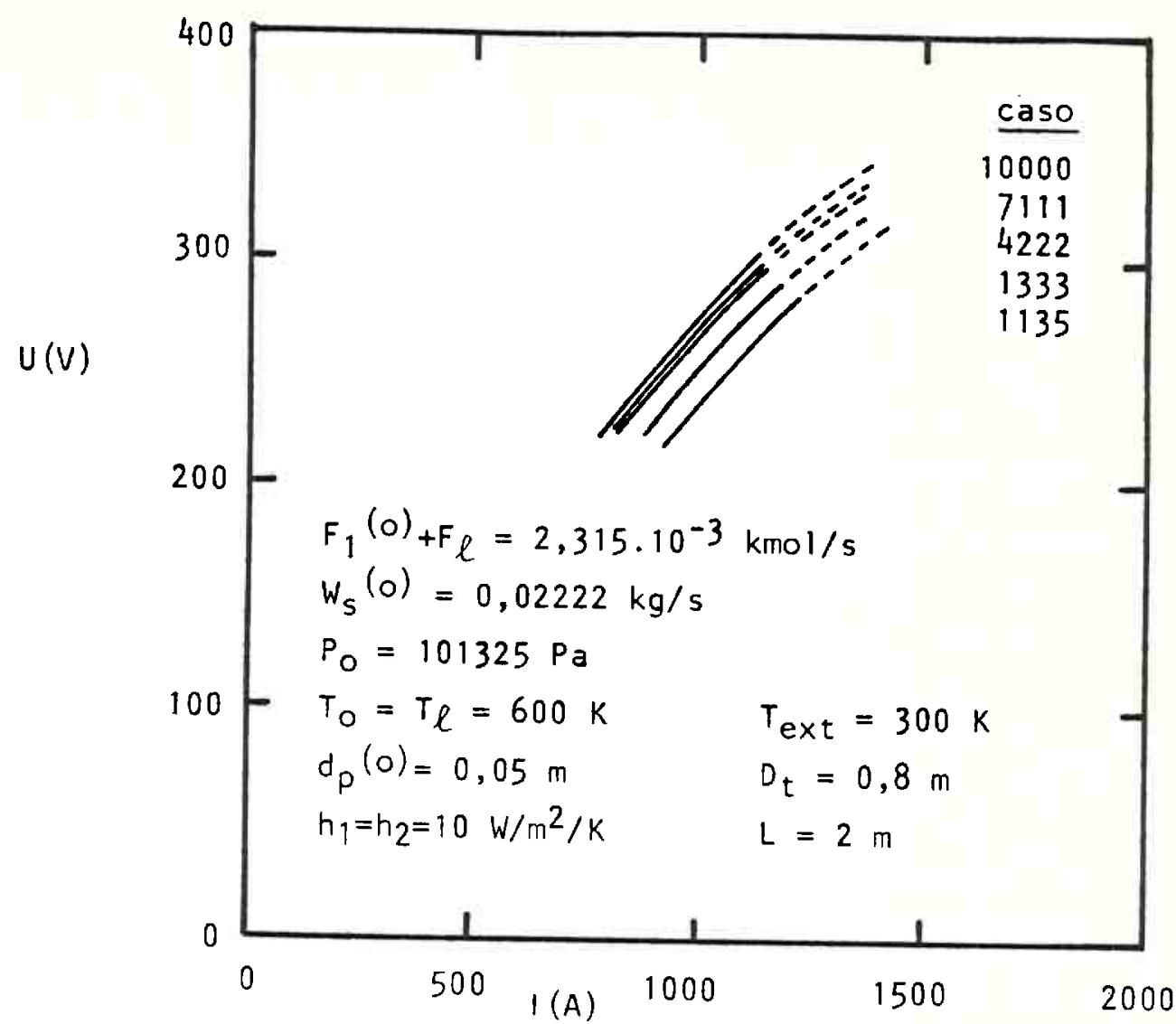

4.36

Fig. 4.21 - Influência da distribuição de vapor pelos pontos de injeção lateral sobre a curva elétrica característica do reator. 
tar a equação diferencial para a pressão total (diminuindo o nú mero de equações diferenciais do modelo) e considerar a pressão constante ao longo do gaseificador.

Os pontos do modelo, cujos tratamentos podem ser ditos não estritamente rigorosos, referem-se às perdas associadas ao eletrodo inferior e às injeçōes laterais de vapor. Embo ra o tratamento adotado nestes casos seja apenas aproximado, os resultados concordam qualitativamente com observações experimen tais dos gaseificadores eletrotērmicos sobre a diminuição da temperatura do leito que ocorrem nestes pontos.

Com exceção aos casos em que a pressão fora feita muito elevada, em todos os casos simulados a formação de metano apresentou-se muito pequena (frações molares menores que 0,002). o modelo prevê, portanto, que operando a pressões próximas à at mosférica, o metano praticamente não é formado na região intereletrodos.

Por fim, o modelo da região intereletrodos necessita, como dados de entrada, da vazão e composição do gás e do sōlido que entram no topo, passando pelo eletrodo superior. E tes dados não correspondem necessariamente às correntes de entrada. A madeira que alimenta o reator sofre os processos de secagem e pirölise, gerando gases e "char" e estes entram na re gião intereletrodos. Um modelo para prever esta distribuição de produtos da pirólise da madeira, necessārio para complementar o modelo da região intereletrodos, é apresentado no Capítú lo seguinte. 


\section{CAPITULO 5}

\section{MOdELO MATEMATICO E SIMULAÇAO DA REgIÁO DE PIRÓLISE E SECAGEM DA MADEIRA EM REATOR ELETROTERMICO}

\section{1 - INTRODUÇAัO}

Neste capitulo apresenta-se um modelo simplifica do para a região acima do eletrodo superior do gaseificador elé trotérmico, onde ocorrem os processos de secagem e pirólise da madeira. Trata-se de um modelo macroscópico, para regime perma nente e supôs-se que a distribuição de produtos seja dada pelo equilíbrio químico entre as espécies presentes.

Este modelo fornece resultados que são usados pos teriormente como dados de entrada do modelo diferencial da região entre os eletrodos, para a simulação do gaseificador eletrotérmico.

A opção pelo modelo macroscópico para a região de pirölise e secagem, ao invés de um modelo diferencial, pode ser justificada pelos seguintes aspectos:

- maior simplicidade do modelo macroscópico;

- dificuldade em se estabelecer um modelo diferencial devido ao pouco conhecimento existente sobre os processos fundamentais dos fenômenos de pirölise da madeira;

- facilidade no acoplamento com o modelo da região intereletrodos.

Modelos diferenciais de pirólise de madeira em leito móvel como os de Chan et alii (1983) e Prado e Moreira (1985), apesar de apresentarem uma correta descrição dos proces sos físicos e químicos, não permitem obter a composição do gás 
produzido. Por outro lado, modelos cinéticos de evolução de ca da gás gerado na pirólise, como o de Hajaligol et alii (1982) tem validade restrita às condições experimentais (taxa de aquecimento, tamanho e origem da amostra, tempo de residência) sob as quais os parâmetros cinéticos foram obtidos. Por isso, tor na-se difícil a utilização destes modelos para prever a distribuição dos produtos da pirỏlise, resultado este necessārio para o acoplamento com o modelo da região intereletrodos.

Finalmente, a abordagem com modelos empiricos e semi-empíricos, baseados em dados experimentais, é de aplicação difícil à medida em que os dados experimentais disponiveis são escassos e incompletos - por exemplo, foram encontrados dados de composição do gás de pirólise de eucalipto em função da temperatura [CESP (1985)] mas não a quantidade relativa de gás e "char" em função da temperatura.

\section{2 - HIPOTESES DO MODELO}

A consideração fundamental deste modelo é a de que a distribuição de produtos resultantes da região de pirólise e secagem obedeça à condição de equilíbrio químico. Esta hi pótese foi discutida no trabalho de Derosiers (1979) onde se afirma que abaixo de $773 \mathrm{~K}$ as reações em fase gasosa são muito lentas e o equilíbrio raramente é obtido, enquanto que acima desta temperatura as reações envolvidas na pirólise são rāpidas e usualmente tendem ao equilíbrio. Adverte-se, entretanto, que esta tendência ao equilíbrio é função não só da temperatura mas também do tempo de residência e taxa de aquecimento do material.

As espécies gasosas consideradas foram as citadas no Capitulo 2: $\mathrm{H}_{2} \mathrm{O}, \mathrm{H}_{2}, \mathrm{CO}, \mathrm{CO}_{2}$ e $\mathrm{CH}_{4}$, todas consideradas com comportamento de gás ideal.

$$
\text { o "char" } \vec{e} \text { tratado simplificadamente como carbo- }
$$


no. As cinzas, presentes em pequena quantidade, foram consideradas inertes.

Alcatrões e produtos pirolenhosos não foram consi derados no modelo; supôs que na saída da região de pirólise tais produtos tenham sido degradados em "char" e gases.

\section{3 - EQUAÇOES DO MODELO}

o cảlculo da distribuição de produtos foi realiza do por um programa de computador que calcula a composição. de equilíbrio químico, estabelecendo as fraçōes (molares) dos dife rentes produtos, a partir da minimização da função de Gibbs do sistema.

Este programa foi obtido na literatura [Gordon e McBride (1971)], tendo sido desenvolvido pela NASA visando a simulação de reações químicas e ondas de choque presentes na de tonaçāo e queima de combustiveis em foguetes.

Partindo da distribuição de produtos em termos de frações molares é necessário calcular as vazões resultantes e o fluxo de calor necessário ao processo.

A relação entre as vazões de gās e de "char" prọ duzidos na região acima dos eletrodos é dada por:

$$
\frac{W_{g}}{W_{\text {char }}}=\frac{M_{g} \sum_{i=1}^{s} Y_{i}}{M_{\text {char }} Y_{C}}=\frac{M_{g}\left(1-Y_{C}\right)}{M_{\text {char }} Y_{C}}
$$

onde Y denota as frações molares de "char" (indice c) e dos gases (indice i).

$\Lambda$ massa molar da mistura gasosa e dada por 


$$
\mathrm{M}_{g}=\sum_{i=1}^{5} y_{i} M_{i}
$$

onde as fraçōes molares de cada gás na fase gasosa ē

$$
y_{i}=\frac{Y_{i}}{1-Y_{C}}
$$

O balanço de massa global do processo de pirólise e secagem, conforme a figura 5.1 , è

$$
\begin{aligned}
& W_{m s}+W_{u}+W_{\text {cinza }}=W_{g}+W_{\text {char }}+W_{\text {cinza }} \\
& \text { Das equações }(5.1) \text { e (5.4) chega-se a } \\
& W_{g}=\frac{W_{m s}+W_{u}}{1+\frac{12 Y_{c}}{M_{g}\left(1-Y_{c}\right)}} \\
& W_{\text {char }}=W_{m s}+W_{u}-W_{g}
\end{aligned}
$$

e a vazão molar de gás é

$$
F_{g}=W_{g} / M_{g}
$$

o fluxo de calor necessärio ao processo pode ser calculado aplicando-se a primeira lei da termodinâmica $[$ Van Wylen e Sontag (1976)] ao sistema aberto em regime permanente, esquematizado na figura 5.1. Considerando desprezíveis a energia cinética e potencial das correntes e sendo nulo o trabalho realizado nas fronteiras do sistema, pode-se escrever:

$$
\begin{aligned}
Q_{P I R} & =\left(W_{\text {char }} h_{\text {char }}+W_{c i n z a} h_{\text {cinza }}+F_{g} \sum_{i=1}^{5} y_{i} h_{i}\right)_{\text {saida }}- \\
& -\left(W_{m s} h_{m s}+W_{u} h_{u}+W_{c i n z a} h_{c i n z a}\right) \text { entrada }
\end{aligned}
$$




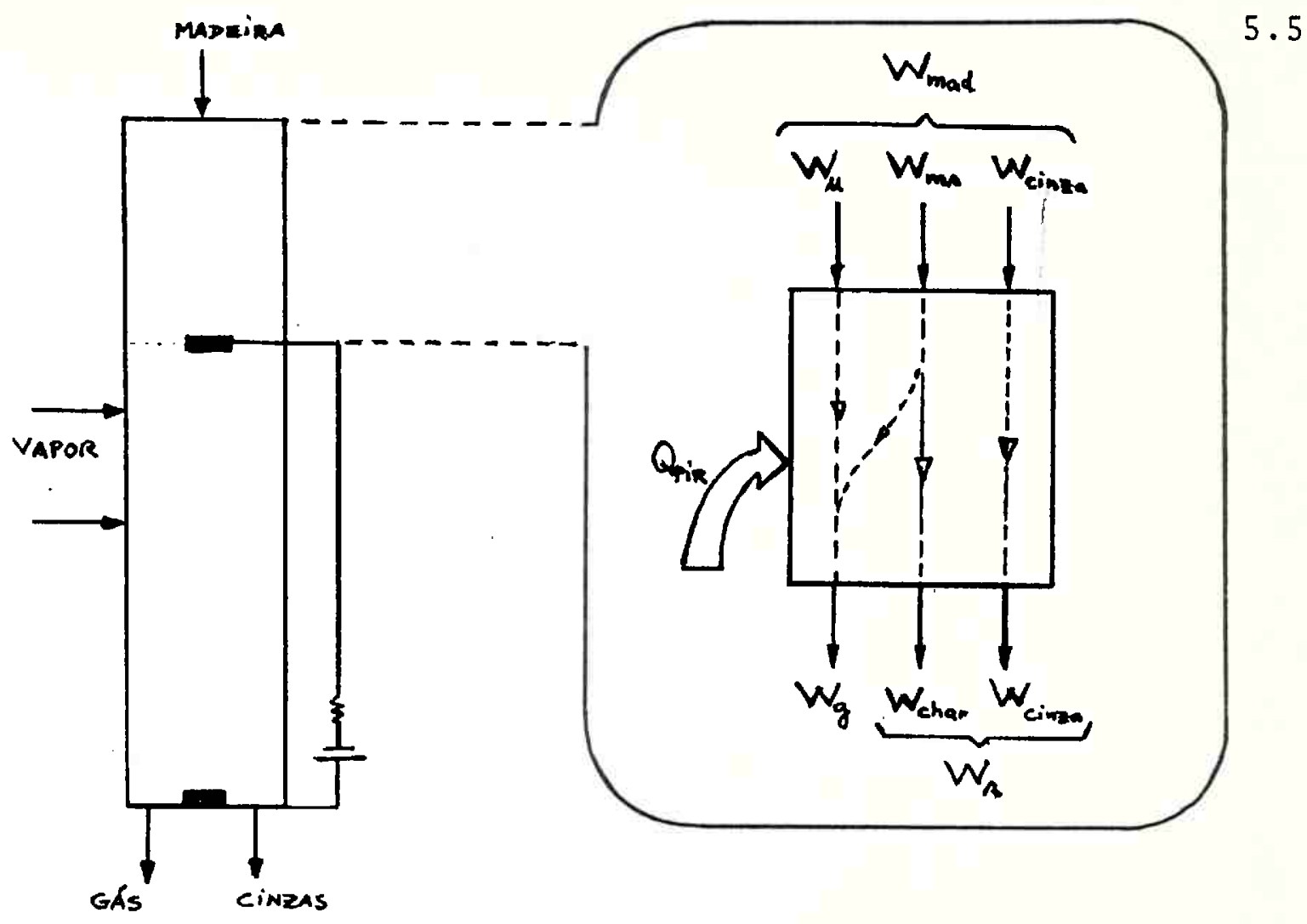

Figura 5.1 - Esquema dos fluxos que entram e saem da região de pirólise e secagem da madeira.

$\mathrm{Na}$ expressão (5.8) considerou-se nula a entalpia de 1 igação da umidade à madeira.

A enta1pia de cada "substância" é calculada a par tir da entalpia de formação padrão e do calor específico. os calores especificos da madeira e o da umidade $\left(\mathrm{H}_{2} \mathrm{O}(\ell)\right.$ ) foram considerados constantes enquanto que o do "char", das cinzas e dos gases são expressos em função da temperatura. Maiores informações sobre estas propriedades são apresentadas no Apêndice B.

\section{4 - PROGRAMAS DE COMPUTADOR UTILIZADOS}

Como foi mencionado no item anterior, o cálculo 
da composição de equilíbrio resultante da região de pirólise e secagem foi realizado por um programa de computador obtido na 1iteratura. Este programa é aqui denominado NASA/OBJ.

São dados de entrada deste programa:

- a composição elementar da corrente de entrada (madeira mais umidade);

- a temperatura e a pressão de operação.

Dados de caracterização da madeira de Eucalipto grandis foram obtidos nos trabalhos de Makray (1984) e CESP (1985a), sendo tais dados apresentados na tabela 5.1.

TABELA 5.1-Dados de caracterização da madeira de Eucalipto grandis.

\begin{tabular}{|c|c|}
\hline $\begin{array}{lc}\text { anälise imediata da madeira seca } \\
\text { - matéria volátil } & 85,1 \% \\
\text { - carbono fixo } & 14,3 \% \\
\text { - cinzas } & 0,6 \%\end{array}$ & CESP (1985a) \\
\hline $\begin{array}{ll}\text { composição el ementar da madeira seca e sem cinza } \\
\text { C } & 50,1 \% \\
\mathrm{H} & 6,1 \% \\
0 & 43,7 \% \\
\mathrm{~N} & 0,1 \%\end{array}$ & Makray (1984) \\
\hline $\begin{array}{l}\text { fórmula em base de } \mathrm{C}_{1} \\
\qquad \mathrm{CH}_{1,461} \mathrm{O}_{0,654} \mathrm{~N}_{0,0017} \quad(\mathrm{M}=23,949 \mathrm{~kg} / \mathrm{kmol}) \\
\text { förmula em base de } \mathrm{C}_{1} \text { desprezando } \mathrm{N} \\
\begin{array}{cc}\mathrm{C} \mathrm{H}_{1,461} \mathrm{O}_{0,654} & (\mathrm{M}=23,925 \mathrm{~kg} / \mathrm{kmo} 1)\end{array}\end{array}$ & $\begin{array}{l}\text { calculada com } \\
\text { os dados acima }\end{array}$ \\
\hline $\begin{array}{l}\text { poder calorifico superior } \\
\qquad 627 \mathrm{kcal} / \mathrm{kg}=1,937 \cdot 10^{7} \mathrm{~J} / \mathrm{kg}= \\
4,634 \times 10^{8} \mathrm{~J} / \mathrm{kmol} \subset \mathrm{H}_{1,461} \mathrm{O}_{0,654}\end{array}$ & CESP (1985a) \\
\hline
\end{tabular}


Como resultados, O programa NASA/OBJ fornece as fraçōes molares de $\mathrm{C}(\mathrm{s})$ e dos gases $\mathrm{H}_{2} \mathrm{O}, \mathrm{H}_{2}, \mathrm{CO}, \mathrm{CO}_{2}$ e $\mathrm{CH}_{4} \cdot \mathrm{Em}$ bora apenas estas espécies sejam de interesse, o programa consi dera värias espécies adicionais mas, em todos os casos simulados, as respectivas frações molares não excederam o valor de $5 \times 10^{-4}$.

Um segundo programa, denominado PIROLISE, foi estruturado para obter as vazōes resultantes da região acima dos eletrodos e o calor necessārio ao processo que aí ocorre. Este programa utiliza as equações $(5.2),(5.3),(5.5),(5.6),(5.7)$ e (5.8) alèm de uma subrotina para o cálculo das entalpias das vārias substâncias envolvidas.

A Iistagem do programa PIROLISE è apresentada no Apêndice D.

\section{5 - Resultados da Simulação do mOdelo da Região acima dos ÉLE TRODOS}

Os resultados da simulação da região de pirólise são apresentados nas tabelas 5.2 a 5.6. Estes resultados foram obtidos variando-se a temperatura de pirólise entre 573 e $1173 \mathrm{~K}$ e a umidade da madeira entre 0 e $40 \%$ em base úmida. Em todos os casos a pressão foi mantida $101325 \mathrm{~Pa}$, a temperatura de entrada $300 \mathrm{~K}$, e a vazão de madeira úmida $1 \mathrm{~kg} / \mathrm{s}$.

Observa-se que para temperatura e umidade menores o modelo prevê valores negativos de $Q$, isto é, o calor não entraria mas sim sairia da região de pirólise. Este resultado po de ser interpretado tendo em vista que o termo $Q$ representa a entalpia de secagem, a entalpia sensível correspondente à eleva ção de temperatura e a entalpia de pirólise (mais reações secun dárias). $\Lambda$ duas primeiras parcclas correspondem a processos endotérmicos e a última a um processo exotërmico. 


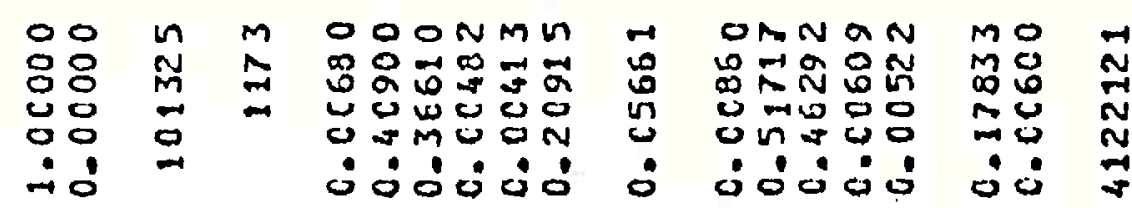

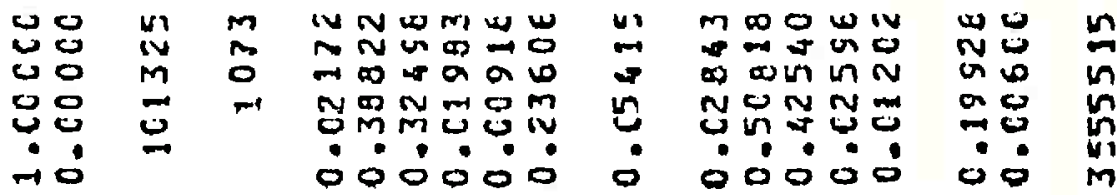

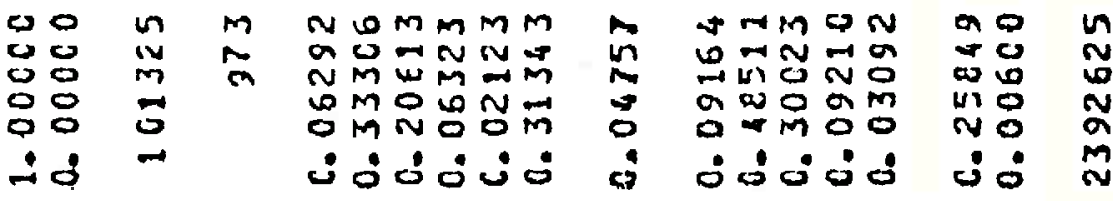

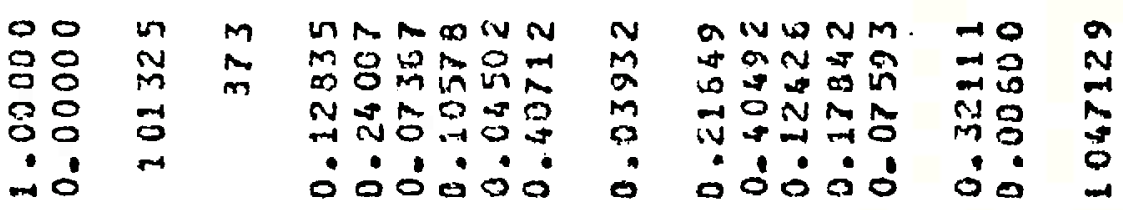

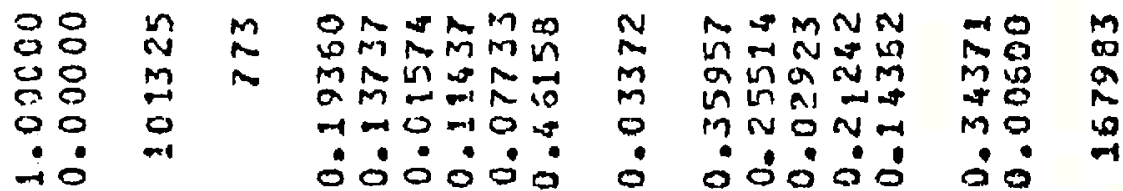

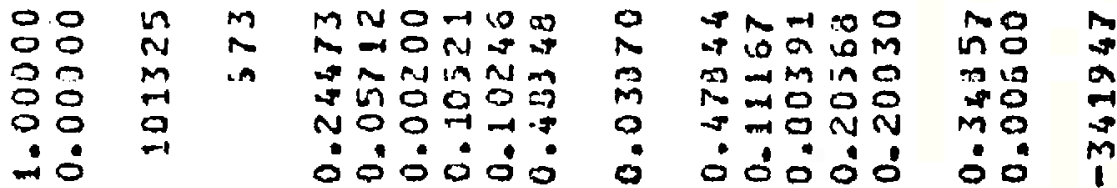

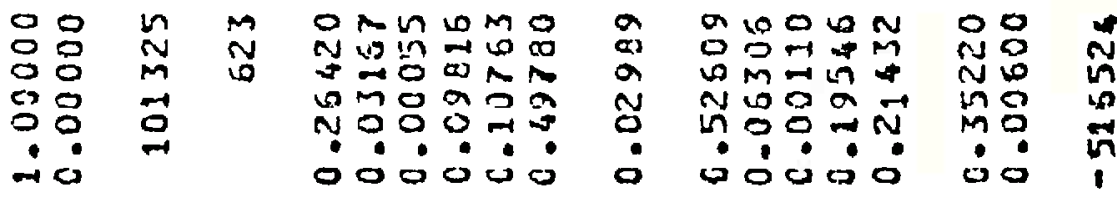

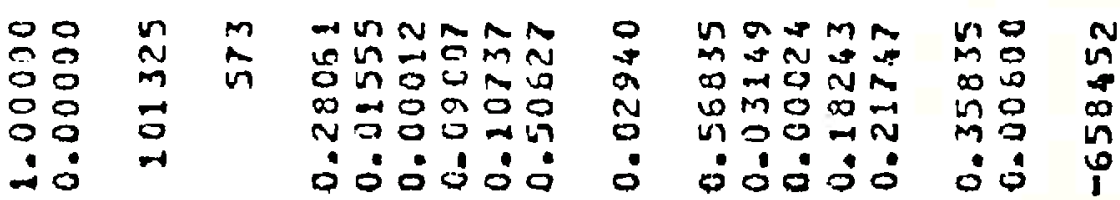

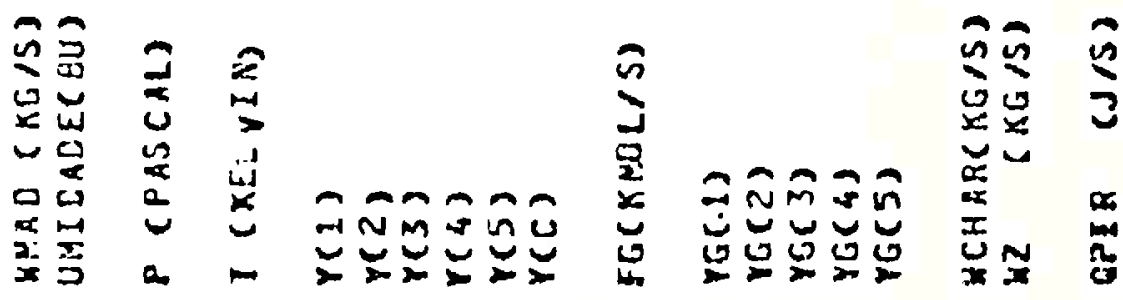




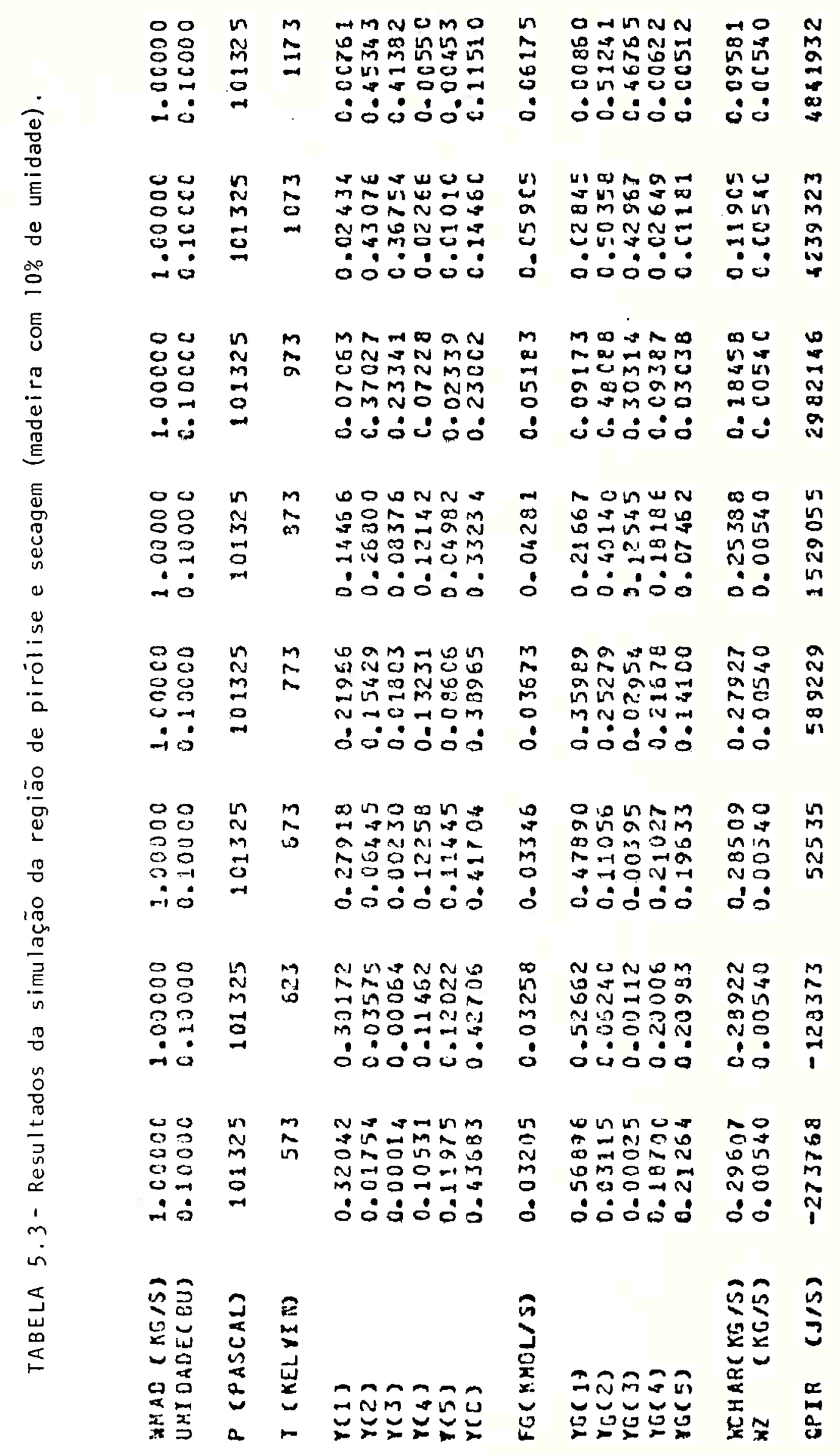




\begin{tabular}{|c|c|c|c|c|c|c|c|}
\hline & 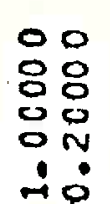 & $\begin{array}{c}n \\
\tilde{m} \\
-1 \\
0 \\
-1\end{array}$ & $\stackrel{m}{m}$ & 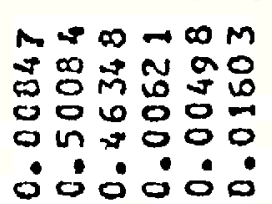 & $\begin{array}{l}0 \\
0 \\
0 \\
0 \\
0 \\
0 \\
0 \\
0\end{array}$ & 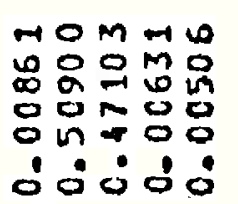 & $\begin{array}{l}\text { Mo } \\
0 \\
0 \\
0 \\
0 \\
0 \\
0 \\
0\end{array}$ \\
\hline 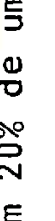 & $\begin{array}{l}00 \\
00 \\
00 \\
00 \\
0 \\
10\end{array}$ & $\begin{array}{l}n \\
N \\
m \\
\tilde{m} \\
m\end{array}$ & $\begin{array}{c}m \\
\tilde{s} \\
-\end{array}$ & 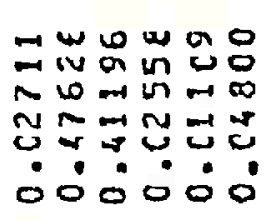 & $\begin{array}{l}4 \\
0 \\
0 \\
0 \\
0 \\
0\end{array}$ & 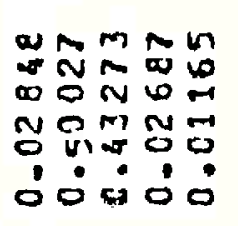 & 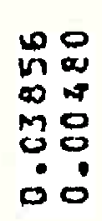 \\
\hline $\begin{array}{l}\frac{0}{2} \\
\frac{2}{2} \\
0 \\
\frac{\pi}{2}\end{array}$ & $\begin{array}{l}00 \\
00 \\
00 \\
80 \\
0 N \\
i 0\end{array}$ & $\begin{array}{c}n \\
N \\
\sim \\
0 \\
-1\end{array}$ & $\frac{M}{a}$ & 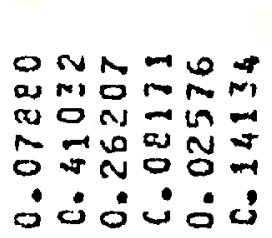 & 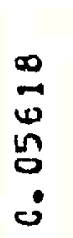 & 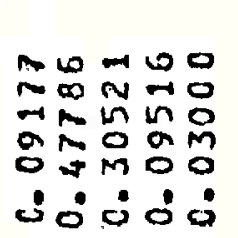 & 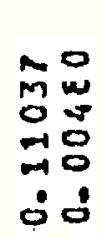 \\
\hline 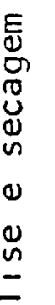 & $\begin{array}{l}00 \\
80 \\
0 \\
80 \\
0 \\
\therefore \\
-10\end{array}$ & $\stackrel{n}{N}$ & $\stackrel{M}{\stackrel{m}{⿴ 囗 十}}$ & 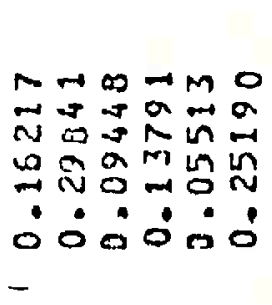 & $\begin{array}{l}0 \\
0 \\
0 \\
0 \\
0 \\
0 \\
0 \\
0\end{array}$ & 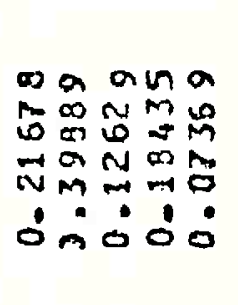 & 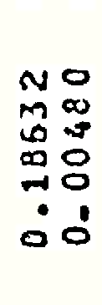 \\
\hline סי & 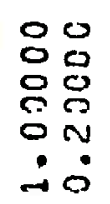 & $\begin{array}{c}w \\
n \\
m \\
\vdots \\
0 \\
-1\end{array}$ & $\stackrel{M}{N}$ & 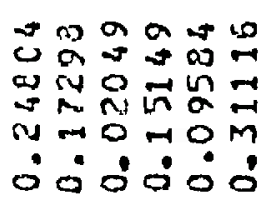 & $\begin{array}{l}0 \\
\$ \\
0 \\
m \\
0 \\
0 \\
0\end{array}$ & 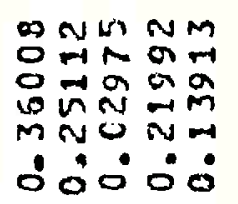 & $\begin{array}{l}m 0 \\
30 \\
50 \\
=0 \\
40 \\
00\end{array}$ \\
\hline$\frac{\pi}{0}$ & $\begin{array}{ll}0 & 0 \\
0 & 0 \\
0 & 0 \\
0 & 0 \\
0 & 1 \\
-1 & 0\end{array}$ & $\begin{array}{l}n \\
\stackrel{n}{0} \\
\ddot{0} \\
0\end{array}$ & $\underset{n}{m}$ & 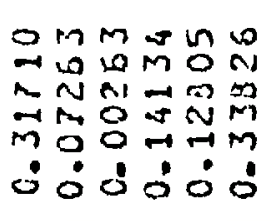 & $\begin{array}{l}\infty \\
0 \\
c \\
0 \\
n \\
0 \\
0 \\
0\end{array}$ & 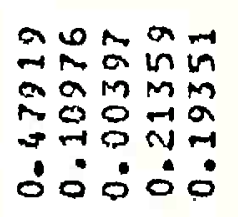 & 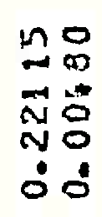 \\
\hline ס & $\begin{array}{ll}9 & 0 \\
0 & 0 \\
0 & 0 \\
0 & 0 \\
0 & 1 \\
-1 & 0\end{array}$ & 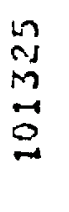 & ్ְ & 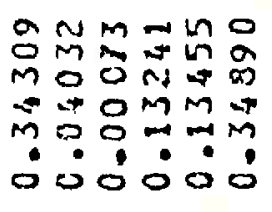 & $\begin{array}{l}m \\
m \\
n \\
m \\
g \\
a\end{array}$ & 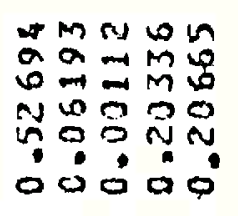 & $\begin{array}{l}\text { No: } \\
\text { ñ } \\
\text { Ny } \\
\text { No } \\
\vdots 0 \\
00\end{array}$ \\
\hline 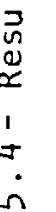 & 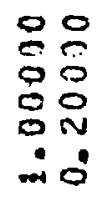 & $\begin{array}{c}u \\
\sim \\
n \\
0 \\
0\end{array}$ & ñ & 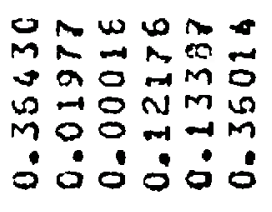 & $\begin{array}{l}w \\
\tilde{a} \\
m \\
0 \\
0\end{array}$ & 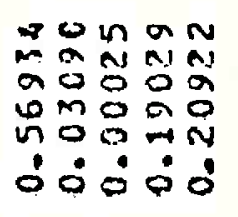 & \begin{tabular}{ll} 
& 0 \\
$M$ & 0 \\
$M$ & 5 \\
$M$ & 0 \\
\hdashline & 0 \\
0 & 0
\end{tabular} \\
\hline & 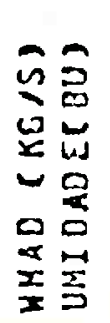 & $\begin{array}{l}a \\
a \\
u \\
0 \\
a \\
0 \\
a \\
a\end{array}$ & 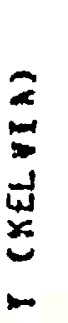 & ニÑシ̃ & 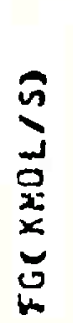 & 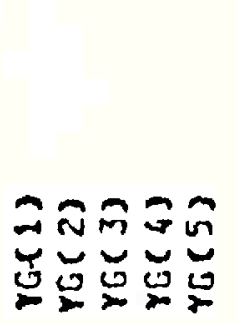 & 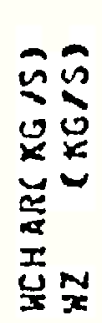 \\
\hline
\end{tabular}




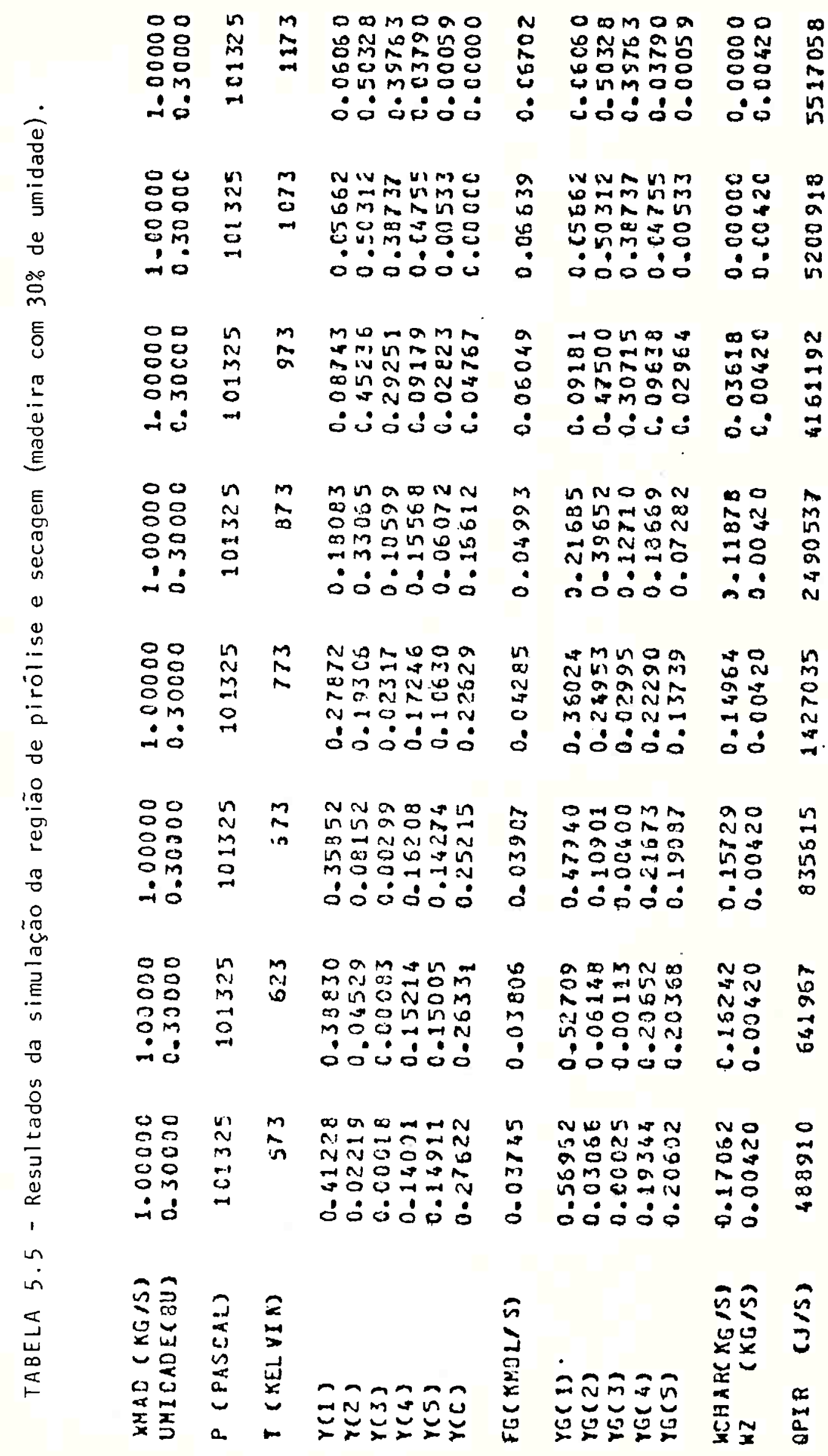




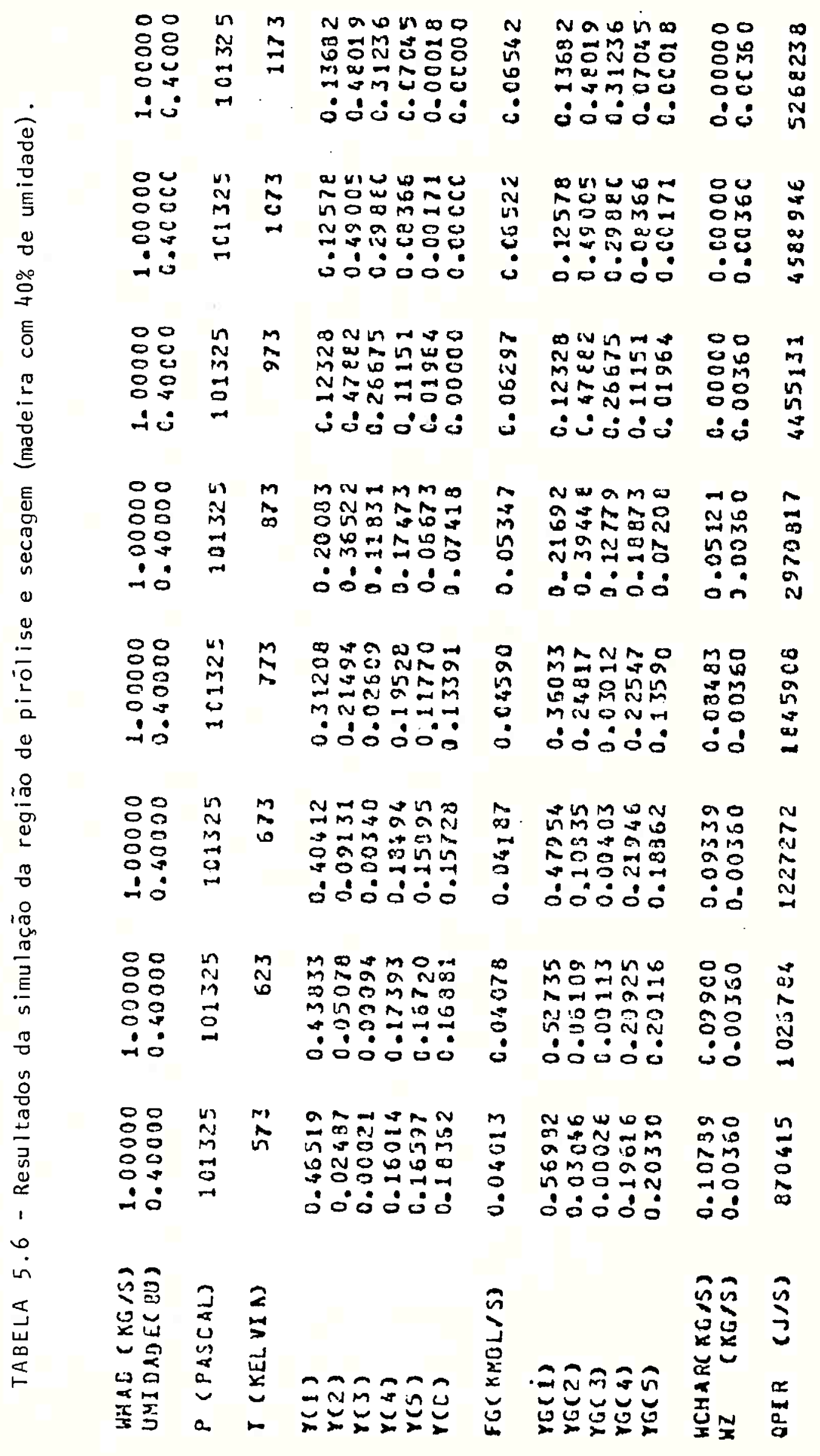


Observa-se ainda, que o modelo prevê uma conversão de mais de $60 \%$ da madeira em gases. Pelo modelo, a umidade da madeira influencia muito mais a relação gás/carvão produzi dos do que a composição do gâs de pirôlise.

Quanto à influência da temperatura na composição dos gases observa-se que para baixas temperaturas o vapor de água, metano e gás carbônico são os produtos preponderantes, ao passo que a geração de hidrogênio e monóxido de carbono é favorecida por temperaturas elevadas.

o modelo prevê que hidrocarbonetos com cadeias maio res que $\mathrm{CH}_{4}$ não aparecem como produtos do equilíbrio. Os alcatrões e pirolenhosos que, na prätica, aparecem na pirólise de madeira são, portanto, produtos de não-equilíbrio. Certamente estes compostos maiores tendem a ser degradados a altas tempera turas. Assim, previsões mais realistas para este modelo de equilíbrio devem ser esperadas em situações de temperaturas ele vadas.

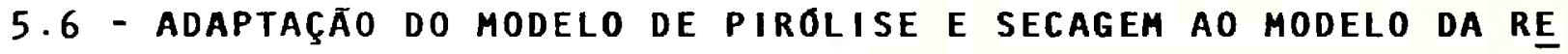 GIĀO INTERELETRODOS}

O calor requerido pela região acima dos eletrodos para o aquecimento, secagem e pirólise da madeira é fornecido a partir da região intereletrodos. Os mecanismos com que se faz esta transferência podem envolver condução através do leito, ra diação ou convecção (atravês de correntes de recirculação de ga ses entre as regiões).

Neste trabalho adotou-se um tratamento simplifica do para a transferência de calor entre as regiōes. Considerouse que o calor transferido da região intereletrodos para a re gião acima tenha saído de uma extensão conhecida de comprimento $\mathrm{L}_{\mathrm{p}} \mathrm{da}$ parte superior da região intereletrodos. 
Assim, o balanço diferencial de energia da região intereletrodos, equação (3.18), deve ser modificado para incluir o termo de transferência para a região de secagem e piró lise, ficando

$$
\frac{\left(F_{g} c_{p g}+W_{S} c_{p s}\right)}{A_{t}} \frac{d T}{d z}=Q_{J}+Q_{R}-Q_{P}-Q_{T}
$$

sendo a taxa de calor transferida para a regiāo de pirólise e secagem dada por:

$$
Q_{T}= \begin{cases}\frac{Q_{P I R}}{A \cdot L_{p}} & \text { para } z<L_{p} \\ 0 & \text { para } z \geqslant L_{p}\end{cases}
$$

O modelo completo incluindo as regiões de secagem, pirólise e gaseificação representa a uniāo do modelo apresentado neste capitulo com o do Capítulo 3 . A modificação que é in troduzida é feita através da adição do termo QT na equação (3.18) resultando a equação (5.9) e as condições expressas na equação (5.10). Os resultados da simulação do modelo completo são apresentados no Capítulo 6 . 


\section{CAPITULO 6}

\section{RESULTADOS DA SIMULAÇÃO DO GASEIFICADOR ELETROTERMICO - ZONAS DE SECAGEM E PIROLISE E DE GASEIFICAÇAO}

\section{1 - INTRODUÇÃo}

Neste capitulo sāo apresentados os resultados da simulação do gaseificador eletrotërmico, utilizando-se, conjuntamente o modelo diferencial (unidimensional) para a região in tereletrodos e o modelo macroscópico de pirólise e secagem para a região acima dos eletrodos.

São apresentados estudos paramétricos dos parâme tros relativos ao acoplamento entre os dois modelos.

Os resultados da simulação são comparados com os dados experimentais da operação dos gaseificadores eletrotérmicos descrito no item 3.2 .

\section{2 - estudo PARAMETRico do modelo COMPLEto}

Considerando os modelos dos capitulos 3 e 5 acoplados, aparecem mais três parâmetros cuja sensibilidade deve ser estudada: a umidade da madeira (parâmetro de processo), a temperatura de pirólise e o comprimento $\mathrm{L}_{\mathrm{p}}$ da região intereletrodos que cede calor à região superior (parâmetros do modelo).

\section{2 .1 - Influência da Umidade da Madeira}

O efeito da umidade da madeira sobre os perfis de temperatura e conversão do sỏlido é mostrado na figura 6.1. 0 


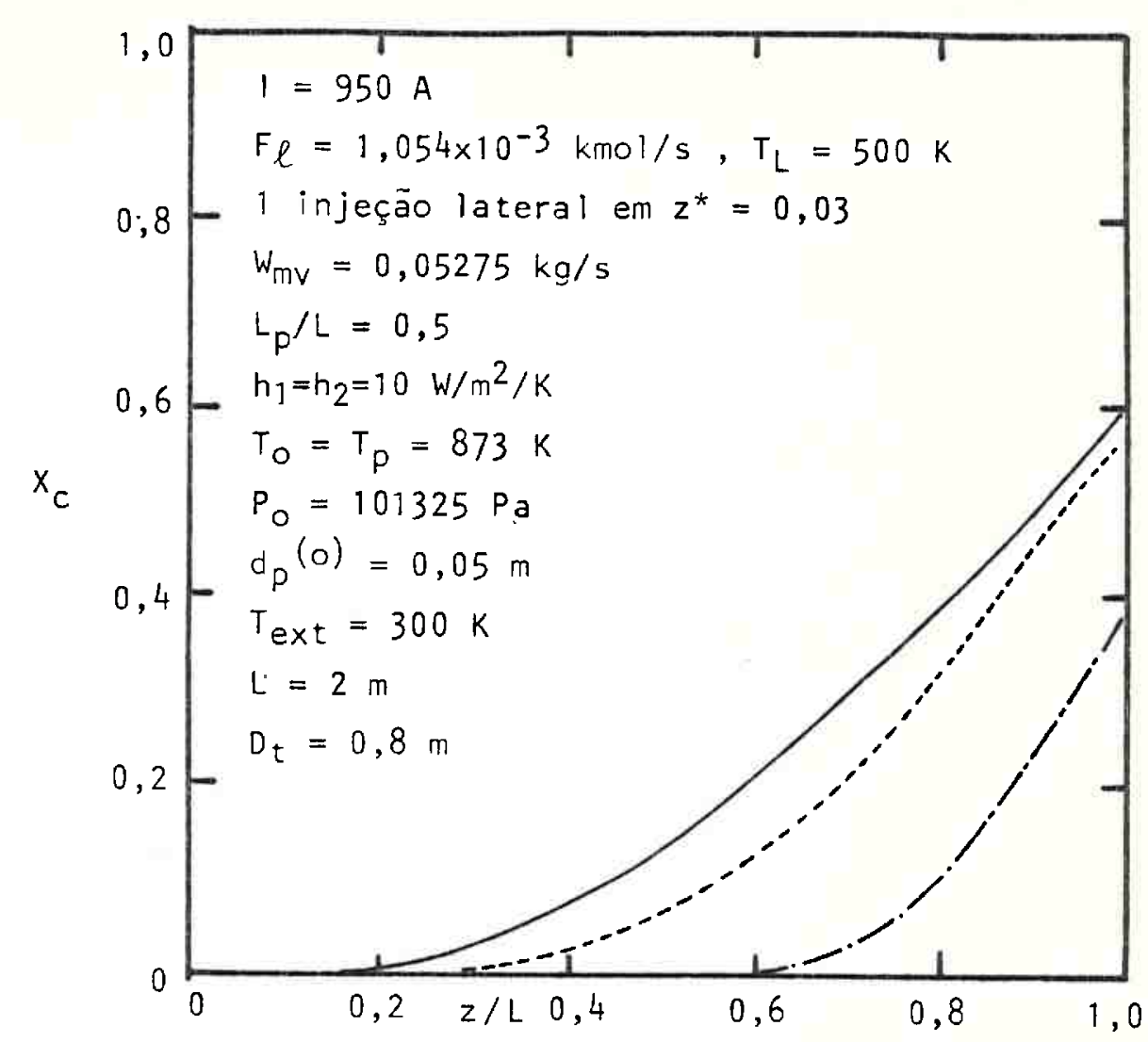

6.2

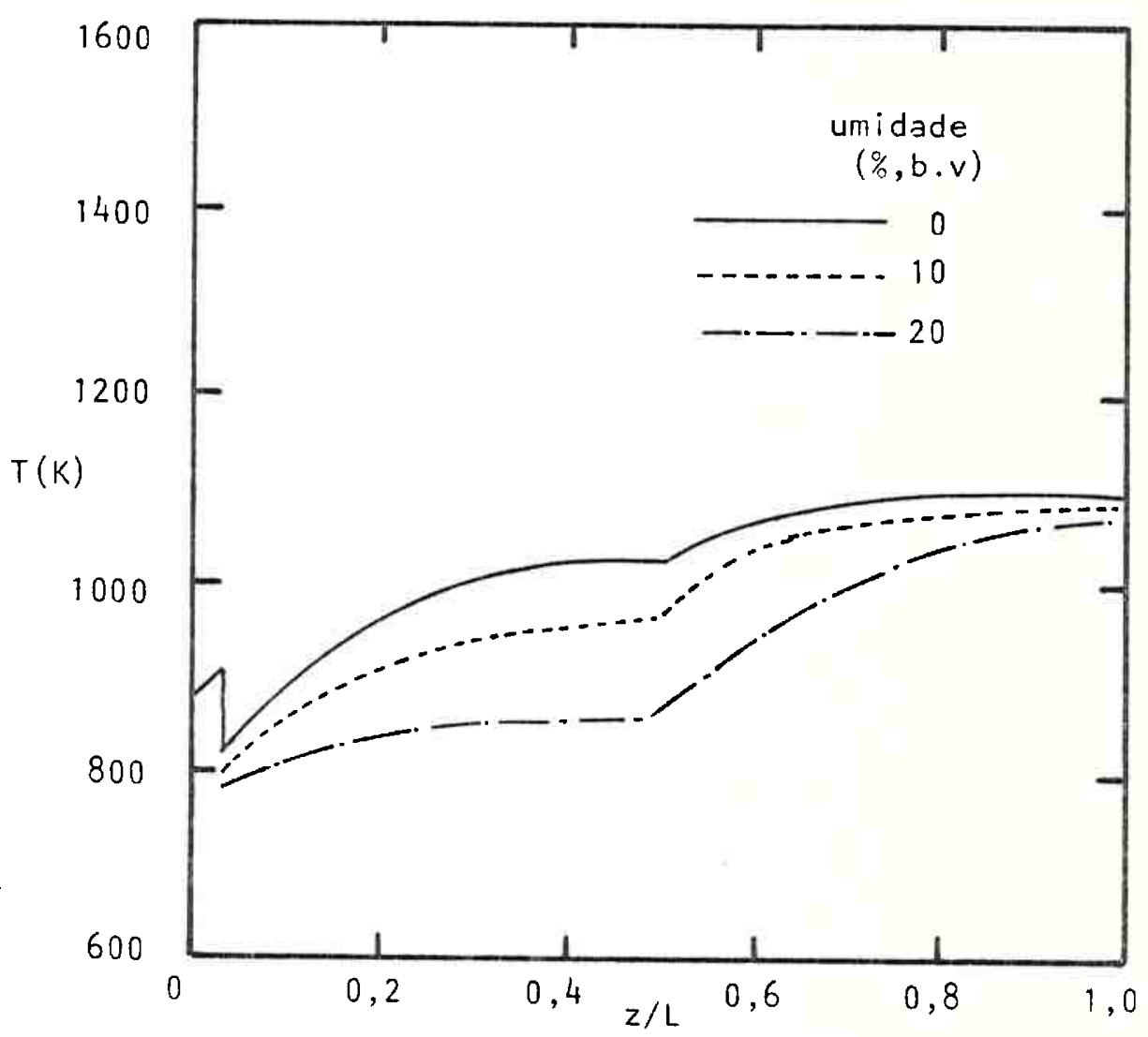

Fig. 6.1 - Influência da umidade da madeira sobre os perfis de conversão do "char" e de temperatura. 
aumento da umidade provoca maior retirada de calor do leito, o que diminui a sua temperatura média com comsequente redução na conversão do sôlido. Este efeito de diminuir a temperatura média do leito deve afetar também a curva elétrica característica, como indica a tabela 6.1.

\subsection{2 - Influência da Temperatura de Pirölise}

A influência da temperatura de pirōlise sobre os perfis de temperatura e conversão é ilustrada na figura 6.2. Ob serva-se que valores de $T_{p}$ levam a menores valores médios de temperatura e, consequentemente, de conversão.

A temperatura de pirólise define a composição do gás de pirólise e a quantidade relativa entre gás e "char". Uma vez que a quantidade de gäs obtida a partir da consideração de equilíbrio é expressamente maior que a de "char", a temperatura de pirólise é um parâmetro do modelo que apresenta influência sobre a composição final do gãs, como ilustrado na tabela 6.2. Entretanto, a influência de $T_{p}$ sobre a composição final é menor que a sobre a composição do gäs de pirólise, pois a composição final depende não sō da composição inicial do gás, mas também das condições da região intereletrodos (principalmente temperatura e excesso ou falta de vapor de ägua).

Como observado nos resultados do Capitulo 4 , a quantidade de metano produzida na região intereletrodos é extre mamente pequena. Sua produção é devido à região de pirölise, có mo função de $\mathrm{T}_{\mathrm{p}}$. Assim, a escolha adequada da temperatura de pirölise no modelo permite ajustar a composição final de $\mathrm{CH}_{4}$.

\section{2 .3 - Influência do Comprimento $L_{p}$}

A influência da extensão $L_{p}$ em que se supôs ocor- 

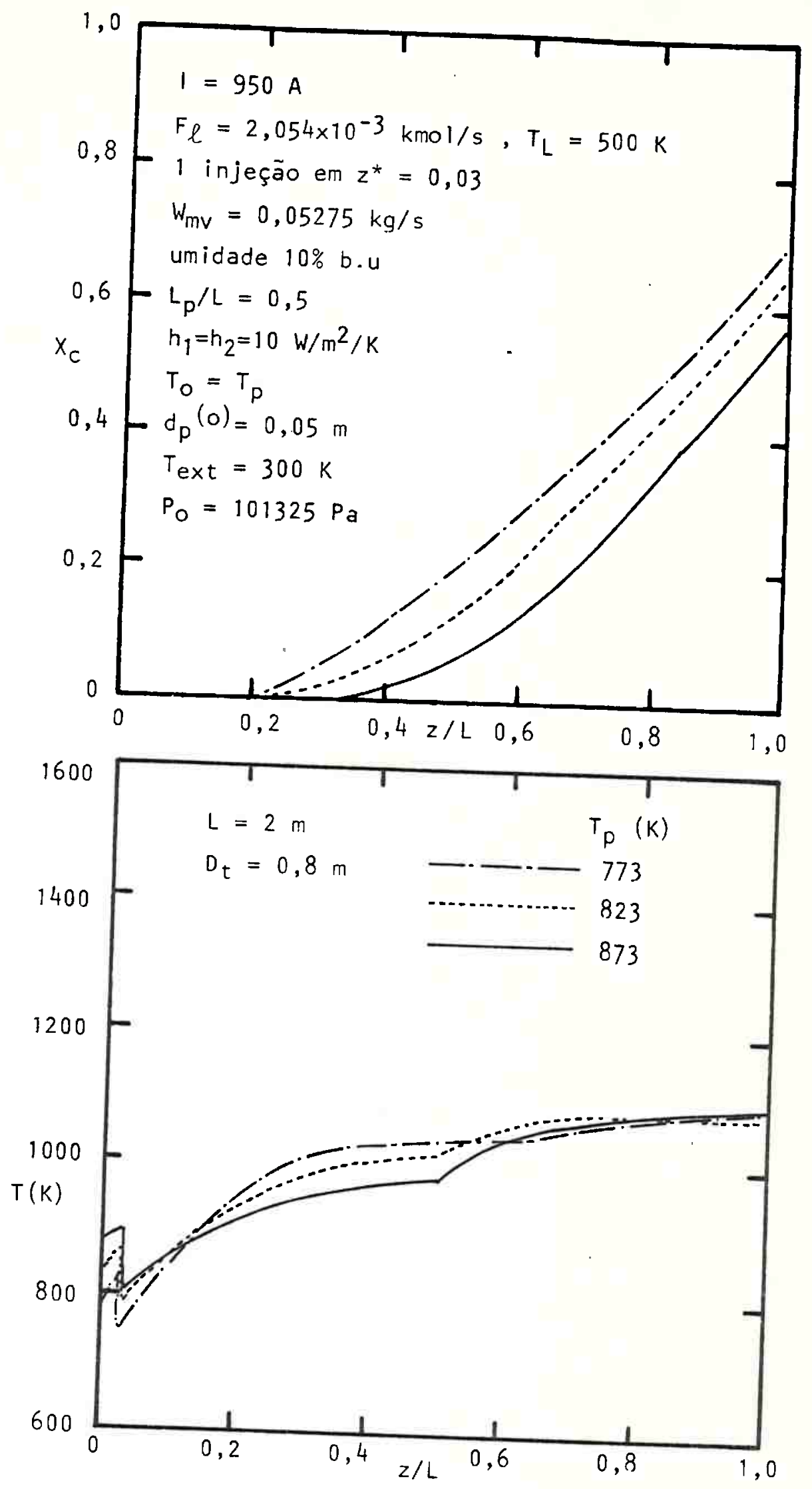

Fig. 6.2 - Influência da temperatura de pirölise sobre os perfis de temperatura e de conversão do "char" na região inter- 
rer uma retirada de calor para suprir a região de pirólise e se cagem è mostrada na figura 6.3. Observa-se que o perfil de tem peratura no trecho inicial do gaseificador é fortemente influen ciado pelo valor de $L_{p}$. Na parte final, a influência é muito pe quena.

A tabela 6.3 mostra que, para os casos simulados a influência de $L_{p}$ é pequena sobre a composição do gás e a con versão dos sólidos, mas é apreciável na tensão entre os eletrodos e, portanto, na curva elétrica.

\section{3 - COMPARAÇÃO de RESULTAdOS DA SIMULAÇÃO COM DAdOS EXPERIMEN TAIS}

Para verificar a validade do modelo apresentado nesta dissertação foram comparados seus resultados com dados ex perimentais dos gaseificadores eletrotérmicos G5 e G3 da CESP.

Os dados básicos referentes a operação tais como vazōes de processo, tipo de material, potência elétrica, composição do gäs produzido, características geométricas do gaseifí cador, foram obtidos nos relatörios CESP (1983), CESP (1984) e CESP (1985).

Alguns parâmetros do modelo foram estimados com base em informações contidas nestes relatórios; por exemplo, os coeficientes convectivos $h_{1}$ e $h_{2}$ foram estimados a partir das informações sobre perdas pelas paredes e perdas pelo eletrodo in ferior refrigerado.

Outros parâmetros foram ajustados para aproximar as previsōes do modelo aos dados experimentais. Este foi o caso do fator utilizado para multiplicar o valor da condutividade elétrica do leito calculada pela equação (3.7). O fator que me lhor se ajustou foi 0,8 . Este tambëm foi o caso da temperatura 


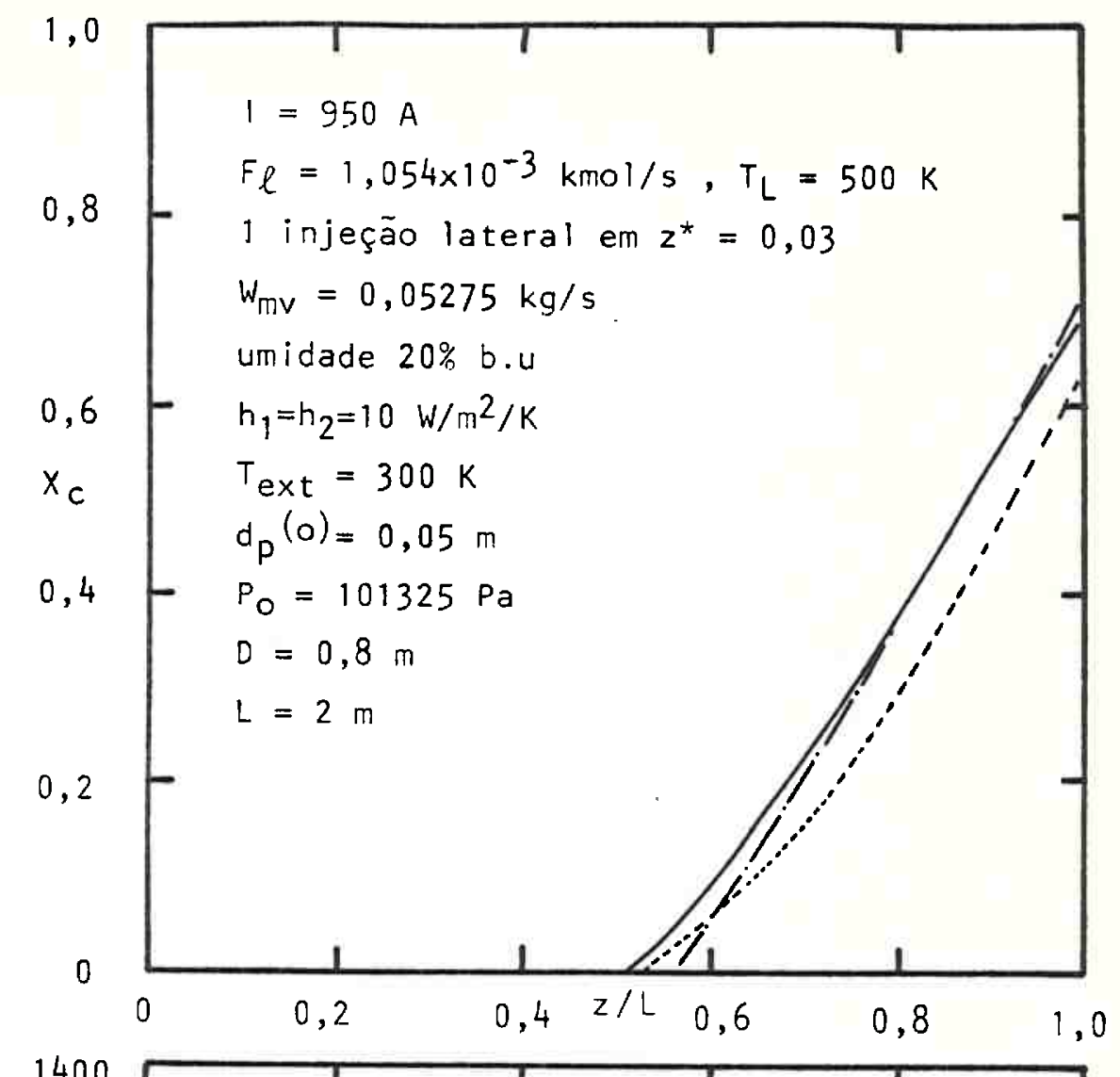

6.6

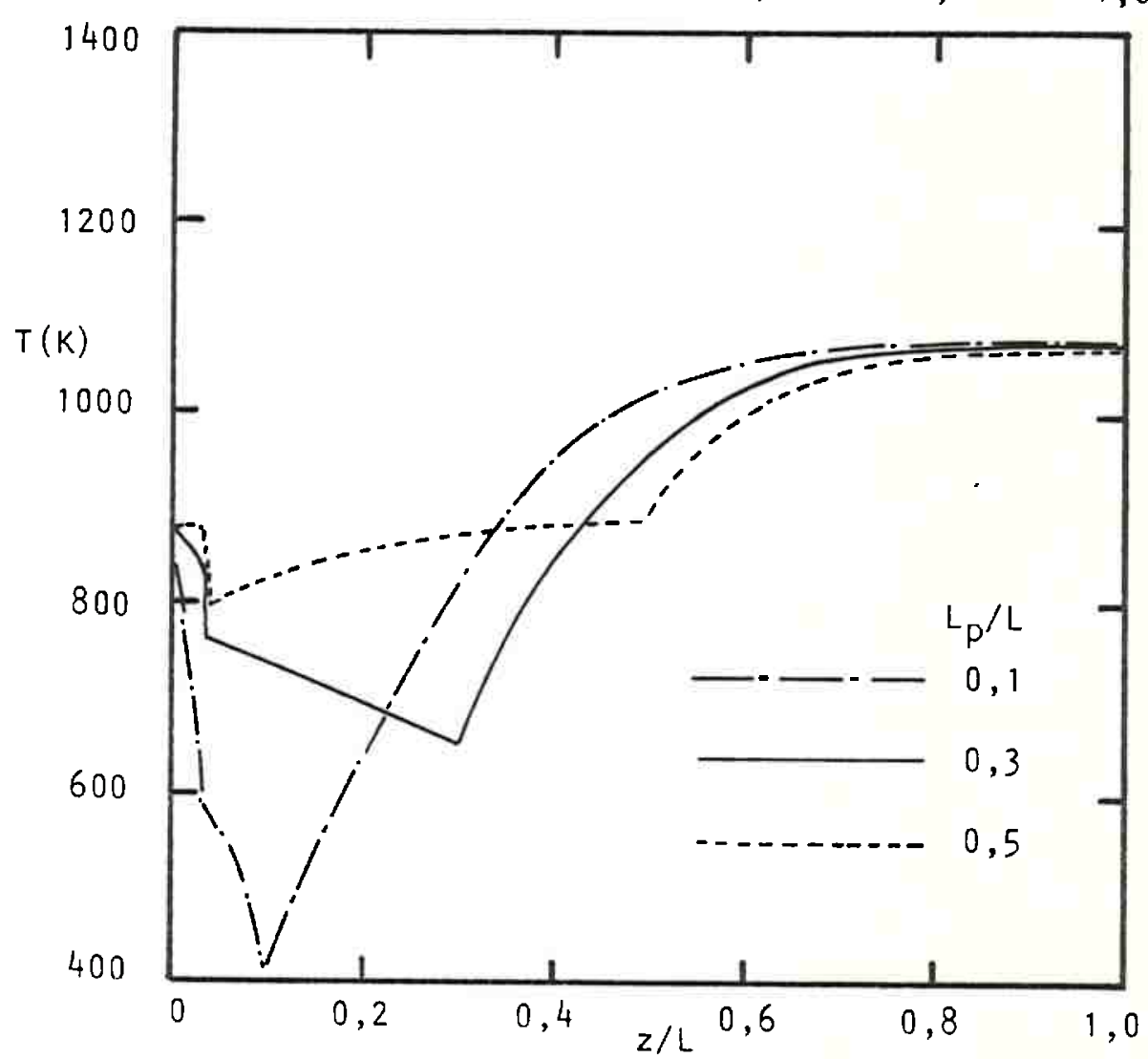

Fig. 6.3 - Influéncia do parämetro $L_{p}$ sobre os perfis de conversão e de temperatura do leito. 
TABELA 6.1 - Influència da umidade da madeira sobre alguns resultados da simulação (mesmas condições da figura 6.1).

\begin{tabular}{|cccccccc|}
\hline $\begin{array}{c}\text { Umidade da madeira } \\
(\%) \text { base úmida }\end{array}$ & $\begin{array}{c}U \\
(\mathrm{~V})\end{array}$ & $\begin{array}{c}\bar{T} \\
(\mathrm{~K})\end{array}$ & $\mathrm{y}_{\mathrm{H}_{2} \mathrm{O}}$ & $\mathrm{y}_{\mathrm{H}}^{\prime}$ & $\mathrm{y}_{\mathrm{CO}}^{\prime}$ & $\mathrm{y}^{\prime} \mathrm{CO}_{2}$ & $\mathrm{y}_{\mathrm{CH}_{4}}^{\prime}$ \\
\hline 0 & 257,8 & 1016 & 0,196 & 0,508 & 0,306 & 0,129 & 0,056 \\
10 & 262,6 & 990 & 0,221 & 0,511 & 0,191 & 0,142 & 0,055 \\
20 & 275,5 & 921 & 0,311 & 0,512 & 0,232 & 0,186 & 0,070 \\
\hline
\end{tabular}

TABELA 6.2 - Influência da temperatura de pirōlise sobre alguns resultados da simulação (mesmas condições da figura 6.2).

\begin{tabular}{|cccccccc|}
\hline $\begin{array}{c}\mathrm{T}_{p} \\
(\mathrm{~K})\end{array}$ & $\begin{array}{c}\mathrm{U} \\
(\mathrm{V})\end{array}$ & $\begin{array}{c}\overline{\mathrm{T}} \\
(\mathrm{K})\end{array}$ & $\mathrm{y}_{\mathrm{H}_{2} \mathrm{O}}$ & $\mathrm{y}_{\mathrm{H}_{2}}^{\prime}$ & $\mathrm{y}_{\mathrm{CO}}^{\prime}$ & $y_{\mathrm{CO}_{2}}^{\prime}$ & ${ }^{\prime} \mathrm{CH}_{4}$ \\
\hline 773 & 260,4 & 1003 & 0,220 & 0,465 & 0,287 & 0,157 & 0,091 \\
823 & 260,9 & 1000 & 0,217 & 0,487 & 0,292 & 0,248 & 0,073 \\
873 & 262,6 & 990,5 & 0,221 & 0,511 & 0,291 & 0,142 & 0,055 \\
\hline
\end{tabular}

TABELA 6.3 - Influência do parâmetro $L_{p}$ sobre alguns resultados da simulação (mesmas condições da figura 6.3).

\begin{tabular}{|llllllll|}
\hline$L_{p} / L$ & $U(V)$ & $\bar{T}(K)$ & $y_{\mathrm{H}_{2} \mathrm{O}}$ & $y_{\mathrm{H}_{2}}^{\prime}$ & $y_{\mathrm{CO}}^{\prime}$ & $y_{\mathrm{CO}_{2}}^{\prime}$ & $y^{\prime} \mathrm{CH}_{4}$ \\
\hline 0,1 & 279,7 & 911,9 & 0,229 & 0,507 & 0,287 & 0,148 & 0,058 \\
0,3 & 278,4 & 912,1 & 0,229 & 0,507 & 0,285 & 0,150 & 0,058 \\
0,5 & 270,1 & 950,5 & 0,249 & 0,509 & 0,272 & 0,158 & 0,061 \\
\hline
\end{tabular}


de pirólise, cujo valor estimado em $873 \mathrm{~K}$ (ou $973 \mathrm{~K}$ ) permite o aparecimento de $\mathrm{CH}_{4}$ nos gases de pirỏlise em proporções adequadas ao bom ajuste dos resultados do modelo.

Os resultados previstos pela simulação são compa rados com os dados experimentais na tabela 6.4, para três condi ções de operação. A primeira refere-se a dados gerais da 5ạ. campanha do G5, a segunda a um período de um dia de operação da mesma campanha e a terceira aos dados da la campanha do G3. Nes te ültimo caso a vazão de vapor não fora medida e o valor utili zado na simulação foi estimado.

Pode-se observar que as previsões do modelo concordam razoavelmente bem em termos de composição do gás seco produzido, vazão de gás, potência elëtrica, diferença de potencial entre os eletrodos. Os desvios entre as previsões do mode lo e os resultados experimentais são inferiores às flutuaçōes típicas de operação de experimentos deste porte e pode-se consi siderar que o ajuste foi satisfatório.

Na tabela 6.5 são apresentadas as comparações com dados de três outras campanhas: a $1 \stackrel{\text { a }}{\text {, } 2 \text { a e }} 3$ ? do 65 .

A primeira observação a ser feita sobre estes casos é que o valor da vazão média de madeira foi calculado cons derando-se o mesmo intervalo de tempo correspondente à geração de gás (na referência original, CESP (1984), os valores de vazão de madeira reportados são menores pois foram calculados so bre o tempo total da operação e não sobre o tempo de operação com geração de gās).

Utilizando os valores obtidos, os resultados da simulação apresentaram em relaçãoaos dados experimentais, desvios bem maiores que os casos da tabela 6.4. Embora alguns dos desvios apresentados pudessem ser explicados pelas flutuações das medidas experimentais, outros foram excessivos, por exemplo os de composição. 
TABELA 6.4 - Comparação dos resultados da simulação com dados experimentais

\begin{tabular}{|c|c|c|c|c|c|c|}
\hline gase ificador/campanha & \multicolumn{2}{|c|}{$65 / 5 a$} & \multicolumn{2}{|c|}{$G 5 / 5 b$} & \multicolumn{2}{|c|}{$\mathrm{G} 3 / 1$} \\
\hline 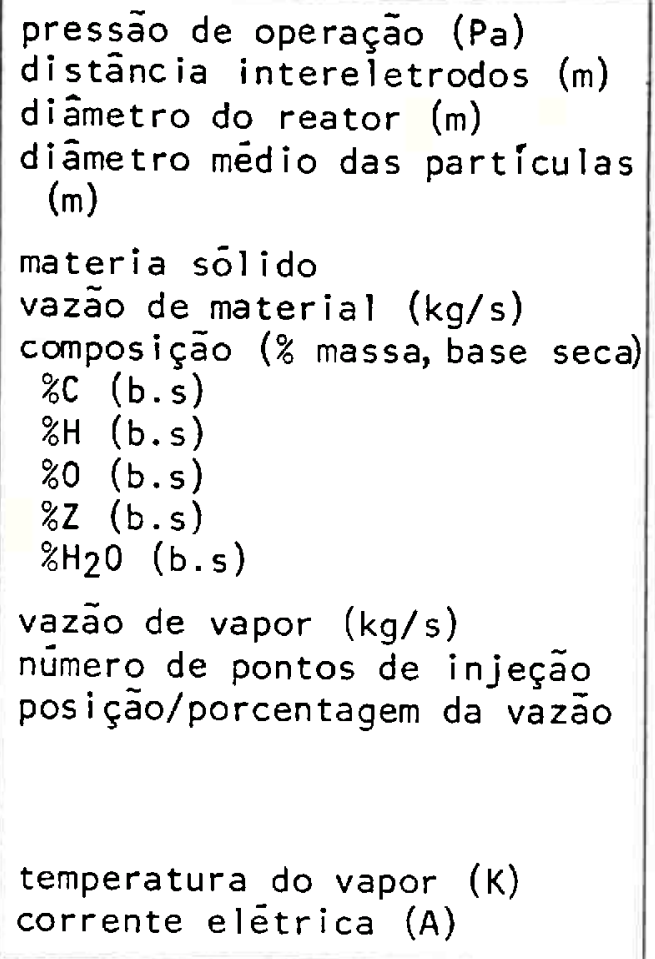 & $\begin{array}{c}49,80 \\
6,06 \\
43,54 \\
0,60 \\
20,0 \\
0,018 \\
4 \\
0,1 / 2 \\
0,3 / 2 \\
0,5 / 2 \\
0,7 / 2 \\
500 \\
989\end{array}$ & $\begin{array}{l} \\
\\
\\
97 \\
5 \% \\
5 \% \\
5 \% \\
5 \%\end{array}$ & $\begin{array}{c}49,80 \\
6,06 \\
43,54 \\
0,60 \\
20,0 \\
0,017 \\
4 \\
0,1 / 2 \\
0,3 / 2 \\
0,5 / 2 \\
0,7 / 2 \\
500 \\
1130\end{array}$ & $\begin{array}{l}7 \\
+ \\
56 \\
5 \% \\
5 \% \\
5 \% \\
5 \%\end{array}$ & $\begin{array}{l}(2,1 \\
- \\
(0,00 \\
2 \\
0,001 \\
0,300 \\
500 \\
(520)\end{array}$ & $\begin{array}{l}15058) \\
125 \% \\
/ 75 \%\end{array}$ \\
\hline $\begin{array}{l}\text { Parämetros } \\
\text { coeficiente convectivo } h_{1} \\
\text { (W/m²/K) } \\
\text { coeficiente convectivo } h_{2} \\
\text { (W/m²/K) } \\
\text { fator multiplicativo da con- } \\
\text { dutividade } \\
\text { temperatura de pirölise (K) } \\
\text { comprimento } L_{p} / L\end{array}$ & \multicolumn{2}{|l|}{$\begin{array}{l}8 \\
40 \\
0,8 \\
873 \\
0,5\end{array}$} & \multicolumn{2}{|l|}{$\begin{array}{l}8 \\
40 \\
\\
0,8 \\
873 \\
0,5\end{array}$} & \multicolumn{2}{|l|}{$\begin{array}{l}8 \\
40 \\
0,8 \\
-* \\
-*\end{array}$} \\
\hline Resultados & Exper. & Simul. & Exper. & Simul. & Exper. & Simul. \\
\hline $\begin{array}{l}\text { diferença de potencial (V) } \\
\text { potēncia elétrica }(\mathrm{kW}) \\
\text { vazäo de gäs seco }(\mathrm{Nm} 3 / \mathrm{h}) \\
\text { composiçäo do gäs }(\% \text { molar,b.s }) \\
\% \mathrm{H}_{2} \\
\% \mathrm{CO} \\
\% \mathrm{CO}_{2} \\
\% \mathrm{CH}_{4} \\
\% \text { outros } \\
\text { queda de pressão (Pạ) }\end{array}$ & $\begin{array}{l}326 \\
322,8 \\
261,7 \\
49,77 \\
34,87 \\
10,48 \\
3,44 \\
1,44 \\
50-600\end{array}$ & $\begin{array}{l}326,3 \\
322,7 \\
290,4 \\
50,1 \\
33,6 \\
11,3 \\
5,0 \\
- \\
42\end{array}$ & $\begin{array}{c}49,33 \\
35,63 \\
9,96 \\
3,35 \\
1,53 \\
50-500\end{array}$ & $\begin{array}{l}354,2 \\
400,2 \\
304,1 \\
48,4 \\
38,3 \\
8,2 \\
5,0 \\
- \\
117\end{array}$ & $\begin{array}{c}- \\
84,7 \\
45,6 \\
\\
52,14 \\
43,22 \\
2,11 \\
2,53 \\
- \\
-\end{array}$ & $\begin{array}{c}175,9 \\
91,46 \\
40,1 \\
52,2 \\
42,0 \\
5,5 \\
0,4 \\
- \\
-\end{array}$ \\
\hline
\end{tabular}

* não se utilizou o modelo de pirölise e secagem.

( ) valor estimado 
Entretanto, a vazão de vapor reportada não é uma medida exata. Sua medição era feita pela vazão de água que ali menta a caldeira; entretanto, eventualmente haviam purgas e des vios do vapor na linha entre a caldeira e o gaseificador. Logo, - valor reportado é apenas indicativo de um valor limite máximo, válido no caso de não ocorrer purgas de vapor.

Uma vez que as previsões de composição do gãs do modelo são sensiveis ao excesso ou falta de vapor, tentou-se re produzir as condições experimentais variando a vazão de vapor. Isto foi razoavelmente conseguido quando se tomou uma vazão de vapor menor que o valor máximo reportado, como pode ser observa do na tabela 6.5 .

Isto indica que, sendo o excesso de vapor um parâ metro ao qual o modelo ê sensível, uma comparação só pode ser feita corretamente se as vazões de madeira e especialmente a de vapor forem bem conhecidas.

Portanto, para uma validação mais segura do mode 10, é necessārio dispor de medidas experimentais mais apuradas, especialmente aquelas de maior influência sobre o modelo.

Na figura 6.4 são comparadas as curvas obtidas pe la simulação com os pontos ou nuvens de pontos experimentais pa ra as previsões de curva elëtrica do reator (tensão $x$ corrente) e curva de produção de gás x potência elétrica, onde se pode ob servar a aproximação dos resultados da simulação aos dados expe rimentais.

\section{4 - estudo de um CASO: PREVisão de Aumento de produção de Ga- SES}

Para ilustrar a utilização dos resultados prevista pelo modelo foi feita uma comparação dos resultados da simú 


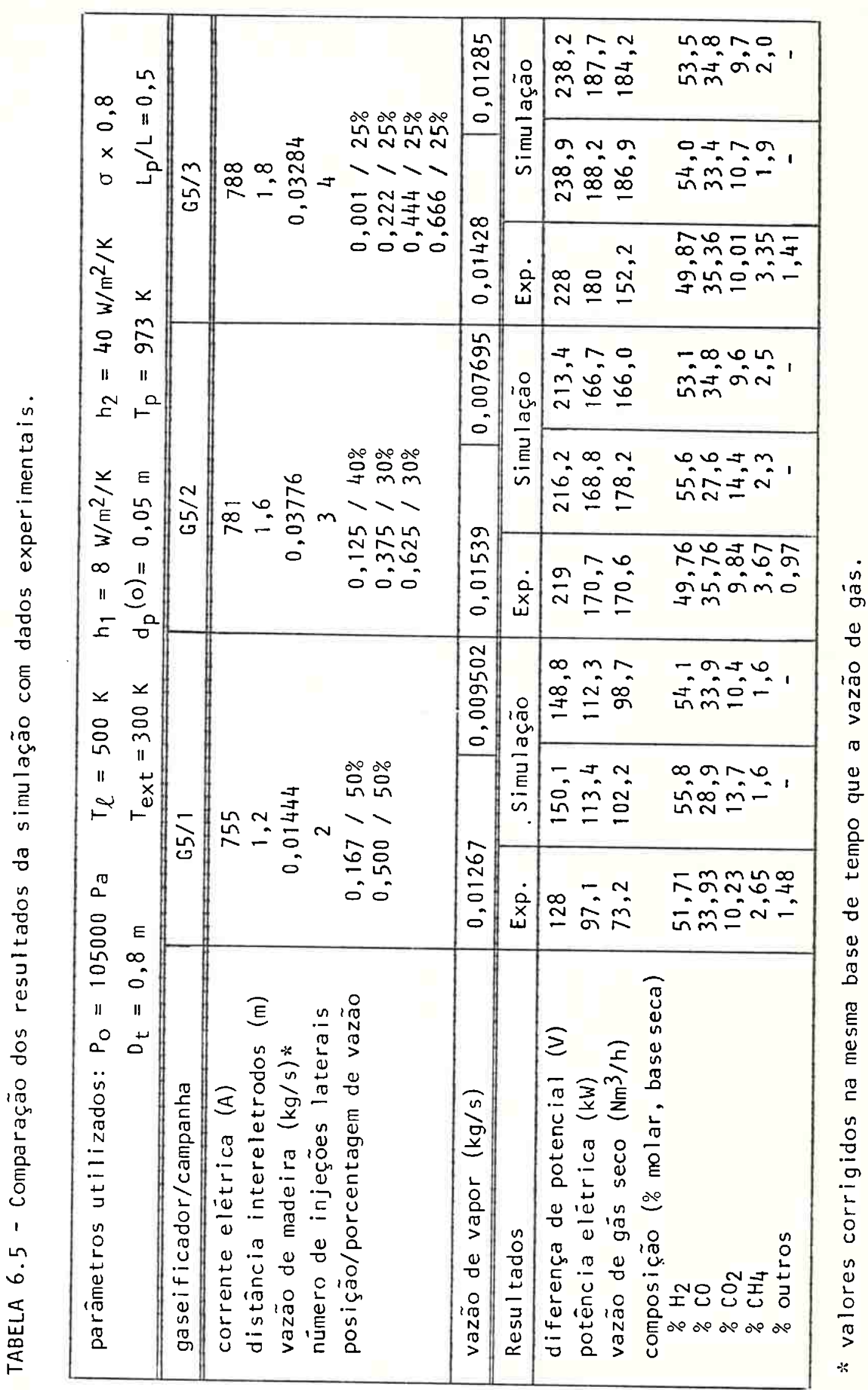




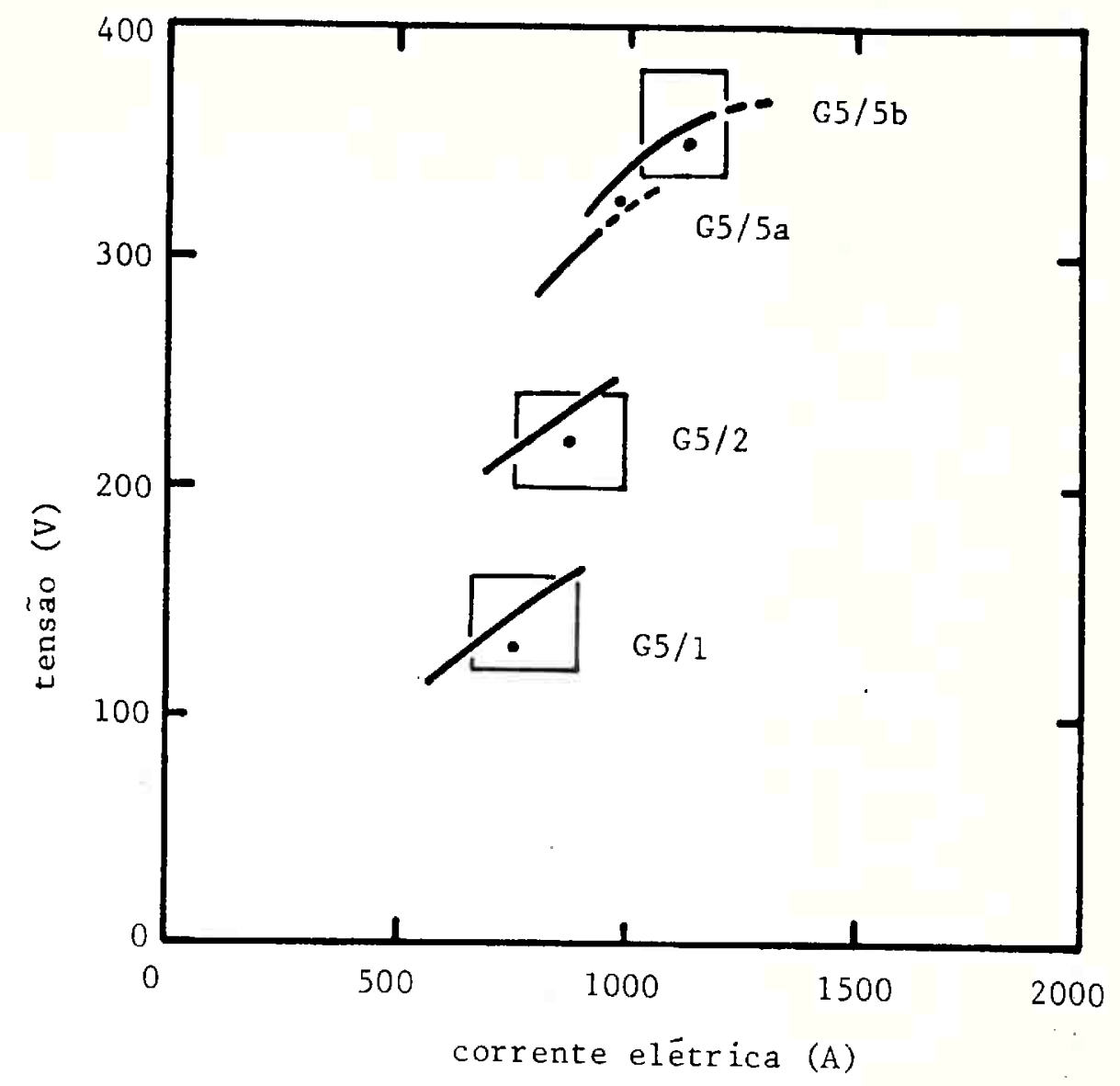

6.12

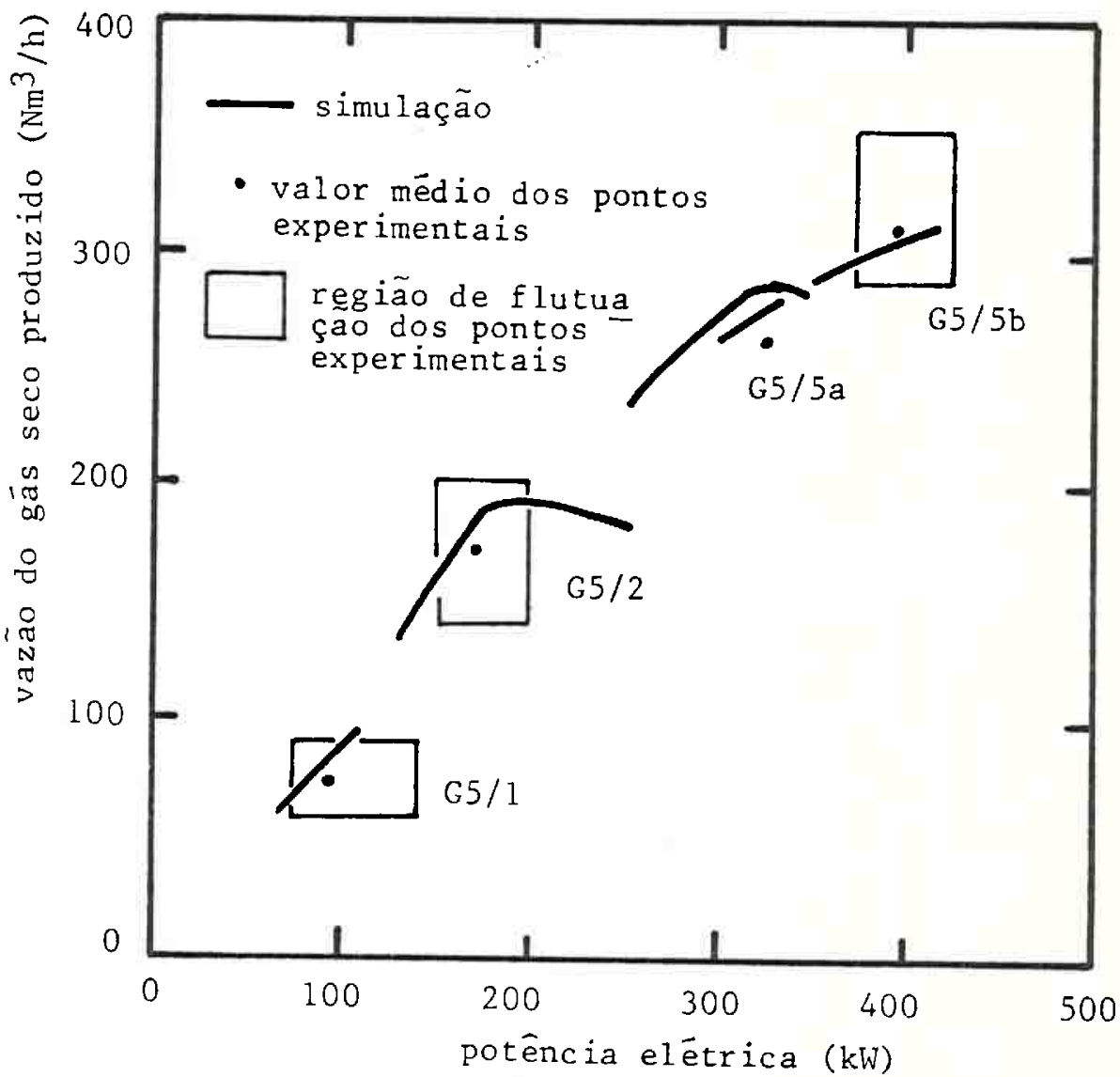

Fig. 6.4 - Comparação das previsões do modelo com dados expe rimentais (condiçoes mesmas das Tabelas 6.4 : 6.5 ). 
lação da 5 a campanha do 65 com os da simulação de um caso simí lar, mas com o dobro da vazão de madeira sendo processada.

Os resultados são mostrados na tabela 6.6. Pelas previsões do modelo, aumentando-se a vazão de madeira, mantida a mesma vazão de vapor e corrente elétrica, diminui a conversão de sólido, mas aumenta substancialmente a vazão de gás, a compo sição terá maior teor de $\mathrm{CO}_{2}$ e $\mathrm{CH}_{4}$ que o caso base e menor teor de CO, porém com praticamente o mesmo poder calorifico. A vazão de "char" não convertido tambëm serä maior.

Os resultados prevêem, portanto, a possibilidade de aumentar a produção de gases sem aumentar substancialmente a potência elêtrica, resultando, contudo, uma maior produção de "char" não gaseificado.

Evidentemente estas previsões não devem ser toma das dissociadas das limitações do modelo matemático. A principal delas refere-se à hipōtese de equilíbrio químico na região de pirólise, implicando no fato de cerca de 70 e $80 \%$ da massa da madeira alimentada ser convertida em gảs jā nesta região. Na região intereletrodos a massa de sólidos restante é gaseificada e a composição do gãs obtido ē alterada em função das reações químicas consideradas. 0 modelo prevê, dessa forma, que aprox madamente metade da vazāo molar de gảs seco produzido é oriundo da região de pirólise.

E esperado que essa situação, na prática, somente deva ocorrer para tempos de residência do sôlido na região de pirólise suficientemente grandes, altas temperaturas, e partícu las pequenas, de modo que a particula como um todo possa ser aquecida e pirolisada, que os volāteis possam ser craqueados e que o equilibrio possa ser atingido.

0 modelo aqui apresentado, devido as suas limitações, não prevê a distância que a madeira deve percorrer para 
TABELA 6.6 - Estudo de um caso em que se dobra a vazão de madeira.

\begin{tabular}{|c|c|c|}
\hline pressão de operação $(\mathrm{Pa})$ & 105000 & \\
\hline distāncia intereletrodos (m) & 2,0 & \\
\hline diāmetro do reator (m) & 0,8 & \\
\hline diâmetro mēdio das partículas (m) & 0,05 & \\
\hline vazão de madeira $(\mathrm{kg} / \mathrm{s})$ & 0,05275 & 0,1055 \\
\hline $\begin{array}{ll}\% & \mathrm{C} \\
\% & \mathrm{H} \\
\% & \mathrm{O} \\
\% & \mathrm{Z} \\
\% & \mathrm{H}_{2} \mathrm{O}\end{array}$ & $\begin{array}{r}49,80 \\
6,06 \\
43,54 \\
0,60 \\
20\end{array}$ & \\
\hline vazão de vapor $(\mathrm{kg} / \mathrm{s})$ & 0,01897 & \\
\hline número de pontos de injeção & 4 & \\
\hline posição adimensional e & $\begin{array}{l}0,1 / 25 \% \\
0,3 / 25 \%\end{array}$ & \\
\hline fração da vazão das injeções & $\begin{array}{l}0,5 / 25 \% \\
0,7 / 25 \%\end{array}$ & \\
\hline temperatura do vapor (K) & 500 & \\
\hline corrente elëtrica (A) & 989 & \\
\hline coeficiente $h_{1}\left(W / \mathrm{m}^{2} / \mathrm{K}\right)$ & 8 & \\
\hline coeficiente $h_{2}\left(W / m^{2} / K\right)$ & 40 & \\
\hline $\begin{array}{l}\text { fator multiplicativo da conduti- } \\
\text { vidade eletrica }\end{array}$ & 0,8 & \\
\hline temperatura de pirōlise (K) & 873 & \\
\hline tensão $(V)$ & 326,3 & 333,6 \\
\hline $\begin{array}{l}\text { vazão de gās seco }(\mathrm{kmol} / \mathrm{s}) \\
\% \mathrm{H}_{2} \\
\% \mathrm{CO} \\
\% \mathrm{CO}_{2} \\
\% \mathrm{CH}_{4}\end{array}$ & $\begin{array}{l}3,601 \times 10^{-3} \\
50,1 \\
33,6 \\
11,3 \\
5,0\end{array}$ & $\begin{array}{l}5,600 \times 10^{-3} \\
49,1 \\
27,4 \\
15,7 \\
7,8\end{array}$ \\
\hline fração molar $\mathrm{H}_{2} \mathrm{O}$ & 16,8 & 25,6 \\
\hline poder calorífico do gás $(\mathrm{J} / \mathrm{kmol})$ & $2,542 \times 10^{8}$ & $2,569 \times 10^{8}$ \\
\hline conversão de "char" & 0,979 & 0,332 \\
\hline vazão de "char" ( $\mathrm{kg} / \mathrm{s})$ & $2,2653 \times 10^{-4}$ & $1,9519 \times 10^{-3}$ \\
\hline vazão de cinzas $(\mathrm{kg} / \mathrm{s})$ & $2,6526 \times 10^{-4}$ & $5,3052 \times 10^{-4}$ \\
\hline temperatura média do leito $(K)$ & 1056 & 1025 \\
\hline potência elétrica (kW) & 322,7 & 330,0 \\
\hline
\end{tabular}


ser completamente carbonizada. Assim para o aumento da vazão de madeira, necessitaria ser estudada a possibilidade de entrada de madeira não carbonizada na região intereletrodos.

\section{5 - DISCUSSÃO}

Os resultados obtidos com o modelo matemätico estão limitados pelas hipöteses adotadas no seu equacionamento. Apesar da concordância com dados experimentais ter sido razoavelmente estabelecida, os resultados devem ser interpretados muito mais quanto ao aspecto qualitativo do que quantitativo.

Deve-se reconhecer que em uma série de pontos do modelo foram estabelecidos procedimentos simplificados, nos quais há necessidade de um maior refinamento do modelo. os prin cipais são comentados a seguir.

0 modelo apresenta dois parâmetros importantes cujos valores,porém, são difíceis de serem estimados a priori: a tempe ratura de pirólise e o comprimento $L_{p}$ sobre o qual a carga térmica da pirölise atua sobre a região intereletrodos.

E necessário empregar um outro modelo para a re gião de pirólise e secagem. 0 modelo macroscópico de equilibrio adotado para esta região apresenta aplicação restrita, pois representa apenas uma condição limite, correspondente a tempos de residencia elevados e altas temperaturas. E desejâvel que o modelo para a pirôlise considere os : processos físicos e químicos fundamentais tais como transferência de calor para a par tícula e cinëtica das reações químicas envolvidas, de modo a se prever corretamente o grau de carbonização e a distribuição (va zões) dos produtos resultantes, que entram na região intereletrodos.

Para o estabelecimento de um modelo mais elabora- 
do para a pirólise, certamente serå necessārio rever as hipóte ses aqui adotadas; por exemplo, a condução de calor e as diferenças entre as temperaturas das fases sólida e gasosa são possivelmente importantes na região de pirỏlise e não poderão ser desprezadas como fora feito no modelo para a região intereletro dos.

De qualquer maneira a maior dificuldade para o es tabelecimento de um modelo mais elaborado para a pirólise está no pouco conhecimento existente sobre este processo. Assim, se ria recomendävel um estudo a nivel experimental capaz de conhecer melhor o processo de pirölise e obter informações necessá rias para um modelo matemático mais confiável.

0 modelo de injeção lateral è também bastante sim plificado pois foi elaborado de maneira a ser adaptado ao modelo diferencial unidimensional. Entretanto, um modelo mais ela borado para este ponto possivelmente envolveria passar a modelos bidimensionais, e com isso elevar substancialmente o esforço computacional para a obtenção dos resultados, talvez sem um ganho substancial de informações.

Um parâmetro que mostrou ser muito importante nos resultados é a condutividade elétrica do leito. Este parâmetro precisou ser ajustado para que o modelo oferecesse melhores pre visōes. Uma vez que o conhecimento sobre a condutividade elétrica de leitos de carvão é pequeno, e muito pouco se sabe sobre resistência de contato entre o eletrodo e um leito móvel (fato este não considerado no modelo) o procedimento de ajustar o valor de $\sigma$ parece ter sido adequado. Porém maior conhecimen to experimental destes parâmetros seria desejāvel. 


\section{CAPITULO 7}

\section{CONCLUSOES}

0 modelo matemático apresentado representa

uma

contribuição à modelagem de gaseificadores eletrotērmicos

leito móvel concorrente, no sentido da previsão do comportamen to elétrico do reator, da vazão e composição do gás gerado.

A partir do estudo feito nesta dissertação, obtive ram-se as seguintes conclusões:

a) as previsões da simulação para a curva elétrica caracteristica do reator eletrotērmico são sensiveis aos se guintes parâmetros: condutividade elêtrica do leito, diâmetro e comprimento da região intereletrodos, coeficiente efetivo de transmissão de calor para o exterior, distribuição da vazão de vapor pelos pontos de injeção lateral;

b) as vazões de gảs e de sólido na região intereletrodos e a pressão apresentam, pela simulação, influência sig nificativa sobre a conversão do sólido;

c) as previsōes de composição do gâs são influenciadas prin cipalmente pelas vazões de madeira e vapor e pela corrente elétrica;

d) o metano e produzido principalmente durante a pirólise, sendo pequena sua produção na região intereletrodos;

e) volāteis pesados (alcatrões e pirolenhosos) gerados na pirölise são produtos de não-equilíbrio;

f) a condutividade elêtrica dos leitos nos gaseificadores 
eletrotêrmicos parece ser cerca de $20 \%$ menor que o valor previsto pelas correlações da literatura;

g) o modelo proposto permitiu uma representação razoável do comportamento dos gaseificadores reais, no tocante à previsão da curva elétrica caracteristica e da produ ção e composição do gảs.

Como sugestões para a continuação deste trabalho, pode-se citar as seguintes:

- procurar eliminar as limitações do modelo para a piróli se, procurando um modelo mais elaborado capaz de prever a distribuição de produtos e o grau de conversão da pirölise, em função dos processos fundamentais de transfé rência de calor entre as regiões do gaseificador;

- levantamento de dados de operação dos gaseificadores de modo a permitir uma verificação mais exata das previsões do mode1o;

- levantamento experimental de operação dos gaseificadores sob novas condições previstas pelo modelo; por exem plo, verificação do caso estudado no item 6.4 , operando com vazões maiores de madeira e utilizando pedaços meno res;

- elaboração de um modelo matemātico unidimensional dinâmico para o estudo do controle do processo. 


\section{APENDICE A \\ EXPRESSAOO DA TAXA DE REAÇAO GAS-SÓLIDO \\ PELO MODELO DE NOCLEO EXPOSTO}

Considerando-se uma partícula de material sólido e um gás reagente $i$ reagindo entre si e formando produtos gasosos de acordo com o modelo de núcleo exposto, pode-se mostrar como se obtém a expressão para a taxa de reação.

São adotadas as seguintes hipöteses:

- partícula esfërica

- regime pseudo-estacionário (retração lenta do diâmetro da particula)

- reação de lạ ordem em relação ao gãs i.

A taxa de consumo do gảs i por unidade de volume de sólido junto à superfície externa da partícula pode ser expressa em função da transferência de massa desde a região ao longe (pressão parcial $\mathrm{p}_{i}$ ) ate a superfície (pressão parcial $\mathrm{p}_{\mathrm{S}}$ ) da particula:

$$
r^{\prime}=k_{p_{i}} a\left(p_{i}-p_{i_{s}}\right)
$$

A mesma taxa pode ser expressa em função da cinētica da reação química entre o sólido e o gâs:

$$
r^{\prime}=n_{j} \quad k_{r_{j}} d_{C}^{(0)} p_{i_{S}}
$$

onde supôs-se a reação de 1ạ ordem em relação ao gás i. o fator de efetividade $n_{j}$ leva em conta o efeito da difusão interna nos poros e reação dentro da partícula. 
Das equaçōes (A.1) e (A.2) tem-se:

$$
\begin{aligned}
& \frac{r^{\prime}}{k_{p_{i}} a}=p_{i}-p_{i_{s}} \\
& \frac{r^{\prime}}{\eta_{j} k_{r_{j}} c_{c}^{(b)}}=p_{i_{s}}
\end{aligned}
$$

que combinadas dão a expressão para a taxa por unidade de volume de partícula sölida:

$$
r^{\prime}=\frac{p_{i}}{\frac{1}{k_{p_{i}} a}+\frac{1}{\eta_{j} k_{r_{j}} C_{C}^{(b)}}}
$$

A ārea específica da partícula esférica é:

$$
a=\frac{\text { superficie externa }}{\text { volume }}=\frac{\pi d_{p^{2}}}{\frac{\pi}{6} d_{p}{ }^{3}}=\frac{6}{d_{p}}=\frac{6}{d_{p} f_{r}}
$$

onde $f_{r}$ é a relação entre o diâmetro da partícula em dado instan te e o diâmetro inicial da partícula.

A taxa de reação por unidade de volume de reator $\dot{\mathrm{e}}$

$$
r=\left(1-\varepsilon_{\ell}\right) r^{\prime}
$$

Combinando as equações (A.5), (A.6) e (A.7) chegase a:

$$
r=\frac{\left(1-\varepsilon_{\ell}\right) p_{i}}{\frac{d_{p}^{o} f_{r}}{6 k_{p_{i}}}+\frac{1}{n_{j} k_{r_{j}} C_{C}^{(b)}}}
$$


Sendo a reação reversível, pode-se utilizar uma força motriz conveniente que represente a limitação da taxa de reação pelo equilíbrio químico:

$$
r=\frac{\left(1-\varepsilon_{l}\right)\left(p_{i}-p_{i e q}\right)}{\frac{d_{p}^{o} f_{r}}{6 k_{p_{i}}}+\frac{1}{n_{j} k_{r_{j}} c_{c}^{(0)}}}
$$




\section{APENDICE B \\ PROPRIEDADES FISICAS E TERMODINAMICAS}

\section{a) DENSIDADE DA MISTURA GASOSA}

Uma vez que os gaseificadores eletrotërmicos operam sob pressões próximas à atmosférica e temperaturas relativa mente elevadas, pode-se utilizar a equação de estado do gás ideal para o cảlculo da densidade da mistura gasosa:

$$
\rho_{g}=\frac{P M_{g}}{R_{g} T}
$$

onde $\mathrm{Mg}_{\mathrm{e}}$ a massa molecular média dos gases:

$$
M_{g}=\sum_{i=1}^{5} M_{i} y_{i}
$$

\section{b) CALOR ESPECIFICO DOS GASES}

Na literatura são encontradas värias equações para o cálculo do calor específico dos gases a pressão constante para gâs ideal [Reid et alii (1977), Yaws et alii (1976), Peisheng et alii (1982) e outros].

Neste trabalho adotou-se a correlação na forma:

$$
c_{p_{i}}=c_{c_{i}}+c_{b_{i}} T+c_{c_{i}} T^{-2}+c_{d_{i}} T^{2}
$$

apresentada por Barin e Knache (1973) e também por Karapetyans (1978). Esta correlação apresenta validade em faixas mais amplas de temperatura que outras correlaçōes existentes na litera tura. 
As constantes utilizadas para cada espécie, dadas na tabela B.1, foram tiradas de Karapetyans (1978).

Para o cálculo do calor específico da mistura gasosa utilizou-se a ponderação em relação à fração molar de cada gás

$$
c p_{g}=\sum_{i=1}^{5} y_{i} \quad c_{p_{i}}
$$

\section{c) CALOR ESPECIFICO DO CARVÃO}

Considerou-se o sólido (carvão) como constituído de "char" e cinzas. Para o "char" utilizou-se o calor específi co do carbono e para as cinzas admitiu-se o calor específico do oxido de silício, que é um de seus principais componentes. A dependência do calor específico com a temperatura segue a equação (B.3), com as constantes dadas na tabela B.1, tiradas de Karapetyans (1978).

o calor especifico do sólido foi obtido por ponde ração pelas frações mássicas destes componentes:

$$
c_{p_{s}}=x_{\text {char }} c_{p_{\text {char }}}+x_{\text {cinza }} c_{p_{\text {cinza }}}
$$

\section{d) CALOR ESPECTFICO DA MADEIRA E UMIDADE}

Para a madeira, o calor específico à temperatura ambiente é da ordem de $2500 \mathrm{~J} / \mathrm{kg} / \mathrm{K}$, conforme Chan et alii (1984).

Para a umidade da madeira (água, estado 1íquido) o calor específico à temperatura ambiente é da ordem de 4186 $\mathrm{J} / \mathrm{kg} / \mathrm{K}$. 


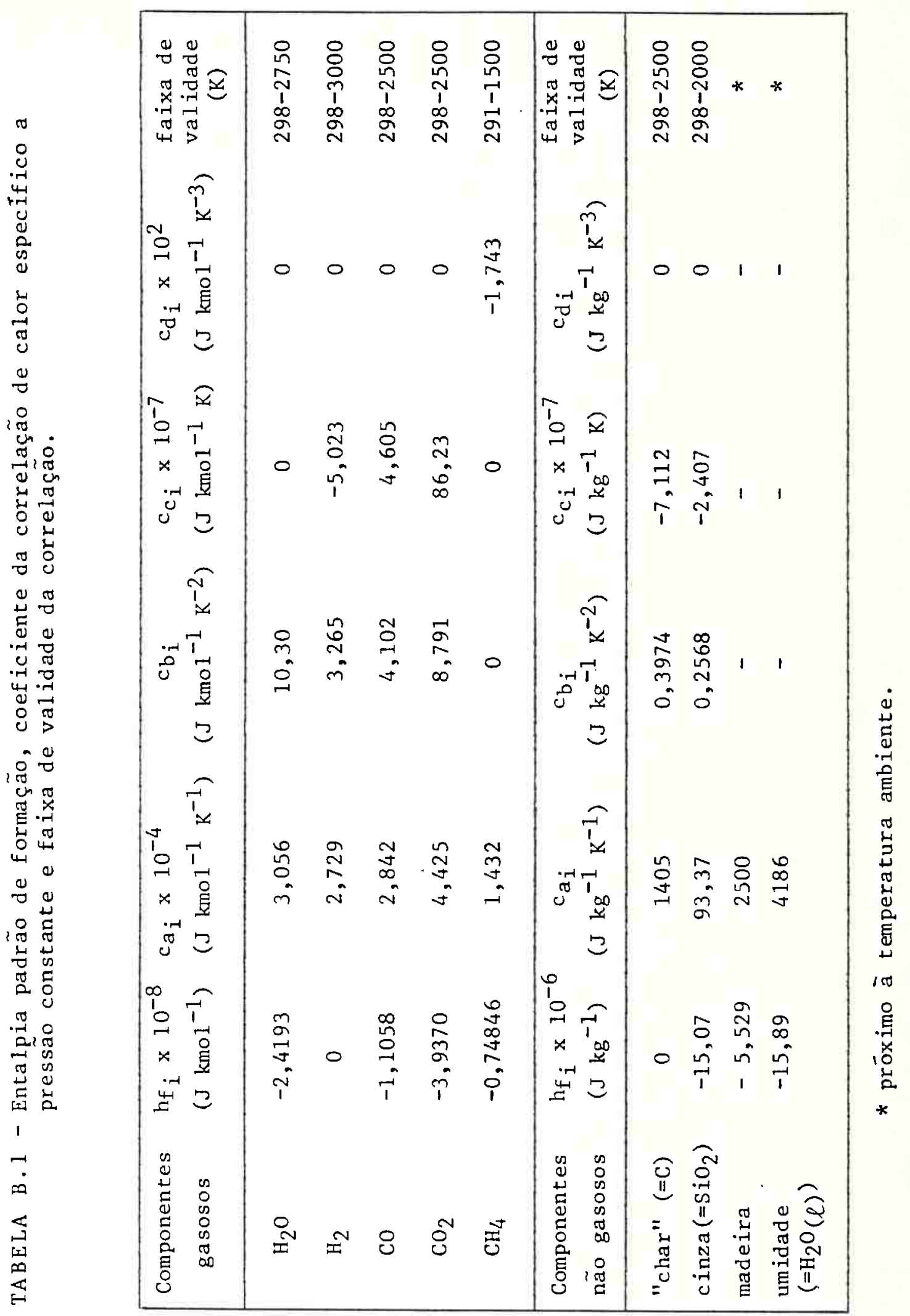




\section{e) ENTALPIA DAS SUBSTÁNCIAS}

A entalpia è calculada pela expressão:

$$
h_{i}=h_{f_{i}}+\int_{298}^{T} c p_{i} d T
$$

onde $h_{f_{i}} \bar{e}$ a entalpia de formação padrão da substância i.

os valores de $h_{O_{i}}$ estão apresentados na tabela B.1.

A entalpia de formação da madeira (seca) foi calculada a partir do valor de seu poder calorifico, como mostrado a seguir.

A combustão da madeira seca pode ser representada por

$$
\mathrm{CH}_{\alpha} \mathrm{O}_{\beta(\mathrm{s})}+\left(\frac{2+\alpha / 2-\beta}{2}\right) \mathrm{O}_{2(\mathrm{~g})} \rightarrow \mathrm{CO}_{2}(\mathrm{~g})+(\alpha / 2) \mathrm{H}_{2} \mathrm{O}(\ell)
$$

onde

$$
\begin{aligned}
\Delta \mathrm{H}_{\mathrm{Comb}} & =-\mathrm{pCS}=\mathrm{h}_{\mathrm{f}_{\mathrm{CO}_{2}}(\mathrm{~g})}+(\alpha / 2) \mathrm{h}_{\mathrm{f}_{\mathrm{H}_{2} \mathrm{O}}(\ell)}-\mathrm{h}_{\mathrm{f}_{\mathrm{mad}}}- \\
& -\left(\frac{2+\alpha / 2-\beta}{2}\right) h_{\mathrm{f}_{\mathrm{O}_{2}}}
\end{aligned}
$$

Lembrando que $h_{\mathrm{f}_{2}}=0$ e que, da tabela $5.1 \alpha=1,461$, $\beta=0,654$ e PCS $=1,937 \times 10^{7} \mathrm{~J} / \mathrm{kg}$, obtém-se

$$
\mathrm{h}_{f_{\mathrm{mad}}}=-5,469 \times 10^{6} \mathrm{~J} / \mathrm{kg}
$$

ou em base isenta de cinza: 


$$
h_{f_{\text {mad }}}=\frac{-5,469 \times 10^{6}}{1-0,006}=-5,529 \times 10^{6} \mathrm{~J} / \mathrm{kg} \text { mad.seca sem cinza }
$$

\section{f) ENTALPIA DE REAÇÃO}

A entalpia de cada reação poderia ser calculada por:

$$
\Delta H_{j}=\sum_{i=1}^{5} v_{i j} h_{i}
$$

Lembrando que $h_{i}$ é calculado pela equação (B.6) e $c_{p_{i}}$ pela equação $(B, 3)$, pode-se obter uma expressão polinomial para $\Delta H_{j}$.

$$
\Delta H_{j}=h_{a_{j}}+h_{b_{j}} T+h_{c_{j}} T^{2}+h_{d_{j}} T^{-1}+h_{e_{j}} T^{3}
$$

$$
\text { As constantes envolvidas na equação acima foram }
$$

calculadas supondo o "char" como carbono simplesmente, e são apresentadas na tabela B.2.

\section{g) VISCOSIDADE DA MISTURA GASOSA}

A viscosidade de cada uma das espécies gasosas foi calculada pela correlação empírica [Yaws et alii (1976)]

$$
\mu_{i}=\mu_{a_{i}}+\mu_{b_{i}} T+\mu_{c_{i}} T^{2}
$$

e as constantes para cada espécie são dadas na tabela B.3.

A viscosidade da mistura gasosa foi obtida pela 
TABELA B. 2 - Constantes para o cálculo das entalpias de reação.

\begin{tabular}{|lccccc|}
\hline \multicolumn{1}{|c}{ Reação } & $\begin{array}{c}\mathrm{h}_{\mathrm{aj}} \times 10^{-8} \\
\left(\mathrm{~J} \mathrm{kmol}^{-1}\right)\end{array}$ & $\begin{array}{c}\mathrm{h}_{\mathrm{b}_{\mathrm{j}} \times 10^{-4}} \\
\left(\mathrm{~J} \mathrm{kmol}^{-1} \mathrm{~K}^{-1}\right)\end{array}$ & $\begin{array}{c}\mathrm{h}_{\mathrm{c}} \\
\left(\mathrm{J} \mathrm{kmol}^{-1} \mathrm{~K}^{-2}\right)\end{array}$ & $\begin{array}{c}\mathrm{h}_{\mathrm{d}} \times 10^{9} \\
\left(\mathrm{~J} \mathrm{kmol}^{-1} \mathrm{~K}\right)\end{array}$ & $\begin{array}{c}\mathrm{h}_{\mathrm{ej}} \times 10^{+3} \\
\left(\mathrm{~J} \mathrm{kmol} \mathrm{k}^{-3}\right)\end{array}$ \\
\hline $\mathrm{C}+\mathrm{H}_{2} \mathrm{C} \rightarrow \mathrm{CO}+\mathrm{H}_{2}$ & 1,321 & 0,8288 & $-3,851$ & $-0,8581$ & 0 \\
$\mathrm{C}+\mathrm{CO}_{2} \rightarrow 2 \mathrm{CO}$ & 1,795 & $-0,4270$ & $-2,679$ & $-1,6241$ & 0 \\
$\mathrm{C}+2 \mathrm{H}_{2} \rightarrow \mathrm{CH}_{4}$ & $-0,5795$ & $-5,7131$ & 31,698 & $-0,7535$ & $-5,812$ \\
$\mathrm{CO}+\mathrm{H}_{2} \mathrm{O} \rightarrow \mathrm{CO}_{2}+\mathrm{H}_{2}$ & $-0,4740$ & 1,2558 & $-1,172$ & $-0,7660$ & 0 \\
\hline
\end{tabular}

TABELA B. 3 - Coeficientes e faixa de validade da correlação de viscosidade dos gases a baixa pressão.

\begin{tabular}{|ccccc|}
\hline componente & $\begin{array}{c}\mu_{\mathrm{a}_{\mathrm{i}} \times 10^{5}} \\
\left(\mathrm{~kg} \mathrm{~m} \mathrm{~m}^{-1}\right)\end{array}$ & $\mu_{\mathrm{b}_{\mathrm{i}} \times 10^{7}}$ & $\mu_{\mathrm{c}_{\mathrm{i}} \times 10^{13}}$ & $\begin{array}{c}\text { faixa de } \\
\text { validade } \\
\left(\mathrm{kg} \mathrm{m} \mathbf{1}^{-1} \mathrm{~K}^{-1}\right)\end{array}$ \\
\hline $\mathrm{H}_{2} \mathrm{O}$ & $-31,89$ & 41,45 & $-8,272$ & $273-1273$ \\
$\mathrm{H}_{2}$ & 21,87 & 22,20 & $-37,51$ & $113-1473$ \\
$\mathrm{CO}^{-1}$ & 32,28 & 47,47 & $-96,48$ & $73-1673$ \\
$\mathrm{CO}_{2}$ & 25,45 & 45,49 & $-86,49$ & $173-1673$ \\
$\mathrm{CH}_{4}$ & 15,96 & 34,39 & $-81,40$ & $193-1273$ \\
\hline
\end{tabular}


seguinte ponderação [Reid et alii (1977)]

$$
\mu=\sum_{i} \frac{y_{i} \mu_{i}}{\sum_{i} y_{k} \psi_{i k}}
$$

onde

$$
\psi_{i k}=\frac{\left[1+\left(\mu_{i} / \mu_{k}\right)^{1 / 2}\left(M_{k} / M_{j}\right)^{1 / 4}\right]^{2}}{\left[8\left(1+M_{i} / M_{k}\right)\right]^{1 / 2}}
$$

h) DENSIdAde aparente do Leito E Fraçáo de Vazios do leito DAS PARTICULAS

Os seguintes valores para densidade aparente do leito, fração de vazios do leito e fração de vazios da partícula de "char" foram utilizados na simulação:

$$
\begin{aligned}
& \rho_{\ell}=280 \mathrm{~kg} / \mathrm{m}^{3} \\
& \varepsilon_{\ell}=0,5 \\
& \varepsilon_{c}=0,3
\end{aligned}
$$




\title{
APENDICE C
}

\section{PROGRAMA DE COMPUTADOR GAS/ELET}

\author{
a) Listagem do Programa de Computador
}

E apresentada a seguir a listagem do programa con tendo o programa principal, as subrotinas e funçōes auxiliares.

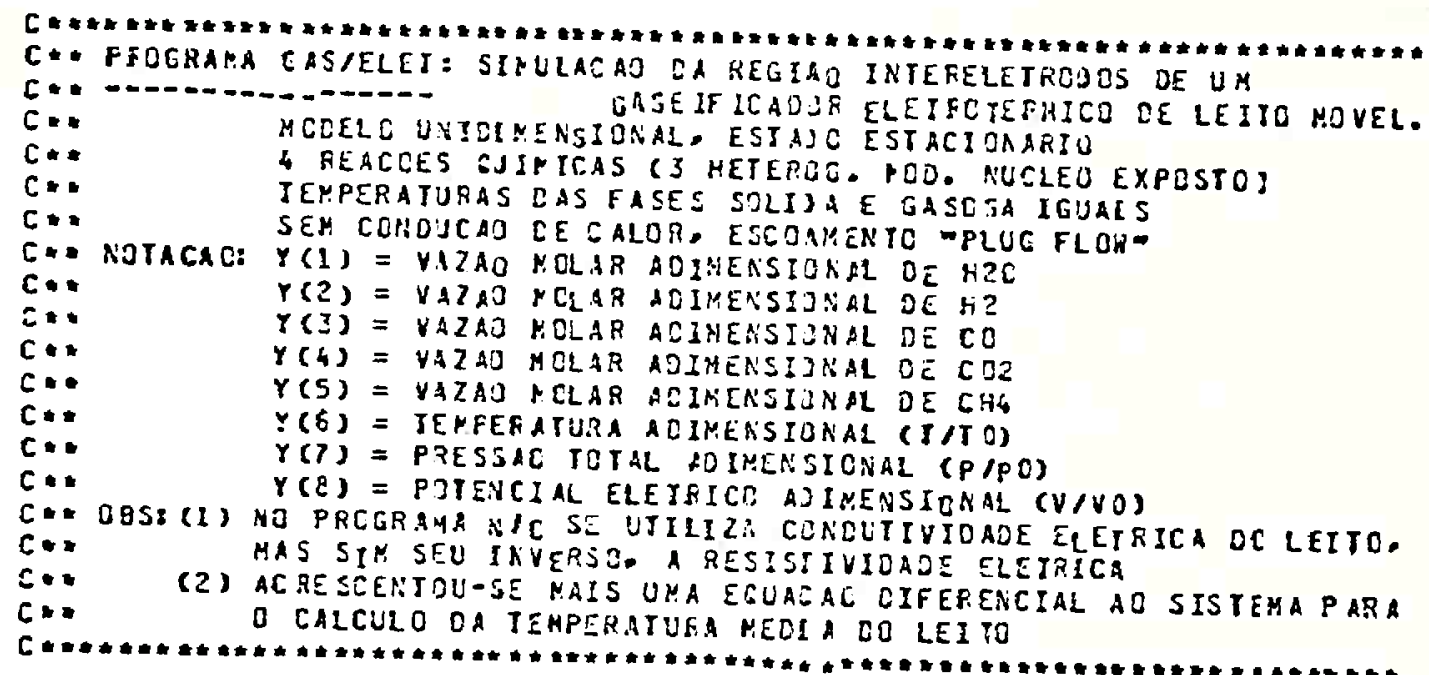

$\operatorname{coc} \cos 0$

c cocesic

$\operatorname{ccc} \operatorname{coc} C$

$\operatorname{ccctsco}$

$\operatorname{coc} \cos 320$

$\cos 2320$

$\cos 0 \cos \mathrm{c}$

$\operatorname{cccc} \csc \mathrm{C}$

COOOCEOO

$\operatorname{COOC700}$

$\operatorname{ccos} \operatorname{coc} \mathrm{c}$

16006500

$\operatorname{cccscco}$

$\cos 1100$

$\cos 01200$

$\operatorname{coc} 1300$

40001400

$\cos 61500$

$\cos 01600$

CIKENSION Y(9).DY(S).EPS( 9$), A(9.9) \cdot L(9) \cdot R K(9)$

DIMENSICA PI(9).PN(9).P2(9).AKI $(9)$. AK2(9). AK3(9)

$\cos 1700$

$\operatorname{coO} 1 E C \mathrm{C}$

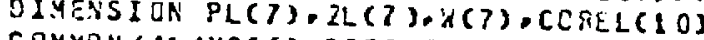

$600 C 1900$

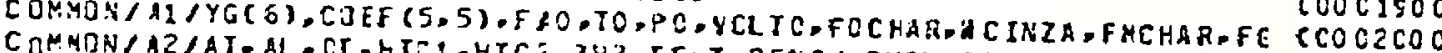

C OMMON

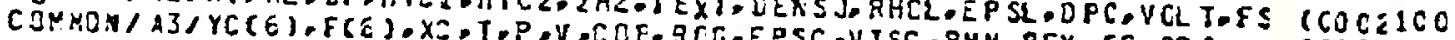

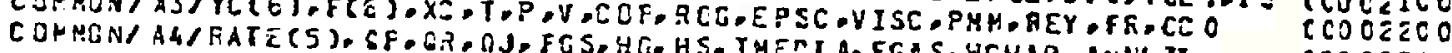

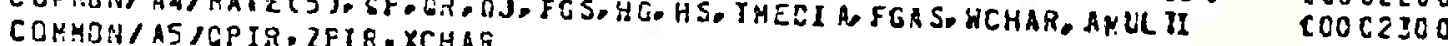

DAT $(\operatorname{COEF}(I, 1)+1=1,5) /-1 \ldots+1 \ldots+1 \ldots 0 \ldots 0.1$

DAI A ( DEF $(1,2), I=1,5), 0 \ldots 0 \ldots+2 \ldots, 1 \ldots 0.1$

DATA $(\operatorname{COEF}(1,3) \cdot 1=!, 5), \quad 0 \ldots-2 \ldots 0, \ldots, \ldots+1.1$

D RTA ( CCEF $(I, 4), I=1-5) 1-1 \ldots+1 \ldots-1 \ldots+1 \ldots 0.1$

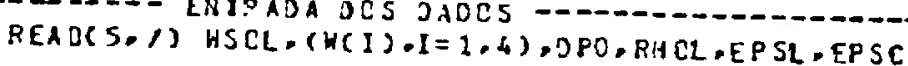

$\cos 2400$

$\operatorname{CCO}<\leq C 0$

$\operatorname{coO} O<E C$

$\cos <>00$

$\cos 2 \operatorname{coc} 0$

$\cos \geq 100$

$\cos 020 \mathrm{C}$

002:001L:1 IS THE LCCATYCN FOR EXEEPTICNAL ACTION ON THE I/C STATERENT IT C

REAJ(S./) FGAS (YG(I).I $=1.5)$. FO

002:0032:1 IS THE ICCATICN EDR EXCEFIICAAL COOC330O

REASCS. T) TO-JEXT.HICI,HTEZ,ZHZ,AL.OT

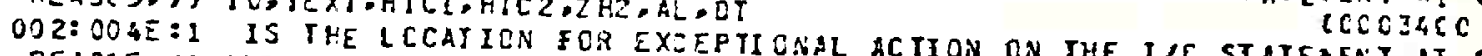

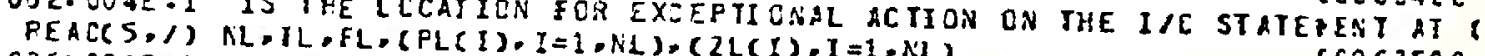

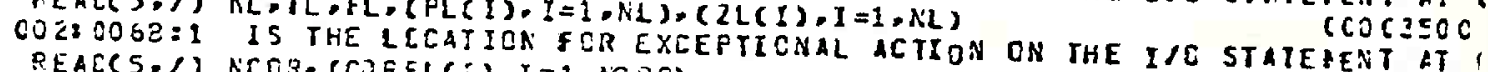

COZZ OOSZ: IS THE LCCATIOA FCR EXCEPTICNAL ACTION ON THE ITC STATE CONT AT,

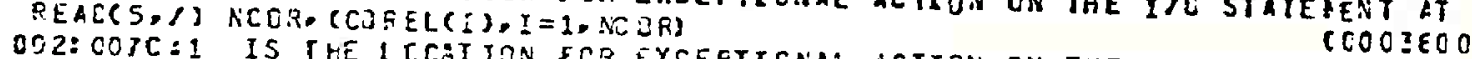

PEADC5. I) CPIR. ZFIF LOI ION FCR EXCEFTICARL ACTICN CN THE I/O STATENENT AT

COZ: COBD:1 IS THE ICCAJION FOR EXEEPTYCNAL ACTIOY ON THE IAC STATESENTATC

C-.-

FAO = FCAS TCOCJECO

$\therefore: 4 \times D=M S C L$

WEINZR $=W(4) \times 45 O L$

HCHAR $=$ KSOL- HCINLL

ALFA $=X(2) \cdot 12.1 \mathrm{H}(1)$

BETA $=H(3)=12 . / W(1) / 16$.

$\operatorname{CCO} \operatorname{coc} 0$
$\cos C \operatorname{coc} 0$

60004100

$\operatorname{ccc} 42 \mathrm{CC}$

$\cos 4300$

$\cos 4400$

$C C O O 4500$ 
PRCHAR = 12. + NLFA + 1J.EBEIA

CCOC AETC

FOCHAR. = NCHAPJONCHAR

$\cos 4700$

AT $=3.1415900 T+2 T=0.25$

RHOC = FHCL/(1. - EFSL

$C E O=\mathrm{S}(\mathrm{C})+\mathrm{BHOC} / 12$.

$\operatorname{COEF}(1-1)=\operatorname{BETA}-1$.

$\operatorname{COEF}(2.1)=1 .-$ EEI $1+0.5 * A L F A$

$\operatorname{COEF}(1.2)=B \leq I A$

CDEF $(2.2)=0.5 A A_{1} A-3 E I A$

$\operatorname{COEF}(1.3)=B E I A$

$\operatorname{COEF}(2.3)=0.5 \cdot A L F A-3 E T A-2$.

AM YAPH $=(F L+F G A S * Y G(1)) * 13 . * 3500$

AH SOLH $=$ HSOL $236 C O$.

$\operatorname{coc} 4 \varepsilon 00$

$\operatorname{coc} \csc c$

$(\cos 000$

$\operatorname{coses} 10$

$\operatorname{ccos} 200$

$\cos 30 \mathrm{cos}$

$(\cos 500$

$\operatorname{coc} \sec c$

CCOCECO

$\cos 05700$

$\cos \leq \varepsilon 0 \mathrm{C}$

WAITE( 6.103$)$

$\cos 5960$

WRITE(6., T) CASO NUYERO =-JK

$\operatorname{coc} \operatorname{cec} c$

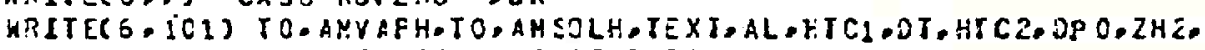

$6 C O O E \overline{C O O}$ 1 FHOL,FAC,EPSL,FGAS.EPSE,CCO.CPIR.ZPIA

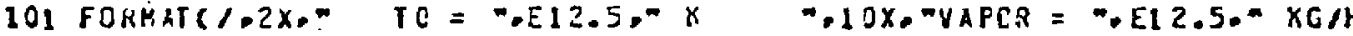

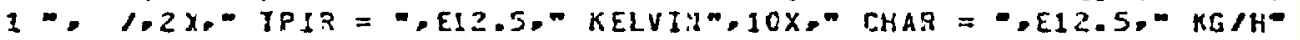

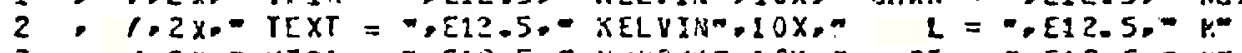

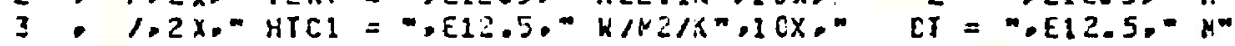

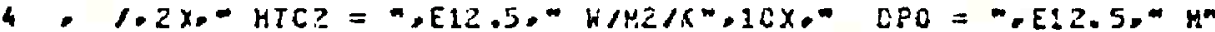

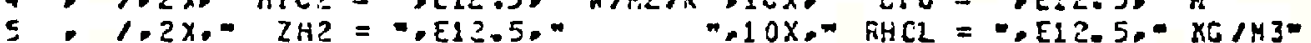

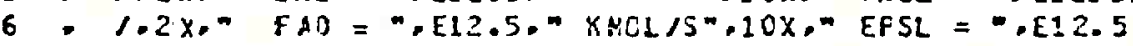

$7,1.2 x_{0}-8 G A S=m, E 12-5,=K H C L / D=10 X,-E P S C=\cdots, E 12.5$

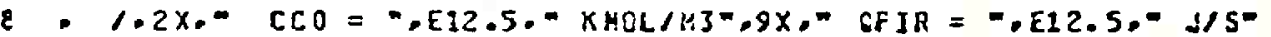

- $1.2 x_{0}-2 P 18=-.212 .5 .83$ XPITE $(6.103)$

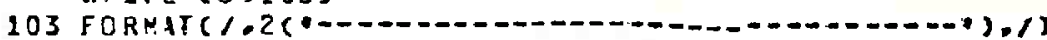

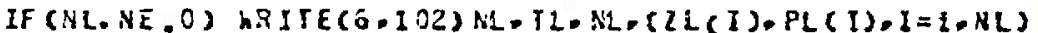

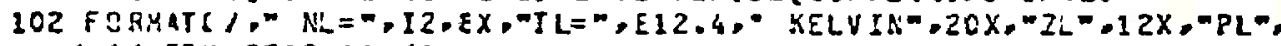
$1=(1,52 x, 2 E(2-4), 1)$

WRITE(6., - CORFENTES OE ENIRACA JUNTO AL ELETROEU SUPERIGR"

HIITE(6.,1) - SBLIOC (KGJS) $=-.45 C L$

WSITE $(6,1)=$ SBL $\quad c(i)=\cdots, i(1)$

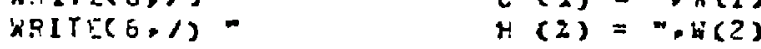

WRITE(G.)

WPII $\{(6,1)=$

XRITE $(6,1) \%$

WITEE(6.1)=

WRITE( 5.1$)=$

WRITE $(5,1)$ -

HRITE(6, 6,1$)=$

WराTE(5, )

GFITE(6,) -

hPITE( 5,1$)$.

Wristes b.

WEITE( 6,1$)=$

$C(z)=\cdots, x(3)$

$\operatorname{CINZA~}(2)=-. X(4)$

$A L F A=-, \lambda L F A$

$B E T A=\because E E T A$

CINZA(KESS) = HCIKZA

$(K M O L, S)=\cdots$. FGAS

$H 20(Y M C L)=-Y Y G(1)$

H2 (IMCL) $=\cdots, Y G(2)$

CO $(z N C L)=\because Y \operatorname{rg}(3)$

$C C 2(Z M O L)=-. Y G(4)$

CHis $(Z M O 2)=\cdots, Y G(5)$

YRITE 6,1$)=$

CORGEN]E DE INLECAD LATERAL

KRITEC

OO 500 ITE=

COR = CDRELCITE)

hitTE(6.513)

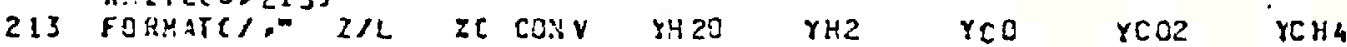

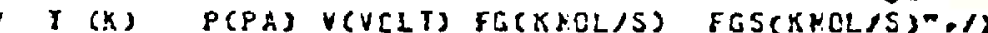
DE NSJ = CER/AT

$\cos (\cos 400$

$\operatorname{coc} \varepsilon \leq 00$

CCOCEEOC

CCOCE7OO

$\operatorname{CCCCECC}$

$\operatorname{rccsscc}$

$\operatorname{coc} ; 00 \mathrm{C}$

$\cos 0 \cos 100$

(cCC7200

$\operatorname{coc} 3 \mathrm{co}$

$6 C 007400$

$r c 00\} 500$

SCCOTEOO

$\cos 07700$

rcoc 7eco

$6 C 00 \& 000$

CCOCE1OC

ICOOEZOO

$\operatorname{coc} \varepsilon 30 \mathrm{C}$

$\operatorname{coc} \cos 0$

10008500

$\angle C O C E E O C$

10001700

$\cos 8720$

CCOCEEC

C COOESOC

$\operatorname{coc} \csc c$

$1 \cos 100$

$\operatorname{coc} \cos$

$6 \operatorname{coc} 360$

10005310

$\operatorname{coc} 5320$

$8 \cos 400$

$1 \cos \leq 00$

C COC SEC C

C $00 \leqslant 700$

C C C C EC C

6000500

CCO 1 CCO

$\cos (1) 0$

c COIC 200 


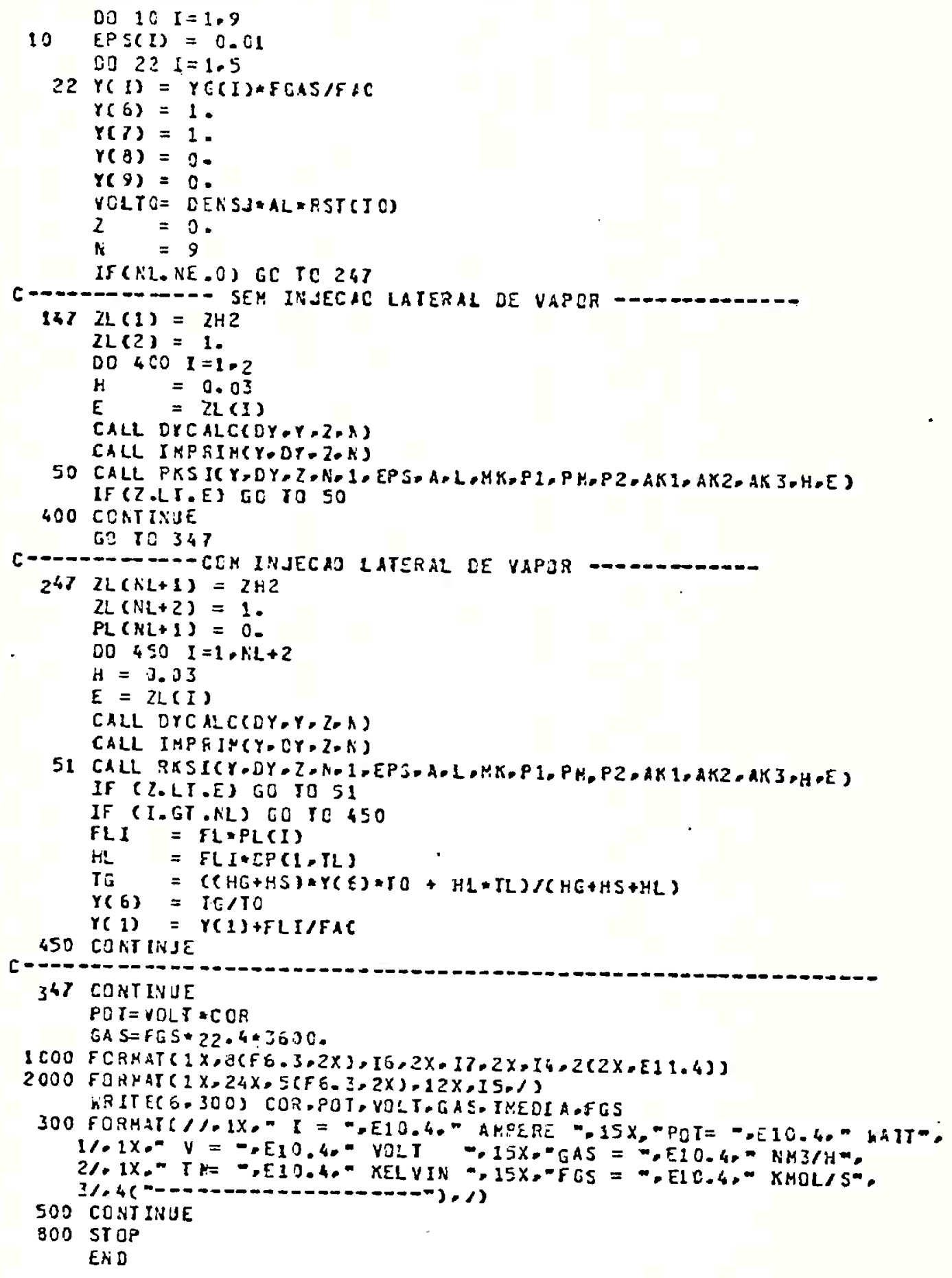

$\operatorname{coc} 16300$

CCCIC4CC

$1 C O I C S O$

C COI $C \leqslant C$

$\operatorname{CCO} 67 C 0$

COOICEOO

C $\operatorname{CO} \operatorname{CSC} C$

C COI ICC

CCOL11CO

C C 11200

C Co11300

(C) $114 C$

(cO115CO

CoG11600

(CC) $170 \mathrm{C}$

CCO11EC

CCOIISOO

C CCL 1200

C CO1 100

$6 C O 1 \angle 2 C D$

$C 001=300$

CCO $1<400$

$\operatorname{COL}=5 \mathrm{C}$

$1001=600$

CCOIETCC

CCOI 280

c CO1 12500

COOIICC

$c 0012100$

$C \cot 2 \pi \mathrm{CC}$

COO1??00

$\operatorname{coc} 13400$

(CC 13500

COO135CO

C 0012700

cco $1 \geq 200$

CCC 13500

$(\mathrm{CO}+200$

$\operatorname{ccos} 4100$

C $C O 14260$

$\cos 2 \geq 00$

CCC $144 C$

CCO145C

CCOL $1 E 0 O$

CCOI470

$\operatorname{rCO} 14800$

CEC $145 C O$

ceciseco

(CC) $\leq 100$

CCOI $2 C O$

$C C O 1 \leq 300$

CCC1 $\leq 400$

CCO1 $\leq 50 \mathrm{C}$

CCOL $\leq E O$

CCOIS RC

(CCISSOC 
SUBRCUIINE OYCALCCOY,Y, $, N, N)$

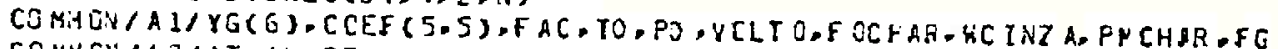

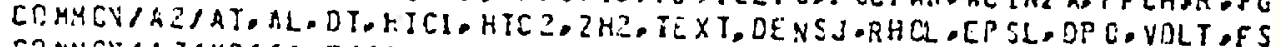

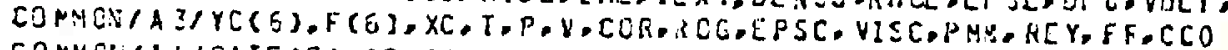

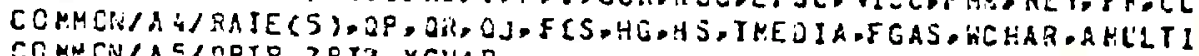
CCMMCH/A S/OPIR.ZPIR . XCHAR

DI MENSICA Y(N),DY(A),R(S),PHCL (S)

DAIA PMOL, 13.015 .2 .016 .28 .01 .46 .01 .16 .043 .28 .054$,

$F(G)=0$.

$56=F(6)$

DO $101=1.5$

IF $(Y(I)$. LT.C. $) Y(I)=1 . E-20$

$F(1)=\gamma(1)+F A]$

$10 F C=F C+F(I)$

$A \cup X=1.18 G$

PMX $=0$.

CD $20 \quad I=1,8$

$Y=(I)=F(I) \cdot A U X$

$5 O P H M=P H A+Y E(])+F H O L(I)$

$I=r(s) * 10$

$P \quad=Y(7)=P O$

ROG $=$ P/O314./T

FCHAR = FDCHAR

DO $30 \quad 1=3.5$

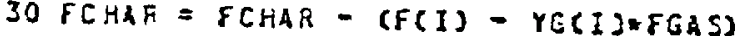

IF (FEHAR.LI.O.) FCHAS $=1 . E-10$

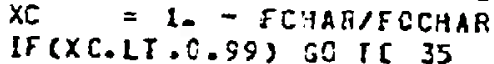

$X C=0.99$

$F C H A B=0.01 \angle F O C H A R$

$35 \mathrm{FR}=\left(1--X_{C}\right) * \pm[.333$

HCHAR = FCHAR PMCHAE

WSCL $=$ WCHAF+ hEINZA

XCHAR = MCHAG/ ASCL

$X=1 \times Z A=1 .-X C H A B$

WOAS $=$ FG/AT/RIO

USCL $=$ USCL/AT/FHOL

US $=U G A S-U S C L$

$V I S C=V I S C M(Y C \cdot I)$

KEY $=$ FF*EPO*1SS*RCQ*PAMIVTSC

REYM = REY/(1, -EPSL)

$F A I=(1.75+150 . / F E Y M)=(1 .-E P S L) /(E P S L+E P S L=E P S L)$

OY $(7)=-2 * * F A T * R Q G * P M M_{1} \times U S * U S J(D P O * F F) \times A L / P O$

$\operatorname{Dr}(9)=r(6)$

TMEOTA $=Y(9) * 10$

CALL RATES

$A U X=A L+A I / F A O$

OD $50 \quad I=1.5$

$R(1)=0$.

DC $40 \mathrm{~J}=1, \mathrm{~s}$

$40 R(1)=R(1)+\operatorname{CDEF}(1 ; J) * R A I E(d)$

50 DY $(I)=A U X=R(I)$

$G R=0$.

OO $60 \mathrm{~J}=1.4$

$60 \mathrm{GR}=0 R-D E L T A H(J \cdot T) \star R A T E(j)$

$H T C=H T C 1$

IF (2.GE. Z H2) HTC $=41 C 2$

$R U X=D E N S J A R S T(T)$

GJ $=$ AUX*CENS J

$C P=H I C *(I-T E X T) * 4.0 \mathrm{r}$

$\operatorname{CCO} E \operatorname{COC}$

$6 \cos E 100$

$\operatorname{CCL} \& 2 \mathrm{CO}$

60028300

(CO1E40C

CCOIESCO

CCOIEEOO

$\operatorname{COC} 1 \in 7 C \mathrm{C}$

CCo16800

CCOI 650

$\operatorname{coc} 17000$

$\operatorname{ccc} 17100$

$\operatorname{ccs} 272 \mathrm{CC}$

$\cos 7300$

(cos 7400

$\operatorname{cc} i \quad \leq \mathrm{CC}$

C COLIEOO

$\cos 17700$

$\cos 17200$

eccissc C

$(0018000$

$2 C O 12100$

$1 C O 28200$

$\cos 28300$

$\operatorname{CO} B 4 C 0$

$\cos 8500$

CCOI EEOC

(c) 18700

CCOIEEOO

SCCIESC C

$\cos 5000$

CCLI5100

$r \cos 5200$

ccols:30

CCC154CC

$8 C O 25500$

CCCISECC

$C C O 15700$

CCO1seco

C COS\$500

CCO2 2000

$6 \mathrm{CO} 2616 \mathrm{C}$

$\mathrm{C} C \mathrm{C} 26200$

60026300

$\operatorname{cc} 24400$

$\operatorname{cc} 2 \csc C$

$\operatorname{CCO} C E C C$

6026700

$\cos \csc c$

cc21c0

(C) $2110 \mathrm{C}$

CCO212CO

10021300

(C)2140C

$\cos 1500$

CCOZ $2 E C O$

CCC21700

(C) 1800

CCO215CC 
HS $=$ HSCL $\star C P C(T, X C H A R)$

SUBROUII NE IMPRIM(Y,CY,Z,N)

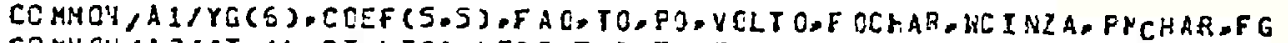

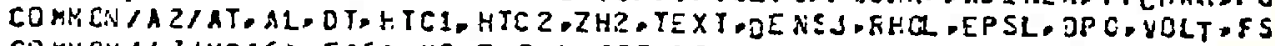

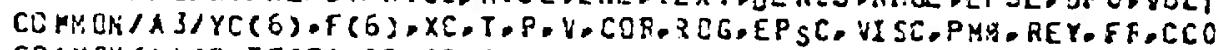

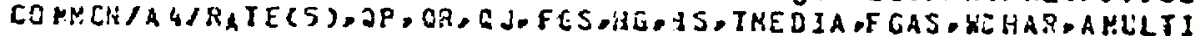
$\cos 3320$ COMYON/ASI GPIR, ZFIR, XCHAR

$\cos 3400$

$F E S=F G *(1 .-Y C(1))$

$A \cup X=0$.

IF (FGS.E G. O. ) GO IE 30

10025500

$\operatorname{CCO} 2 \pm 600$

$\operatorname{co0} 37700$

$\operatorname{CCC} 2] \varepsilon C 0$

$\lambda \cup X=1-15 E S$

$30 \quad 0020 \quad 1=2.6$

$20 \quad$ YQS(I) $=F(I)+A y X$

$D E L P=F O-P$

YOLT $=Y(8) * Y C L T O$

WPITE( 6.1000$)$ Z, XC, $(Y C(1), I=1,5), T, P, Y O L J$, F T.FES

KRITE( 6.2000$)$ (YQS(I).I=2.5)

CCCC WFITE(6.3COC) (F(I),I=1.6).Y(9).HG.HS

CCCC WRITE( 6.3000$)$ (AATE(J).J=1-5). GP.OR. C.-VISC.FR

K. ITE( 5,3000$)$ (DY (I), I $=1, E), C E L P$

IF $67 . \mathrm{L} .0 .99993 \mathrm{HC}$ JC 50

$z=1.01$

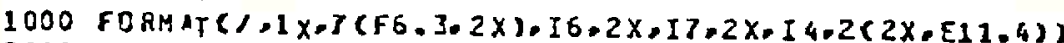

2000 FORMAT $(1 X .24 X+6(F 6.3,2 X)=10 X=17)$

3000 FCBKAT $(1 x, 3 x, 1](E) .3,2 x))$

SO RE TUSN

END

$\operatorname{COZ} \geq 500$

$\operatorname{cc} 2<\operatorname{coc}$

$1 \cos 4100$

10024200

$\cos 4300$

$\operatorname{coc} 24400$

$\operatorname{COO} 45 \mathrm{CO}$

TCOZ $\angle E O C$

$\cos 2330$

$\operatorname{COO} 48 \mathrm{CO}$

$\cos 24900$

$\operatorname{ccs} 2 \cos 0$

$1 \mathrm{CO}=1 \mathrm{CO}$

$\cos 25200$

$\operatorname{coc} 2530 \mathrm{C}$

$(0025400$

$\operatorname{cc} 25560$

CCOZSEOO

SUERCUTI RE RATES

DIMENISION AKR $(E)$-FI (S).ETR( 6$)$

$\operatorname{ccc}=700$

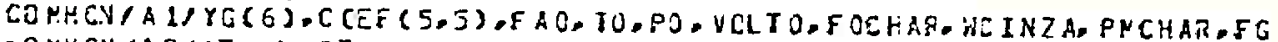

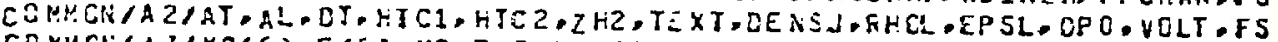

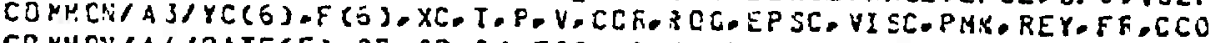

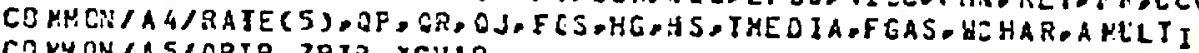

CO KYON/A SIOPIR, ZPIR, XCHAR

$Y H 2 O=Y C(1)$

$Y H Z=Y C(2)$

$Y=0=Y(3)$

$Y C G Z=Y C(4)$

$Y C H 4=Y C(j)$

$\operatorname{CCZ} \leq E C O$

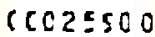

$\cos \cos 0$

CCCZE1CC

$C 0 O 2 E 200$

50026300

CCOZE4C

10026500

COC2E6OC

$\operatorname{co0} 2 \notin 700$

CCC $2 \in E C O$

$\mathrm{COO} 6500$ 
AUX $=2778 . \times E X P(-1511.17)$

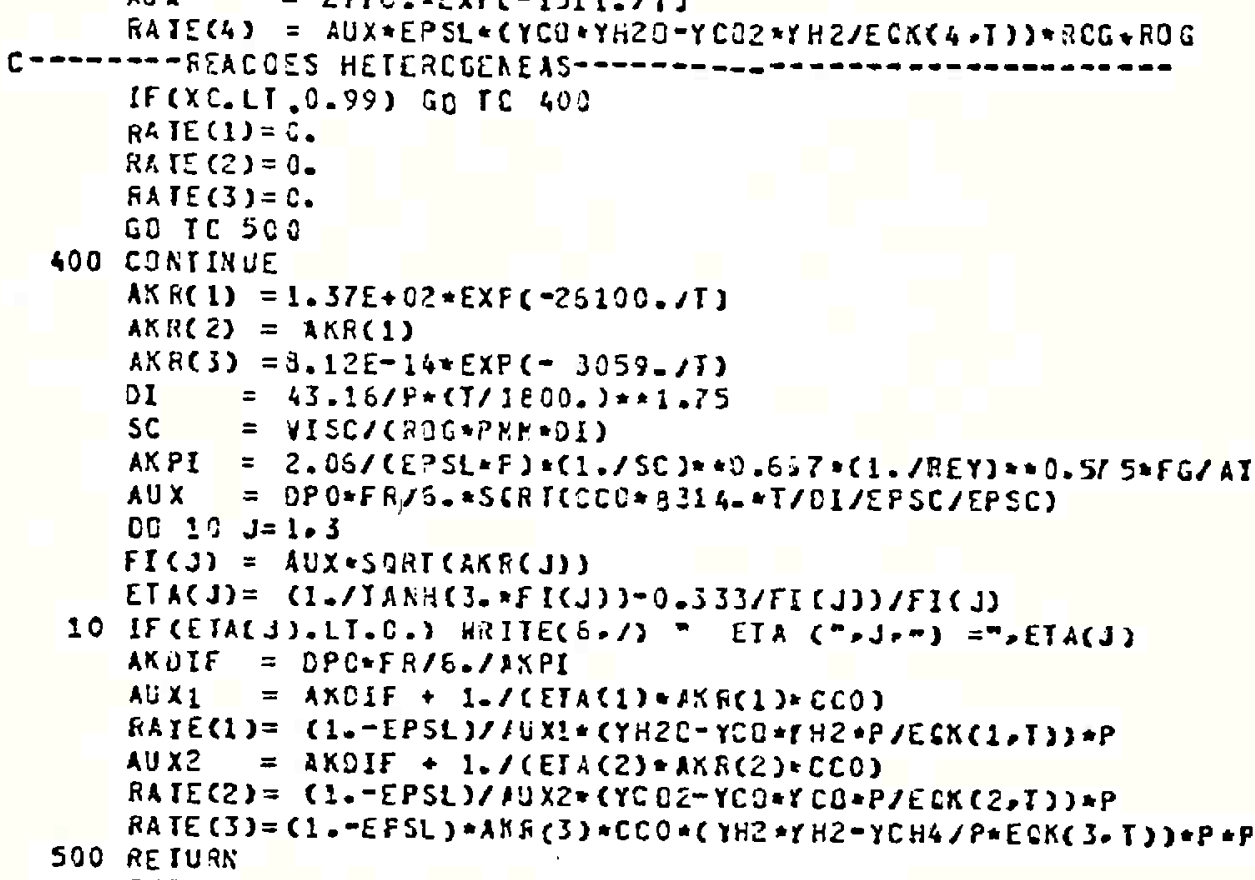

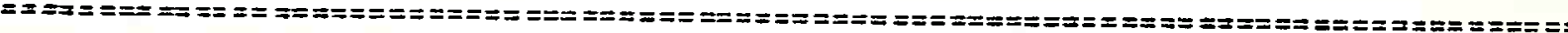

FUACIION CP(I.IK)

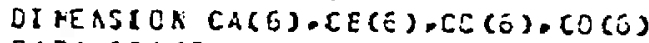

DAJA ( $[A(I), I=1.5) / 30557.8 .27292 .7 .28422 .9 .44246 .02 .14324 .5 /$

$\cos \sec 0$

DAIA $(C B(I), I=1.5) / 10.23756,3.2651 .4 .1023 .8 .7906 .74 .6992 /$

$\cos \cos 6$

10036000

DAIA (CC (I). I=1.5)/ $. .-5.023 \mathrm{CE}+7.4 .6046 E+7.3 .8232 E+8.0 .1$

$\cos \cos 100$

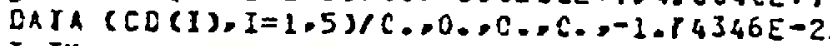

$\operatorname{ccc} 36200$

$I=I K$

$\cos 3630$

IF (T.GT. 2300.) T=23CO.

$\cos 3400$

$\operatorname{ccc} 3<500$

$C P=[A(I)+C B(I)+T-C C(T) / T / T+C O(I)+T+Y \quad$ CCC 3 (ECC

$\begin{array}{ll}\text { RE TUFN } & \text { CCC } 36 E C \\ \text { END } & \text { CCC } 3 C 700\end{array}$

EN D

FUNCIIDN VISCMCY,TK

DINEASION Y(E), PHCL $(E), F I(E, E)$.VISA(6). VISE(E), VISC(6). VISCOI (6)

CATA PKDL, 13.015.2.016.28.01.46.01.15.C43.20.054,

DAIA V!5 $11-31.20 .21 .97 .32 .22 .25 .45,15.96 .3 .5961$

DAIA VISE/41-4SE-2. $22.25-2.47-47 E-2.45-49 E-2,34-39 E-2.35 .13 E-2 /$

DAIA VISCI-8.27?E-5.-37.SIE-E. -96.69E-6.-E6.49E-6.-81.40E-6.

$I=I K$ $-80.55 \varepsilon-6$,

IF (T-GT.1300.) T $T=13 C \mathrm{C}$.

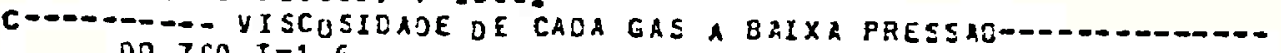
Do 7 CD $I=1,6$

$\cos \csc 0$

$\cos 3 \cos$

(c) 31100

Ccosi2co

$\{c 031300$

$\mathrm{COO}_{13 \mathrm{CO}}$

$\cos 1 \leq \mathrm{co}$

(cos 31600

$500317 c 0$

CCE $180 C$

60031500 
$700 \vee \operatorname{Isct}(I)=0$. DO $701 \quad I=1.6$

701 VISCC( $(1)=V I S A(I)+V I S E(1) \times T+12 S C(1)+1=1$

DI $705 I=1.6$ CADE DI KISTURA GASOSA A EAIXA PRESSAD-.......

DD $705, j=1.6$

RELVIS $=(V I S C O Z(1) M I S C O I(j))$

RE LPEH $=P \times C L(J) / P A C L(I)$

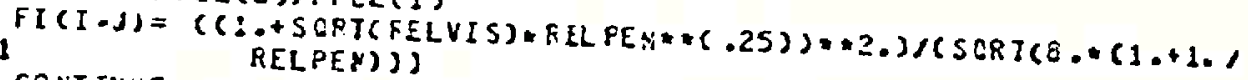

702 CONTENUE

705 CONTINAE

$\checkmark$ I SC $P P=0$.

DS $7<7 \quad I=1,6$

S) $\mathrm{MY} F \mathrm{FI}=0$

DO $703 \quad J=1.6$

SU PYFI = SURYEI $+Y(J)=F I(I-J)$

703 CONTINUE

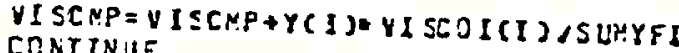

707 CONTINUE

VI SC $Y=V I S C H P=1, E-7$

RE TUIIN

ENO

$6 \cos =600$

$c \cos 2100$

$\cos 22200$

$\cos 2300$

$\cos 34 c 0$

$\cos 35000$

$\cos 32800$

$\cos 3700$

$c \cos 2800$

$\mathrm{C} C O 3 \leq 5 \mathrm{CO}$

$\operatorname{ccc} 33 \cos 0$

$\cos 33100$

$\cos 32 \mathrm{co}$

$\cos 33300$

$\operatorname{ccc} 33400$

$\operatorname{CCC} 3 \geq \leq 00$

$\operatorname{ccc} 3380 \mathrm{C}$

$\cos 3700$

$\cos 38 c 0$

$\cos 35500$

$\cos 4000$

66031100

$\cos 42 \mathrm{CO}$

\section{FUNCIION CPCTE.XEHER)}

$T=I X$

IF (T.GT.2000.) $T=2000$.

CP CHAR $=14 C 5 .+.3924=3-7.112 E+3 / 1 / 1$

CPCIKZ $=932 .+.2564+1-2.403 E+31 T / T$

CPC = CPCHAR*XCHAS+CPCYNZ:(1.-XCHAR2

EKD

$6 \mathrm{CO} 34 E 00$

$(\cos 470 \mathrm{C}$

$\cos 4 \& 60$

$\cos 2500$

$\operatorname{ccc} 5 \operatorname{ccc} C$

FUNCIION FST(T)

RS $T=0.1137 * E X P(-6.89 E-04 \times(T-273.1) \times 1.25$

$(\cos 5100$

$\cos =200$

$\cos \leq 30 \mathrm{C}$

END

$(\cos 5400$

FU.KC II ON EQK(J.T)

DIAEASIOX A(5), ER(S)

DATA A $3.139 E+12.1 .238 E+14.1 .453 E-11.2 .65 E-2.2 .15035 E+230$

$1 \cos \leq 500$

CATA ER/ $16335 . .20282 .0-10905 .-3956.027334 .1+2.15035 E+23$

$\operatorname{tCO} \operatorname{seC} \mathrm{E}$

$E O K=A(d)=E \times P C-E K C$ (J)

$\cos 5700$

RE JU RN

$\operatorname{ccc} 3 \leq 8 \mathrm{CC}$

END

$\cos \leq 500$

$\operatorname{CCO} \operatorname{seC} \mathrm{C}$

$\cos \cos C$ 
FUNCTION DELTAH(SETH)

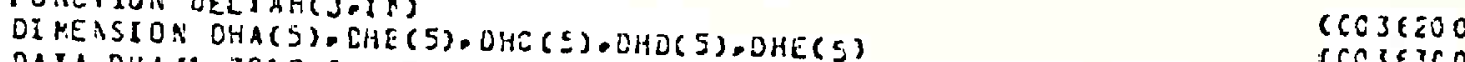

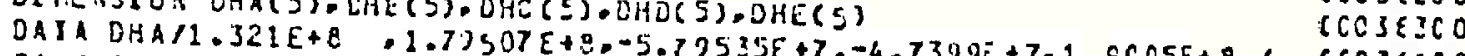

DAF OHB DATA OHB DAIA DHO/-9.5813E+8,-1.52904 $0.31 .593485,-1.17203,-35.5495$ ' CCC3EECC DATE DHE/C.

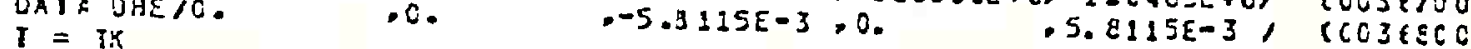

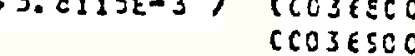

IF (T.GT. 2000.$) r=2000$.

$\cos c 037000$

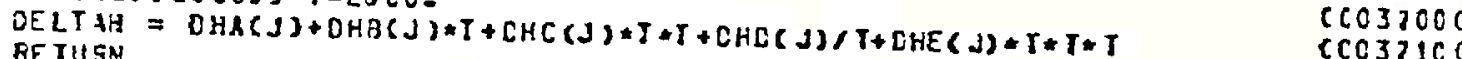

$\operatorname{ccs} 320 \mathrm{C}$

END

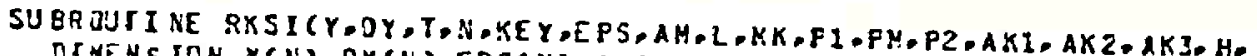

DIHENSION Y $(N)$-OY (N).CPSE DIMENSICN LCN

$82=C .75$

$831=-0.630172$

$832=-C .24235$

$R I=1.03758$

$R 2=0.83496$

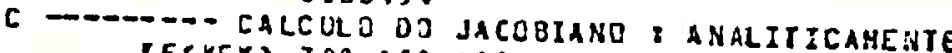

I $F($ HEY) 300.400 .400

300 CALL AOERIV(AH.Y,T.N) 6010500

C DOO CALCULD DO JACOBIAND : NUMERICAHENTE

J $430 \mathrm{~J}=1, N$

CALL OYCALCCDY,Y-T,H)

$00410 \quad I=1, K$

$410 \quad A K([-J)=0 Y(I)$

DEL IA $=0.0001 *(\operatorname{ReS}(Y(J))+A B S(E P S(j))$

$Y(J)=Y(j)+D E L T A$

CALL DYEALC(DY,Y,T,N)

$00 \quad 420 \quad I=2, \Lambda$

$420 \quad A M(I, J)=(D Y(I)-A H(I, J)) / D E L T A$

$430 \quad Y(J)=Y(J)-D E L T A$

SCO CONIINUE

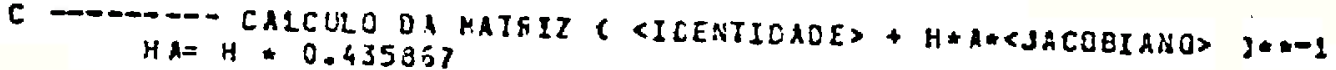

$00600 \quad I=1 . N$

$00 \leqslant 00 \quad j=1 . \mathrm{N}$

$600 \quad A M(I-3)=-H A \cdot A+(I-J)$

D $0 \cos \quad I=1$. N

$605 \quad A M(I .1)=A M(I . I)+1$.

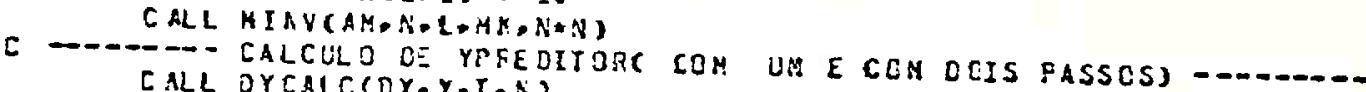

CALL OYCALCCDY,Y,T.A

CALL HH.ATF(AKI,H,AP,CY,N)

DO $619 \quad I=1$.

$610 \quad P l(I)=Y(1)+Z_{2}=4 K I(I)$

CALL DYCALCCDY,PI, I, N)

CALL AMATF (AK2.HEAH,CY.N)

620

0] $620 \quad I=1-N$

$P 1(I)=B 31 * A \times I(I)+8 ? 2 * A \times 2(I)$

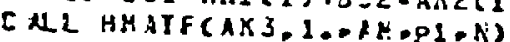

$\cos 7500$

$\cos 7600$

$\cos 3780$

$\cos 3800$

$c \cos 7500$

$\operatorname{ccos} 2 \operatorname{ccc}$

$t \cos 210 \mathrm{c}$

C CO $E$ ECC

$C \cos E 3 C \mathrm{C}$

$\cos 8400$

CCC $\& \leq C C$

C $\cos \& 600$

$\operatorname{toc} 3870 \mathrm{C}$

$\operatorname{ccc} 31860$

$\cos 1500$

$\operatorname{ccc} 3 \sec c$

$\cos 5100$

TCC $C 2 \angle C$

60035300

$\cos 5400$

$\cos 5500$

CCOJSECO

60035700

c $\cos 58 c \mathrm{C}$

$\operatorname{ccos} 5 \mathrm{cc}$

ccoscoor

$\mathrm{CCO} 4 \mathrm{C} 1 \mathrm{C}$

cos c20

CCO4C3C

CCO4C4O

C C 4 C 501

C

$\mathrm{CCO} 4 \mathrm{CPCO}$

CCO 4 CEO O

$\mathrm{CO}_{4} \mathrm{CSCO}$

c cosicoo

(CC41100

C CO412CO

$\operatorname{COO} 41300$

CCO43400

$\mathrm{COO}_{415 C \mathrm{C}}$ 
$D C 630 \quad I=1,1$

$630 \quad P 1(I)=Y(I)+R 1 * A K I(I)+R 2 * A K 2(I)+A K 3(I)$

$\cos 11600$ $H H C I O=H \cdots 0.5$

CALL DYCALCCDY,Y,T,N)

[ALL AMATF (AKL - HME IE, AH D DY, A]

DC $640 \quad 1=1, N$

$640 \quad P K([)=Y(1)+42+A K 1(1)$

CALL BYCALCCDY-PH. I

CALL HKATFCAK2-HKEICPAH, CY.AY

D. $550 \quad I=1 \cdot \mathrm{N}$

$650 \quad \operatorname{PK}(I)=B 31 \cdot A K 1(I)+B 32 \cdot A K 2(I)$

CALL HNATF(AK3.1.,AH-PH,N)

$00660 \quad I=1$. N

$660 \quad P H(I)=Y(I)+R I * A K I(I)+R I * A K 2(I)+A K 3(I)$

CALL OYCALCECY,FH,T,N)

CALL AMATF (AK1. HMEIS.AM DO - A)

DO $570 \quad I=1-11$

$P Z(I)=P R(1)+8 Z+A K I(I)$

C ALL OYCALC COY,P2, T, N)

CALL HMATF(AXZ. HHEIO,AH,OY. $N$

DO $690 \quad I=1 . N$

$P 2(1)=E 31 * A K 1(I)+B 32 * A K 2(I)$

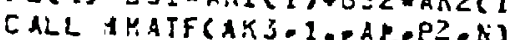

DO $690 \quad I=1 . \AA$

$690 P 2(1)=P R(I)+R 1 \times A K I(I)+R Z * A K 2(I)+A K 3(I)$

C -...- CALCULC DO ERFC E CHECA PRECISAO OHAX $=4 B S(P 2(1)-P I(1)) \pi P S C 1)$

DO $800 \quad I=2$.

E00 G=AOSCP2(I)-PI(I))/EPSC I

IF $($ GMAX.LT.O) GNAX=6

IF(SAX.LI.1.) GD IC 1100

$H=H M E \perp C$

$001000 \quad I=1 . N$

$1000 \quad P_{1}(T)=P_{K}(I)$

GO IC 700
$P L C D$

C -O-.-. FIM DO PASSE; PREPARA AOYO PASSC

$1100 \quad 001200 \quad I=1$.N

$1200 \quad Y(I)=P 2(I)+(P 2(I)-P 1(I)) / 7$.

$\mathbf{I}=\mathbf{T}+\mathrm{H}$

CALL UY CALCCLY, Y,T $=A)$

CALL IYPFINCY.DY,T

A MI $\lambda=3$.

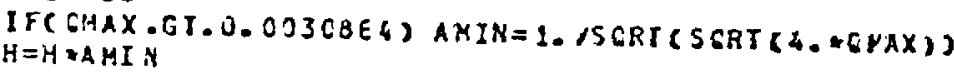

I F ( $\because-G Y-E-T) \quad H=E-Y$

RET JRY

E $M 0$

10041700

$\operatorname{ccs} 41 E C C$

(CC 41500

रCO420:C

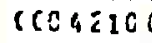

60042200

$1604 \approx 300$

$\cos 42400$

$\cos 42560$

( $C O 4 \angle E O O$

C $C O 4<700$

C CO4 $28 C \mathrm{C}$

c004:50

C 6045000

$\cos 43100$

C CO\& 5200

$\operatorname{coc} 43300$

$\operatorname{cc0} 42400$

$200435 \mathrm{CC}$

(CO4?ECO

(co43700

10342800

$\mathrm{COO} 43500$

CCC44CCC

$\cos 4100$

$\operatorname{ccc} 44200$

$\cos 4300$

$\csc 44400$

$\operatorname{ccc} 4450 \mathrm{C}$

CCO 4 \&ECO

CCC44300

$(C \mathrm{C} 44800$

$\cos 4900$

$\mathrm{CCO} 4 \mathrm{sccc}$

(CC4:100

C C $4 \leq 200$

$6004 \leq 200$

$\operatorname{ccc} \leq 500$

$(\mathrm{CO} 4 \leq 5 \mathrm{CO}$

COO4 EEOO

$\operatorname{COO4} 57 \mathrm{CO}$

$\cos 45800$

CCE $4 \leq 500$

CCO4ECOO

CCO\&8100

$\operatorname{CC} 4 \in \angle C O$

$S E$

SUBACUT INE HMATF $(A H, H, A M, F, A)$

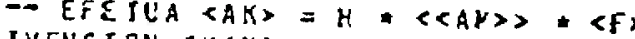

$\mathrm{CCO}_{4} \mathrm{3CC}$

$\operatorname{cc0} 4 \notin 400$

EIHENSION AKCN)-AM $(N-N)$ - F (N)

$\cos 4 \notin 560$

$A S(I)=0$.

DO $10 \quad J=1 . N$

$A K(S)=A K(1)+\operatorname{Ax}\left(1 \cdot \int\right) \times f(J)$

CCO\& $6 E O O$

CCO $4 E 7 C O$

CCCAEECO

CCOAE9CO

$\cos 43000$ 
RETURN

SUBROJTINE AOERIV(IJAC, Y,TAN)

DIMENSION AJAC $(N, N)=Y(N)$

c

SUBRSUIINE MINV(A.H.L.HK,NN)

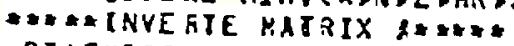

OI MENSION $A(N N)=2(N), N K(N)$

$D=1$.

$M K=-N$

DO $80 \quad S=1$. N

$A K=N K+N$

$L(x)=K$

$M X(K)=K$

$K K=N K+X$

BI GA $=A(K K)$

DO $20 \quad J=x_{0} N$

$I I=N:(J-1)$

$0020 I=X+N$

$I J=I Z+I$

10 IF $(A B S(B I E A)-A B S(X(I J))) 15.2 C-20$

$15 B I G A=A(I J)$

$L(K)=I$

$H K(K)=J$

20 CONI INUE

*.* IROC a CE COLUNAS \#."

$J=L(K)$

If $(J-k) 35 \cdot 35.25$

$25 K I=K-N$

DC $3: I=1, N$

$K I=K I+M$

HOLO $=-A(K I)$

$J I=K[-K+J$

$A(K I)=A(J I)$

$30 A(J I)=10<0$

C *** TROCA DE COLUNIS \#***

$35 I=H K(K)$

IF $(I-K) 4 S .45 .39$

38 i $=N *(1-1)$

DO $40 J=L-N$

$J K=N R+j$

$J I=J P+J$

HOLD $=-A(J K)$

$A(X K)=A(J I)$

$40 A(J I)=H O L D$

6 A** DIVICE CCLUARA FER - PIVCT

45 If $(B I G A) 48.46 .43$

$46 D=0$.

$\cos 7 \varepsilon c 0$

$\operatorname{coc} 4750 C$

10048000

CCO4\$100

( $6448=00$

$\operatorname{ccc} 4 \varepsilon 30 \mathrm{C}$

$\cos 4500$

CCC4E560

CCO4EEOO

$\operatorname{ccc} 4 \leqslant 700$

CCO4\&ECO

CCC4ESCO

C $\mathrm{CO} 45 \mathrm{SOO}$

COO491C C

CCO45200

c $c 04536 \mathrm{C}$

$\cos 45400$

c C 45500

COC 45600

(CO 45700

CCC4SECO

$\cos 45900$

$\operatorname{cocsccco}$

C COE $10 \mathrm{C}$

$c \cos c 200$

$\cos c 360$

$\cos 6400$

$\operatorname{cosecoc}$

CCOSCEOO

$\cos C 70 \mathrm{C}$

C COECEOC

C $\cos 19 C \mathrm{C}$

$\cos 1000$

COCS1100

$\cos 1260$

C COS 1200

(COs 1400

C COS $15 C \mathrm{C}$

$(\cos 1800$

$\cos 170 \mathrm{C}$

c $c 051800$

C 051500

c cos 2000 


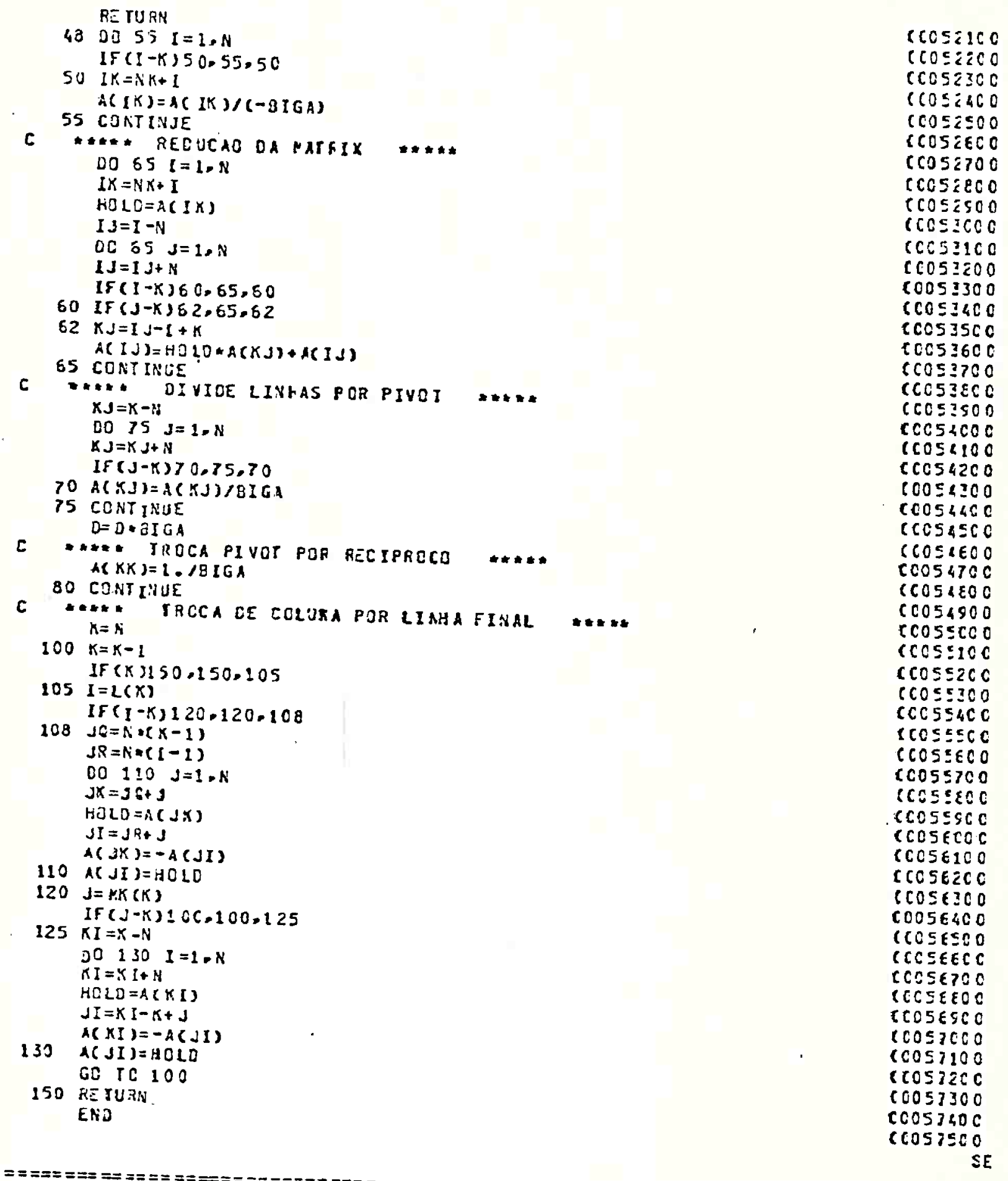


b) Dados de Entrada do Programa

A Tabela C.I define os dados de entrada do progra ma. A titulo de exemplo e apresentado abaixo um arquivo de dados típico, com a respectiva listagem de saida dada no item (c) deste Apêndice.

- exemplo de arquivo de dados para o programa GAS/ELET.

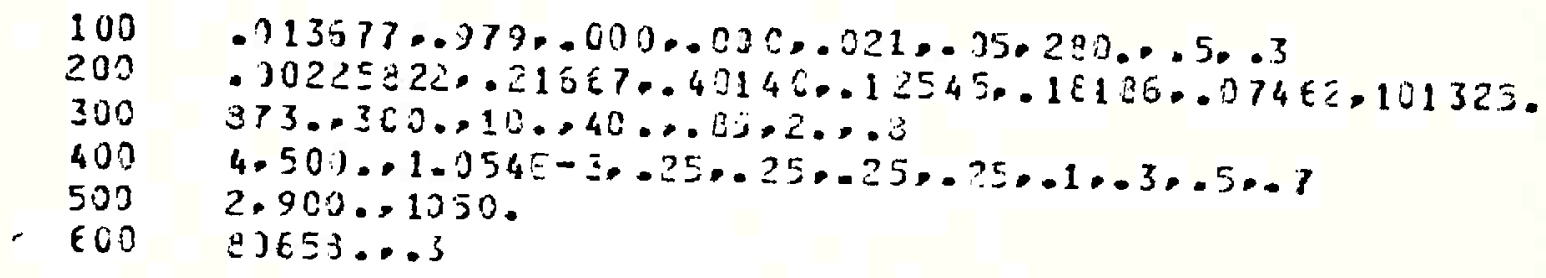


TABELA C. 1 - Dados de entrada do programa GAS/ELET.

\begin{tabular}{|c|c|c|c|}
\hline LINHA & VARIAVEL & $D E S \subset R \mid \subset A \cap 0$ & UNIDADE \\
\hline 19 & $\begin{array}{l}\text { WSOL } \\
\text { W(I) } \\
\text { DPO } \\
\text { RHOL } \\
\text { EPSL } \\
\text { EPSC }\end{array}$ & $\begin{array}{l}\text { vazão de sölido que entra em } z=0 \\
\text { frações mássicas de C, H, o e cinzas } \\
\text { diaametro inicial das partículas } \\
\text { densidade aparente do leito } \\
\text { fração de vazio do leito } \\
\text { fração de vazio da partícula }\end{array}$ & $\begin{array}{l}\mathrm{kg} / \mathrm{s} \\
\operatorname{adim} . \\
\mathrm{m} \\
\mathrm{kg} / \mathrm{m}^{3} \\
\text { adim. } \\
\text { adim. }\end{array}$ \\
\hline $2 a$ & $\begin{array}{l}\text { FGAS } \\
Y G(1) \\
\text { PO }\end{array}$ & $\begin{array}{l}\text { vazão molar de gãs que entra em } z=0 \\
\text { frações molares de } \mathrm{H}_{2} \mathrm{O}, \mathrm{H}_{2}, \mathrm{CO}, \mathrm{CO}_{2} \text { e } \mathrm{CH}_{4} \\
\text { pressão do gäs em } z=0\end{array}$ & $\begin{array}{l}\mathrm{kmol} / \mathrm{s} \\
\mathrm{adim} \\
\mathrm{Pa}\end{array}$ \\
\hline $3 a$ & $\begin{array}{l}\text { TO } \\
\text { TEXT } \\
\text { HTC1 } \\
\text { HTC2 } \\
\text { ZH2 } \\
\text { AL } \\
\text { DT }\end{array}$ & $\begin{array}{l}\text { temperatura do leito em } z=0 \\
\text { temperatura do meio ambiente } \\
\text { coeficiente de transferéncia de calor } \\
\text { coeficiente de transferência de calor para } \\
\text { a região próxima ao eletrodo inferior } \\
\text { fração do comprimento do leito a partir do } \\
\text { qual atua o coeficiente HTC2 } \\
\text { comprimento do reator } \\
\text { diâmetro do reator }\end{array}$ & $\begin{array}{l}k \\
W / m^{2} / K \\
W / m^{2} / K \\
\text { adim. } \\
m \\
m\end{array}$ \\
\hline $4 a$ & $\begin{array}{l}\mathrm{NL} \\
\mathrm{TL} \\
\mathrm{FL} \\
\mathrm{PL}(1) \\
\mathrm{ZL}(1)\end{array}$ & $\begin{array}{l}\text { nümero de injeções laterais } \\
\text { temperatura do vapor de injeção lateral } \\
\text { vazão molar total de vapor de injeção late } \\
\text { ral } \\
\text { frações da vazão } \mathrm{FL} \text { que entram em cada co- } \\
\text { ta de injeção lateral } \\
\text { pontos de localização dos bocais de inje- } \\
\text { çâo lateral no comprimento do reator }\end{array}$ & $\begin{array}{l}\text { adim. } \\
\mathrm{k} \\
\mathrm{kmol} / \mathrm{s} \\
\text { adim. } \\
\text { adim. }\end{array}$ \\
\hline \multicolumn{4}{|c|}{$\begin{array}{l}\text { OBS.: no caso de não haver injeção lateral, deve-se colocar cinco zeros } \\
\text { na } 4 \text { ạ linha. }\end{array}$} \\
\hline 5 & $\begin{array}{l}\text { NCOR } \\
\text { COREL ( } 1)\end{array}$ & $\begin{array}{l}\text { nümero de valores de corrente elétrica que } \\
\text { se deseje simular } \\
\text { valores de corrente elétrica }\end{array}$ & $\begin{array}{c}\text { adim. } \\
\text { A }\end{array}$ \\
\hline $6 a$ & $\begin{array}{l}\text { QPIR } \\
Z P I R\end{array}$ & $\begin{array}{l}\text { carga térmica dos processos de secagem e pi- } \\
\text { rólise } \\
\text { distãncia adimensional da região intereletro } \\
\text { dos onde se atribui a carga QPIR }\end{array}$ & $\begin{array}{c}\text { W } \\
\text { adim. }\end{array}$ \\
\hline
\end{tabular}


c) Exemplo de Resultados do Programa GAS/ELET

E apresentada a seguir uma cópia da listagem dos resultados correspondente ao exemplo de arquivo de dados apresentado no item (b).
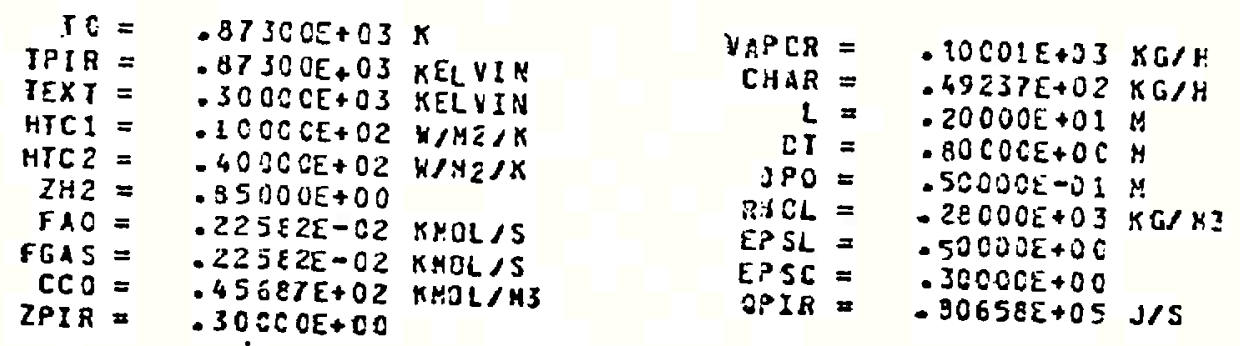

$\mathrm{NL}=4$

$I L=.5000 E+63 \mathrm{KELVIA}$

24

PL

$-1000 E+00 \quad-2500 E+C O$

$.3000 E+C O \quad .2500 E+C C$

$.5000 E+00 \quad .250 C E+C C$
$.7000 E+00$

CCRRENTES OE ENIRACA JUKTO LJ ELE 1RODO SUPERIOA.

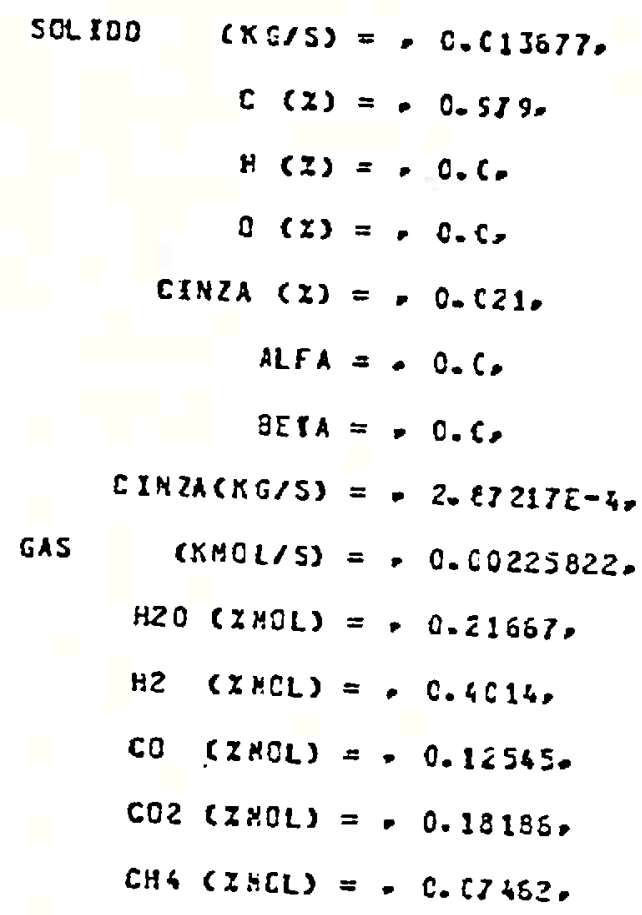




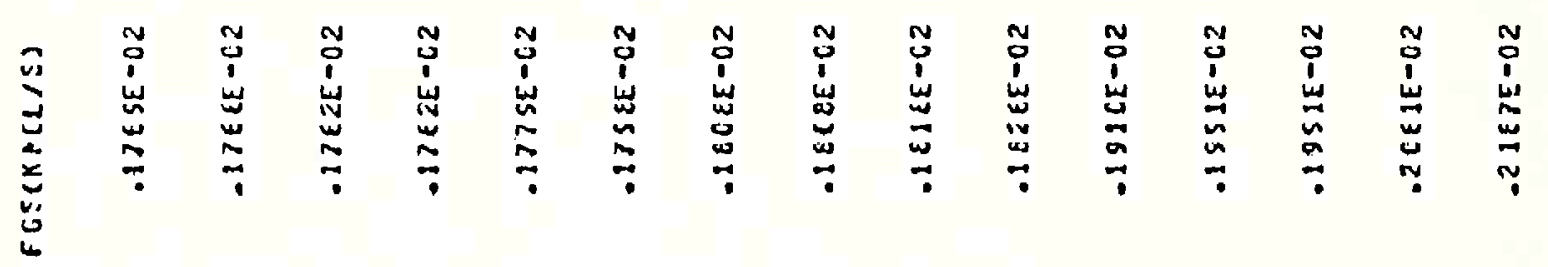

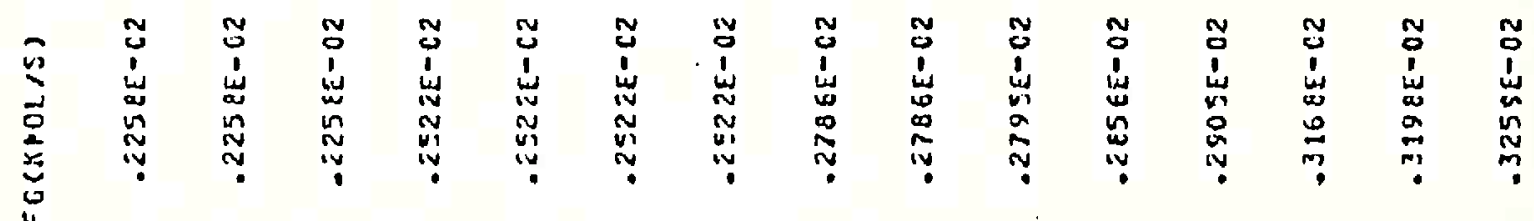

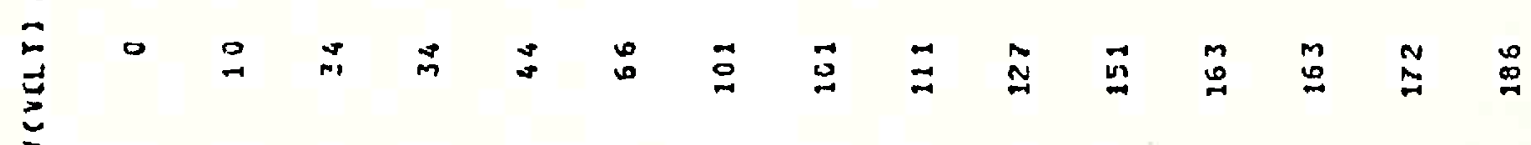

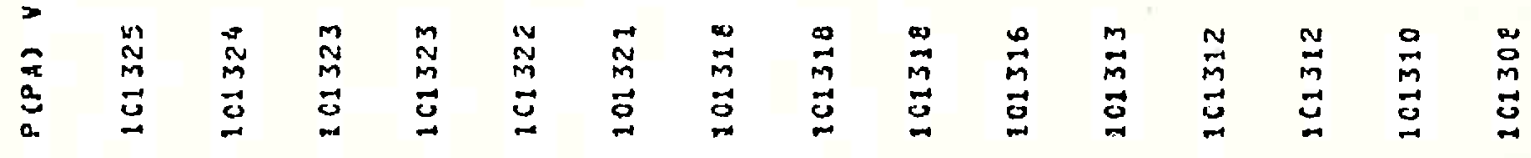

$$
\begin{aligned}
& \text { 买 } \\
& \text { 美 }
\end{aligned}
$$

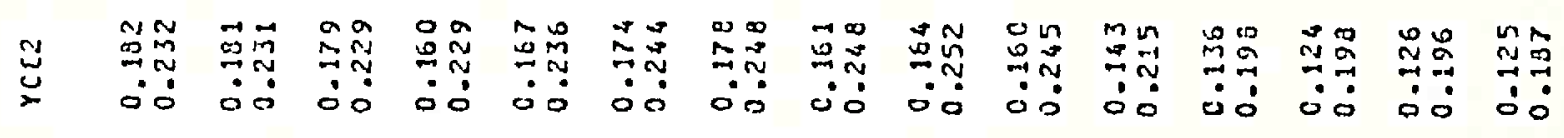

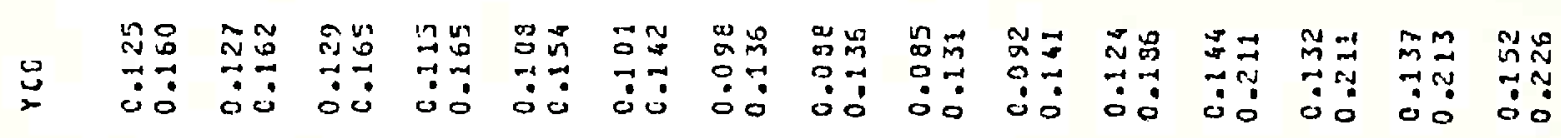

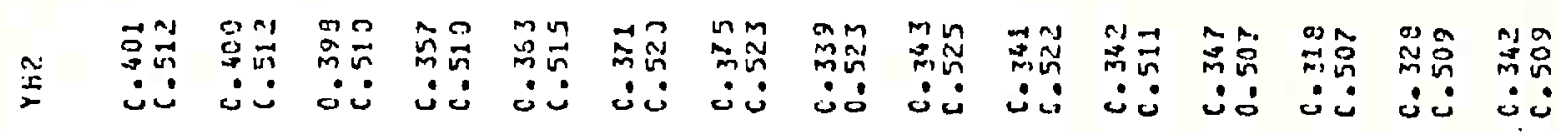

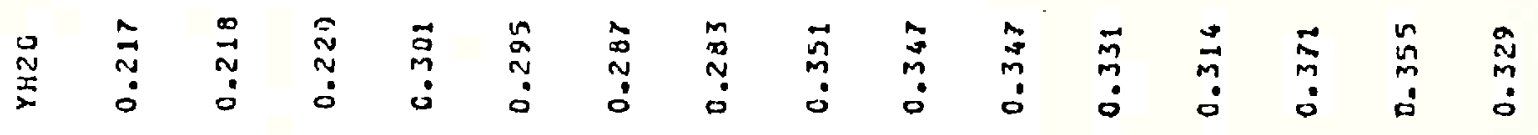

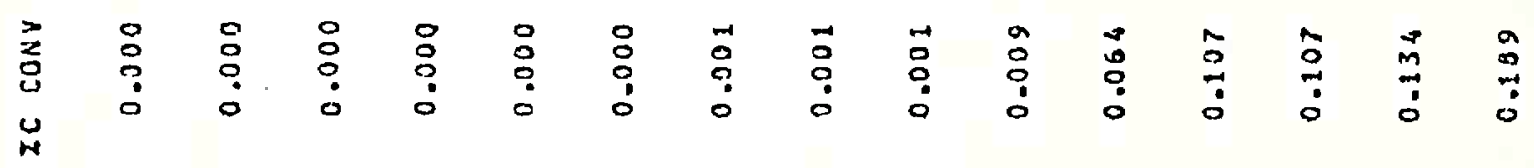

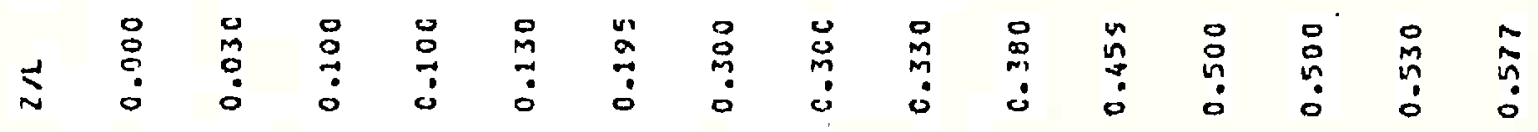




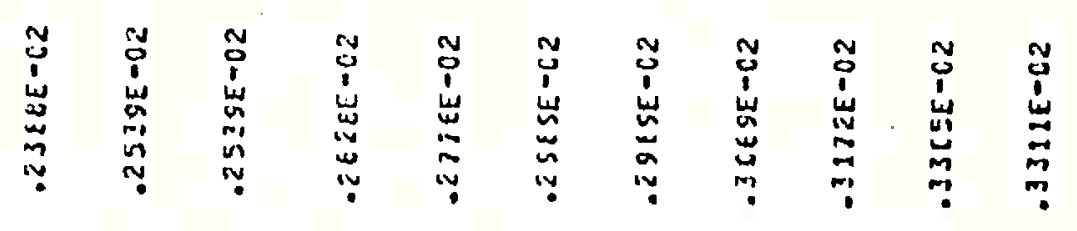

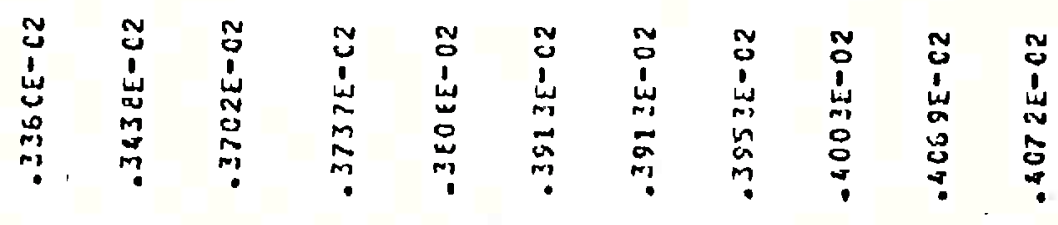

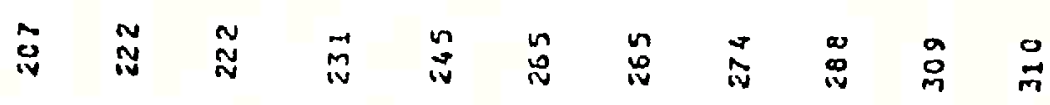

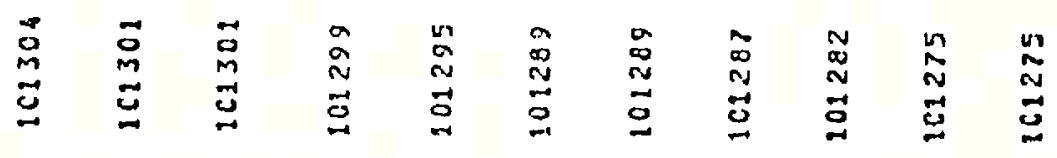

ఏ

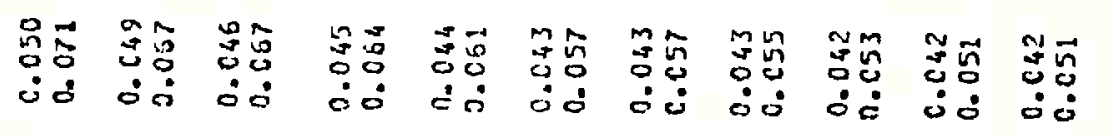

=

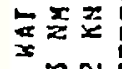

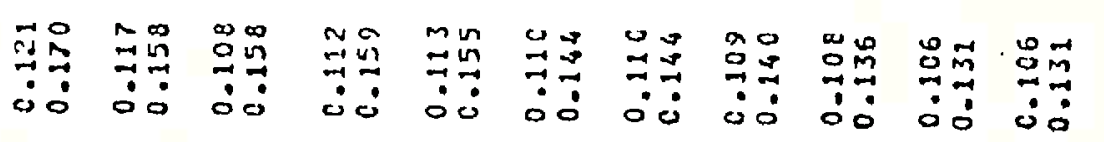

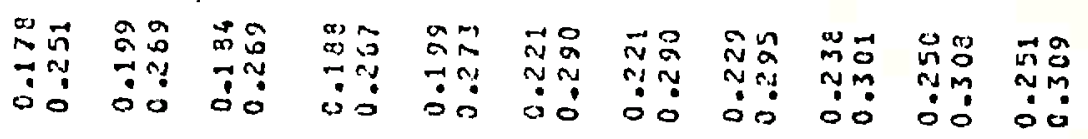

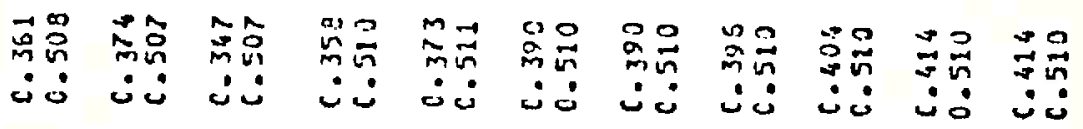

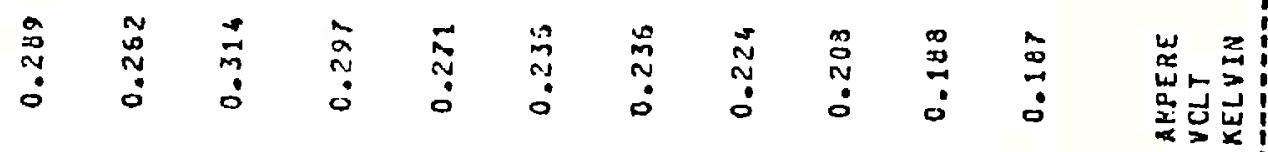

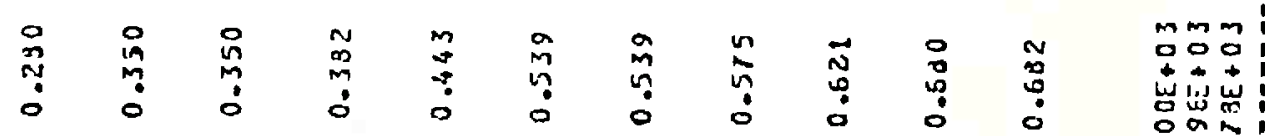

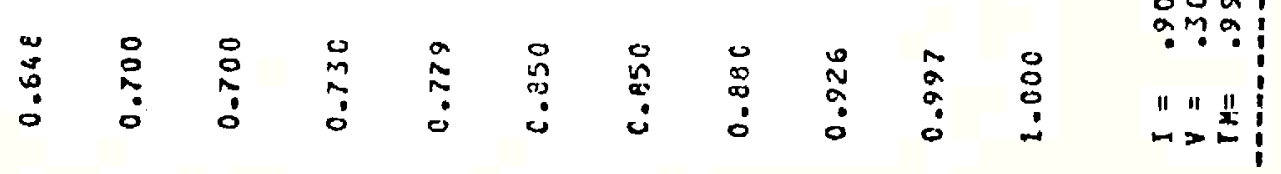




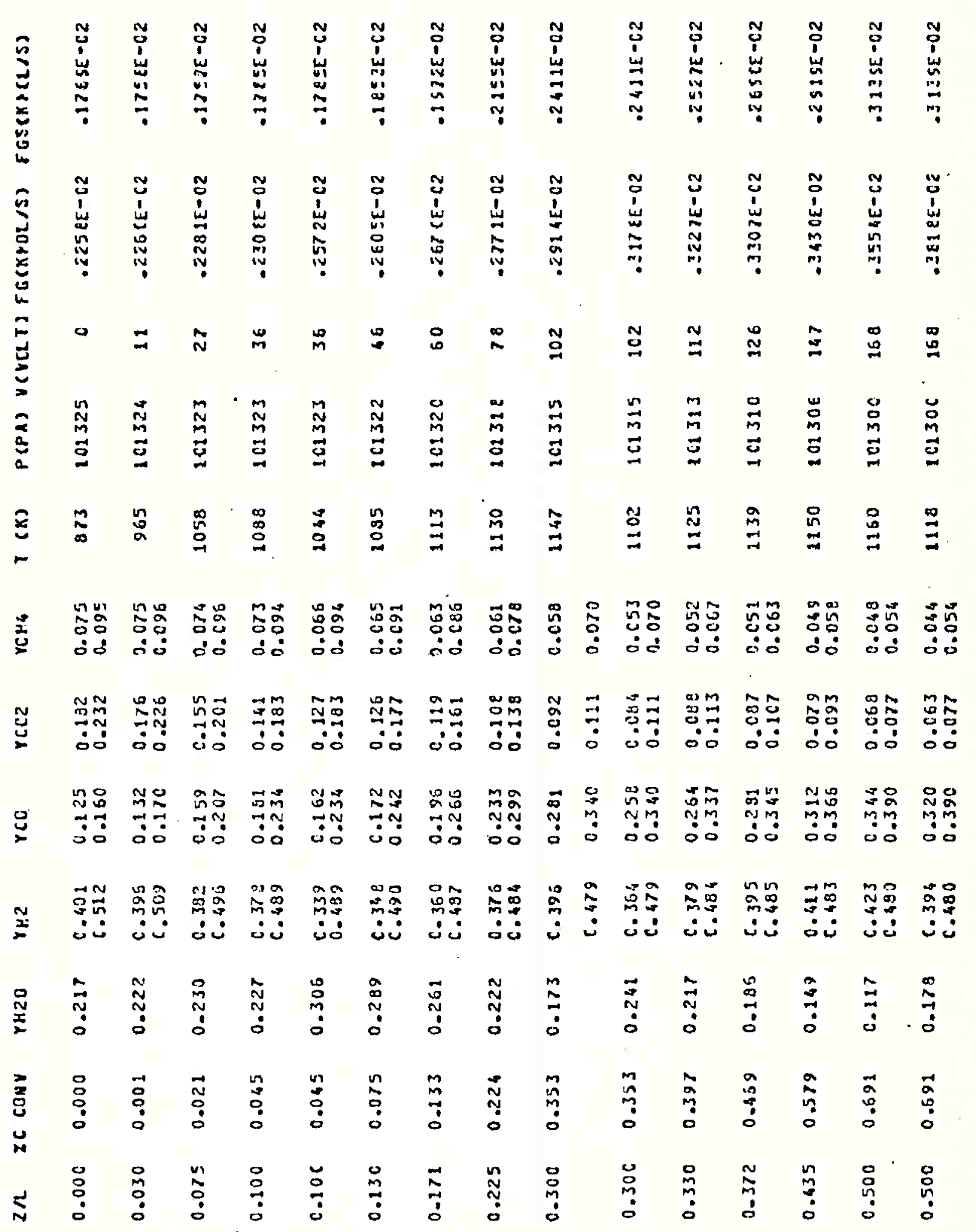




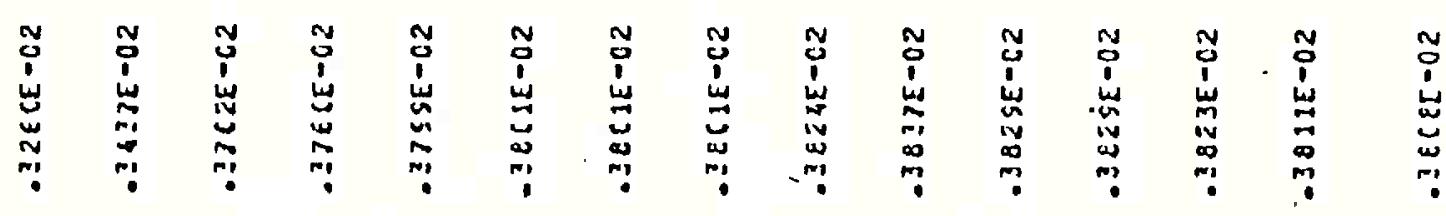

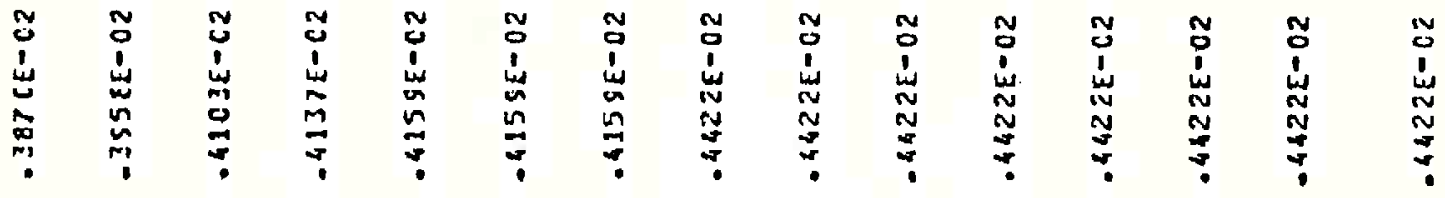

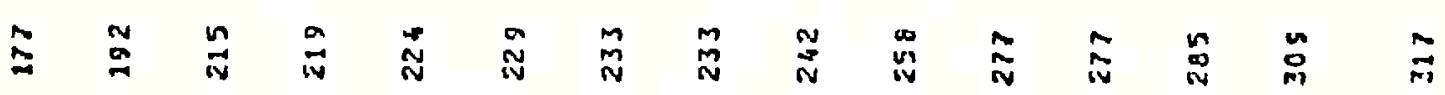

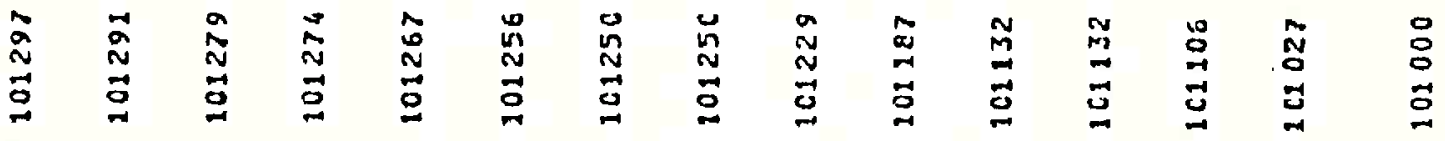

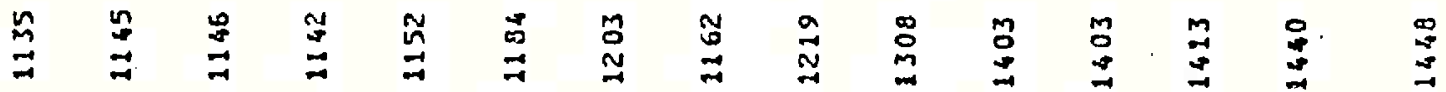

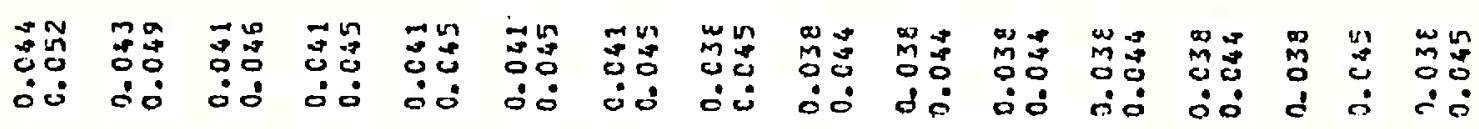

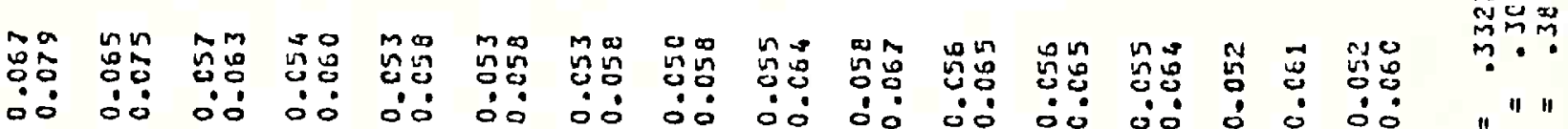

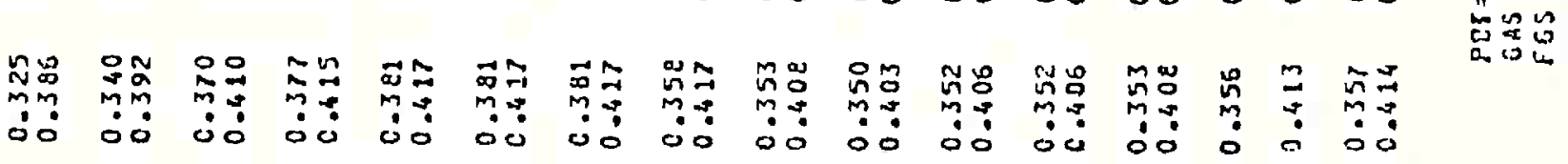

焉

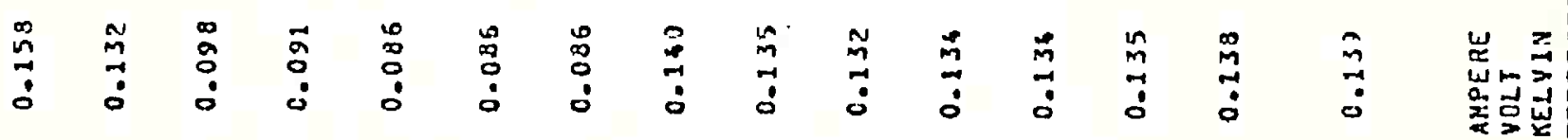

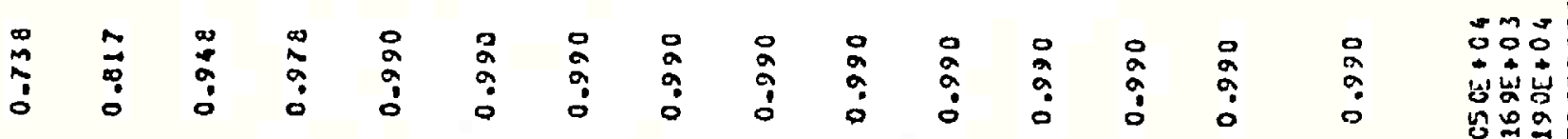

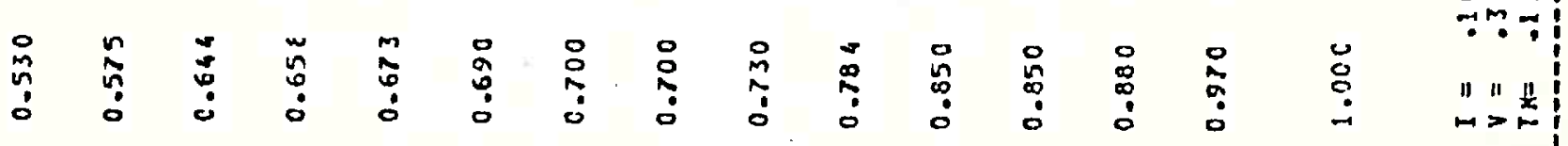




\title{
APENDICE D
}

\section{PROGRAMA DE COMPUTADOR PIROLISE}

\author{
a) Listagem do Programa de Computador
}

A listagem, apresentada a seguir, contém o progra ma principal e a função auxiliar.

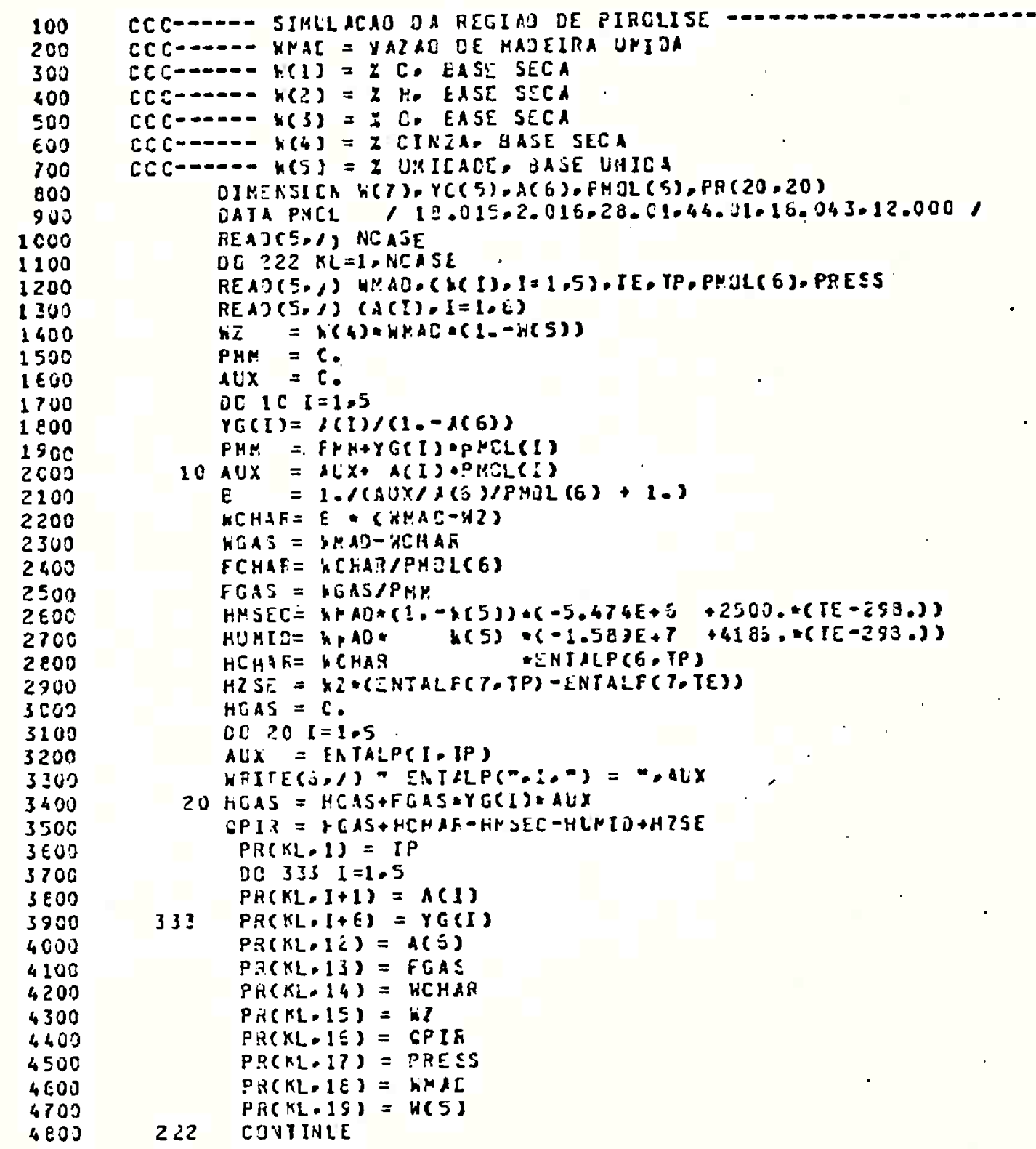


HaItE(E, 10)) (PF(1,12), I =1,NCASE) HतITE(E, 111) (PFC $1=10), I=1$ - NCISE) HEITE(E,1IJ) (PE(I,17),I=1, NCASE) HSTIE(E,1)1) (FF(IDI),I=1-NCAEE) [3 $444 \mathrm{~J}=1,5$ HAI $I[(\varepsilon, 10 \geq) 3:(P R(1]+1),, I=1, N C A S E)$

HAITE(E, 103) (PR $(1,12), 1=1$ - NCASE) H. ITE( $\varepsilon, 103)$ (Ph $(1,13), 1=1, N C A S E)$ DO $55 \bar{j} \mathrm{j}=1.5$

WRITE(6,104) J, (PR $(1+3+6), 1=1$, NCASE $)$

HATTECE.105) (PR(1.14). I=1. NCASE)

WITIE(E.105) (PF(I, 15): $I=1$, NCASE)

HRTTE(E, 1OT) (PF $(1.15) \cdot 1=1$. NC ISE)

FORAAT(1H1. WMAO (NG/S)"

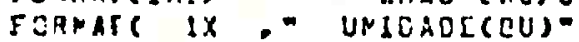

- $\theta(F 10.5)$

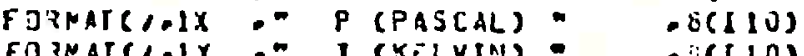

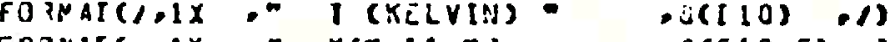

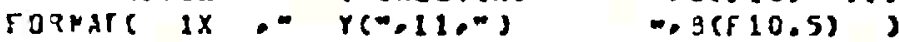

fuqmatc $[x:-$ rec)

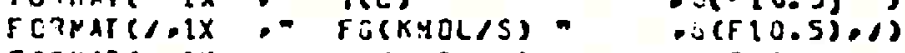

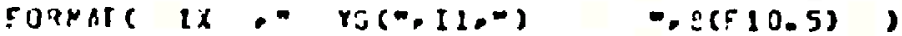

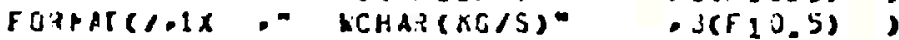

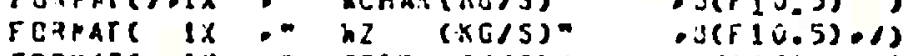

fozmatc ix:- spia (J/S)"

ST BP

FUSTIITS ENTALOCIOTH)

DI $A E A S I C A C A(7), C E(7),=C(7), C[(7)-H E(7)$

CATA CA/30500.2723). 20420..4432C..14320..

$1405 . \quad .53 .326$

LIA $[3 / 1 \mathrm{C} .30,3.265 .4 .102 .8 .191 .74 .70$.

.39740 .25681

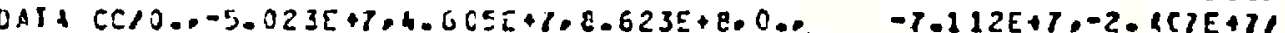

OATA CU/6..J..0.,0..-1.743C-2. C..C.J

CAIA HJ1-2.4193E+8.0..-1.1053E+9.-3.837E+8.-7.4346E+7.C.-1.ECIE+71 $T=I K$

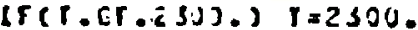

ENTALP $=40(i)+C A(1)+(1-293)+.C 3(1)+.5+(1+1-82814)+.C(C(1)+(1.1)$ $13.3557 E-3)+C 0(1) / 3 \cdot *(1+1+7-2.6453592[+7)$ RE TIRN

END 
b) Dados de Entrada do Programa

A tabela D.1 define os dados de entrada do progra ma PIROLISE. Um exemplo de arquivo de dados é apresentado a sé guir, sendo a respectiva listagem de saída dada no item (c).

Deve-se observar que para se utilizar este progra ma ē preciso conhecer as frações molares de "char" e de cada gäs considerado $\left(\mathrm{H}_{2} \mathrm{O}, \mathrm{H}_{2}, \mathrm{CO}, \mathrm{CO}_{2}, \mathrm{CH}_{4}\right)$. No caso dos resultados apresentados nesta dissertação, tais frações molares foram obtidas por um programa de cảlculo de equilíbrio químico. Porëm, o programa PIROLISE pode ser utilizado também com dados ex perimentais, destas frações molares, se estes dados forem dispó niveis.

- exemplo de arquivo de dados do programa PIROLISE.

\footnotetext{
$100 \quad 5$

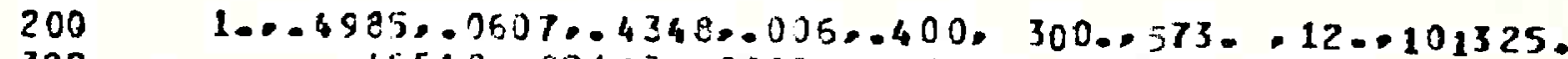

$300 \quad .45519 .002487 .00021 .0 .6014 .016597 . .18362$

$400 \quad 1 \ldots 4905.0507 \ldots 434 E .0036 .0400 .300 .0623 .012 .0101325$.

$500 \quad-43 E 33 \ldots-0507 E \ldots 00094 \ldots 17393 \ldots 16720 .-16981$

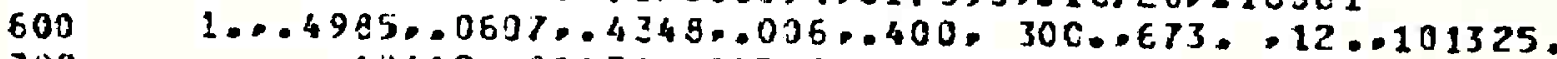

$700 \quad-43412.009131 .00330 .018494 \ldots .15895 .-15728$

$800 \quad 1 \ldots 4985.0607, .4348 .0036, .400 .300 \ldots 773 . .12 \ldots 101325$.

$900 \quad .31208 \ldots 214340.02639 .229528 .-11770 . .13391$

$1000 \quad 1 . .4585 .00637 . .4546 .0006 . .400 .36 C \ldots . .73 . .12 .0101325$.

1100

1200

1300

1400

1500

1600

1700

$.20683 . .36522 \ldots .11931 . .17473 \ldots 06673.007418$

$1 . .4585, .0607 \ldots 4348 \ldots 005 . .400 .300 . .373 . .12 . .101325$. $.12328 . .47882 . .26675 \ldots 11151 \ldots 01964.1 .2-10$

$1 \ldots 4985.0067 .4348 .056 \ldots 400,30 \mathrm{C} \ldots 1 \mathrm{CI} 3 \ldots 12 \ldots 101325$.

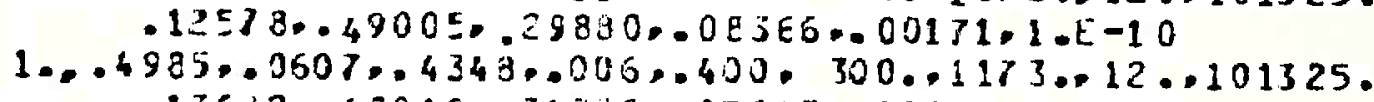
$.13 E d 2 . .42015 . .3123 E \cdot .07045 \cdot .00012 \cdot 1 . E-10$
} 
TABELA D.1 - Dados de entrada do programa PIROLISE.

\begin{tabular}{|c|c|c|c|}
\hline LINHA & VAR IAVEL & DESCR IÇÃO & UNIDADE \\
\hline 19 & NCASE & nümero de simulaçõesa serem realizadas & - \\
\hline $2 \stackrel{a}{9}$ & $\begin{array}{l}\text { WMAD } \\
\text { W(1) } \\
W(2) \\
W(3) \\
W(4) \\
W(5) \\
\text { TE } \\
\text { TP } \\
\text { PMOL (6) }\end{array}$ & $\begin{array}{l}\text { vazão de madeira úmida e com cinza } \\
\text { fração mässica de } C \text {, base seca } \\
\text { fração mässica de } H \text {, base seca } \\
\text { fração mässica de } 0 \text {, base seca } \\
\text { fração mässica de cinzas, base seca } \\
\text { fração mässica de umidade, base úmida } \\
\text { temperatura de entrada } \\
\text { temperatura de pirōlise } \\
\text { massa molar do "char" }\end{array}$ & $\begin{array}{c}\mathrm{kg} / \mathrm{s} \\
- \\
- \\
- \\
- \\
- \\
\mathrm{K} \\
\mathrm{K} \\
\mathrm{kg} / \mathrm{kmol}\end{array}$ \\
\hline $3:$ & $\begin{array}{l}Y(1) \\
Y(2) \\
Y(3) \\
Y(4) \\
Y(5) \\
Y C\end{array}$ & $\begin{array}{l}\text { fração molar de } \mathrm{H}_{2} \mathrm{O} \\
\text { fração molar de } \mathrm{H}_{2} \\
\text { fração molar de } \mathrm{CO} \\
\text { fração molar de } \mathrm{CO}_{2} \\
\text { fração molar de } \mathrm{CH}_{4} \\
\text { fração molar do "char" }\end{array}$ & $\begin{array}{l}- \\
- \\
- \\
- \\
-\end{array}$ \\
\hline
\end{tabular}

Repetir linhas 2a e 3a para os demais casos. 
c) Exemplo de resultados do programa PIROLISE

A 1 istagem de resultados correspondente aos dados do item (c) è apresentada a seguir.

\begin{tabular}{|c|c|c|c|c|c|c|c|c|}
\hline $\begin{array}{l}\text { WHAS (KG/S) } \\
\text { UMIDADE( } 8 U)\end{array}$ & $\begin{array}{l}1.00000 \\
0.40000\end{array}$ & $\begin{array}{l}1.00000 \\
0.40000\end{array}$ & $\begin{array}{l}1.00000 \\
0.40000\end{array}$ & $\begin{array}{l}1.000000 \\
0.40000\end{array}$ & $\begin{array}{l}1.00000 \\
0.40000\end{array}$ & $\begin{array}{l}\text { 1. } 00000 \\
\text { C. } 40 C 60\end{array}$ & $\begin{array}{l}1.00000 \\
C .400 C C\end{array}$ & $\begin{array}{l}1.00000 \\
c .46000\end{array}$ \\
\hline P (PASCal) & 101325 & 102325 & 101325 & 101325 & 101325 & 101325 & $1 C 1325$ & 101325 \\
\hline I (KEL UI h) & 572 & 623 & 673 & 773 & 873 & 973 & $1 \mathrm{Cr3}$ & 1173 \\
\hline $\begin{array}{l}r(1) \\
r(2) \\
r(3) \\
r(4) \\
r(5) \\
r(c)\end{array}$ & $\begin{array}{l}0.46519 \\
0.02487 \\
0.00021 \\
0.16014 \\
0.16337 \\
0.18352\end{array}$ & $\begin{array}{l}0.43833 \\
0.05078 \\
0.03094 \\
0.17393 \\
0.15720 \\
0.16881\end{array}$ & $\begin{array}{l}0.40412 \\
0.09131 \\
0.00340 \\
0.13596 \\
0.15195 \\
0.15728\end{array}$ & $\begin{array}{l}0.31200 \\
0.211496 \\
0.02589 \\
0.19528 \\
0.11720 \\
0.13391\end{array}$ & $\begin{array}{l}0.20083 \\
0.36522 \\
0.12831 \\
0.17673 \\
0.06673 \\
3.07618\end{array}$ & $\begin{array}{l}c .12328 \\
6.47282 \\
0.26675 \\
0.11151 \\
c .01964 \\
c .00000\end{array}$ & $\begin{array}{l}0.12578 \\
0.4906 E \\
0.898 E C \\
0.08366 \\
0.00171 \\
0.00 C C C\end{array}$ & $\begin{array}{l}0.13632 \\
0.42019 \\
0.31236 \\
c .67045 \\
0.00018 \\
c .00000\end{array}$ \\
\hline FG(KROL/S) & 0.04013 & c.04078 & 0.04187 & 0.64590 & 0.05347 & c. 06297 & $c \cdot \cos 22$ & $c .06562$ \\
\hline $\begin{array}{l}x \in(1) \\
r C(2) \\
r G(3) \\
\operatorname{rg}(4) \\
\operatorname{rg}(5)\end{array}$ & $\begin{array}{l}0.56992 \\
0.03646 \\
0.00026 \\
0.19516 \\
0.20330\end{array}$ & $\begin{array}{l}0.52735 \\
0.00109 \\
0.09113 \\
0.25925 \\
0.20116\end{array}$ & $\begin{array}{l}0.47756 \\
0.13535 \\
0.03603 \\
0.21368 \\
0.18362\end{array}$ & $\begin{array}{l}0.35033 \\
0.210817 \\
0.03012 \\
0.22547 \\
0.13596\end{array}$ & $\begin{array}{l}0.21632 \\
0.39448 \\
2.12779 \\
0.18873 \\
0.07208\end{array}$ & $\begin{array}{l}\text { C. } 12320 \\
C .17628 \\
C .26675 \\
0.11151 \\
\text { c. } 01964\end{array}$ & $\begin{array}{l}0.12578 \\
0.49005 \\
0.29826 \\
0.08366 \\
0.06171\end{array}$ & $\begin{array}{l}0.13692 \\
0.4019 \\
0.31236 \\
0.07065 \\
0.06018\end{array}$ \\
\hline 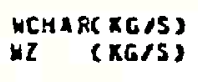 & $\begin{array}{l}0.10758 \\
0.00350\end{array}$ & $\begin{array}{l}(.03990 \\
0.03350\end{array}$ & & $\begin{array}{l}0.03483 \\
0.00350\end{array}$ & $\begin{array}{l}0.05121 \\
2.00360\end{array}$ & $\begin{array}{l}\text { c. } 00080 \\
\text { c. } 00350\end{array}$ & $\begin{array}{l}0.10000 \\
0.0036 C\end{array}$ & $\begin{array}{l}0.00000 \\
0.00350\end{array}$ \\
\hline $\operatorname{OP}(\mathbb{R} \quad(J / S)$ & 870425 & 1025786 & $1227 \geq 72$ & $1: 453 c 8$ & 2970817 & 4455131 & $4 \operatorname{set} 946$ & 5262238 \\
\hline
\end{tabular}




\section{REFERENCIAS BIBLIOGRAFICAS}

AMUNDSON, N.R. \& ARRI, L.E. Char gaseification in a countercurrent reactor, AIChE Journal, 24(1), 87-101, 1978.

ANTAL, M.J., Jr. Effects of reactor severity on the gas-phase pyrolysis of celulose - and kraft lignin-derived volatile mat ter, Ind. Eng. Chem. Process Des. Dev., 22 (2), 366-375, 1983.

ANTHONY, D.B. \& HOWARD, J.B. Coal devolatilization and hydrogasification, AIChE Journal, 22 (4), 625-656, 1976.

ANTHONY, D.B.; HOWARD, J.B.; HOTTEL, H.C. \& MEISSNER, H.P. Rapid devolatilization and hydrogasification of betuminous coal, Fuel, 55, 121, 1976.

ARRI, L.E. \& AMUNDSON, N.R. An analytical study of single particle char gasification. AIChE Journal, 24 (1), 72-87, 1978.

ASSUMPÇÃO, R.M.V. Gaseificação de madeira e carvão vegetal . Energia - Fontes Alternativas, 3 (16), 23-42, 1981.

BALTCHELDER, H.R.; BUSCHE, R.M. \& ARMSTRONG, W.P. Kinetics of coal gasification - proposed mechanism of gasification - Deve lopment of reaction rate equations - Development of heat transfer equation and method of calculation. Ind.Eng.Chem., 45 (9), 1856-1878, 1953.

BARIN, I. \& KNACHE, O. Thermochemical properties of inorganic substances. Verlag Stahleisen m.b.H. Dusseldorf, 1973.

BEESON, J.L.; PULSIFER, A.H. E WHEELOCK, T.D. Coal char gasification in a continuous electrofluid reactor. Ind.Eng.Chem. Process Des. Dev., 13 (2), 159-164, 1974. 
BENNATON, J.; UEHARA, O.K. \& GAMBIRASIO, G. Configuração do campo elétrico obtida pelo método das diferenças finitas, em meios dependentes da temperatura. Trabalho apresentado no Se minärio sobre Cälculo de Campos Elétricos com Métodos Numéricos, São Paulo, 1985.

BIBA, V.; MACAK, J.; KLOSE, E. \& MALECHA, J. Mathematical model for the gasification of coal under pressure. Ind. Eng. Chem. Process Des. Dev., 17 (1), 92-98, 1978.

BIRD, R.B.; STEWART, W.E. \& LIGHTFOOT, E.N. Transport Phenomena, John Wiley, New York, 1960.

BROIDO, A. Kinetics of solid-phase cellulose pyrolysis, in Thermal uses and Properties of Carbohydrates and Lignins, 172 Nat' 1 Meet. ACS, ed. F. Shafizadeh, K.V. Sarkanen, D.A. Tili man, Academic Press, 1976, [citado em WATANABE (1983)].

CARAM, H.S. e AMUNDSON, N.R. Fluidized bed gasification reactor modeling 1 . Model description and numerical results for a single bed. Ind. Eng. Chem. Process Des. Dev., 18 (1), 80-96, 1979.

CARBERRY, J.J. Chemical and Catalytic Reaction Engineering, Mc Graw-Hill, New York, 1976.

CESP - Companhia Energética de São Paulo. Relatōrio de Ativida des $R A-R O / C 001 / 83,1983$.

CESP - Companhia Energética de São Paulo, 19a a 3 a campanha do gaseificador G-5. Relatório tëcnico RT-ROEE/005/84, 1984.

CESP - Companhia Energētica de São Paulo. 5a Campanha do gase bicador G-5. Relatōrio técnico RT-ROEE/002/85, 1985.

CHAN, W.C.R.; KELBON, M. \& KRIEGER, B.B. Modeling and experi- 
mental verification of physical and chemical processes during pyrolysis of a large biomass particle. Trabalho apresentado no ACS Symposium on Mathematical Modeling of Biomass Pyrolysis Phenomena, Washington, USA, 1983.

CHIAPPETTA, A.; NASCIMENTO, C.A.O. \& GAMBIRASIO, G. Proprieda des elétricas de um leito de particulas condutoras de carvão. Trabalho apresentado no XIII Encontro sobre Escoamento em Meios Porosos, São Paulo, 1985 a.

CHIAPPETTA, A.; GAMBIRASIO, G. \& NASCIMENTO, C.A.o. Modelagem matemática e simulação de um gaseificador eletrotérmico. Revista Politécnica, 187, 32-36, 1985b.

CHIAPPETTA, A.; GIUDICI, R. \& NASCIMENTO, C.A.O. Modelagem matemática e simulação de gaseificador eletrotérmico. Trabalho apresentado nas XIII Jornadas sobre Investigation in Ciências de la Ingenieria Quimica y Quimica Aplicada, San Juan, Argentina, $1985 \mathrm{c}$.

CHO, Y.S. \& JOSEPH, B. Heterogeneous model for moving-bed coal gasification reactors. Ind. Eng. Chem. Process Des. Dev., 20 (2) , 314-318, 1981 .

CROWE, C.M.; HAMIELEC, A.E.; HOFFMAN, T.W.; JOHNSON, A.I.; SHAN NON, P.T. \& WOODS, D.R. Chemical Plant Simulation, Mc Mastē University, Hamilton, Canada, 1969.

DENN, M.M.; YU, W.C. \&WEI, J. Parameter sensitivity and kinetics-free modeling of moving bed coal gasifiers, Ind. Eng. Chem. Process Des. Dev., 18 (3), 286-288, 1979.

DEROSIERS, R.E. Thermodynamics of gas-char reactions, in A Survey of Biomass Gasification II. Principles of Gasification (SERI, Golden', CO, 1979), SERI/TR-33-239, 132-175, 1979. 
DEROSIERS, R.E. Gasification Engineering. SERI/PR-622-1153. Golden, CO: Solar Energy Research Institute, 1981.

DESAI, P.R. \& WEN, C.Y. Computer Modeling of Morgantown Energy Research Center's Fixed Bed Gasifier, Relatório Técnico MERC/ $\mathrm{CR}-78 / 3,1978$.

FREDERSDORF, C.G. \& ELLIOT, M.A. Coal Gasification, in Chemistry of Coal Utilization, Supplementary Volume, ed. H.H. Lowry, New York, 1963.

FROMENT, G.F. \& BISCHOFF, K.B. Chemical Reactor Analysis and Design, Wiley, New York, 1979.

GAMBIRASIO, G. \& BENNATON, J. Consideraçōes sobre o cálculo da configuração do campo elétrico em meios dependentes da temperatura. Trabalho apresentado no Seminário sobre Cálculo de Campos Elétricos com Métodos Numëricos, São Paulo, 1985.

GLIDDEN, H.J. \& PULSIFER, A.H. Electrode contact resistance in a fluidized bed. Can. J. Chem. Eng., 46 476-478, 1968.

GOLDBERGER, W.M.; HANWAY, J.E., Jr. \& LANGSTON, B.G. The electro thermal fluidized bed. Chem. Eng. Progress, 61 (2), 63-67, 1965 .

GOLDSCHMIDT, D. \& LE GOFF, P. Resistance electrique des lits fluidises - I. Resistances moyennes de grains conducteurs fluidises par air - resultats preliminaires. Chem.Eng.Sci., $18,805-806,1963$.

GORDON, S. \& MCBRIDE, B.J. Computer program for calculation of complex chemical equilibrium, compositions, rocket performances, incident and reflected shocks, and Chapman-Jouguet detonations. CEC-71, NASA-SP273, 1971. 
GOVIND, R. \& SHAH, J. Modeling and simulation of an entrained flow coal gasifier, AIChE Journal, 30 (1), 79-92, 1984.

GRABOSKY, M. ¿ BAIN, R. Properties of Biomass Relevant to Gasi fication, in A Survey of Biomass Gasification. II. Principles of Gasification (SERI, Golden, CO, 1979), SERI/TR-33-239, 2065,1979 .

GRABOSKY, M. Kinetics of Char Gasification Reactions, in A Sur vey of Biomass Gasification. II. Principles of Gasification (SERI, Golden, CO, 1979), SERI/TR-33-239, 176-218, 1979.

GRAHAM, W- $\&$ HARVEY, E.A. The electrical resistance of fluidized beds of coke and graphite. Can. J. Chem. Eng., 13, 146-149, 1965 .

GUPTA, A.S. \& THODOS, G. Direct analogy between mass and heat transfer to beds of spheres. AIChE Journal, 9, 751-754, 1963.

HAJALIGOL, M.R.; HOWARD, J.B.; LONGWE, J.P. \& PETERS, W.A. Pro duct composition and kinetics for rapid pyrolysis of cellu1ose. Ind. Eng. Chem. Process Des. Dev., 21 (3), 457-465,
1982.

HAYNES, H.W., Jr. An improved single particle char gasification model. AIChE Journal, 28 (3), 517-521, 1982.

HOLLAND, C.D. \& LIAPIS, A.I. Computer methods for solving dynamic separation problems. Mc Graw-Hill, New York, 1983.

HUGHES, R. Non-Catalytic Gas-Solid Reactions, Apostila, COPPE/ UFRJ, 1979 .

IEUSP - Instituto de Eletrotëcnica da Universidade de São Paulo. Medição da resistividade do carvão na faixa de temperatura de $600^{\circ} \mathrm{C}$ a $1200^{\circ} \mathrm{C}$. Relatório técnico, 1982. 
IEUSP - Instituto de Eletrotêcnica da USP. Considerações sobre a modelagem de reatores eletrotérmicos (I). Relatörio Tëcnico $n^{\circ} 1$ para a CESP, $1984 \mathrm{a}$.

IEUSP - Instituto de Eletrotêcnica da USP. Modelagem de reator eletrotêrmico (duas dimensões, regime permanente, somente equações elêtricas e tērmicas). Relatório técnico n 2 para a CESP, 1984b.

IEUSP - Instituto de Eletrotécnica da USP. Modelagem de reator eletrotermico (conbiguração bäsica, regime permanente, condutividades variāveis). Relatörio técnico n 6 para a CESP, $1984 \mathrm{c}$.

IEUSP - Instituto de E1etrotēcnica da USP. Modelagem de reator eletrotêrmico lconfiguraçāo 620 , regime permanente, condutivi dades variāueis). Relatörio técnico n: 7 para a CESP, 1984d.

IEUSP - Instituto de Eletrotécnica da USP. Gaseificador de flu xos paralelos (I) Imodelo de 1 dimensão, fenômenos quimicos, tērmicos e elétricos, regime permanentel. Relatório técnico $\mathrm{n}: 4$ para a CESP, $1984 \mathrm{e}$.

IEUSP - Instituto de Eletrotëcnica da USP. Gaseificador eletro térmico - Fluxos paralelos com condução de calor no leito. Relatörio técnico n: 11 para a CESP, $1984 f$.

IEUSP - Instituto de Eletrotécnica da USP. Gaseificador de blu xos cruzados lmodelo de 1 dimensão, benômenos quỉmicos, regime dinâmicol. Relatório técnico n? 3 para a CESP, $1984 \mathrm{~g}$.

JOHNSON, H.S. Reactions in a fluidized coke bed with selfresistive heating. Can. J. Chem. Eng., 39, 145-147, 1961.

JOHNSON, J.L. Kinetics of Coal Gasification. John Wiley \& Sons, New York, 1979. 
KANSA, E.J. A model of drying: drying and pyrolysis of solid fuels at five intensity conditions, in Drying'82, ed. A.S. Mu jumdar, Hemisphere, Washington, 1982 .

KARAPETIANTZ, M. Thermodinnamique chimique. Mir, Moscou, 1978.

KLM, M. \& JOSEPH, B. Dynamic behavior of moving-bed coal gasifiers, Ind. Eng. Chem. Process Des. Dev., 22(2), 212-217, 1983.

KNIGTH, J.A. Pyrolysis of pine sawdust, in Thermal uses and Properties of Carbohydrates and Lignins, 172 Nat'I Meet. ACS, ed. F. Shafizadeh, K.V. Sarkanen, D.A. Tillman, Academic Press, 1976 [citado em Watanabe (1983)].

KNOWLTON, T.M.; PULSIFIER, A.H. \& WHEELOCK, T.D. Prediction of fluidized bed resistance using field theory, AIChE Symposium Series, 69 (128), 94-105, 1973.

KOSKY, P.G. \& FLOESS, J.K. Global model of countercurrent coal gasifier, Ind. Eng. Chem. Process Des. Dev., 19 (4), 586-592, 1980 .

KUMPINSKY, E.; SCHMAL, M. \& VARGAS, A.S. Gaseificação transien te e isotérmica de particula esférica de carbono, COPPE/UFRJ, PDD 09/79, 1979.

LEVENSPIEL, 0 . Chemical Reaction Engineering, 2a. ed. John Wiley New York, 1974.

LOUREIRO, L.V. Analyse Comparative entre les Procedes de Gase $\underline{i}$ ficarion de Biomasse a Lit Fixe et a Lit Entraine: Modelisation, Simulation et Bilans Economiques Prospectifs, These de Docteur Ingenieur, Ecole Centrale des Arts et Manufactures, Paris, França, 1984 .

MASSAquOI, J.G.M. ERIGGS, J.B. One dimensional model of the 
physico-chemical processes occurring inside a burning coal surface, AIChE Journal, 29 (6), 975-981, 1983.

MAKRAY, Z.T. Gaseificação de madeira em gaseificador co-corren te para a produção de gās de mêdio poder calorífico e gās de sintese. Tese de doutoramento. Universidade Estadual de Cam pinas, Campinas, 1984.

MCINTOSH, M.J. Mathematical model of drying in a brown coal mill system 1. Formulation of Model, Fuel, 55, 47-52, 1976.

MICHELSEN, M.L. An efficient general purpose method for the integration of stiff ordinary differential equation. AIChE Journal, 22 (3), 594-597, 1976.

MILNE, T. Pyrolysis - The Thermal Behavior of Biomass Bollow $600{ }^{\circ} \mathrm{C}$ in A Survey of Gasification. II. Principles of Gasification (SERI, Golden, CO, 1979), SERI/TR-33-239: 96-131,1979.

MOE, J.M. Design of water-gas shift reactors. Chem. Eng. Progress, 58 (3), 33-36, 1962.

NASCIMENTO, C.A.O. Coking and Regeneration of Catalyst Pellets, Ph.D. Thesis, University of Salford, England, 1982.

PAQUET, J.L. \& FOULKES, P.B. Calcination of fluid coke in an electrically heated fluidized bed. Can. J. Chem. Eng.,43(4), 94-96, 1965.

PAULA, C.P. Desenvolvimento tecnológico da gaseificação eletro térmica da madeira. Engenharia Quimica, 6 (1/2), 23-27, 1982 .

PEISHENG, M.; MINGSHU, G.; BIYUN, J. \& JIANHOU, Z. Correlation of recent ideal gas heat-capacity data with temperature. Selected Papers of J. of Chem. Ind. \& Eng. (China), 1, 12-35, 1982. 
PILCHER, J.M.; WALKER, P.L., Jr. \& WRIGHT, C.C. Kinetic study of steam-carbon reaction - Influence of temperature, partial pressure of water vapor and nature of carbon on gasification rates. Ind. Eng. Chem., 47 (9): 1742-1749, 1955.

PRADO, C. e MOREIRA, J.R. Pirölise de madeira em gaseificadores eletrotérmicos. Trabalho apresentado no XIII Encontro so bre Escoamento em Meios Porosos, São Paulo, 1985.

PROBSTEIN, R.F. \& HICKS, R.E. Synthetic Fuels. Mc Graw-Hill, Kogakusha, Tokyo, 1982.

PULSIFER, A.H.; KNOWLTON, T.M. \& WHEELOCK, T.D. Coal char gasi fication in an electrofluid reactor. Ind. Eng. Chem. Process Des. Dev., 8 (4), 539-545, 1969.

PULSIFER, A.H. \& WHEELOCK, T.D. Production of hydrogen from coal char in an electrofluid reactor. Ind.Eng. Chem. Process Des. Dev., 11 (2), 229-237, 1972 .

PULSIFER, A.H. \& WHEELOCK, T.D. Electrofluid gasification of coal with nuclear energy. Fuel Processing Technology, 1, 117 $-132,1977 / 78$.

PURDY, M.J.; FELDER, R.M. \& FERREL, J.K. Coal gasification in a pilot scale fluidized bed reactor. 1. Gasification of a devolatilized bituminous coal, Ind. Eng. Chem. Process Des.Dev., 20 (4), 675-682, 1981.

PYLE, D.L. \& ZAROR, C.A. Heat transfer and kinetics in the low temperature pyrolysis of solids. Chem. Eng. Sci., 39 (1), 147 $-158,1984$.

RAMAN, P.; WALAWENDER, W.P.; FAN, L.T. \& CHANG, C.C. Mathematical model for the fluid-bed gasification of biomass mate rials. Application to feedlot manure. Ind. Eng. Chem. Process Des. Dev., 20, 686-692, 1981. 
REID, R.C.; PRAUSNITZ, J.M. \& SHERWOOD, T.K. The properties of gases and liquids, 3a. ed. Mc Graw-Hi11, 1977.

RENSFELT, E.; BLOMKVIST, G.; EASTROM, C.; EASTROM, S.; ESPERAS, B.G. \& LIINANKI, L. Basic gasification studies for development of biomass medium-btu gasification processes. Energy from Biomass wastes, IGT, 1978. [citado em Grabosky (1979)].

ROBERTS, A.F. A review of kinetics data for the pyrolysis of wood and related substances. Combustion and Flame, 14, 261272,1970 .

SAMPATH, B.S., RAMACHANDRAN, P.A. \& HUGHES, R. Modeliing of Non-Catalytic Gas-Solid Reactions - I. Transient Analysis of Particle-Pellet Model. Chem. Eng. Sci., 30, 125-134, 1975.

SCHMALL, M.; MONTEIRO, J.L.F. \& CASTELLAN, J.L. Kinetics of Coal Gasification. Ind. Eng. Chem. Process Des. Dev., 21,256 $-266,1982$.

SERI - Solar Energy Research Institute. A Survey of biomass ga sification, SERI/TR-33-239, UC-61, 1979.

SERI - Solar Energy Research Institute. Gasification Engineering, SERI/TP-622-1153, UC-61a, 1981 .

SHEEL, J.G.P. \& CROWE, C.M. Simulation and optimization of an existing ethilbenzene dehydrogenation reactor. Can. J. Chem. Eng., 47, 183-187, 1969 .

SHREVE, R.N. \& BRINK, J.A., Jr. Chemical Process Industries. Mc Graw-Hil1, Kogakusha, Tokyo, 1977.

SILVEIRA, R.C. \& MELO, M.A.L. Influência da granulometria do carvão vegetal na produtividade dos fornos de redução, Metalurgia-ABM, 29 (189), 543-546, 1973. 
SILVEIRA, R.C. O modelo elétrico do forno elëtrico de redução. Metalurgia - ABM, 33 (230), 57-64, 1977.

SINGH, C.P.P. \& SARAF, D.N. Simulation of high temperature water-gas shift reactors, Ind. Eng. Chem. Process Des. Dev., 16 (3), 313-319, 1977.

SMITH, J.M. Chemical Engineering Kinetics, Mc Graw-Hill, Kogakusha, Tokyo, 1970.

SMOOT, L.D. \& PRATT, D.T. Pulverized - Coal Combustion and Gasification, Plenum Press, New York, 1979.

SOUZA SANTOS, M.L. \& JEN, L.C. Desenvolvimento de um modelo ma temático e um programa para computador digital de processo de gaseificação de biomassa em leito fixo contra-corrente e cocorrente, in YOKAICHIYA, N.S. Aproveitamento de Residuos Ve getais para Fins Energéticos, Relatório n? 16223, Parte B, IPT - Instituto de Pesquisas Tecnológicas do Estado de São Paulo S.A. para a SICCT - Secretaria de Estado da Indūstria, Comércio, Ciência e Tecnologia do Estado de São Paulo, 1982.

SOUZA SANTOS, M.L. Modelagem matemātica e simulação abrangente de gaseificação em leito fixo contra-corrente para carvão mineral e biomassa. Anais do VI Congresso Brasileiro de Enge nharia Quimica, volume 3, 546-559, Campinas, 1984.

SRINIVAS, B. \& AMUNDSON,N.R. A single-particle char gasification model, AIChE Journal, 26 (3), 487-496, 1980.

STILLMAN, R. Simulation of a moving bed gasifier for a Western Coal, IBM J. Res. Develop., 23 (3), 240-252, 1979.

THURNER, F. \& MANN, U. Kinetics investigation of wood pyrolysis, Ind. Eng. Chem. Process Des. Dev., 20 (3), 482-488, 1981.

VAN WYLEN, G.J. \& SONNTAG, R.E. Fundamentos da termodinâmica clássica, trad. 2ạ ed., Edgar Blücher, São Paulo, 1976. 
WALKER, P.L., Jr.; RUSINKO, F., Jr. \& AUSTIN, G. Advances in Catalysis, 11, 133-164, Academic Press, New York, 1959.

WATANABE, S., Jr. Modelo matemātico de gaseificação de Biomassa, Dissertação de Mestrado, Instituto de Física da Universidade de São Paulo, 1983.

WEI, J. A stoichiometric analysis of coal gasification. Ind. Eng. Chem. Process Des. Dev., 18 (3), 554-558, 1979.

WEN, C.Y. Noncatalytic heterogeneous solid fluid reaction models. Ind. Eng. Chem:, 60 (9), 34-54, 1968.

WEN, C.Y. Thermal and diffusional effects in noncatalytic solid gas reactions. Ind. Eng. Chem., 62 (8), 30-51, 1970.

WEN, C.Y. \& WU, N.T. An analysis of slow reactions in a porous particle. AIChE Journal, 22 (6), 1012-1021, 1976.

WEN, C.Y. \& CHEN, L.H. A model for coal pyrolysis, in WEN, C.Y. \& LEE, E.S. Coal Conversion Technology, Addison-Wesley, London, 1979.

WEN, C.Y. \& CHUANG, T.Z. Entrainment coal gasification modeling, Ind. Eng. Chem. Process Des. Dev., 18 (4), 684-695, 1979.

WEN, C.Y. \& DUTTA, S. Rates of coal pyrolysis and gasification reactions, in WEN, C.Y. \& LEE, E.S. Coal Conversion Technology, Addison-Wesley, London, 1979.

YAWS, C.L.; MILLER, J.W.; SHAH, P.N.; SCHORR, G.R. \& PATEL, P. M. Correlation constante for chemical compounds. Chem. Eng., $22,153-162,1976$.

YOON, H.; WEI, J. \& DENN, M.M. A model for moving-bed coal gasification reactors. AIChE Journal, 24 (5), 885-903, 1978. 
YOON, H.; WEI, J. \& DENN, M.M. Transient behaviors of movingbed coal gasification reactors. AIChE Journal, 25 (3), 429439,1979 a.

YOON, H.; WEI, J. \& DENN, M.M. Feasible operating regions for moving bed coal gasification reactors. Ind. Eng. Chem. Process Des. Dev., 18 (2), 306-312, 1979 b.

ZAGATTO, A.J.A.G. Gaseificador de mëdio e grande porte. Energia - Fontes Alternativas, 3 (16), 44-53, 1981.

ZIELKE, C.W. \& GORIN, E. Kinetics of carbon gasification, Ind. Eng. Chem., 47, 820-825, 1955. 